\section{Arsenic removal by}

\section{iron based co-precipitation}

Mechanisms in groundwater treatment

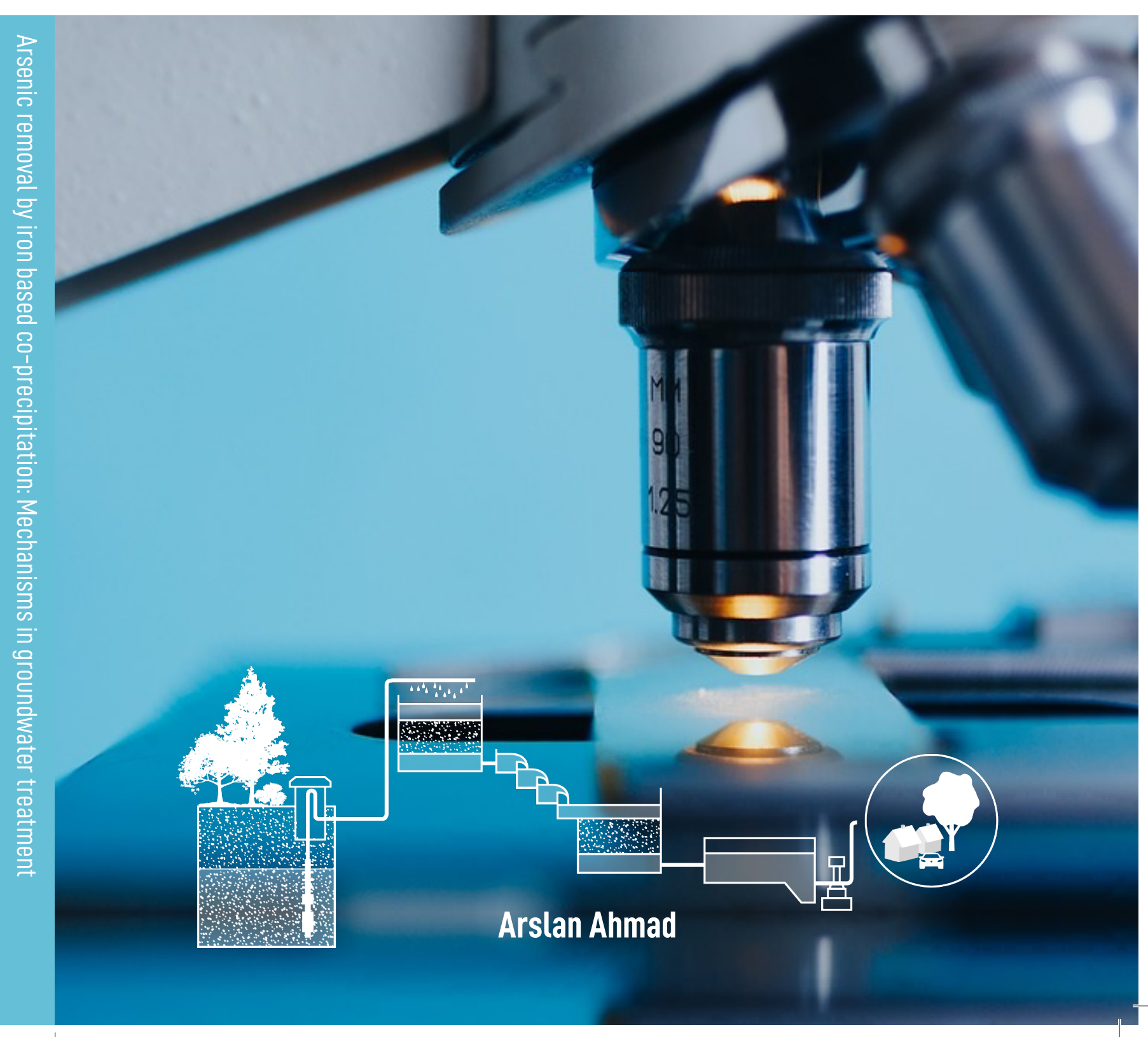

Date: 05 June 2020

Location: Auditorium, Wageninge

University

Group: Environmental Technolo

Wageningen University

based co-precipitation

Promotors

rof. Dr. Albert van der Wal Professor of Electrochemical Water Treatment

niversity \& Resear

Prof. Dr. Prosun Bhattacharya

KTH Royal Institute of Technology

Stockholm, Sweden

Co-promotor

Assistant professor, Environment

Technology

Other members

Prof. Dr. Rob N.J. Comans
Wageningen University \& Research

Prof. Dr. Jon Petter Gustafsson

Swedish University of Agricultural Sciences

Uppsala, Sweden

Dr. Mieke W.J. Luiten - Olieman

University of Twente, Enschede

Dr. Stephan Hug, Eawag

and Technology Düben dquatic Science

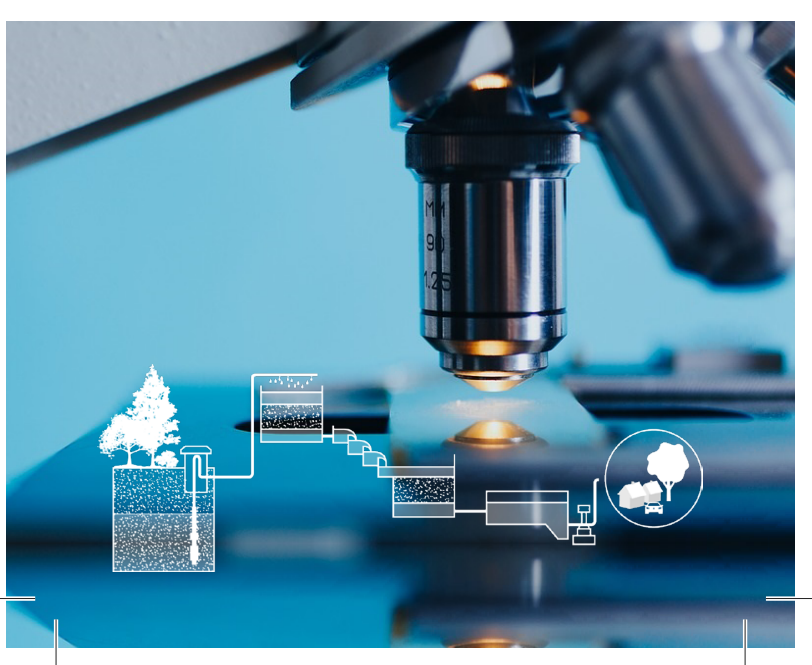




\section{Propositions}

1. A reduction of $\mathrm{pH}$ facilitates the removal of oxidized arsenic species from groundwater by iron based co-precipitation (this thesis).

2. Reduction of arsenic levels in a drinking water treatment plant is more effectively achieved by focussing on the effluent water of a rapid sand filter instead of the influent (this thesis).

3. Removal of arsenic from drinking water is possible to levels much lower than the WHO guideline $(10 \mu \mathrm{g} / \mathrm{L})$ and therefore global drinking water limits should be reassessed.

4. Availability of medical information on the internet is a health threat.

5. More nuclear power plants should be built in the Netherlands to rapidly reduce Dutch $\mathrm{CO}_{2}$ emissions and effectively combat climate change.

6. A legal market in organs is required to increase the number of organ transplantations and therefore save lives.

7. Only in low-income countries with democratically chosen governments is international aid an effective method to reduce poverty.

Propositions belonging to the thesis, entitled

Arsenic removal by iron based co-precipitation:

Mechanisms in groundwater treatment

Arslan Ahmad

Wageningen, 5 June 2020 


\section{Arsenic removal by iron based co-precipitation Mechanisms in groundwater treatment}




\section{Thesis committee}

\section{Promotors}

Prof. Dr. Albert van der Wal

Professor of Electrochemical Water Treatment

Wageningen University \& Research

Prof. Dr. Prosun Bhattacharya

Professor of Groundwater Chemistry

KTH Royal Institute of Technology, Stockholm, Sweden

\section{Co-promotor}

Dr. Harry Bruning

Assistant professor, Environmental Technology

Wageningen University \& Research

\section{Other members}

Prof. Dr. Rob N.J. Comans, Wageningen University \& Research

Prof. Dr. Jon Petter Gustafsson, Swedish University of Agricultural Sciences, Uppsala, Sweden

Dr. Mieke W.J. Luiten - Olieman, University of Twente, Enschede

Dr. Stephan Hug, Eawag, Swiss Federal Institute of Aquatic Science and Technology, Dübendorf, Switzerland

This research was conducted under the auspices of Research School for the Socio-Economic and Natural Sciences of the Environment (SENSE). 


\title{
Arsenic removal by iron based co-precipitation \\ Mechanisms in groundwater treatment
}

\author{
Arslan Ahmad
}

Thesis

submitted in fulfilment of the requirements for the degree of doctor at Wageningen University

by the authority of the Rector Magnificus,

Prof. Dr A.P.J. Mol, in the presence of the

Thesis Committee appointed by the Academic Board to be defended in public on Friday 5 June 2020 at 11 a.m. in the Aula. 


\section{A. Ahmad}

Arsenic removal by iron based co-precipitation: Mechanisms in groundwater treatment, 194 pages.

$\mathrm{PhD}$ thesis, Wageningen University, Wageningen, the Netherlands (2020) With references, with summary in English

ISBN 978-94-6395-374-0

DOI https://doi.org/10.18174/519635 
To my father and mother And, to wife and daughter 


\section{TABLE OF CONTENTS}

\section{Introduction}

$\begin{array}{lll}1.1 & \text { Arsenic in groundwater } & 12\end{array}$

1.2 Arsenic and drinking water in the Netherlands 14

1.3 Arsenic removal by co-precipitation with iron 16

1.4 Oxidation of As(III) to As $(\mathrm{V})$ with strong oxidants 18

1.5 Iron based co-precipitation with low-pressure membrane 19 filtration

$\begin{array}{lll}1.6 & \text { Research objectives } & 20\end{array}$

$\begin{array}{lll}1.7 & \text { Thesis outline } & 21\end{array}$

References $\quad 22$

\section{Arsenite removal in groundwater treatment plants by permanganate and ferric treatment}

Abstract $\quad 32$

2.1 Introduction 33

2.2 Materials and methods 36

2.2.1 Treatment layout and water quality of WTP Dorst 36

2.2.2 Optimizing $\mathrm{MnO}_{4}^{-}-\mathrm{Fe}$ (III) doses to achieve $<1 \mu \mathrm{g} / \mathrm{L}$ As 36

2.2.3 Influence of $\mathrm{MnO}_{4}^{-}-\mathrm{Fe}$ (III) dosing on removal of $\mathrm{As}, \mathrm{Fe}, \mathrm{Mn}$ and $\mathrm{NH}_{4}^{+}$

2.2.4 Influence of $\mathrm{MnO}_{4}^{-}-\mathrm{Fe}$ (III) dosage on filter backwash solids 39 characteristics

2.2.5 Settling characteristics of filter backwash solids 39

2.2.6 Solid phase characterization $\quad 40$

2.2.7 Analysis of water samples 40

2.3 Results and discussion $\quad 41$

2.3.1 Optimizing $\mathrm{MnO}_{4}^{-}-\mathrm{Fe}(\mathrm{III})$ doses to achieve $<1 \mu \mathrm{g} / \mathrm{L}$ As $\quad 41$

2.3.2 Influence of $\mathrm{MnO}_{4}^{-}-\mathrm{Fe}$ (III) dose on $\mathrm{As}, \mathrm{Fe}, \mathrm{Mn}$ and $\mathrm{NH}_{4}^{+}$ removal profiles

2.3.3 Influence of $\mathrm{MnO}_{4}^{-}-\mathrm{Fe}$ (III) dosing on filter backwash solids 46

2.4 Conclusions 50

Acknowledgements $\quad 51$

References $\quad 52$ 
3. Characteristics of Fe and $\mathrm{Mn}$ bearing precipitates generated by $\mathrm{Fe}(\mathrm{II})$ and $\mathrm{Mn}$ (II) co-oxidation with $\mathrm{O}_{2}, \mathrm{MnO}_{4}$ and $\mathrm{HOCl}$ in the presence of groundwater ions

Abstract $\quad 58$

3.1 Introduction $\quad 59$

3.2 Materials and Methods $\quad 60$

$\begin{array}{lll}3.2 .1 & \text { Chemicals } & 60\end{array}$

3.2.2 Oxidation and precipitation experiments 60

$\begin{array}{lll}3.2 .3 & \text { Settling experiments } & 62\end{array}$

3.2.4 X-ray absorption spectroscopy $\quad 62$

3.3 Results 65

3.3.1 Macroscopic precipitate properties $\quad 65$

$\begin{array}{lll}\text { 3.3.2 } \mathrm{Mn} / \mathrm{Fe} \text { solid ratios } & 67\end{array}$

3.3.3 Fe K-edge EXAFS spectroscopy $\quad 68$

3.3.4 Mn K-edge XANES spectroscopy 69

3.3.5 Mn K-edge EXAFS spectroscopy 70

3.4 Discussion 75

3.4.1 Effect of oxidant and solution chemistry on Fe(III) speciation $\quad 75$ and particle aggregation

3.4.2 Behavior of $\mathrm{Mn}(\mathrm{II})$ during co-oxidation with Fe(II) $\quad 78$

3.4.3 Impact of ionic composition 79

3.5 Conclusions and implications for water treatment 80

Acknowledgement $\quad 82$

Supplementary Information $\quad 82$

References $\quad 88$

4. Mobility and redox transformation of arsenic during treatment of artificially recharged groundwater for drinking water production Abstract 94

4.1 Introduction 95

4.2 Materials and methods 96

4.2.1 Water treatment plants 96

4.2.2 Sampling campaigns 98

4.2.3 Batch experiments 99

4.2.4 Chemical characterization of rapid sand filter material $\quad 100$

4.2.5 Microbial community analysis on rapid sand filter material 101

4.2.6 Chemicals and other apparatus 101

4.2.7 Conservation and analysis of water samples 102 
$\begin{array}{lll}4.3 & \text { Results and discussion } & 102\end{array}$

4.3.1 Arsenic removal during dune-water treatment 102

4.3.2 Oxidation and removal of arsenic over filter bed height 103

$\begin{array}{ll}\text { 4.3.3 Rapid sand filter media surface coating } & 106\end{array}$

4.3.4 Taxonomic community profiling of 16S rRNA sequences 106

4.3.5 Arsenic adsorption onto rapid sand filter material 108

4.3.6 Impact of extended residence time in supernatant 110

4.3.7 Arsenic reduction below $1 \mu \mathrm{g} / \mathrm{L}$ at dune-water treatment plants 111

4.4 Conclusions and implications for water treatment 114

Acknowledgments 114

Supplementary Information $\quad 115$

$\begin{array}{ll}\text { References } & 117\end{array}$

5. Impact of phosphate, silicate and natural organic matter on the size of Fe(III) precipitates and arsenate co-precipitation efficiency in calcium containing water

$\begin{array}{ll}\text { Abstract } & 124\end{array}$

$\begin{array}{lll}5.1 & 125\end{array}$

5.2 Materials and methods 126

$\begin{array}{lll}\text { 5.2.1 Chemicals and stock solutions } & 126\end{array}$

$\begin{array}{ll}\text { 5.2.2 Composition of initial solutions } & 126\end{array}$

$\begin{array}{lll}\text { 5.2.3 Co-precipitation experiments } & 127\end{array}$

$\begin{array}{ll}\text { 5.2.4 Wet analysis } & 129\end{array}$

$\begin{array}{ll}\text { 5.2.5 Particle characterization } & 129\end{array}$

$\begin{array}{lll}5.3 & \text { Results and discussion } & 130\end{array}$

5.3.1 Size distribution and filterability of Fe(III) precipitates $\quad 130$

$\begin{array}{lll}\text { 5.3.2 Arsenic removal } & 134\end{array}$

5.4 Conclusions and implications for water treatment 139

Acknowledgement 139

Supplementary information $\quad 140$

References $\quad 142$

6. Mechanisms of arsenate removal and membrane fouling in ferric based co-precipitation and low pressure membrane filtration systems

Abstract 148

$\begin{array}{lll}6.1 & 149\end{array}$

6.2 Materials and methods 150 
6.2.1 Feed water 150

6.2.2 Membrane and module characteristics 151

6.2.3 Membrane filtration apparatus and filtration procedure 151

6.2.4 Reagents and chemicals $\quad 152$

6.2.5 Analysis methods for water samples 153

6.2.6 SEM-EDX analysis 153

6.2.7 Calculations 154

6.3 Results and discussion $\quad 156$

6.3.1 Arsenic removal efficiency 156

6.3.2 Membrane fouling 159

6.4 Conclusions and implications for the practice 162

Acknowledgement 164

Supplementary Information $\quad 165$

$\begin{array}{ll}\text { References } & 169\end{array}$

\section{General discussion and outlook}

$\begin{array}{lll}7.1 & \text { Main findings and perspectives } & 174\end{array}$

7.1.1 Rapid sand filters are the arsenic removal hotspots $\quad 174$

7.1.2 Dosing strong oxidant improves arsenic removal but impacts $\quad 174$ iron and manganese oxidation mechanisms in rapid sand filters

7.1.3 Oxidant identity impacts the composition and structure of iron 175 and manganese oxidation products

7.1.4 Ionic composition of water affects arsenic removal by iron based $\quad 176$ co-precipitation

7.1.5 Ferric based co-precipitation of arsenic in combination with $\quad 176$ ultrafiltration is a highly viable arsenic removal technology post rapid sand filtration

$\begin{array}{lll}\text { 7.2 Implementation of results and further considerations } & 177\end{array}$

$\begin{array}{ll}\text { References } & 179\end{array}$

Summary $\quad 184$

$\begin{array}{ll}\text { Samenvatting } & 187\end{array}$

List of publications in this thesis $\quad 190$

Acknowledgements 191

About the author 192 



\section{Chapter 1}

Introduction

Parts of this chapter have been published as:

Ahmad, A., van der Wens, P., Baken, K., de Waal, L., Bhattacharya,P., \& Stuyfzand, P. (2020). Arsenic reduction to $<1 \mu \mathrm{g} / \mathrm{L}$ in Dutch drinking water. Environment International, 134, 105253.

Ahmad, A., Richards, L. A., \& Bhattacharya, P. (2017). Arsenic remediation of drinking water: an overview. In P. Bhattacharya, D. A. Polya, \& D. Jovanovic (Eds.), Best Practice Guide on the Control of Arsenic in Drinking Water (pp. 79-98). IWA Publishing. London, UK. 


\subsection{ARSENIC IN GROUNDWATER}

Arsenic (As) is a naturally occurring metalloid, widely found in groundwater. In reducing aqueous environments, trivalent arsenite As(III) is prevalent and in oxidizing environments pentavalent arsenate $[\mathrm{As}(\mathrm{V})]$ is prevalent. The distribution of aqueous As species as a function of $\mathrm{pH}$ and redox conditions is given in Fig 1.1. Arsenic is highly toxic for humans. Chronic intake of As can cause several types of cancer and other adverse effects on human health, as indicated in Fig 1.2 (Das and Sengupta 2008, Ferreccio et al. 2013, Gibb et al. 2011, IARC 2012, Islam et al. 2012, Jovanovic et al. 2013, Marshall et al. 2007, Parvez et al. 2011, Rahman et al. 2011, Sengupta et al. 2008, Smith et al. 1992).

Millions of people worldwide rely on As contaminated groundwater for potable use (Fig 1.3). Most of the affected populations live in South Asia, particularly in Bangladesh, India, Pakistan and Nepal (Ahmad and Bhattacharya 2018a, b, Ahmed et al. 2004, Bhattacharya et al. 2002b, Mukherjee et al. 2006, Mushtaq et al. 2018). Major reports of As contaminated groundwater have also emerged from several countries in the Eurasian region such as Turkey, Greece, Romania, Slovakia, Croatia, Serbia, Hungary, Spain (Baba and Sözbilir 2012, Bundschuh et al. 2013, GarcíaSánchez et al. 2005, Lindberg et al. 2006, Papić et al. 2012, Rowland et al. 2011, Varsányi and Kovács 2006) and several Latin American countries such as Argentina, Bolivia, Chile and Uruguay (Bundschuh et al. 2010, Kapaj et al., 2006, Litter et al. 2010, Ormachea Muñoz et al. 2013, 2016, Quino Lima et al., 2019, 2020, Ramos Ramos et al. 2012). The World Health Organization (WHO) guideline for As in drinking water is currently set at $10 \mu \mathrm{g} / \mathrm{L}$. However, recent studies suggest that As can cause a considerable damage to human health even at concentrations lower than the WHO guideline (Ahmad and Bhattacharya 2019, Kozisek 2017, Saint-Jacques et al. 2018, Schmidt 2014). Consequently, several drinking water companies in the Netherlands are making efforts to reduce As concentrations in drinking water to very low concentrations, below $1 \mu \mathrm{g} / \mathrm{L}$ (Ahmad et al. 2020, Van der Wens et al. 2016).

Arsenic removal from water has been extensively investigated in recent years. Arsenic removal methods can be broadly grouped into four categories; (i) co-precipitation, (ii) adsorption, (iii) ion exchange and (iv) membrane separation. Salient features of different As removal methods are described in Table 1.1 (Ahmad et al. 2017, Hao et al. 2018, Hering et al. 2017, Litter et al. 2010, Luong et al. 2018, Mondal et al. 2013, Singh et al. 2015, Zouboulis and Katsoyiannis 2005). 


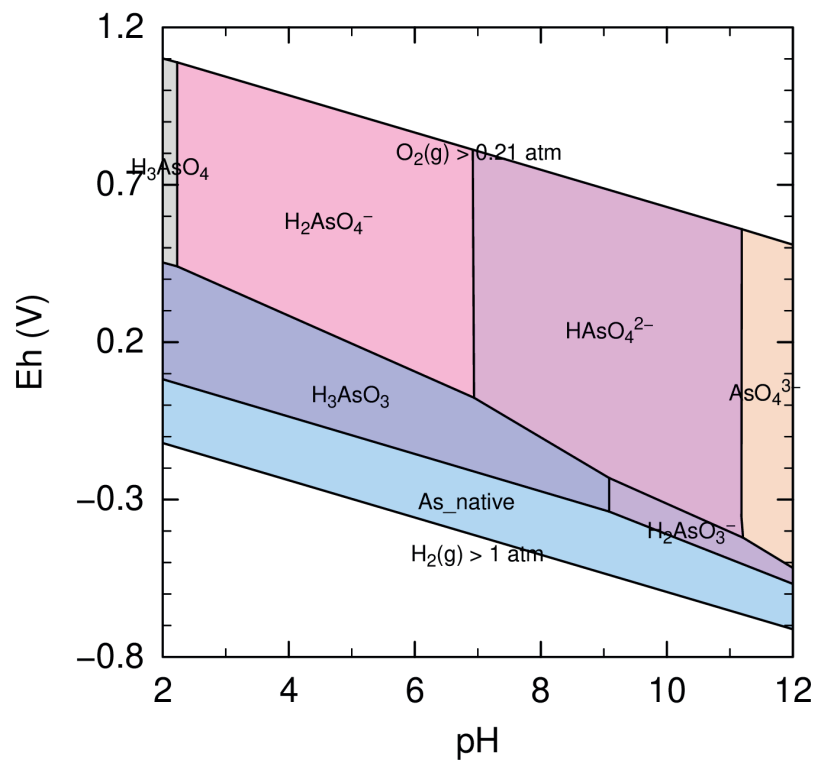

Figure 1.1 Eh-pH diagram for aqueous As species in the system $\mathrm{As}-\mathrm{O}_{2}-\mathrm{H}_{2} \mathrm{O}$ at $25^{\circ} \mathrm{C}$ and 1 bar total pressure, produced with PhreePlot using the wateq 4 f.dat database.

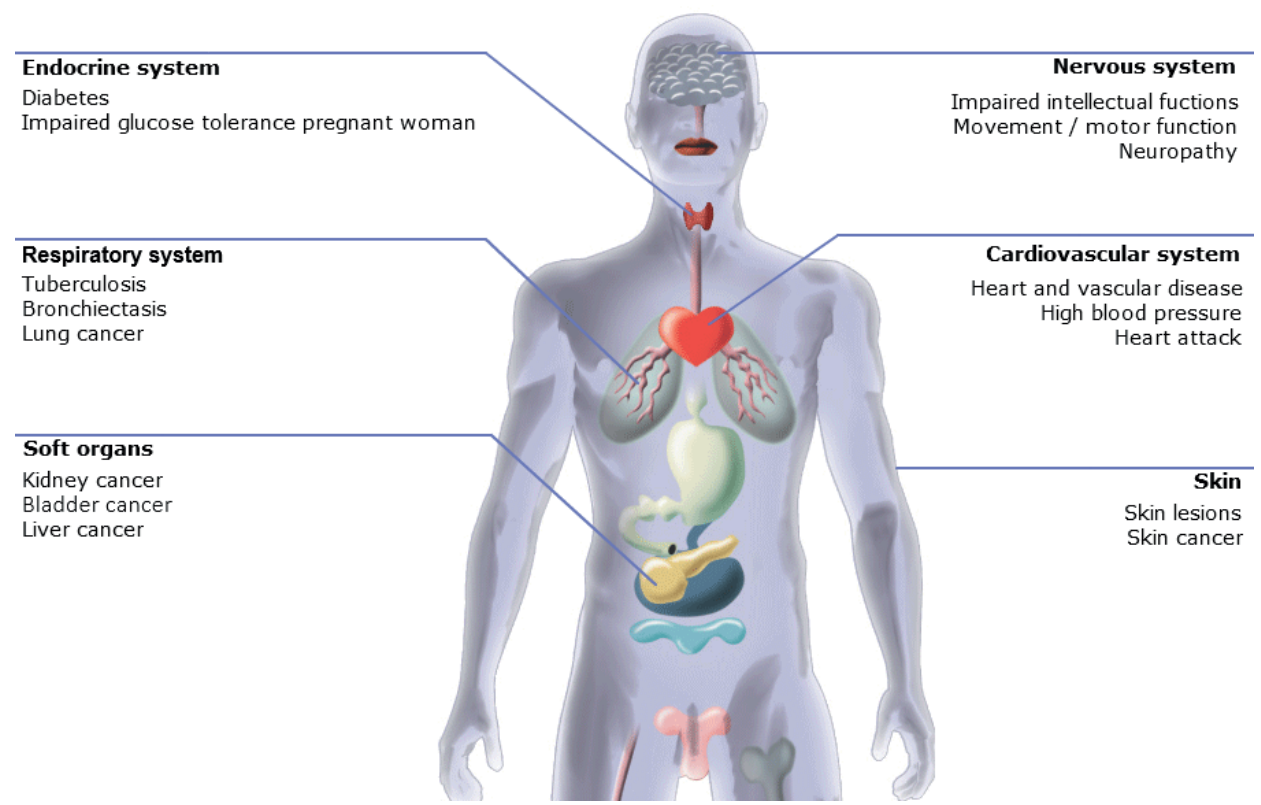

Figure 1.2 Adverse health effects due to chronic As intake through drinking water. 


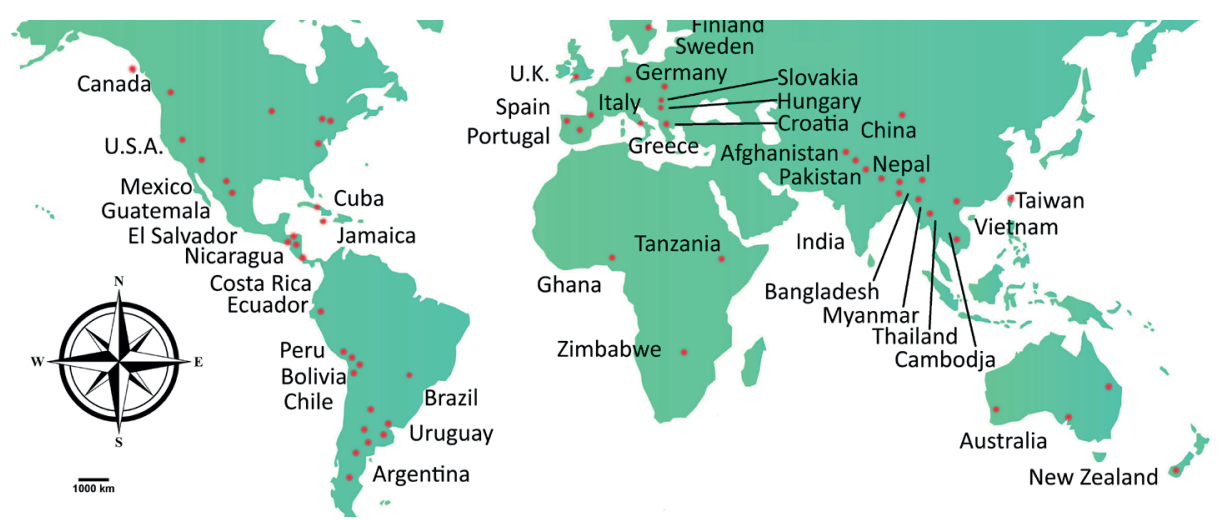

Figure 1.3 Arsenic contamination of groundwater in various countries around the world.

\subsection{ARSENIC AND DRINKING WATER IN THE NETHERLANDS}

In the Netherlands, drinking water is produced at about 180 centralized water treatment plants. Most of the drinking water $(65 \%)$ is obtained by treating natural or artificially infiltrated groundwater. In Public Supply Well Fields (PSWFs) ${ }^{1}$ mean As concentrations range between $<0.5-70 \mu \mathrm{g} / \mathrm{L}$ (Fig 1.4A). The As concentrations exceeding the $\mathrm{WHO}$ guideline $(10 \mu \mathrm{g} / \mathrm{L})$ are mainly observed in anoxic sand aquifers whereby As(III) is the predominant species (Ahmad et al. 2020, Flink 1985, Stuyfzand et al. 2008). Arsenic concentrations in the produced drinking water ranged between $<0.5-6 \mu \mathrm{g} / \mathrm{L}$, until recently (Fig 1.4B). Since 2017, several WTPs have received an upgrade to meet the $1 \mu \mathrm{g} / \mathrm{L}$ drinking water As guideline which has been voluntarily established by several water supply companies in the Netherlands since 2016 (Van der Wens et al. 2016).

Traditionally, As has been managed at the well-field level, e.g. by adjusting abstraction flows and well combinations. Some water treatment plants also exhibit natural As removal capacity up to some extent, attributed to co-precipitation of As with $\mathrm{Fe}(\mathrm{III})$ (oxyhydr)oxides that are formed due to oxidation of native $\mathrm{Fe}(\mathrm{II})$ in groundwater and subsequent hydrolysis (Gude et al. 2016). However, during groundwater treatment many interdependent physicochemical and biological processes (e.g. $\mathrm{Fe}(\mathrm{II}), \mathrm{Mn}(\mathrm{II})$ and $\mathrm{NH}_{4}^{+}$oxidation, taste and color removal etc.) take place whereby the fate of As is not yet fully elucidated. This knowledge is required to identify the water quality and operational parameters that can improve As removal at water treatment plants in order to produce drinking water with low As concentrations, below $1 \mu \mathrm{g} / \mathrm{L}$.

1. A PSWF is typically a coherent set of pumping wells delivering natural groundwater, artificially recharged surface water or river bank filtrate to the public as drinking water, mostly with and rarely without treatment. 
Table 1.1 Arsenic removal methods and their key advantages and disadvantages.

\begin{tabular}{|c|c|c|}
\hline Method & Advantages & Disadvantages \\
\hline \multicolumn{3}{|l|}{ Co-precipitation } \\
\hline $\begin{array}{l}\text { - Aeration-filtration of } \\
\text { natural Fe(II) containing } \\
\text { groundwater }\end{array}$ & $\begin{array}{l}\text { - High As }(V) \text { removal } \\
\text { efficiency over a wide pH } \\
\text { range }\end{array}$ & $\begin{array}{l}\text { - Pre-oxidation of As(III) by } \\
\text { dosing a strong oxidant is } \\
\text { required which increases cost of } \\
\text { treatment }\end{array}$ \\
\hline $\begin{array}{l}\text { - Coagulation-filtration with } \\
\text { Fe or Al coagulants }\end{array}$ & $\begin{array}{l}\text { Partial to complete As(III) } \\
\text { oxidation during Fe(II) } \\
\text { oxidation }\end{array}$ & $\begin{array}{l}\text { - As removal efficiency is reduced } \\
\text { due to competing ions }\end{array}$ \\
\hline $\begin{array}{l}\text { - Electrocoagulation with Fe } \\
\text { or Al electrodes }\end{array}$ & $\begin{array}{l}\text { - Partial to complete As(III) } \\
\text { oxidation during rapid sand } \\
\text { filtration }\end{array}$ & $\begin{array}{l}\text { - As removal efficiency is lower at } \\
\text { high pH (above PZC of solids) }\end{array}$ \\
\hline $\begin{array}{l}\text { - Natural corrosion of } \mathrm{Fe}(0) \text { in } \\
\text { the presence of oxygen }\end{array}$ & $\begin{array}{l}\text { - Seasonal higher As } \\
\text { concentrations can be } \\
\text { managed by increasing } \\
\text { coagulant dose }\end{array}$ & - As laced sludge is produced \\
\hline
\end{tabular}

\section{Adsorption}

- Oxides and hydroxides of metals such as $\mathrm{Fe}, \mathrm{Al}$, zirconium and titanium

- Fe-Mn binary oxides

- Low cost Geological materials

- Nanoparticles
- Simple operation with low maintenance

- Suitable for house hold filters

- Availability of wide range of adsorption media in market
- Production of As contaminated (exhausted) adsorption media which require regeneration or safe disposal

- As removal efficiency is low above PZC of solids and therefore $\mathrm{pH}$ adjustment may be required

- Pre-treatment for the removal of suspended solids is required to avoid bed clogging with suspended solids

- Competing ions reduce As adsorption capacity

\section{Ion exchange}

- Synthetic resins

- High As removal efficiency

- Zeolites

- Commercial availability of resins

- Not suitable for As(III) removal. Pre-oxidation of As(III) by dosing a strong oxidant is required

- Regeneration and brine disposal is costly

- High capital cost for automated water production and media regeneration cycles

\section{Membrane separation}

- Nanofiltration (NF)

- High As removal efficiency

- High capital and operation costs, especially due to replacement of the membranes due to scaling

- Reverse Osmosis (RO) 

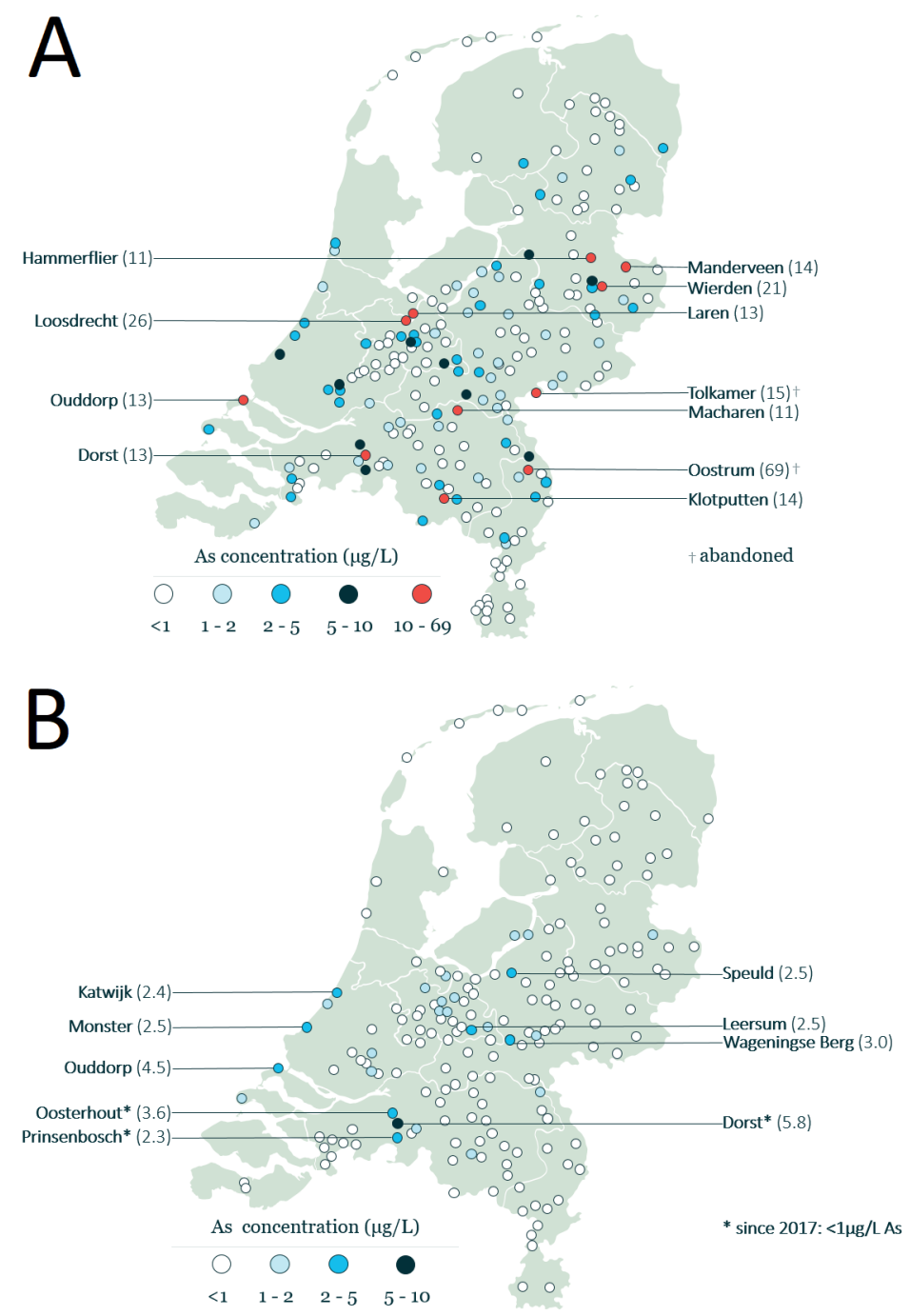

Figure 1.4 Mean As concentrations in (A) raw water pumped by the 241 PSWFs in the Netherlands (Stuyfzand et al. 2008) and (B) produced drinking water (Ahmad et al. 2015). The PSWFs with As concentrations higher than $10 \mu \mathrm{g} / \mathrm{L}$ are indicated. The abandoned PSWFs are marked with a graveyard icon. The water treatment plants with As concentrations higher than $1 \mu \mathrm{g} / \mathrm{L}$ are also indicated.

\subsection{ARSENIC REMOVAL BY CO-PRECIPITATION WITH IRON}

When $\mathrm{Fe}(\mathrm{III})$ (oxyhydr)oxides are produced in an As contaminated solution, As adsorbs to the surface of freshly formed $\mathrm{Fe}(\mathrm{III})$ precipitates by forming inner-sphere complexes (Fig. 1.5) (Hering et al. 1996a, Jain et al. 1999, Qiao et al. 2012, Van 
Genuchten et al. 2012b, Waychunas et al. 1993). The As bearing Fe(III) precipitates are removed by filtration to produce As-safe water. Fe(III) precipitates can be generated by several methods, including oxidation of naturally occurring $\mathrm{Fe}(\mathrm{II})$ in groundwater by $\mathrm{O}_{2}$ (Luong et al. 2018, Roberts et al. 2004, Vries et al. 2017, Xie et al. 2015), dosing an Fe(III) coagulant such as $\mathrm{FeCl}_{3}$ in water (Hering et al. 1996b, Qiao et al. 2012), electrolytic dissolution of Fe(0) (Lakshmanan et al. 2009, Müller et al. 2019, Van Genuchten et al. 2012b, Wan et al. 2011) and by natural corrosion of $\mathrm{Fe}(0)$ filings under oxic conditions (Bang et al. 2005). The adsorption efficiency of As onto $\mathrm{Fe}$ (III) precipitates and the size of As bearing Fe(III) particles is governed by several interdependent factors such as oxidation state of As, solution $\mathrm{pH}$ and the concentration of As and co-occurring ions with respect to Fe in the initial solution (Jain and Ali 2000, Kanematsu et al. 2013b, Pierce and Moore 1982, Raven et al. 1998, Senn et al. 2017, Wilkie and Hering 1996).
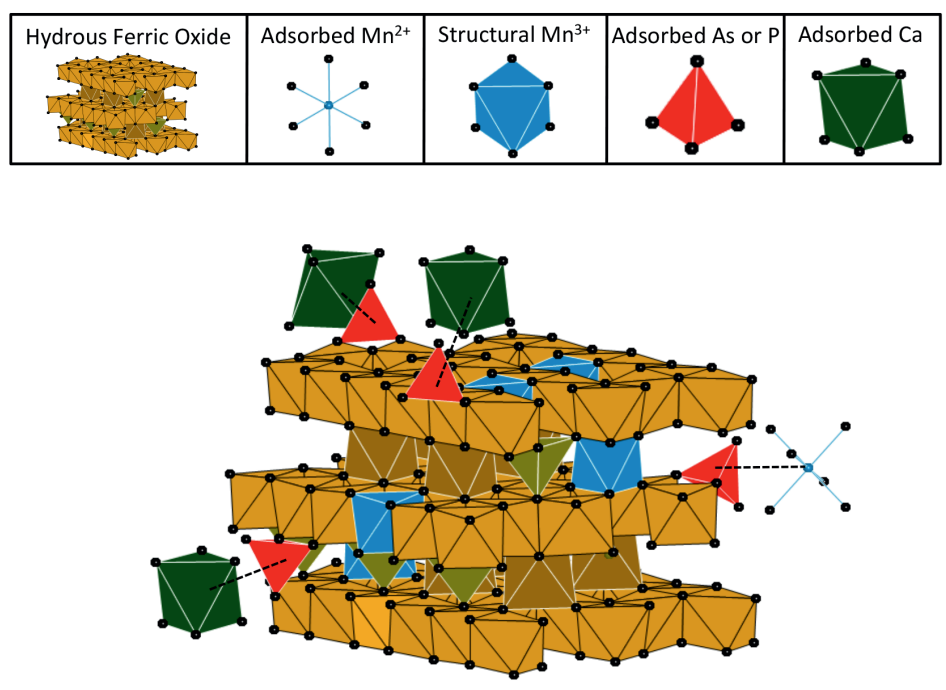

Figure 1.5 Co-precipitation of groundwater ions with Fe(III)(oxyhydr)oxides. Inner-sphere adsorption of As and P, ternary complex formation between oxyanions and $\mathrm{Ca}$, oxyanions and reduced $\mathrm{Mn}$ and structural incorporation of partially oxidized $\mathrm{Mn}$ is illustrated.

At $\mathrm{pH}$ relevant to most groundwaters (6.5-8.5), As $(\mathrm{V})$ is negatively charged and exhibits a higher affinity for the surface of Fe(III) precipitates than As(III) which is uncharged (Fig 1.1) (Hering et al. 1996a, Lakshmanan et al. 2008, Smedley and Kinniburgh 2002). Therefore, in order to effectively remove As from groundwater, oxidizing As(III) to As(V) before co-precipitation with Fe(III)(oxyhydr)oxides has 
been suggested (Guan et al. 2009a, Guan et al. 2009b, Sorlini and Gialdini 2010).

The most abundant oxyanions in natural waters which may reduce As coprecipitation are phosphate (i.e. $\mathrm{H}_{2} \mathrm{PO}_{4}^{-}$or $\mathrm{HPO}_{4}^{2-}$ ) and silicate (i.e. $\mathrm{H}_{4} \mathrm{SiO}_{4}$ ), denoted further as Si and P respectively (Fig 1.5) (Meng et al. 2000, Van Genuchten et al. 2012b, Van Genuchten et al. 2014b). Moreover, natural organic matter (NOM), especially humic substances (HS), can adversely affect As removal (Davis and Edwards 2017, Sharma et al. 2010, Weng et al. 2009). Besides competing with As for adsorption sites, these inorganic and organic solutes can modify the structure, composition and identity of the $\mathrm{Fe}(\mathrm{III})$ precipitates, thereby affecting their size and As uptake behaviour (Sposito 2008, Van Genuchten et al. 2014b). A detailed understanding of the interdependencies between As co-precipitation with $\mathrm{Fe}(\mathrm{III})$ precipitates, precipitate structure and precipitation conditions is not yet fully obtained. Groundwaters usually also contain significant concentration of bivalent cations, such as calcium $(\mathrm{Ca})$ and magnesium $(\mathrm{Mg})$, which have been shown to counteract the negative effects of oxyanions on As removal by Fe based coprecipitation through mechanisms such as neutralization of the $\mathrm{Fe}(\mathrm{III})$ precipitate surface charge (Wilkie and Hering 1996), suppression of electrostatic repulsion (Masue et al. 2007) and the formation of ternary complexes (Kanematsu et al. 2013b, Van Genuchten et al. 2014a). Previous studies have mostly focused on the interactions between As and $\mathrm{Fe}(\mathrm{III})$ precipitates in simple, single and binary solute systems (Laky and Licskó 2011, Weng et al. 2008, Weng et al. 2009). Systematic studies providing understanding of the As-Fe(III) interactions in complex multisolute solutions are limited which hampers accurate prediction and control of As removal by Fe based co-precipitation during water treatment.

\subsection{OXIDATION OF AS(III) TO AS(V) WITH STRONG OXIDANTS}

During groundwater treatment, dissolved Fe(II) in raw water oxidizes homogeneously, heterogeneously or biologically, or by a combination of these processes (Jessen et al. 2005, Van Beek et al. 2012, Vries et al. 2017). Oxidation of $\mathrm{Mn}$ (II) by $\mathrm{O}_{2}$ alone in a treatment plant is generally negligible because of the slow oxidation kinetics (Diem and Stumm 1984, Lytle et al. 2005), nevertheless bacteria and surface catalysts on the filter media grains transform $\mathrm{Mn}(\mathrm{II})$ to insoluble $\mathrm{MnO}_{\mathrm{x}}$ precipitates (Bruins et al. 2015, Katsoyiannis et al. 2008). The removal of $\mathrm{NH}_{4}^{+}$occurs in the filter bed, attributed to the biological oxidation (nitrification) executed by different bacterial species in the filter bed (De Moel et al. 2006, De Vet 2011).

Oxidation of As(III) by aeration introduced $\mathrm{O}_{2}$ is thermodynamically possible, however the reaction proceeds very slowly (Frank and Clifford 1986, Kim and Nriagu 
2000), rendering the traditional aeration techniques, e.g. spray or cascade aeration, inefficient in oxidizing As(III) (Jessen et al. 2005, Katsoyiannis et al. 2008, Lytle et al. 2007). To improve As removal capacity of water treatment plants, rapid oxidation of As(III) can be achieved by dosing a strong oxidant, such as $\mathrm{KMnO}_{4}$ or $\mathrm{NaOCl}$ (Ghurye and Clifford 2001, Lihua et al. 2009, Sorlini and Gialdini 2010). Previous work has shown that strong oxidants can oxidize other groundwater constituents such as Fe(II) and Mn(II) (Allard et al. 2013, Hao et al. 1991, Knocke et al. 1991, Van Benschoten et al. 1992) and may also interfere with nitrification in rapid sand filters. Detailed understanding of the impact of oxidant dosing on the pre-established $\mathrm{Fe}(\mathrm{II}), \mathrm{Mn}(\mathrm{II})$ and $\mathrm{NH}_{4}{ }^{+}$removal processes in rapid sand filters is not yet clear.

The structure, reactivity towards As and other ions, as well as the aggregation behaviour of Fe and Mn precipitates depend on $\mathrm{Fe}(\mathrm{II})$ and $\mathrm{Mn}$ (II) oxidation rates. For example, previous work has shown that poorly-ordered Fe(III) precipitates result from rapid $\mathrm{Fe}(\mathrm{II})$ oxidation by $\mathrm{H}_{2} \mathrm{O}_{2}$ and moderately crystalline $\mathrm{Fe}(\mathrm{III})$ precipitates form from slower Fe(II) oxidation by $\mathrm{O}_{2}$ (Van Genuchten and Pena 2017a, Voegelin et al. 2010). Such differences in crystallinity are important because poorly-ordered $\mathrm{Fe}(\mathrm{III})$ (oxyhydr) oxides have a higher specific surface area than crystalline solids, which would increase adsorption of ions (e.g. As) per mass of added Fe. The differences in the structure and composition of Fe(III) precipitates also affect their availability as terminal electron acceptors in redox-sensitive environments (Hyacinthe et al. 2008, Voegelin et al. 2010). Little is known about how other strong oxidants such as $\mathrm{KMnO}_{4}$ and $\mathrm{NaOCl}$ impact key properties e.g. structure, composition and precipitate aggregation behaviour of the Fe and Mn bearing precipitates generated by $\mathrm{Fe}(\mathrm{II})$ and $\mathrm{Mn}(\mathrm{II})$ co-oxidation.

\subsection{IRON BASED CO-PRECIPITATION WITH LOW-PRESSURE MEMBRANE FILTRATION}

At most groundwater treatment plants the As bearing $\mathrm{Fe}(\mathrm{III})$ precipitates are typically removed by rapid sand filtration (Gude et al. 2018a, Gude et al. 2016, 2018c, McNeill and Edwards 1995, Ruiping et al. 2009). These precipitates can also be removed by low-pressure membranes like microfiltration (MF) and ultrafiltration (UF), especially when effective removal of colloidal As bearing Fe(III) particles in a limited space is to be achieved (Brandhuber and Amy 1998, Choi and Dempsey 2004, Ghurye et al. 2004, Lee et al. 2004, Ruiping et al. 2009, Zouboulis and Katsoyiannis 2002). Depending on the size of Fe(III) particles and membrane pores, fouling in low-pressure membranes can be reversible or irreversible, involving mechanisms such as pore blocking, pore narrowing, entrapment (Zhang and Song 
2000) and/or adsorption onto the membrane surface. Currently, one of the reasons for the restriction of wide-scale application of low-pressure membrane filtration for As removal is a lack of detailed knowledge about membrane fouling due to $\mathrm{Fe}(\mathrm{III})$ particles and operational consequences.

\subsection{RESEARCH OBJECTIVES}

The overall objective of this thesis is to discern mechanistic understanding of As removal by co-precipitation with $\mathrm{Fe}(\mathrm{III})$ (oxyhydr)oxides under differential redox, ion composition and filtration conditions and to investigate routes to reduce As in drinking water to very low levels, below $1 \mu \mathrm{g} / \mathrm{L}$.

The specific research questions are:

I. What are the most important mechanisms that determine the mobilization and attenuation of As during groundwater treatment?

II. What is the impact of $\mathrm{KMnO}_{4}$ dosing on the co-precipitation of As with $\mathrm{Fe}$ (III) (oxyhydr)oxides? And, how does dosing $\mathrm{KMnO}_{4}$ affect $\mathrm{As}(\mathrm{III}), \mathrm{Fe}(\mathrm{II}), \mathrm{Mn}(\mathrm{II})$ and $\mathrm{NH}_{4}^{+}$removal mechanisms in rapid sand filters?

III. What impact different oxidants $\left(\mathrm{O}_{2}, \mathrm{KMnO}_{4}, \mathrm{NaOCl}\right)$ have on the structure of formed $\mathrm{Fe}$ and $\mathrm{Mn}$ bearing precipitates? Also, how does the common groundwater ions such as $\mathrm{Si}, \mathrm{P}$ and $\mathrm{Ca}$ affect the structure of the precipitates?

IV. What are the opportunities to reduce As to very low levels in produced drinking at water treatment plants which use artificially infiltrated groundwater as source?

V. How does $\mathrm{Si}, \mathrm{P}$ and NOM influence As co-precipitation efficiency with $\mathrm{Fe}(\mathrm{III})$ (oxyhydr)oxides and the size of $\mathrm{Fe}(\mathrm{III})$ particles in waters with high Ca hardness?

VI. How does in-line $\mathrm{FeCl}_{3}$ dosing improve As removal in low-pressure membranes and what are the predominant membrane fouling mechanisms? 


\subsection{THESIS OUTLINE}

Chapter 1 (this chapter) presents introduction and objectives of this thesis.

In Chapter 2 we provide details on pilot and full-scale investigations that were carried out at a groundwater treatment plant in the Netherlands. We discern mechanistic details of As removal during aeration and rapid sand filtration type anaerobic groundwater treatment systems (Research Question I). Moreover, we investigate the potential of As(III) oxidation with $\mathrm{KMnO}_{4}$ and co-precipitation of resulting $\mathrm{As}(\mathrm{V})$ with $\mathrm{Fe}(\mathrm{III})$ (oxyhydr)oxides for As removal to below $1 \mu \mathrm{g} / \mathrm{L}$. In this chapter we also reveal the effects of adopting $\mathrm{KMnO}_{4}$ and $\mathrm{FeCl}_{3}$ dosing on the preexisting $\mathrm{Fe}(\mathrm{II}), \mathrm{Mn}(\mathrm{II})$ and $\mathrm{NH}_{4}{ }^{+}$removal mechanisms in rapid sand filters (Research Question II).

Chapter 3 is based on laboratory investigations whereby macroscopic measurements of precipitate aggregation and chemical composition are combined with X-ray absorption spectroscopy to investigate the solids formed by co-oxidation of Fe(II) and $\mathrm{Mn}(\mathrm{II})$ with $\mathrm{O}_{2}, \mathrm{KMnO}_{4}$, and $\mathrm{NaOCl}$ in the presence and absence of groundwater ions such as Si, P and Ca (Research Question III).

In Chapter 4 we present insights into the mobility and redox transformation of As during treatment of artificially recharged groundwater which is typically much more extensive than the treatment of natural groundwater (Research Question I). In this chapter we also explore opportunities for reducing As in drinking water to very low levels, below $1 \mu \mathrm{g} / \mathrm{L}$ (Research Question IV).

Chapter 5 provides a detailed understanding of the independent and combined effects of Si, P and NOM on As removal by co-precipitation with Fe(III)(oxyhydr) oxides and the size of resulting $\mathrm{Fe}(\mathrm{III})$ precipitates in waters with high $\mathrm{Ca}$ hardness (Research Question V).

In Chapter 6 we present a laboratory study performed with different water types and low-pressure membranes to gain insights into the mechanisms of As removal and membrane fouling in $\mathrm{Fe}$ (III) based coprecipitation followed by low pressure membrane filtration systems (Research Question VI).

In Chapter 7 the results from this thesis are combined to address the main problem definition and research questions stated in Chapter 1. 


\section{REFERENCES}

Ahmad, A. \& Bhattacharya, P. (2018a). Arsenic Contamination of Groundwater in Indus River Basin of Pakistan. In A. Mukherjee (Ed.), Groundwater of South Asia (pp. 393-403). Singapore: Springer Singapore

Ahmad, A. \& Bhattacharya, P. (2018b). Environmental Arsenic in a Changing World - Report on The 7th International Congress on Arsenic in the Environment, 1-7 July 2018 Beijing, China. Groundwater for Sustainable Development. doi:https://doi.org/10.1016/j.gsd.2018.11.001

Ahmad, A. \& Bhattacharya, P. (2019). Arsenic in Drinking Water: Is $10 \mu \mathrm{g} / \mathrm{L}$ a Safe Limit? Current Pollution Reports, 5, 1-3. doi:10.1007/s40726-019-0102-7

Ahmad, A., Kools, S., Schriks, M., Stuyfzand, P., \& Hofs, B. (2015). Arsenic and chromium concentrations and their speciation in groundwater resources and drinking water supply in the Netherlands. KWR BTO Report 2015.017. Nieuwegein, the Netherlands

Ahmad, A., Richards, L. A., \& Bhattacharya, P. (2017). Arsenic remediation of drinking water: an overview. In P. Bhattacharya, D. A. Polya, \& D. Jovanovic (Eds.), Best Practice Guide on the Control of Arsenic in Drinking Water (pp. 79-98). IWA Publishing. London, UK

Ahmad, A., van der Wens, P., Baken, K., de Waal, L., Bhattacharya, P., \& Stuyfzand, P. (2020). Arsenic reduction to $<1 \mu \mathrm{g} / \mathrm{L}$ in Dutch drinking water. Environ Int, 134, 105253. doi:https://doi. org/10.1016/j.envint.2019.105253

Ahmed, K. M., Bhattacharya, P., Hasan, M. A., Akhter, S. H., Alam, S. M. M., Bhuyian, M. A. H., . . Sracek, O. (2004). Arsenic enrichment in groundwater of the alluvial aquifers in Bangladesh: an overview. Applied Geochemistry, 19(2), 181-200. doi:https://doi.org/10.1016/j. apgeochem.2003.09.006

Allard, S., Fouché, L., Dick, J., Heitz, A., \& von Gunten, U. (2013). Oxidation of Manganese(II) during Chlorination: Role of Bromide. Environmental Science \& Technology, 47(15), 87168723

Baba, A., \& Sözbilir, H. (2012). Source of arsenic based on geological and hydrogeochemical properties of geothermal systems in Western Turkey. Chemical Geology, 334, 364-377. doi:https://doi. org/10.1016/j.chemgeo.2012.06.006

Bang, S., Korfiatis, G. P., \& Meng, X. (2005). Removal of arsenic from water by zero-valent iron. J Hazard Mater, 121(1-3), 61-67. doi:10.1016/j.jhazmat.2005.01.030

Bhattacharya, P., Jacks, G., S.H., F., E., S., Naidu, R., \& Sarkar, B. (2002). Arsenic in the Environment: A Global Perspective. In B. Sarkar (Ed.), Heavy Metals in the Environment (pp. 147-215). New York. Basel: Marcel Dekker, Inc.

Brandhuber, P., \& Amy, G. (1998). Alternative methods for membrane filtration of arsenic from drinking water. Desalination, 117(1), 1-10. doi:http://dx.doi.org/10.1016/S0011-9164(98)00061-7

Bruins, J. H., Petrusevski, B., Slokar, Y. M., Kruithof, J. C., \& Kennedy, M. D. (2015). Manganese removal from groundwater: Characterization of filter media coating. Desalination and Water Treatment, 55(7), 1851-1863. doi:10.1080/19443994.2014.927802

Bundschuh, J., Litter, M., Ciminelli, V. S. T., Morgada, M. E., Cornejo, L., Hoyos, S. G., . . . Bhattacharya, P. (2010). Emerging mitigation needs and sustainable options for solving the arsenic problems of rural and isolated urban areas in Latin America - A critical analysis. Water Research, 44(19), 5828-5845. doi:https://doi.org/10.1016/j.watres.2010.04.001

Bundschuh, J., Maity, J. P., Nath, B., Baba, A., Gunduz, O., Kulp, T. R., . . Chen, C.-Y. (2013). Naturally occurring arsenic in terrestrial geothermal systems of western Anatolia, Turkey: Potential role in contamination of freshwater resources. Journal of Hazardous Materials, 262, 951-959. doi:https://doi.org/10.1016/j.jhazmat.2013.01.039

Choi, K. Y.-j., \& Dempsey, B. A. (2004). In-line coagulation with low-pressure membrane filtration. 
Water Research, 38(19), 4271-4281. doi:https://doi.org/10.1016/j.watres.2004.08.006

Das, N. K., \& Sengupta, S. R. (2008). Arsenicosis: diagnosis and treatment. Indian J Dermatol Venereol Leprol 74(6), 571-581

Davis, C. C., \& Edwards, M. (2017). Role of Calcium in the Coagulation of NOM with Ferric Chloride. Environmental Science \& Technology, 51(20), 11652-11659. doi:10.1021/acs.est.7b02038

De Moel, P. J., Verberk, J. Q. J. C., \& van Dijk, J. C. (2006). Drinking Water: Principles and Practices. Delft, The Netherlands

De Vet, W. (2011). Biological drinking water treatment of anaerobic groundwater in trickling filters. $\mathrm{PhD}$ thesis at Technical University of Delft. Delft, the Netherlands

Diem, D., \& Stumm, W. (1984). Is dissolved $\mathrm{Mn}^{+2}$ being oxidized by $\mathrm{O}_{2}$ in absence of Mn-bacteria and surface catalysts? Geochimica et Cosmochimica Acta, 48, 1571-1573.

Ferreccio, C., Yuan, Y., Calle, J., Benítez, H., Parra, R. L., Acevedo, J., . . . Steinmaus, C. (2013). Arsenic, tobacco smoke, and occupation: Associations of multiple agents with lung and bladder cancer. Epidemiology, 24(6), 898-905. doi:10.1097/EDE.0b013e31829e3e03

Flink, J. (1985). The distribution of arsenic in the groundwater of the southern parts of the province of Noord-Brabant (in Dutch). RIVM Report. The Netherlands

Frank, P., \& Clifford, D. (1986). Arsenic(III) oxidation and removal from drinking water. USEPA Report EPA/600/2-86/021

García-Sánchez, A., Moyano, A., \& Mayorga, P. (2005). High arsenic contents in groundwater of central Spain. Environmental Geology, 47(6), 847-854. doi:10.1007/s00254-004-1216-8

Ghurye, G., Clifford, D., \& Tripp, A. (2004). Iron Coagulation and Direct Microfiltration to Remove Arsenic from Groundwater. American Water Works Association, 96(4), 143-152

Ghurye, G., \& Clifford, D. A. (2001). Laboratory Study on the Oxidation of Arsenic III to As V. USEPA Report EPA/600/R-01/021

Gibb, H., Haver, C., Gaylor, D., Ramasamy, S., Lee, J. S., Lobdell, D., . . Sams, R. (2011). Utility of recent studies to assess the National Research Council 2001 estimates of cancer risk from ingested arsenic. Environ Health Perspect, 119(3), 284-290. doi:10.1289/ehp.1002427

Guan, X., Dong, H., Ma, J., \& Jiang, L. (2009). Removal of arsenic from water: Effects of competing anions on As(III) removal in KMnO4-Fe(II) process. Water Research, 43(15), 3891-3899. doi:http://dx.doi.org/10.1016/j.watres.2009.06.008

Guan, X., Ma, J., Dong, H., \& Jiang, L. (2009). Removal of arsenic from water: Effect of calcium ions on As(III) removal in the KMnO4-Fe(II) process. Water Research, 43(20), 5119-5128. doi:http://dx.doi.org/10.1016/j.watres.2008.12.054

Gude, J. C. J., Joris, K., Huysman, K., Rietveld, L. C., \& van Halem, D. (2018). Effect of supernatant water level on As removal in biological rapid sand filters. Water Research X, 1, 100013. doi:https://doi.org/10.1016/j.wroa.2018.100013

Gude, J. C. J., Rietveld, L. C., \& van Halem, D. (2016). Fate of low arsenic concentrations during full-scale aeration and rapid filtration. Water Research, 88, 566-574. doi:10.1016/j. watres.2015.10.034

Gude, J. C. J., Rietveld, L. C., \& van Halem, D. (2018). Biological As(III) oxidation in rapid sand filters. Journal of Water Process Engineering, 21, 107-115. doi:https://doi.org/10.1016/j. jwpe.2017.12.003

Hao, L., Liu, M., Wang, N., \& Li, G. (2018). A critical review on arsenic removal from water using iron-based adsorbents. RSC Advances, 8(69), 39545-39560. doi:10.1039/C8RA08512A

Hao, O., P. Davis, A., \& H. Chang, P. (1991). Kinetics of Manganese(II) Oxidation with Chlorine. Journal of Environmental Engineering, 117(3)

Hering, J. G., Chen, P.-Y., Wilkie, J. A., Elimelech, M., \& Liang, S. (1996). Arsenic removal by ferric chloride. American Water Works Association, 88(4), 155-167

Hering, J. G., Chen, P. Y., Wilkie, J. A., \& Elimelech, M. (1996). Arsenic removal by ferric chloride. 
Journal of the American Water Works Association, 88, 155 - 167

Hering, J. G., Katsoyiannis, I. A., Theoduloz, G. A., Berg, M., and Hug, S. J. (2017). Arsenic Removal from Drinking Water: Experiences with Technologies and Constraints in Practice. Journal of Environmental Engineering, 143(5): 03117002.

Hyacinthe, C., Bonneville, S., \& Van Cappellen, P. (2008). Effect of Sorbed Fe(II) on the Initial Reduction Kinetics of 6-Line Ferrihydrite and Amorphous Ferric Phosphate by Shewanella putrefaciens. Geomicrobiology Journal, 25(3-4), 181-192. doi:10.1080/01490450802081911

IARC. (2012). A Review of Human Carcinogens: Arsenic, Metals, Fibres, and Dusts. IARC Monographs. Lyon, France

Islam, M. R., Khan, I., Hassan, S. M. N., McEvoy, M., Deste, C., Attia, J., . . Milton, A. H. (2012). Association between type 2 diabetes and chronic arsenic exposure in drinking water: A cross sectional study in Bangladesh. Environmental Health: A Global Access Science Source, 11(1). doi:10.1186/1476-069X-11-38

Jain, A., Raven, K., \& R.H., L. (1999). Arsenite and Arsenate Adsorption on Ferrihydrite: Surface Charge Reduction and Net OH- Release Stoichiometry. Environmental Science \& Technology, $33(8), 1179-1184$

Jain, C. K., \& Ali, I. (2000). Arsenic: Occurrence, toxicity and speciation techniques. Water Research, 34(17), 4304-4312. doi:10.1016/S0043-1354(00)00182-2

Jessen, S., Larsen, F., Koch, C. B., \& Arvin, E. (2005). Sorption and Desorption of Arsenic to Ferrihydrite in a Sand Filter. Environmental Science \& Technology, 39(20), 8045-8051. doi:10.1021/es050692x

Jovanovic, D., Rasic-Milutinovic, Z., Paunovic, K., Jakovljevic, B., Plavsic, S., \& Milosevic, J. (2013). Low levels of arsenic in drinking water and type 2 diabetes in Middle Banat region, Serbia. International Journal of Hygiene and Environmental Health, 216(1), 50-55. doi:10.1016/j. ijheh.2012.01.001

Kanematsu, M., Young, T. M., Fukushi, K., Green, P. G., \& Darby, J. L. (2013). Arsenic(III, V) adsorption on a goethite-based adsorbent in the presence of major co-existing ions: Modeling competitive adsorption consistent with spectroscopic and molecular evidence. Geochimica et Cosmochimica Acta, 106, 404-428. doi:https://doi.org/10.1016/j.gca.2012.09.055

Katsoyiannis, I. A., Zikoudi, A., \& Hug, S. J. (2008). Arsenic removal from groundwaters containing iron, ammonium, manganese and phosphate: A case study from a treatment unit in northern Greece. Desalination, 224(1-3), 330-339. doi:10.1016/j.desal.2007.06.014

Kapaj, S., Peterson, H., Liber K., \& Bhattacharya, P. (2006). Human health effects from chronic arsenic poisoning - A Review. J. Environ. Sci. Health, Part A., 41(10): 2399-2428 https://doi. org/10.1080/10934520600873571.

Kim, M.-J., \& Nriagu, J. (2000). Oxidation of arsenite in groundwater using ozone and oxygen. Science of the Total Environment, 247(1), 71-79. doi:https://doi.org/10.1016/S0048-9697(99)00470-2

Knocke, W. R., Van Benschoten, J. E., Kearney, M. J., Soborski, A. W., \& Reckhow, D. A. (1991). Kinetics of Manganese and Iron Oxidation by Potassium Permanganate and Chlorine Dioxide. AWWA, 83(6), 80-87

Kozisek, F. (2017). Regulatory aspects of Arsenic in drinking water. In P. Bhattacharya, D. A. Polya, \& D. Jovanovic (Eds.), Best Practice Guide on the Control of Arsenic in Drinking Water. . IWA Publishing. London, UK

Lakshmanan, D., Clifford, D., \& Samanta, G. (2008). Arsenic Removal by Coagulation with Aluminum, Iron, Titanium, and Zirconium. American Water Works Association, 100(2), 76-88

Lakshmanan, D., Clifford, D. A., \& Samanta, G. (2009). Ferrous and Ferric Ion Generation During Iron Electrocoagulation. Environmental Science \& Technology, 43(10), 3853-3859. doi:10.1021/es8036669

Laky, D., \& Licskó, I. (2011). Arsenic removal by ferric-chloride coagulation - effect of phosphate, 
bicarbonate and silicate. Water Science and Technology, 64(5), 1046-1055. doi:10.2166/ wst.2011.419

Lee, N., Amy, G., Croué, J.-P., \& Buisson, H. (2004). Identification and understanding of fouling in low-pressure membrane (MF/UF) filtration by natural organic matter (NOM). Water Research, 38(20), 4511-4523. doi:https://doi.org/10.1016/j.watres.2004.08.013

Lihua, S., Ruiping, L., Shengji, X., Yanling, Y., \& Guibai, L. (2009). Enhanced As(III) removal with permanganate oxidation, ferric chloride precipitation and sand filtration as pretreatment of ultrafiltration. Desalination, 243(1), 122-131. doi:http://dx.doi.org/10.1016/j. desal.2008.04.019

Lindberg, A.-L., Goessler, W., Gurzau, E., Koppova, K., Rudnai, P., Kumar, R., . . Vahter, M. (2006). Arsenic exposure in Hungary, Romania and Slovakia. Journal of Environmental Monitoring, 8(1), 203-208. doi:10.1039/B513206A

Litter, M. I., Ingallinella, A. M., Olmos, V., Savio, M., Difeo, G., Botto, L., . . Ahmad, A. (2019a). Arsenic in Argentina: Occurrence, human health, legislation and determination. Science of the Total Environment. doi:https://doi.org/10.1016/j.scitotenv.2019.04.262

Litter, M. I., Ingallinella, A. M., Olmos, V., Savio, M., Difeo, G., Botto, L., . . Ahmad, A. (2019b). Arsenic in Argentina: Technologies for arsenic removal from groundwater sources, investment costs and waste management practices. Science of the Total Environment. doi:https://doi. org/10.1016/j.scitotenv.2019.06.358

Litter, M. I., Morgada, M. E., \& Bundschuh, J. (2010). Possible treatments for arsenic removal in Latin American waters for human consumption. Environmental Pollution, 158(5), 1105-1118. doi:https://doi.org/10.1016/j.envpol.2010.01.028

Luong, V. T., Cañas Kurz, E. E., Hellriegel, U., Luu, T. L., Hoinkis, J., \& Bundschuh, J. (2018). Ironbased subsurface arsenic removal technologies by aeration: A review of the current state and future prospects. Water Research, 133, 110-122. doi:https://doi.org/10.1016/j.watres.2018.01.007

Lytle, D. A., Chen, A. S., Sorg, T. J., Phillips, S., \& French, K. (2007). Microbial As(III) oxidation in water treatment plant filters. American Water Works Association, 99(12), 72-86.

Lytle, D. A., Sorg, T. J., \& Snoeyink, V. L. (2005). Optimizing arsenic removal during iron removal: Theoretical and practical considerations. Journal of Water Supply: Research and Technology AQUA, 54(8), 545-560.

Marshall, G., Ferreccio, C., Yuan, Y., Bates, M. N., Steinmaus, C., Selvin, S., .. Smith, A. H. (2007). Fifty-Year study of lung and bladder cancer mortality in Chile related to arsenic in drinking water. Journal of the National Cancer Institute, 99(12), 920-928. doi:10.1093/jnci/djm004

Masue, Y., Loeppert, R. H., \& Kramer, T. A. (2007). Arsenate and Arsenite Adsorption and Desorption Behavior on Coprecipitated Aluminum:Iron Hydroxides. Environmental Science \& Technology, 41(3), 837-842. doi:10.1021/es061160z

McNeill, L. S., \& Edwards, M. (1995). Soluble arsenic removal at water treatment plants. American Water Works Association, 87(4), 105-113

Meng, X., Bang, S., \& Korfiatis, G. P. (2000). Effects of silicate, sulfate, and carbonate on arsenic removal by ferric chloride. Water Research, 34(4), 1255-1261. doi:10.1016/s0043-1354(99)00272-9

Mondal, P., Bhowmick, S., Chatterjee, D., Figoli, A., \& Van der Bruggen, B. (2013). Remediation of inorganic arsenic in groundwater for safe water supply: a critical assessment of technological solutions. Chemosphere, 92(2), 157-170. doi:10.1016/j.chemosphere.2013.01.097

Mukherjee, A., Sengupta, M. K., Hossain, M. A., Ahamed, S., Das, B., Nayak, B., . . Chakraborti, D. (2006). Arsenic contamination in groundwater: A global perspective with emphasis on the Asian scenario. Journal of Health, Population and Nutrition, 24(2), 142-163.

Müller, S., Behrends, T., \& Van Genuchten, C. M. (2019). Sustaining efficient production of aqueous iron during repeated operation of $\mathrm{Fe}(0)$-electrocoagulation. Water Research, 155, 455-464. doi:https://doi.org/10.1016/j.watres.2018.11.060 
Mushtaq, N., Younas, A., Mashiatullah, A., Javed, T., Ahmad, A., \& Farooqi, A. (2018). Hydrogeochemical and isotopic evaluation of groundwater with elevated arsenic in alkaline aquifers in Eastern Punjab, Pakistan. Chemosphere, 200, 576-586. doi:https://doi.org/10.1016/j. chemosphere.2018.02.154

Ormachea Muñoz, M., Garcia Aróstegui, J. L., Bhattacharya, P., Sracek, O., Garcia Moreno, M. E., Kohfahl, C., . . . Bundschuh, J. (2016). Geochemistry of naturally occurring arsenic in groundwater and surface-water in the southern part of the Poopó Lake basin, Bolivian Altiplano. Groundwater for Sustainable Development, 2-3, 104-116. doi:https://doi.org/10.1016/j. gsd.2016.04.002

Ormachea Muñoz, M., Wern, H., Johnsson, F., Bhattacharya, P., Sracek, O., Thunvik, R., . . . Bundschuh, J. (2013). Geogenic arsenic and other trace elements in the shallow hydrogeologic system of Southern Poopó Basin, Bolivian Altiplano. Journal of Hazardous Materials, 262, 924940. doi:https://doi.org/10.1016/j.jhazmat.2013.06.078

Papić, P., Ćuk, M., Todorović, M., Stojković, J., Hajdin, B., \& Atanacković, N. P. i., D. . (2012). Arsenic in Tap Water of Serbia’s South Pannonian Basin and Arsenic Risk Assessment. Polish Journal of Environmental Studies, 21(6), 1783-1790

Parvez, F., Wasserman, G. A., Factor-Litvak, P., Liu, X., Slavkovich, V., Siddique, A. B., . . Graziano, J. H. (2011). Arsenic exposure and motor function among children in Bangladesh. Environ Health Perspect, 119(11), 1665-1670. doi:10.1289/ehp.1103548

Pierce, M. L., \& Moore, C. B. (1982). Adsorption of arsenite and arsenate on amorphous iron hydroxide. Water Research, 16(7), 1247-1253. doi:10.1016/0043-1354(82)90143-9

Qiao, J., Jiang, Z., Sun, B., Sun, Y., Wang, Q., \& Guan, X. (2012). Arsenate and arsenite removal by $\mathrm{FeCl} 3$ : Effects of $\mathrm{pH}, \mathrm{As} / \mathrm{Fe}$ ratio, initial As concentration and co-existing solutes. Separation and Purification Technology, 92, 106-114. doi:10.1016/j.seppur.2012.03.023

Quino Lima, I., Ormachea Muñoz, M., Ramos Ramos, O.E., Bhattacharya, P., Quispe Choque, R., Quintanilla Aguirre, J. \& Sracek, O. (2019). Hydrochemical assessment with respect to arsenic and other trace elements in the Lower Katari Basin, Bolivian Altiplano. Groundwater for Sustainable Development 8: 281-293 http://doi.org/10.1016/j.gsd.2018.11.013.

Quino Lima, I., Ramos Ramos, O.E., Ormachea Muñoz, M., Quintanilla Aguirre, J., Duwig, C., Maity, J.P., Sracek, O., \& Bhattacharya, P. (2020). Spatial dependency of arsenic, antimony, boron and other trace elements in the shallow groundwater systems of the Lower Katari Basin, Bolivian Altiplano. Science of the Total Environment 719: 137505. https://doi.org/10.1016/j. scitotenv.2020.137505.

Rahman, A., Vahter, M., Ekström, E. C., \& Persson, L. Å. (2011). Arsenic exposure in pregnancy increases the risk of lower respiratory tract infection and diarrhea during infancy in Bangladesh. Environ Health Perspect, 119(5), 719-724. doi:10.1289/ehp.1002265

Ramos Ramos, O. E., Cáceres, L. F., Ormachea Muñoz, M. R., Bhattacharya, P., Quino, I., Quintanilla, J., . . García, M. E. (2012). Sources and behavior of arsenic and trace elements in groundwater and surface water in the Poopó Lake Basin, Bolivian Altiplano. Environmental Earth Sciences, 66(3), 793-807. doi:10.1007/s12665-011-1288-1

Raven, K. P., Jain, A., \& Loeppert, R. H. (1998). Arsenite and arsenate adsorption on ferrihydrite: Kinetics, equilibrium, and adsorption envelopes. Environmental Science and Technology, 32(3), 344-349. doi:10.1021/es970421p

Roberts, L. C., Hug, S. J., Ruettimann, T., Billah, M. M., Khan, A. W., \& Rahman, M. T. (2004). Arsenic Removal with Iron(II) and Iron(III) in Waters with High Silicate and Phosphate Concentrations. Environmental Science \& Technology, 38(1), 307-315. doi:10.1021/es0343205

Rowland, H. A. L., Omoregie, E. O., Millot, R., Jimenez, C., Mertens, J., Baciu, C., . . Berg, M. (2011). Geochemistry and arsenic behaviour in groundwater resources of the Pannonian Basin (Hungary and Romania). Applied Geochemistry, 26(1), 1-17. doi:https://doi.org/10.1016/j. 
apgeochem.2010.10.006

Ruiping, L., Lihua, S., Jiuhui, Q., \& Guibai, L. (2009). Arsenic removal through adsorption, sand filtration and ultrafiltration: In situ precipitated ferric and manganese binary oxides as adsorbents. Desalination, 249(3), 1233-1237. doi:https://doi.org/10.1016/j.desal.2009.06.032

Saint-Jacques, N., Brown, P., Nauta, L., Boxall, J., Parker, L., \& Dummer, T. J. B. (2018). Estimating the risk of bladder and kidney cancer from exposure to low-levels of arsenic in drinking water, Nova Scotia, Canada. Environ Int, 110, 95-104. doi:https://doi.org/10.1016/j.envint.2017.10.014

Schmidt, C. W. (2014). Low-Dose Arsenic: In Search of a Risk Threshold. Environ Health Perspect, 122(5), A131-134

Sengupta, S. R., Das, N. K., \& Datta, P. K. (2008). Pathogenesis, clinical features and pathology of chronic arsenicosis Indian J Dermatol Venereol Leprol 74(6), 559-570.

Senn, A.-C., Hug, S. J., Kaegi, R., Hering, J. G., \& Voegelin, A. (2017). Arsenate co-precipitation with $\mathrm{Fe}(\mathrm{II})$ oxidation products and retention or release during precipitate aging. Water Research. doi:https://doi.org/10.1016/j.watres.2017.12.038

Sharma, P., Ofner, J., \& Kappler, A. (2010). Formation of Binary and Ternary Colloids and Dissolved Complexes of Organic Matter, Fe and As. Environmental Science \& Technology, 44(12), 44794485. doi:10.1021/es100066s

Singh, R., Singh, S., Parihar, P., Pratap Singh, V., \& Mohan Prasad, S. (2015). Arsenic contamination, consequences and remediation techniques: A review. Ecotoxicology and Environmental Safety, $112,247-270$

Smedley, P. L., \& Kinniburgh, D. G. (2002). A review of the source, behaviour and distribution of arsenic in natural waters. Applied Geochemistry, 17(5), 517-568. doi:10.1016/s0883-2927(02)00018-5

Smith, A. H., Hopenhayn-Rich, C., Bates, M. N., Goeden, H. M., Hertz-Picciotto, I., Duggan, H. M., ... Smith, M. T. (1992). Cancer risks from arsenic in drinking water. Environ Health Perspect, 97, 259-267

Sorlini, S., \& Gialdini, F. (2010). Conventional oxidation treatments for the removal of arsenic with chlorine dioxide, hypochlorite, potassium permanganate and monochloramine. Water Research, 44(19), 5653-5659. doi:10.1016/j.watres.2010.06.032

Sposito, G. (2008). The Chemistry of Soils. Oxford University Press. New York

Stuyfzand, P., van Rossum, P., \& Mendizabal, I. (2008). Does arsenic, in groundwaters of the compound Rhine-Meuse-Scheldt-Eems delta, menace drinking water supply in the Netherlands? In T. Appelo (Ed.), Arsenic in groundwater - A world problem (pp. 102-125). Netherlands National Committee of the IAH. Utrecht, The Netherlands

Van Beek, C. G. E. M., Hiemstra, T., Hofs, B., Bederlof, M. M., van Paassen, J. A. M., \& Reijnen, G. K. (2012). Homogeneous, heterogeneous and biological oxidation of iron(II) in rapid sand filtration. Journal of Water Supply: Research and Technology-AQUA, 61(1), 1-2012.

Van Benschoten, J. E., Lin, W., \& Knocke, W. R. (1992). Kinetic modeling of manganese(II) oxidation by chlorine dioxide and potassium permanganate. Environmental Science \& Technology, 26(7), 1327-1333. doi:10.1021/es00031a008

Van der Wens, P., Baken, K., Schriks, M., 2016. Arsenic at low concentrations in Dutch drinking water: assessment of removal costs and health benefits. In: Bhattacharya, P., et al., (Eds.), Arsenic Research and Global Sustainability: Proceedings of the Sixth International Congress on Arsenic in the Environment (As2016), June 19-23, 2016, Stockholm, Sweden, CRC Press, pp. 563-564

Van Genuchten, C., \& Pena, J. (2017). Mn(II) Oxidation in Fenton and Fenton Type Systems: Identification of Reaction Efficiency and Reaction Products. Environmental Science \& Technology, 51(5), 2982-2991. doi:10.1021/acs.est.6b05584

Van Genuchten, C. M., Addy, S. E. A., Peña, J., \& Gadgil, A. J. (2012). Removing Arsenic from Synthetic Groundwater with Iron Electrocoagulation: An Fe and As K-Edge EXAFS Study. Environmental Science \& Technology, 46(2), 986-994. doi:10.1021/es201913a 
Van Genuchten, C. M., Gadgil, A. J., \& Peña, J. (2014). Fe(III) Nucleation in the Presence of Bivalent Cations and Oxyanions Leads to Subnanoscale $7 \AA$ Polymers. Environmental Science \& Technology, 48(20), 11828-11836. doi:10.1021/es503281a

Van Genuchten, C. M., Pena, J., Amrose S, E., \& Gadgil, A. J. (2014). Structure of Fe(III) precipitates genberated by the electrolytric dissolution of $\mathrm{Fe}(0)$ in the presence of groundwater ions. Geochimica et Cosmochimica Acta, 127, 285-304.

Varsányi, I., \& Kovács, L. Ó. (2006). Arsenic, iron and organic matter in sediments and groundwater in the Pannonian Basin, Hungary. Applied Geochemistry, 21(6), 949-963. doi:https://doi. org/10.1016/j.apgeochem.2006.03.006

Voegelin, A., Kaegi, R., Frommer, J., Vantelon, D., \& Hug, S. J. (2010). Effect of phosphate, silicate, and $\mathrm{Ca}$ on $\mathrm{Fe}$ (III)-precipitates formed in aerated Fe(II)- and As(III)-containing water studied by X-ray absorption spectroscopy. Geochimica et Cosmochimica Acta, 74(1), 164-186. doi:https:// doi.org/10.1016/j.gca.2009.09.020

Vries, D., Bertelkamp, C., Schoonenberg Kegel, F., Hofs, B., Dusseldorp, J., Bruins, J. H., . . van den Akker, B. (2017). Iron and manganese removal: Recent advances in modelling treatment efficiency by rapid sand filtration. Water Research, 109, 35-45. doi:10.1016/j.watres.2016.11.032

Wan, W., Pepping, T. J., Banerji, T., Chaudhari, S., \& Giammar, D. E. (2011). Effects of water chemistry on arsenic removal from drinking water by electrocoagulation. Water Research, 45(1), 384-392. doi:https://doi.org/10.1016/j.watres.2010.08.016

Waychunas, G. A., Rea, B. A., Fuller, C. C., \& Davis, J. A. (1993). Surface chemistry of ferrihydrite: Part 1. EXAFS studies of the geometry of coprecipitated and adsorbed arsenate. Geochimica et Cosmochimica Acta, 57(10), 2251-2269. doi:https://doi.org/10.1016/0016-7037(93)90567-G

Weng, L., Van Riemsdijk, W. H., \& Hiemstra, T. (2008). Humic nanoparticles at the oxide-water interface: Interactions with phosphate ion adsorption. Environmental Science and Technology, 42(23), 8747-8752. doi:10.1021/es801631d

Weng, L., Van Riemsdijk, W. H., \& Hiemstra, T. (2009). Effects of Fulvic and Humic Acids on Arsenate Adsorption to Goethite: Experiments and Modeling. Environmental Science \& Technology, 43(19), 7198-7204. doi:10.1021/es9000196

Wilkie, J. A., \& Hering, J. G. (1996). Adsorption of arsenic onto hydrous ferric oxide: Effects of adsorbate/adsorbent ratios and co-occurring solutes. Colloids and Surfaces A: Physicochemical and Engineering Aspects, 107, 97-110. doi:10.1016/0927-7757(95)03368-8

Xie, X., Wang, Y., Pi, K., Liu, C., Li, J., Liu, Y., . . D Duan, M. (2015). In situ treatment of arsenic contaminated groundwater by aquifer iron coating: Experimental study. Science of the Total Environment, 527-528, 38-46. doi:https://doi.org/10.1016/j.scitotenv.2015.05.002

Zhang, M., \& Song, L. (2000). Mechanisms and parameters affecting flux decline in cross-flow microfiltration and ultrafiltration of colloids. Environmental Science and Technology, 34(17), 3767-3773. doi:10.1021/es990475u

Zouboulis, A., \& Katsoyiannis, I. (2002). Removal of arsenate from contaminated water by coagulationdirect filtration. Separation Science and Technology, 37(12), 2859-2873. doi:10.1081/SS120005470

Zouboulis, A. I., \& Katsoyiannis, I. A. (2005). Recent advances in the bioremediation of arseniccontaminated groundwater. Environ Int, 31(2), 213-219. doi:10.1016/j.envint.2004.09.018 



\section{Chapter 2}

\section{Arsenite removal in groundwater treatment plants by permanganate and ferric treatment}

This chapter has been published as:

Ahmad, A., Cornelissen, E., van de Wetering, S., van Dijk, T., Van Genuchten, C., Bundschuh, J., van der Wal, A. Bhattacharya, P. (2018). Arsenite removal in groundwater treatment plants by sequential Permanganate - Ferric treatment. Journal of Water Process Engineering, 26, 221-229. 


\section{ABSTRACT}

The Dutch drinking water sector is actively investigating methods to reduce arsenic (As) to $<1 \mu \mathrm{g} / \mathrm{L}$ in drinking water supply. We investigated (1) the effectiveness of sequential permanganate $\left(\mathrm{MnO}_{4}^{-}\right)$- ferric $(\mathrm{Fe}(\mathrm{III}))$ dosing during aeration - rapid sand filtration to achieve $<1 \mu \mathrm{g} / \mathrm{L}$ As, (2) the influence of $\mathrm{MnO}_{4}^{-}-\mathrm{Fe}(\mathrm{III})$ dosing on pre-established removal patterns of $\mathrm{As}(\mathrm{III}), \mathrm{Fe}(\mathrm{II}), \mathrm{Mn}(\mathrm{II})$ and $\mathrm{NH}_{4}{ }^{+}$in rapid sand filters and (3) the influence of $\mathrm{MnO}_{4}^{-}-\mathrm{Fe}(\mathrm{III})$ dosing on the settling and molecularscale structural properties of the filter backwash solids. We report that $\mathrm{MnO}_{4}^{-}-$ $\mathrm{Fe}$ (III) dosing is an effective technique to improve arsenite [As(III)] removal at groundwater treatment plants. At a typical aeration - rapid sand filtration facility in the Netherlands effluent As concentrations of $<1 \mu \mathrm{g} / \mathrm{L}$ were achieved with $1.2 \mathrm{mg} / \mathrm{L}$ $\mathrm{MnO}_{4}^{-}$and $1.8 \mathrm{mg} / \mathrm{L} \mathrm{Fe}(\mathrm{III})$. The optimized combination of $\mathrm{MnO}_{4}^{-}$and $\mathrm{Fe}(\mathrm{III})$ doses did not affect the removal efficiency of $\mathrm{Fe}(\mathrm{II}), \mathrm{Mn}(\mathrm{II})$ and $\mathrm{NH}_{4}^{+}$in rapid sand filters, however, the removal patterns of $\mathrm{Fe}(\mathrm{II})$ and $\mathrm{Mn}$ (II) in rapid sand filter were altered, as well as the settling behaviour of backwash solids. The characterization of backwash solids by Fe K-edge X-ray absorption spectroscopy (XAS) and X-ray diffraction (XRD) showed that the changed settling velocity of backwash solids with $\mathrm{MnO}_{4}^{-}-\mathrm{Fe}$ (III) in place was not due to changes in the molecular-scale structure of Fe-precipitates that constitute the major portion of the backwash solids. 


\section{$2.1 \quad$ INTRODUCTION}

Arsenic (As) in drinking water is one of the largest human health risks known at the present time, with well over 200 million people around the world being exposed to high As concentrations (McCarty et al. 2011, Murcott 2012, Naujokas et al. 2013). Arsenic can be released from the Earth's crust into drinking water sources by both natural (e.g. leaching from rocks and sediments, volcanism) and anthropogenic processes (e.g. mining, agrochemicals, wood preservatives) (Bhattacharya et al. 2002a, Borba et al. 2003, Bundschuh et al. 2017, Gunduz et al. 2010, MacDonald et al. 2016, Marszałek and Wąsik 2000, Nriagu et al. 2007, Woo and Choi 2001). In aqueous environments As may occur in organic and inorganic forms, whereby the latter is known to predominate in fresh water (Bhattacharya et al. 2007, Pontius et al. 1994, Smedley and Kinniburgh 2002). Inorganic As predominantly occurs in two oxidation states; +3 and +5 , with varying level of protonation, depending on the pH (Ferguson and Gavis 1972, Pontius et al. 1994, Smedley and Kinniburgh 2002, Wang and Mulligan 2006).

Arsenic can cause a number of carcinogenic and non-carcinogenic adverse effects on human health (Schuhmacher-Wolz et al. 2009, Smith et al. 1992, Vahter 2008, Vahter et al. 2012), however, its mode of action and dose-response characteristics allowing for the identification of a safe exposure level are still not well-understood (Kozisek 2017, Pontius et al. 1994, Schmidt 2014, WHO 2011). This leads to considerable uncertainties about the actual risks of As exposure, especially at low concentrations (Kozisek 2017). Following a preventive approach, the Dutch drinking water sector is actively investigating treatment options to reduce trace levels of As from drinking water to $<1 \mu \mathrm{g} / \mathrm{L}$ (Van der Wens et al. 2016). Groundwater is the main source of drinking water in the Netherlands and As concentration in raw groundwater ranges between $<0.5-70 \mu \mathrm{g} / \mathrm{L}$ (Ahmad et al. 2015, Stuyfzand et al. 2008). In drinking water, produced at approximately 180 centralized Water Treatment Plants (WTPs), the concentration of As ranges between <0.5-6.2 $\mu \mathrm{g} / \mathrm{L}$ (Ahmad et al. 2015, Stuyfzand et al. 2008) which shows that As is removed with varying efficiencies during treatment and the resulting concentrations in drinking water are well below the WHO guideline $(10 \mu \mathrm{g} / \mathrm{L})$.

Most groundwater treatment plants in the Netherlands typically apply aeration followed by rapid sand filtration to accomplish the removal of dissolved iron $[\mathrm{Fe}(\mathrm{II})]$, manganese $[\mathrm{Mn}(\mathrm{II})]$ and ammonium $\left(\mathrm{NH}_{4}^{+}\right)$from water through distinct removal pathways (De Moel et al. 2006). Iron(II) may oxidize homogeneously, heterogeneously and biologically, or by a combined mechanism involving these processes, leaving hydrous ferric oxide (HFO) precipitates (Fe(III)-precipitates) in the supernatant, in the pores and on the surface of the filter media (Jessen et al. 
2005, Van Beek et al. 2012, Vries et al. 2017). Direct oxidation of Mn(II) by oxygen $\left(\mathrm{O}_{2}\right)$ is generally negligible (Diem and Stumm 1984, Lytle et al. 2005) and bacteria and surface catalysts on the filter media grains are known to transform $\mathrm{Mn}$ (II) to insoluble hydrous manganese oxide $\left(\mathrm{MnO}_{2}\right)$ (Bruins et al. 2015, Katsoyiannis et al. 2008). Ammonium is removed by nitrification which takes place in the filter bed, mediated by different bacterial species (De Moel et al. 2006, De Vet 2011). These treatment plants also remove As, attributed to adsorption to the precipitated HFO (Ahmad et al. 2015, Gude et al. 2016), as observed by McNeill and Edwards (1995) and Lytle et al. (2007) in several groundwater treatment plants in the United States, by Sorlini et al. (2014) in Italy and by Katsoyiannis et al. (2008) in Greece. The presence of anions in groundwater e.g. phosphate, sulfate, carbonate, silicate, as well as the natural organic matter may reduce the adsorption of As to $\mathrm{Fe}(\mathrm{III})$ precipitates due to their competition for adsorption sites (Dixit and Hering 2003, Hering et al. 1996a, Qiao et al. 2012, Su and Puls 2001, Wilkie and Hering 1996, Youngran et al. 2007), sometimes rendering the amount of natural Fe in raw water insufficient to achieve the target effluent As concentration. The concentration of Fe nevertheless can be increased by dosing an $\mathrm{Fe}$ (III) or $\mathrm{Fe}$ (II) based coagulant such as ferric chloride $\left(\mathrm{FeCl}_{3}\right)$ or ferrous sulfate $\left(\mathrm{FeSO}_{4}\right)$. The As removal efficiency may differ when $\mathrm{Fe}(\mathrm{II})$ or $\mathrm{Fe}$ (III) is dosed, per equal concentration of precipitated $\mathrm{Fe}$ (Gude et al. 2017, Roberts et al. 2004). In the Netherlands, $\mathrm{FeCl}_{3}$ is the most widely used coagulant in drinking water production and for this reason we chose it as the source of $\mathrm{Fe}$ in this study.

The adsorption of As to $\mathrm{Fe}$ (III)-precipitates is also sensitive to As species in water (Jain and Ali 2000, Pierce and Moore 1982, Raven et al. 1998, Wilkie and Hering 1996). The adsorption of $\mathrm{As}(\mathrm{V})$ to $\mathrm{Fe}(\mathrm{III})$-precipitates at low As/Fe molar ratios and $\mathrm{pH}$ relevant for most groundwater (6.5-8.5) is more efficient compared to As(III) (Hering et al. 1996a, Hsu et al. 2008, Lakshmanan et al. 2008, Lytle et al. 2005, Qiao et al. 2012), mainly because of the anionic character of As(V). Therefore, at WTPs where As(III) is a dominant species in source water, (pre-)oxidation of As(III) to $A s(\mathrm{~V})$ could increase As removal. Oxidation of As(III) by dissolved $\mathrm{O}_{2}$ alone is thermodynamically possible, however the reaction proceeds very slowly (Frank and Clifford 1986, Kim and Nriagu 2000), rendering the traditional aeration techniques, e.g. spray or cascade aeration, inefficient in oxidizing As(III) (Jessen et al. 2005, Katsoyiannis et al. 2008, Lytle et al. 2007). Chemical oxidants, such as chlorine, ozone, hydrogen peroxide, permanganate $\left(\mathrm{MnO}_{4}^{-}\right)$etc. have been shown to achieve rapid oxidation of $\mathrm{As}(\mathrm{III})$ (Bissen and Frimmel 2003). In this study $\mathrm{MnO}_{4}^{-}$was used for As(III) oxidation because it has the ability to oxidize As(III) over a broad $\mathrm{pH}$ range and within time frame of seconds to one minute (Ghurye and Clifford 2001, Lihua et al. 2009, Sorlini and Gialdini 2010). Furthermore, $\mathrm{MnO}_{4}^{-}$does not 
form harmful by-products such as chlorination in the presence of humic substances (Smeets et al. 2009) and ozonation with bromide present (Von Gunten 2003) and is easy to dose and affordable (Borho and Wilderer 1996, Guan et al. 2009b).

Arsenic removal from water involving $\mathrm{MnO}_{4}$ and $\mathrm{Fe}(\mathrm{III})$ dosing has been previously investigated. Borho and Wilderer (1996) demonstrated at pilot scale that $\mathrm{MnO}_{4}$ dosing followed by $\mathrm{Fe}$ (III) dosing could lead to very low residual As concentration, provided the As containing $\mathrm{Fe}(\mathrm{III})$-precipitates were sufficiently removed from water. Lihua et al. (2009) studied the $\mathrm{MnO}_{4}$ and $\mathrm{Fe}$ (III) dosing in water with the aim of developing a small system for rural populations in low income countries. They used tap water spiked with As(III) in their experiments and filtration was accomplished through a sand filter followed by ultrafiltration (UF). It was shown that when water was pre-treated with $\mathrm{MnO}_{4}$ - for $\mathrm{As}$ (III) oxidation, lower and more stable effluent As concentrations were achieved and the sand filtration was mainly responsible for the removal of As-laced Fe(III)-precipitates. Bordoloi et al. (2013) studied As(III) removal from groundwater water by $\mathrm{MnO}_{4}^{-}$and $\mathrm{Fe}(\mathrm{III})$ dosing at mild alkaline $\mathrm{pH}$ that was achieved through the addition of $\mathrm{NaHCO}_{3}$ in water. Their study was also aimed at developing a process for rural application in low income countries. With laboratory and field experiments, Bordoloi et al. (2013) showed that As(III) could be efficiently removed to meet the WHO guideline for As in drinkingwater $(10 \mu \mathrm{g} / \mathrm{L})$.

All these studies show that $\mathrm{MnO}_{4}^{-}-\mathrm{Fe}$ (III) dosing is a promising method to increase the As(III) removal efficiency at typical aeration - rapid sand filtration type groundwater treatment facilities where As(III) is present in the raw water, however As removal to $<1 \mu \mathrm{g} / \mathrm{L}$, as aimed in this study, has never been a goal of any of the previous studies. The effects of adopting $\mathrm{MnO}_{4}^{-}-\mathrm{Fe}(\mathrm{III})$ dosing on the existing removal efficiencies of $\mathrm{Fe}(\mathrm{II}), \mathrm{Mn}(\mathrm{II})$ and $\mathrm{NH}_{4}{ }_{4}$ at typical aeration - rapid sand filtration type groundwater treatment facilities are also not well documented in literature. Moreover, the influence on settling characteristics of filter backwash water, which is an important parameter affecting the design and operation of backwash water treatment at WTPs, has not been studied before. Consequently, the aim of this study was (1) to achieve $<1 \mu \mathrm{g} / \mathrm{L}$ As by $\mathrm{MnO}_{4}^{-}-\mathrm{Fe}$ (III) dosing at a typical aeration - rapid sand filtration facility (2) to study the influence of $\mathrm{MnO}_{4}^{-}-\mathrm{Fe}(\mathrm{III})$ dosing on the removal of As, $\mathrm{Fe}, \mathrm{Mn}$ and $\mathrm{NH}_{4}^{+}$in rapid sand filtration and (3) to study the influence of $\mathrm{MnO}_{4}^{-}-\mathrm{Fe}(\mathrm{III})$ dosing on the settling and molecular scale structural properties of the filter backwash solids. The study, including batch, pilot and full-scale experiments, was carried out at a groundwater treatment facility (WTP Dorst) in the Netherlands with typical aeration-rapid sand filtration based treatment scheme. 


\subsection{MATERIALS AND METHODS}

\subsubsection{Treatment layout and water quality of WTP Dorst}

WTP Dorst is a typical groundwater treatment facility $\left(10 \mathrm{Mm}^{3} /\right.$ year production) in the Netherlands which treats anaerobic groundwater in 10 parallel treatment trains, each comprising of a cascade aeration step followed by a submerged rapid sand filter (Fig 2.1). The surface area and bed height of the sand filters are $27 \mathrm{~m}^{2}$ and $1.8 \mathrm{~m}$ respectively. They contain a single media filter material (silica sand $\mathrm{D} 50=1.3$ $\mathrm{mm}$ ) and are operated at an average (superficial) filtration velocity of $4.6 \mathrm{~m} / \mathrm{h}$ (filter loading $\mathrm{Q}=125 \mathrm{~m}^{3} / \mathrm{h}$ ). Table 2.1 presents the raw and treated water quality at WTP Dorst.

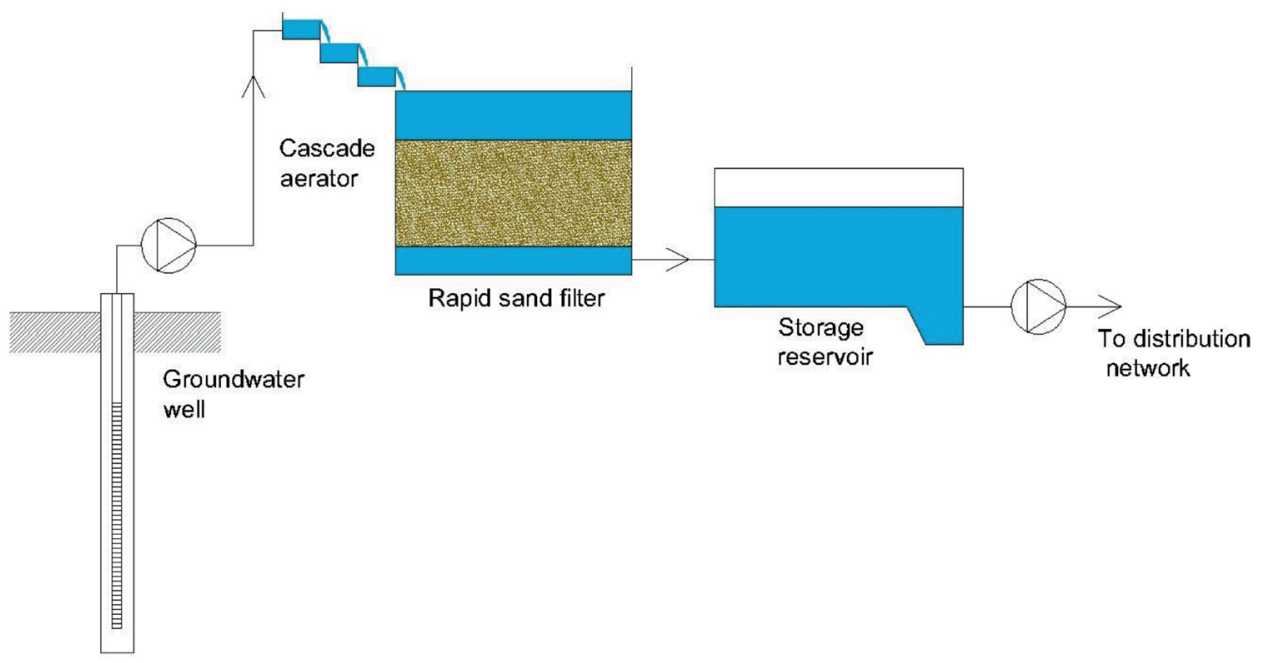

Figure 2.1 Typical groundwater treatment layout in the Netherlands.

\subsubsection{Optimizing $\mathrm{MnO}_{4}^{-}-\mathrm{Fe}(\mathrm{III})$ doses to achieve $<1 \mu \mathrm{g} / \mathrm{L}$ As}

\subsubsection{Preliminary batch experiments}

To gain preliminary information on $\mathrm{MnO}_{4}-\mathrm{Fe}$ (III) doses required to remove As to $<1 \mu \mathrm{g} / \mathrm{L}$, a series of batch tests was carried out using the raw water of WTP Dorst (Table 2.1). The experiments were performed with a jar test apparatus, which comprised a set of six transparent jars (2 L capacity each). Each jar was equipped with a dosing unit to add $\mathrm{MnO}_{4}^{-}$and $\mathrm{Fe}(\mathrm{III})$, a paddle for mechanical stirring and a sampling point in the bottom. The timing of $\mathrm{MnO}_{4}^{-}$and $\mathrm{Fe}(\mathrm{III})$ dosing and mixing speed in the jars could be automatically controlled. A $0.03 \mathrm{M} \mathrm{KMnO}_{4}(3.6 \mathrm{~g} / \mathrm{L}$ $\mathrm{MnO}_{4}^{-}$) solution was used to dose $\mathrm{MnO}_{4}^{-}$. It was prepared by dissolving $948 \mathrm{mg}$ of 
solid $\mathrm{KMnO}_{4}$ (Cairox ${ }^{\oplus}$, Carus Corporation) in $200 \mathrm{~mL}$ deionized (DI) water directly before the start of the batch experiments. $\mathrm{A} \mathrm{FeCl}_{3}$ solution $(2.0 \mathrm{~g} \mathrm{Fe}(\mathrm{III}) / \mathrm{L})$ was used to dose $\mathrm{Fe}(\mathrm{III})$ in water. It was prepared by dissolving $1936 \mathrm{mg}$ solid $\mathrm{FeCl}_{3} \cdot 6 \mathrm{H}_{2} \mathrm{O}$ (J.T. Baker ${ }^{\oplus}$ ) in $200 \mathrm{~mL}$ DI water directly before the start of the batch experiments.

The jar test procedure was designed to represent the process conditions at the fullscale facility, especially with respect to the residence time of water during aeration and rapid sand filtration. The jar test procedure included the following steps. Firstly, the 6 jars were filled with anaerobic raw groundwater of WTP Dorst (Table 2.1). Afterwards, a predetermined aliquot of $\mathrm{MnO}_{4}^{-}$and/or $\mathrm{Fe}(\mathrm{III})$ was dosed in each jar while the solutions were mixed at $300 \mathrm{RPM}$. In the $\mathrm{MnO}_{4}^{-}-\mathrm{Fe}(\mathrm{III})$ dosing experiments, the interval between $\mathrm{MnO}_{4}^{-}$and $\mathrm{Fe}(\mathrm{III})$ doses was kept constant at 2 min. This interval was chosen to make sure that complete oxidation of As(III) to As(V) occurred before Fe(III) dosing, though Ghurye and Clifford (2001) and Sorlini and Gialdini (2010) found complete As(III) oxidation within 1 min of $\mathrm{MnO}_{4}$ - dosing in their experiments with both synthetic and real groundwater samples. After 3 min of mixing at 300 RPM, the mixing speed was reduced to 50 RPM for the next 13.5 min to allow Fe(III) precipitates to grow into larger flocs. Finally, the process water was sampled from the jars by opening the bottom tap and filtering immediately using $0.45 \mu \mathrm{m}$ filters (GE's GD/XP disposable syringe filters with nylon membrane). The filtered samples were analyzed for As and Fe. During the experiments the jars were kept open to the atmosphere, therefore the agitation caused by stirring at 300 RPM not only accomplished mixing of the chemicals, but also aeration of the raw water.

\subsubsection{Pilot experiments}

Pilot experiments were performed to optimize the dosing of $\mathrm{MnO}_{4}^{-}$and $\mathrm{Fe}(\mathrm{III})$. The pilot plant, installed at WTP Dorst, was fed with the raw water of WTP Dorst (Table 2.1). Fig 2 shows a schematic diagram of the pilot setup. The pilot setup consisted of an aeration cascade followed by a filtration column ( $0.3 \mathrm{~m}$ diameter, $2.5 \mathrm{~m}$ height) and peristaltic pumps for $\mathrm{MnO}_{4}^{-}$and $\mathrm{Fe}(\mathrm{III})$ dosing. The column contained filtration media (1.8 m height) obtained from the full-scale filter of WTP Dorst (silica sand D50=1.3 $\mathrm{mm}$ ) in an attempt to achieve a similar rapid sand filtrate quality as the full-scale facility. Permanganate was dosed using $0.03 \mathrm{M} \mathrm{KMnO}_{4}(3.6$ $\mathrm{g} / \mathrm{L} \mathrm{MnO}_{4}^{-}$) solution prepared onsite in $20 \mathrm{~L}$ jerry cans by dissolving solid $\mathrm{KMnO}_{4}$ $\left(\mathrm{Cairox}^{\odot}\right)$ in DI water 2-3 times per week. Ferric was dosed using $40 \mathrm{w} / \mathrm{w} \% \mathrm{FeCl}_{3}$ solution (Ferralco Nederland $\mathrm{BV}$ ). $\mathrm{MnO}_{4}^{-}$was dosed at the top of the cascade for As(III) oxidation and Fe(III) was dosed for As(V) removal at the bottom, as shown in Fig 2.2. Two separate membrane pumps (GALA1602, ProMinent ${ }^{\oplus}$ ) were used for dosing $\mathrm{MnO}_{4}^{-}$and $\mathrm{Fe}(\mathrm{III})$. 
The pilot experiments were performed under three conditions, based on the outcomes of the preliminary batch experiments and further optimization of chemical dosing to achieve $<1 \mu \mathrm{g} / \mathrm{L}$ in pilot filtrate. In the first condition, the pilot plant was operated for 6 weeks without dosing of $\mathrm{MnO}_{4}^{-}$and $\mathrm{Fe}(\mathrm{III})$ to replicate a filtrate quality similar to that of the full-scale facility. In the second condition, $0.8 \mathrm{mg} / \mathrm{L}$ $\mathrm{MnO}_{4}^{-}$and $1.8 \mathrm{mg} / \mathrm{L} \mathrm{Fe}(\mathrm{III})$ were dosed for 4 -weeks, and in the third condition, $1.2 \mathrm{mg} / \mathrm{L} \mathrm{MnO}_{4}^{-}$and $1.8 \mathrm{mg} / \mathrm{L} \mathrm{Fe}(\mathrm{III})$ were dosed for 4 weeks in the pilot cascade. During all the experiments the pilot was operated at the filtration velocity of 4.6 $\mathrm{m} / \mathrm{h}$ (filter loading $\mathrm{Q}=1.3 \mathrm{~m}^{3} / \mathrm{h}$ ). Unfiltered and $0.45 \mu \mathrm{m}$ filtered samples were collected from the pilot filtrate during 8-12 runs at each condition and analyzed for the determination of $\mathrm{As}, \mathrm{Fe}, \mathrm{Mn}$ and $\mathrm{NH}_{4}{ }^{+}$concentrations.

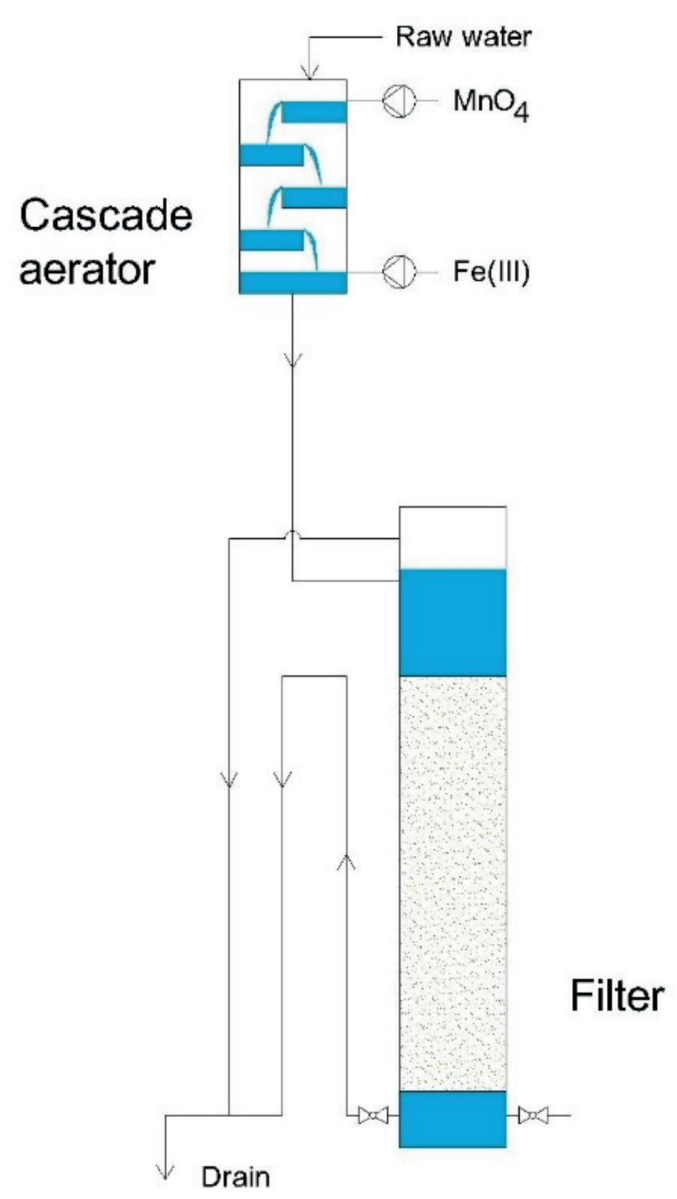

Figure 2.2 Schematic diagram of the pilot set-up. 


\subsubsection{Influence of $\mathrm{MnO}_{4}^{-}-\mathrm{Fe}$ (III) dosing on removal of $\mathrm{As}, \mathrm{Fe}, \mathrm{Mn}$ and $\mathrm{NH}_{4}^{+}$}

Soon after the completion of the pilot experiments, the full-scale facility received an upgrade with $\mathrm{MnO}_{4}^{-}-\mathrm{Fe}(\mathrm{III})$ dosing. This enabled us to study the influence of $\mathrm{MnO}_{4}^{-}-\mathrm{Fe}(\mathrm{III})$ dose on the removal of As, Fe, $\mathrm{Mn}$ and $\mathrm{NH}_{4}^{+}$on full-scale. Reference measurements were obtained before the upgrade, i.e. when the raw water (Table 2.1) was only treated with aeration - rapid sand filtration. The measurements with $\mathrm{MnO}_{4}^{-}-\mathrm{Fe}(\mathrm{III})$ dosing were obtained one year after the upgrade, with 1.2 $\mathrm{mg} / \mathrm{L} \mathrm{MnO}_{4}^{-}$and $1.8 \mathrm{mg} / \mathrm{L} \mathrm{Fe}(\mathrm{III})$ dosed (dosing was based on the results of the pilot experiments) to achieve $<1 \mu \mathrm{g} / \mathrm{L}$ As in the produced drinking water. In both sampling campaigns, unfiltered and $0.45 \mu \mathrm{m}$ filtered raw water, supernatant and filtrate samples were collected. Supernatant refers to the water storage on the top of the filter bed. Concentrations of As, Fe and Mn were determined in unfiltered and $0.45 \mu \mathrm{m}$ filtered samples. Concentrations of $\mathrm{NH}_{4}^{+}$were determined in unfiltered samples only. Dissolved arsenic species were determined in $0.45 \mu \mathrm{m}$ filtered samples.

\subsubsection{Influence of $\mathrm{MnO}_{4}^{-}-\mathrm{Fe}(\mathrm{III})$ dosage on filter backwash solids characteristics}

The influence of $\mathrm{MnO}_{4}^{-}-\mathrm{Fe}(\mathrm{III})$ dosing on the settling and molecular scale structural characteristics of the backwash solids was also studied at the full scale installation. Backwash water samples were collected under 3 conditions: (1) without dosing (no dose), i.e. prior to the upgrade (2) with only dosing $1.2 \mathrm{mg} / \mathrm{L} \mathrm{MnO}_{4}$ - and (3) with dosing $1.2 \mathrm{mg} / \mathrm{L} \mathrm{MnO}_{4}^{-}$and $1.8 \mathrm{mg} / \mathrm{L} \mathrm{Fe}(\mathrm{III})$. Under each condition the backwash water sample were collected at the $60^{\text {th }}$ hour of the filter run. To collect each sample during filter backwash, $5 \mathrm{~L}$ of backwash water was collected every minute during the first 4 minutes. The samples were subsequently mixed to form a secondary suspension, which was subsequently used for settling experiments and for solids characterization. Unfiltered and $0.45 \mu \mathrm{m}$ filtered backwash water samples, collected at each setting, were analyzed for Fe and Mn concentration.

\subsubsection{Settling characteristics of filter backwash solids}

The settling characteristics of the filter backwash solids were studied using a method previously used by Van Genuchten et al. (2014b). 1.8 L transparent jars were filled with the backwash water samples, mixed with a magnetic stirrer for $1 \mathrm{~min}$ to achieve a homogeneous suspension of filter backwash solids and then allowed to settle under gravity for $1 \mathrm{~h}$. During settling, an aliquot of sample was taken approximately 10 $\mathrm{cm}$ below the surface of the suspension, every $15 \mathrm{~min}$ between $\mathrm{t}=0$ and $60 \mathrm{~min}$, using a wide-mouthed syringe for turbidity measurements using a Hach $2100 \mathrm{~N}$ Turbidimeter. The settling behaviour was also recorded through photographs. 


\subsubsection{Solid phase characterization}

Solids were collected on $0.45 \mu \mathrm{m}$ filters from the backwash water samples under no dose and $1.2 \mathrm{mg} / \mathrm{L} \mathrm{MnO}_{4}$ - dose conditions. The samples were air dried for 24 hours at room temperature and then stored in closed containers at room temperature until analysis in 2 weeks. The solids were characterized by Fe K-edge X-ray absorption spectroscopy (XAS) and X-ray diffraction (XRD). Fe K-edge XAS data were collected at the DUBBLE beam line (BM-26) of the European Synchrotron Radiation Facility (ESRF). Spectra were recorded at room temperature in transmission mode out to $\mathrm{k}$ of $13 \AA^{-1}$. X-Ray diffraction measurements (XRD) were performed at the X-Ray facility in Utrecht University, The Netherlands. The Samples for powder XRD measurements, were ground into a powder using an agate mortar and pestle. Powder diffraction patterns were collected with a Bruker D8 Advance diffractometer using $\mathrm{Cu} \mathrm{K}$-alpha radiation and a rotating sample stage. Measurements were performed from 5 to $75^{\circ} 2 \emptyset$ with $0.02^{\circ}$ step sizes and total data collection time of approximately $4 \mathrm{~h}$ per sample.

\subsubsection{Analysis of water samples}

Determination of As, Fe and Mn concentrations was carried out by Inductively Coupled Plasma Mass Spectrometry (ICP_MS) (SXERIES 2, Thermo Fisher Scientific) at Aqualab Zuid laboratory in the Netherlands. The detection limits (DLs) for As, Fe, Mn were 0.5, 10 and $10 \mu \mathrm{g} / \mathrm{L}$ respectively. Samples for As, Fe, $\mathrm{Mn}$ analysis were preserved immediately after sampling by adding $250 \mu \mathrm{L}$ of $10 \%$ ultra-pure nitric acid $\left(\mathrm{HNO}_{3}\right)$. To obtain $0.45 \mu \mathrm{m}$ filtered samples, GE's GD/ $\mathrm{XP}$ disposable syringe filters were used. For the determination of $\mathrm{Fe}$ and $\mathrm{Mn}$ in the backwash water samples, samples were digested in acid and microwaved before ICP_-MS. Arsenic speciation (As(III) versus As(V)) was determined using Amberlite ${ }^{\oplus}$ IRA-400 chloride form AIEX resin. The procedure included passing $100 \mathrm{~mL}$ of $0.45 \mu \mathrm{m}$ filtered water through a $30 \mathrm{~mL}$ syringe filled with $20 \mathrm{~mL}$ of the resin. The As concentration that remained in the effluent after contact with the resin was considered to be uncharged As(III). As(V) was calculated by subtracting As(III) from the As concentration in the column influent (Clifford et al. 1983). $\mathrm{NH}_{4}^{+}$was analyzed by a discrete analyzer spectrophotometry (Aquakem 250, Thermo Scientific) at Aqualab Zuid laboratory (accredited NEN-EN-ISO/IEC 17025:2005). The method DL was $30 \mu \mathrm{g} / \mathrm{L} \mathrm{NH}_{4}^{+}$. 


\subsection{RESULTS AND DISCUSSION}

\subsubsection{Optimizing $\mathrm{MnO}_{4}^{-}-\mathrm{Fe}(\mathrm{III})$ doses to achieve $<1 \mu \mathrm{g} / \mathrm{L} \mathrm{As}$}

\subsubsection{Preliminary batch experiments}

To gain preliminary information on $\mathrm{MnO}_{4}$ - and $\mathrm{Fe}(\mathrm{III})$ doses required to remove As to $<1 \mu \mathrm{g} / \mathrm{L}$, a series of batch tests was carried out. Fig 2.3a presents the residual As concentration in function of the Fe(III) dose. An As concentration of $<1 \mu \mathrm{g} / \mathrm{L}$ was not achieved even with a high dose of Fe(III) $(10 \mathrm{mg} / \mathrm{L})$. The residual concentration of As decreased with increasing Fe(III) dose which can be attributed to the increasing amount of Fe(III)-precipitates with each incremental Fe(III) dose (Cornell and Schwertmann 2003, Hering et al. 1996a, Wilkie and Hering 1996). The actual raw water of WTP Dorst used in these experiments (Table 2.1) contained As(III) as the predominant As species. As(III) adsorbs to the Fe(III)-precipitates produced by Fe(III) coagulants in solution (Hering et al. 1996a, Lakshmanan et al. 2008). Fig 2.3a shows that the residual As concentration in the absence of Fe(III) dosing was 8.7 $\mu \mathrm{g} / \mathrm{L}$, thus significantly lower than the As concentration in the raw water (11.9 $\mu \mathrm{g} / \mathrm{L})$. This reduction can be attributed to coprecipitation of As with the natural Fe in raw groundwater of WTP Dorst (Edwards 1994, McNeill and Edwards 1995).

The residual As concentration as a function of $\mathrm{MnO}_{4}^{-}$and $\mathrm{MnO}_{4}^{-}-\mathrm{Fe}$ (III) dose is presented in Fig 2.3b. An As concentration of $<1 \mu \mathrm{g} / \mathrm{L}$ As was achieved when $\geq 1.2 \mathrm{mg} / \mathrm{L} \mathrm{MnO}_{4}$ - was combined with an $\mathrm{Fe}(\mathrm{III})$ dose of $2.0 \mathrm{mg} / \mathrm{L}$. Residual As concentrations decreased with increasing $\mathrm{MnO}_{4}$ - dose for each $\mathrm{Fe}$ (III) dose and the curves appear to level-off beyond $1.2 \mathrm{mg} / \mathrm{L}$ of $\mathrm{MnO}_{4}$ - dose indicating ineffectiveness of further increase in $\mathrm{MnO}_{4}$ - dose for As removal. This result indicates that $\mathrm{MnO}_{4}$ dosages of $<1.2 \mathrm{mg} / \mathrm{L}$ may not be sufficient to completely oxidize As(III) to As(V), thus limiting the As adsorption to Fe(III)-precipitates that were formed in water due to the oxidation and hydrolysis of the natural Fe(II) and dosed Fe (III) (Hering et al. 1996a, Hsu et al. 2008, Lakshmanan et al. 2008, Lytle et al. 2005, Qiao et al. 2012). It is worth mentioning that the residual Fe concentration in the entire series of batch experiments was $<10 \mu \mathrm{g} / \mathrm{L}$, indicating the Fe(III) precipitation was not limiting the As removal efficiency.

Comparing the residual As concentrations at $2.0 \mathrm{mg} / \mathrm{L} \mathrm{Fe}(\mathrm{III})$ dose with and without $\mathrm{MnO}_{4}^{-}$(Fig 2.3a and 2.3b respectively), it is evident that a significantly lower residual As was achieved when $\mathrm{MnO}_{4}{ }^{-}$and $\mathrm{Fe}(\mathrm{III})$ were dosed. The results of the batch experiments indicated that the dosing of around $1.0 \mathrm{mg} / \mathrm{L} \mathrm{MnO}_{4}^{-}$and $2.0 \mathrm{mg} / \mathrm{L} \mathrm{Fe}(\mathrm{III})$ would be required to achieve As removal to $<1 \mu \mathrm{g} / \mathrm{L}$ at WTP Dorst. Using these concentrations as a starting point, the next topic is optimizing the $\mathrm{MnO}_{4}^{-}-\mathrm{Fe}(\mathrm{III})$ dose in pilot experiments. 

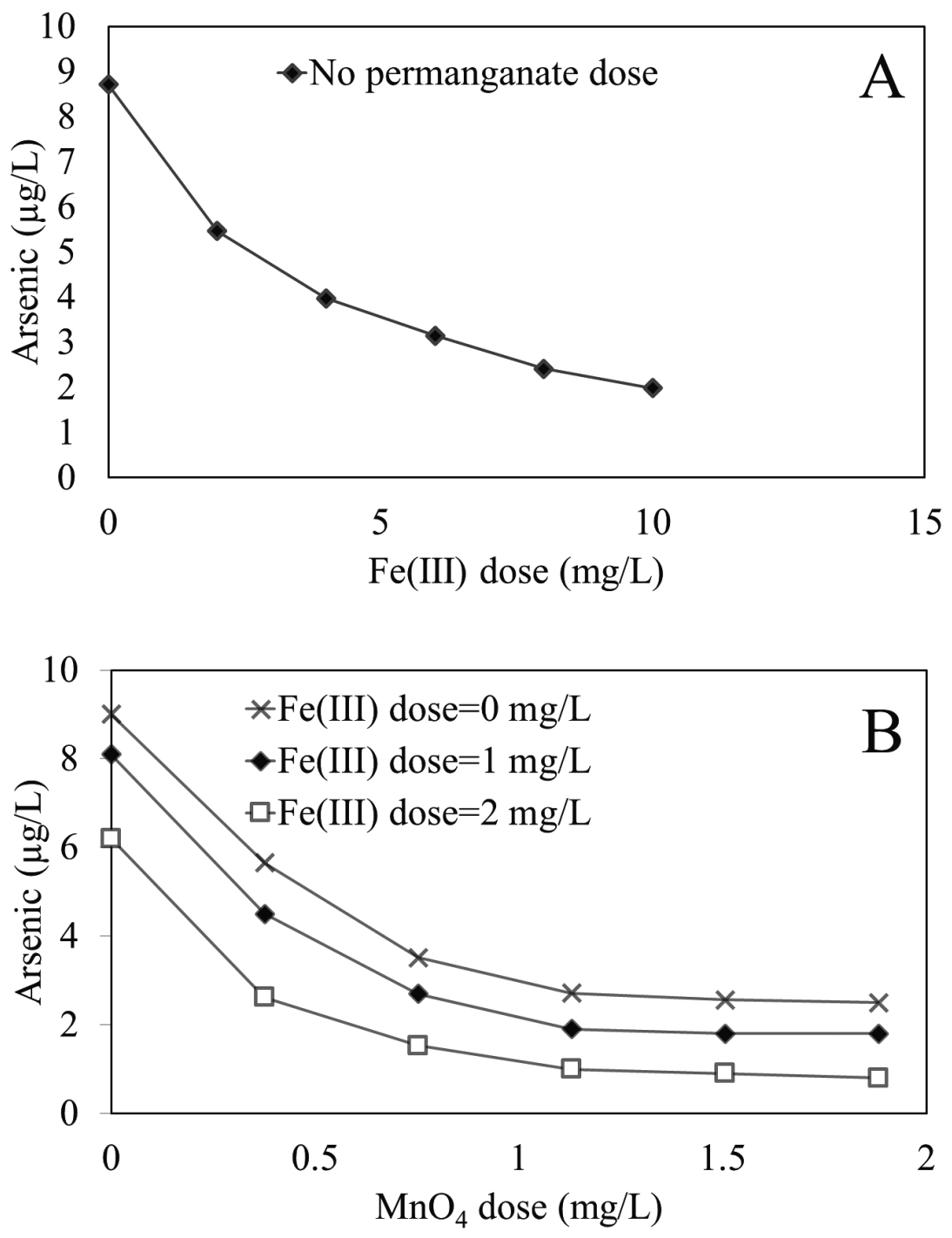

Figure 2.3 Residual concentration of $\mathrm{As}(\mathrm{A})$ as a function of $\mathrm{Fe}$ (III) dose and (B) as a function of $\mathrm{MnO}_{4}^{-}$and $\mathrm{MnO}_{4}^{-}-\mathrm{Fe}(\mathrm{III})$ dose. Results are based on batch experiments (single trials).

\subsubsection{Pilot experiments}

Arsenic and Fe concentrations in the pilot filtrate are presented in Fig 2.4a and 2.4b, respectively. In the absence of $\mathrm{MnO}_{4}^{-}-\mathrm{Fe}$ (III) dosing, the average As concentration in the pilot filtrate was $6.3 \mu \mathrm{g} / \mathrm{L}$, which was comparable to the full-scale effluent quality (Table 2.1). However, the pilot filtrate contained a higher Fe concentration 
$(24.4 \pm 5.3 \mu \mathrm{g} / \mathrm{L})($ Fig $2.4 \mathrm{~b})$ compared to the effluent of the full-scale facility where Fe was undetectable $\left(<10 \mu \mathrm{g} / \mathrm{L}\right.$ ) (Table 2.1). When $0.8 \mathrm{mg} / \mathrm{L} \mathrm{MnO}_{4}^{-}$and $1.8 \mathrm{mg} / \mathrm{L}$ $\mathrm{Fe}(\mathrm{III})$ were dosed in the pilot cascade, the As concentration in the filtrate decreased to an average of $1.4 \mu \mathrm{g} / \mathrm{L}$ and the Fe concentration decreased to an average of 21.1 $\mu \mathrm{g} / \mathrm{L}$. When the $\mathrm{MnO}_{4}$ - dose was increased further to $1.2 \mathrm{mg} / \mathrm{L}$ with $\mathrm{Fe}(\mathrm{III})$ dose maintained at $1.8 \mathrm{mg} / \mathrm{L}$, the As concentration in the filtrate decreased to an average of $0.9 \mu \mathrm{g} / \mathrm{L}$ and the Fe became undetectable $(<10 \mu \mathrm{g} / \mathrm{L})$.

The increased As removal with increment of $\mathrm{MnO}_{4}^{-}$dose may be due to the oxidation of As(III) to As(V) (Bordoloi et al. 2013) and subsequent more efficient uptake of As(V) by Fe(III)-precipitates (Edwards 1994, Qiao et al. 2012, Wilkie and Hering 1996). The Fe speciation (Fe in unfiltered and $0.45 \mu \mathrm{m}$ filtered samples) in the pilot filtrate showed that the dissolved Fe concentration in the pilot filtrate was consistently $<10 \mu \mathrm{g} / \mathrm{L}$ (DL) during the experiments with the three settings. This shows that the precipitation of Fe was not dependent on $\mathrm{MnO}_{4}^{-}$. Thus the observed decrease in the Fe concentration in the pilot filtrate with the increase in $\mathrm{MnO}_{4}^{-}$dose from 0 to $1.2 \mathrm{mg} / \mathrm{L}$ was apparently not related to the oxidizing capacity of $\mathrm{MnO}_{4}^{-}$. It may, however, be due to improved aggregation (flocculation) and filterability of $\mathrm{Fe}(\mathrm{III})$-precipitates triggered by $\mathrm{MnO}_{\mathrm{x}}$ precipitates that form upon $\mathrm{MnO}_{4}$ - reduction and oxidation of natural $\mathrm{Mn}$ (II) (Lihua et al. 2009).

Under all three experimental conditions, $\mathrm{Mn}$ and $\mathrm{NH}_{4}{ }^{+}$concentrations in the pilot filtrate remained below the detection limit $\left(10 \mu \mathrm{g} / \mathrm{L}\right.$ for $\mathrm{Mn}$ and $\left.30 \mu \mathrm{g} / \mathrm{L}_{\text {for }} \mathrm{NH}_{4}^{+}\right)$. This result indicates that the dosing of $\mathrm{MnO}_{4}$ - and $\mathrm{Fe}(\mathrm{III})$ did not decrease the overall removal efficiency of $\mathrm{Mn}(\mathrm{II})$ and $\mathrm{NH}_{4}^{+}$in the pilot filter.

It is worth mentioning that the run time of the pilot filter was reduced when $\mathrm{MnO}_{4}$ - and $\mathrm{Fe}(\mathrm{III})$ were dosed. This can be attributed to the increased rate of filter clogging due to increased load of $\mathrm{Fe}(\mathrm{III})$-precipitates and $\mathrm{MnO}_{\mathrm{x}}$ precipitates to the filter compared to the condition when $\mathrm{MnO}_{4}^{-}$and $\mathrm{Fe}(\mathrm{III})$ were not dosed.

\subsubsection{Influence of $\mathrm{MnO}_{4}^{-}-\mathrm{Fe}(\mathrm{III})$ dose on $\mathrm{As}, \mathrm{Fe}, \mathrm{Mn}$ and $\mathrm{NH}_{4}^{+}$removal profiles}

Fig 2.5a, b, c and d presents $\mathrm{As}, \mathrm{Fe}, \mathrm{Mn}$ and $\mathrm{NH}_{4}^{+}$concentrations in the raw, supernatant and filtrate before the upgrade of the full-scale facility (no dose) and after the upgrade when $1.2 \mathrm{mg} / \mathrm{L} \mathrm{MnO}_{4}^{-}$and $1.8 \mathrm{mg} / \mathrm{L} \mathrm{Fe}(\mathrm{III})$ were dosed $\left(\mathrm{MnO}_{4}^{-}\right.$ - Fe(III)). Fig 2.5a shows that As was approximately $11.5 \mu \mathrm{g} / \mathrm{L}$ in the unfiltered and $0.45 \mu \mathrm{m}$ filtered raw water samples, indicating the presence of As in dissolved form. In the supernatant, the As concentration in the unfiltered samples was similar to the raw water, indicating that As was not removed during aeration. However, approximately $1 \mu \mathrm{g} / \mathrm{L}$ As $(8.7 \%$ of the total As) was removed by the $0.45 \mu \mathrm{m}$ filter in the supernatant with no dose and $11.4 \mu \mathrm{g} / \mathrm{L}(99.2 \%$ of the total As) As became filterable in the supernatant with $\mathrm{MnO}_{4}^{-}-\mathrm{Fe}(\mathrm{III})$ dose. Fig 2.5b shows that the raw 

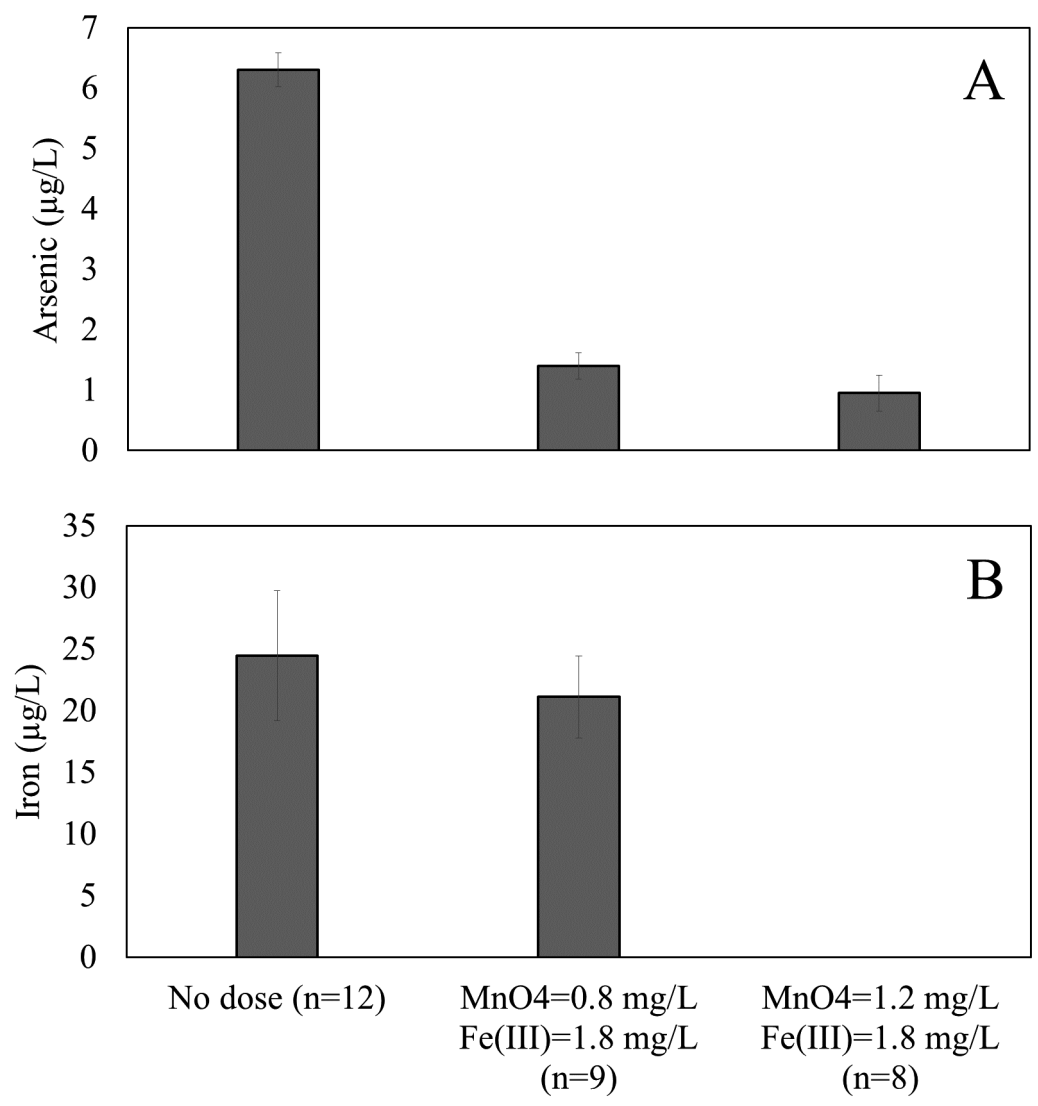

Figure 2.4 (A) Arsenic and (B) Fe concentrations in the pilot filtrate under three pilot experimental conditions.

water contained $1400 \mu \mathrm{g} / \mathrm{L} \mathrm{Fe}$, which entirely passed through the $0.45 \mu \mathrm{m}$ filter. In the supernatant, $942.5 \mu \mathrm{g} / \mathrm{L} \mathrm{Fe}(66.2 \%$ of total $\mathrm{Fe})$ passed through the 0.45 $\mu \mathrm{m}$ filter in the absence of dosing. The As uptake in the supernatant is calculated to be $(1 / 0.942=) 1.1 \mu \mathrm{g} / \mathrm{mg}$ Fe in the absence of $\mathrm{MnO}_{4}^{-}-\mathrm{Fe}(\mathrm{III})$ dosing. The $\mathrm{Fe}$ concentration in the supernatant with $\mathrm{MnO}_{4}^{-}-\mathrm{Fe}(\mathrm{III})$ dose was much higher due to $\mathrm{Fe}(\mathrm{III})$ dosing in the feed, with $3682.3 \mu \mathrm{g} / \mathrm{L} \mathrm{Fe}(97.6 \%$ of the total $\mathrm{Fe}$ ) filterable through $0.45 \mu \mathrm{m}$ filter. The As uptake in the supernatant is calculated to be $(11.4 / 3.37=) 3.3 \mu \mathrm{g} / \mathrm{mg} \mathrm{Fe}$ with $\mathrm{MnO}_{4}^{-}-\mathrm{Fe}(\mathrm{III})$ dosing. The 3-fold higher uptake of As in the supernatant with $\mathrm{MnO}_{4}^{-}-\mathrm{Fe}$ (III) dose can be attributed to As(III) oxidation to $\mathrm{As}(\mathrm{V})$ by $\mathrm{MnO}_{4}^{-}$(Borho and Wilderer 1996, Lihua et al. 2009). In the filtrate, a significant difference in As concentration was observed, with $6.1 \mu \mathrm{g} / \mathrm{L}$ at no dose and $0.54 \mu \mathrm{g} / \mathrm{L}$ with $\mathrm{MnO}_{4}^{-}-\mathrm{Fe}(\mathrm{III})$ dose. In both the cases, As passed through the 0.45 
$\mu \mathrm{m}$ filter, indicating its presence as dissolved As. Iron was below the detection limit $(10 \mu \mathrm{g} / \mathrm{L})$ in the filtrate in both the cases. Since most of the Fe was precipitated in the supernatant, homogeneous $\mathrm{Fe}(\mathrm{II})$ oxidation followed by flocculative removal can be regarded as the principle Fe removal mechanism both at no dose and with $\mathrm{MnO}_{4}^{-}-$ $\mathrm{Fe}(\mathrm{III})$ dosing. However, a significantly higher concentration of Fe was precipitated in the supernatant when $\mathrm{MnO}_{4}^{-}-\mathrm{Fe}(\mathrm{III})$ was dosed.

Manganese did not pass through $0.45 \mu \mathrm{m}$ filter in the raw water (Fig 2.5c), indicating its presence in dissolved form. It remained unfilterable in the supernatant at no dose. This showed that the cascade aeration was ineffective in oxidizing $\mathrm{Mn}$ (II) and confirmed the previous results (Diem and Stumm 1984, Lytle et al. 2005) that the transformation of $\mathrm{Mn}(\mathrm{II})$ to $\mathrm{MnO}_{2}$ by dissolved $\mathrm{O}_{2}$ alone is a slow process at $\mathrm{pH}$ below 9. At no dose, $\mathrm{Mn}$ was below the detection limit $(10 \mu \mathrm{g} / \mathrm{L})$ in the filtrate. This Mn removal can be attributed to the autocatalytic removal mechanism in which dissolved $\mathrm{Mn}(\mathrm{II})$ adsorbs to the filter media grains where it is oxidized to form $\mathrm{MnO}_{2}$ coating (Bruins et al. 2015, Katsoyiannis et al. 2008). On the other hand, the $\mathrm{Mn}$ concentration in the supernatant with $\mathrm{MnO}_{4}^{-}-\mathrm{Fe}$ (III) dose, though much higher due to $\mathrm{MnO}_{4}$ - dosing, was entirely filterable through $0.45 \mu \mathrm{m}$ filter. Thus, $\mathrm{Mn}$ entered the rapid sand filter mainly as particles $\left(\mathrm{MnO}_{\mathrm{x}}\right)$ and its removal mechanism in the filter bed changed to flocculative.

At no dose, $\mathrm{NH}_{4}^{+}$removal took place entirely in the filter bed (Fig 2.5d), which is consistent with biological nitrification (De Vet 2011). With $\mathrm{MnO}_{4}-\mathrm{Fe}(\mathrm{III})$ dose, the $\mathrm{NH}_{4}^{+}$concentration in the filtrate remained below the detection limit $(30 \mu \mathrm{g} / \mathrm{L})$, indicating that the nitrification was not affected in the filter bed.

Arsenic speciation was carried out in the raw, supernatant and filtrate samples to gain further mechanistic insight of the As removal process. Fig 2.6a presents As(III) and $\mathrm{As}(\mathrm{V})$ concentrations in $0.45 \mu \mathrm{m}$ filtered samples. As(III) was the dominant form of As in the raw water (97.2\%). In the supernatant, As(III) remained dominant $(89.6 \%)$, indicating the inefficiency of the cascade aeration in oxidizing As(III) to a significant level, in agreement with Gude et al. (2016). In the filter effluent, the As concentration was lower than the supernatant due to co-removal with Fe in the filter bed although As(V) dominated (80\%). The observed oxidation of As(III) in 9.3 min of rapid sand filtration was higher-than-expected because As(III) oxidation by dissolved oxygen alone proceeds slowly (Frank and Clifford 1986, Kim and Nriagu 2000). Similar rapid oxidation of As(III) during rapid sand filtration was reported by Gude et al. (2016) and Katsoyiannis et al. (2008) and may be attributed to the manganese oxides or microbial activity in the filter bed (Driehaus et al. 1995, Gude et al. 2017, Lytle et al. 2007). With $\mathrm{MnO}_{4}^{-}-\mathrm{Fe}(\mathrm{III})$ dosing, the dissolved As in the supernatant and filtrate consisted entirely of As(V) (Fig 2.6b). 

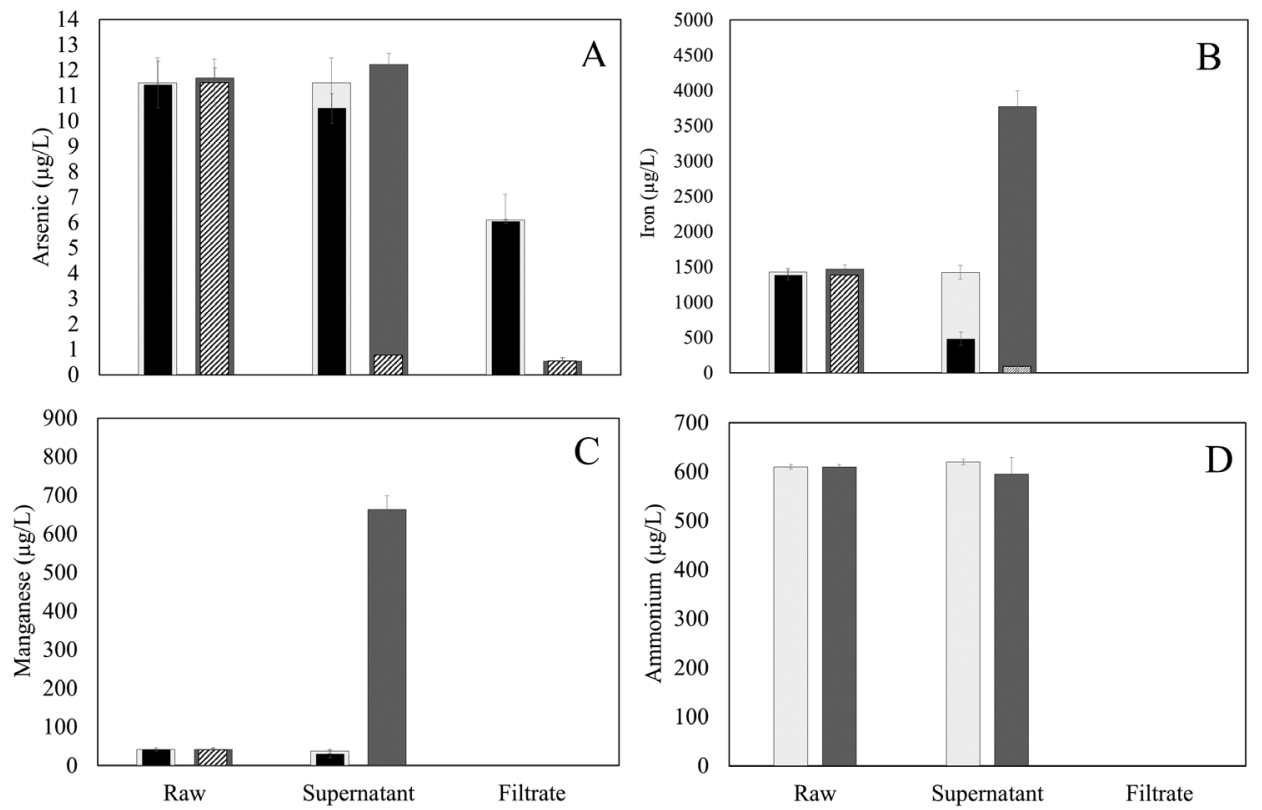

$$
\begin{aligned}
& \square \text { Unfiltered (No dose) } \\
& \square \text { Unfiltered (MnO4 - FeIII) } \\
& \square 0.45 \text { um filtered (No dose) } \\
& \square 0.45 \text { um filtered (MnO4 - FeIII) }
\end{aligned}
$$

Figure 2.5 Concentrations of (A) As, (B) Fe, (C) $\mathrm{Mn}$ and (D) $\mathrm{NH}_{4}^{+}$in unfiltered and $0.45 \mu \mathrm{m}$ filtered raw, supernatant and filtrate without and with $\mathrm{MnO}_{4}^{-}-\mathrm{Fe}(\mathrm{III})$ dosing. Supernatant refers the water storage on the top of the filter bed.

\subsubsection{Influence of $\mathrm{MnO}_{4}^{-}-\mathrm{Fe}$ (III) dosing on filter backwash solids}

\subsubsection{Settling characteristics of filter backwash solids}

Fig 2.7 presents the results of turbidity measurements in the top $10 \mathrm{~cm}$ of the backwash water samples as a function of time, as well as a visual comparison of the beginning $(t=0)$ and the end ( $t=60 \mathrm{~min})$ of settling tests among the backwash water samples that were collected under three conditions: without dosing (no dose), i.e. prior to the upgrade, with only dosing $1.2 \mathrm{mg} / \mathrm{L} \mathrm{MnO}_{4}^{-}$and with dosing $1.2 \mathrm{mg} / \mathrm{L} \mathrm{MnO}_{4}^{-}$and $1.8 \mathrm{mg} / \mathrm{L} \mathrm{Fe}(\mathrm{III})$. The color of the backwash water with $\mathrm{MnO}_{4}^{-}$and $\mathrm{MnO}_{4}^{-}-\mathrm{Fe}(\mathrm{III})$ dosing was darker, indicating the presence of solid phase $\mathrm{MnO}_{\mathrm{x}}$. The presence of $\mathrm{Mn}$ was also confirmed when backwash water samples were analyzed for $\mathrm{Fe}$ and Mn concentration by ICP-MS (see Table S2.1). The backwash water samples with $\mathrm{MnO}_{4}^{-}$and $\mathrm{MnO}_{4}^{-}-\mathrm{Fe}(\mathrm{III})$ dose settled faster than the sample collected at no dose (Fig 2.7). Thus, the dosing of $\mathrm{MnO}_{4}^{-}$and $\mathrm{MnO}_{4}^{-}-\mathrm{Fe}(\mathrm{III})$ improved the settling rate of the filter backwash solids. 

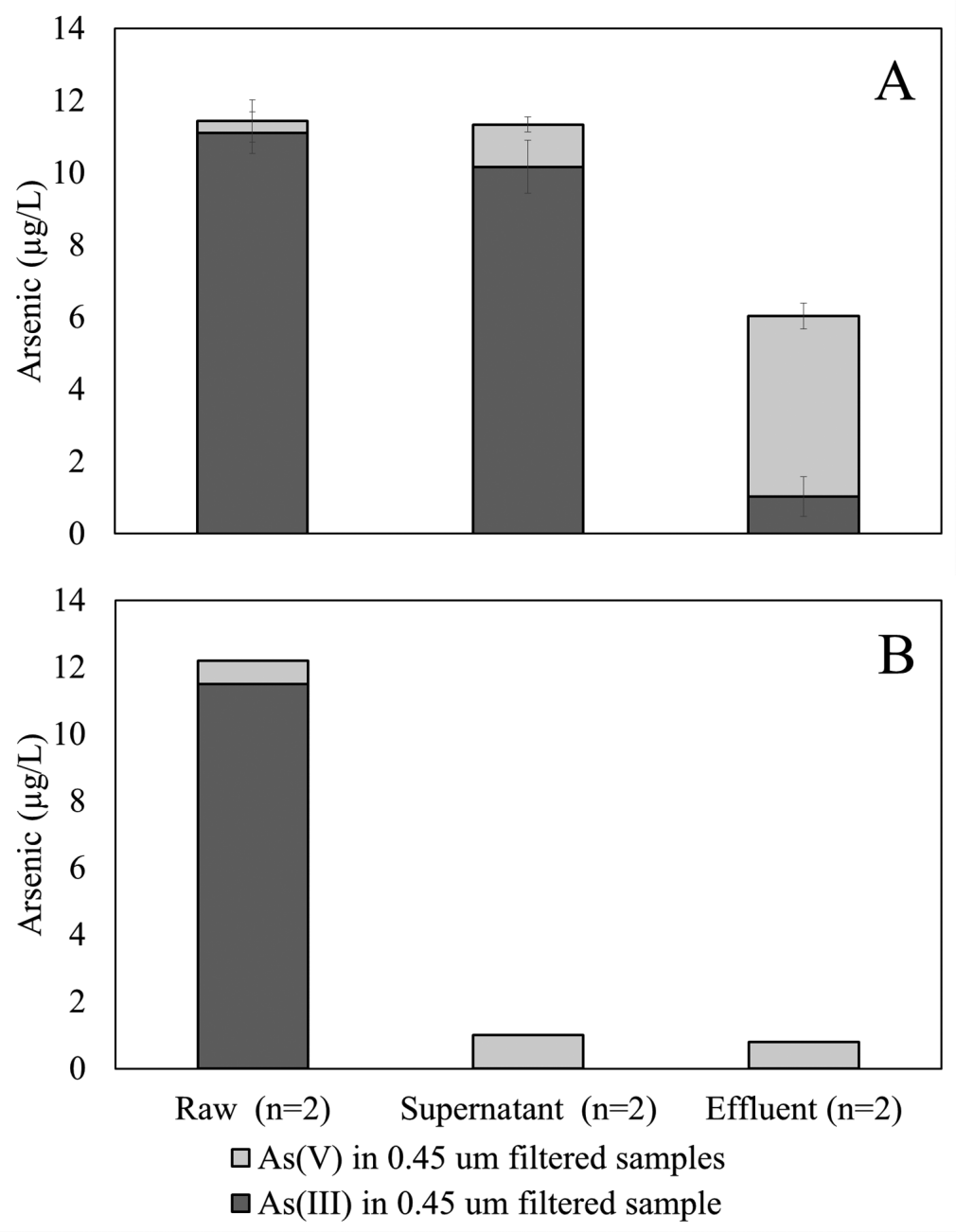

Figure 2.6 Dissolved As species in raw, supernatant and filtrate (A) without and (B) with $\mathrm{MnO}_{4}^{-}-$ $\mathrm{Fe}$ (III) dosing. Supernatant refers the water storage on the top of the filter bed.

The dosing of $\mathrm{MnO}_{4}^{-}$might have modified the floc characteristics by altering the molecular-scale structure of the $\mathrm{Fe}$ (III)-precipitates in backwash solids. The structure of Fe-oxides depends largely on the synthesis conditions (Cornell and Schwertmann 2003, Van Genuchten et al. 2014b) and since dosing of $\mathrm{MnO}_{4}^{-}$oxidized $\mathrm{Fe}(\mathrm{II})$ faster than $\mathrm{O}_{2}$, the molecular-scale structure of the produced $\mathrm{Fe}(\mathrm{III})$-precipitates might also be affected. Therefore, the backwash water solids produced under two conditions: without dosing (no dose), i.e. prior to the upgrade and with only dosing $1.2 \mathrm{mg} / \mathrm{L}$ $\mathrm{MnO}_{4}^{-}$were characterized by Fe K-edge XAS (XANES and EXAFS) and XRD. 


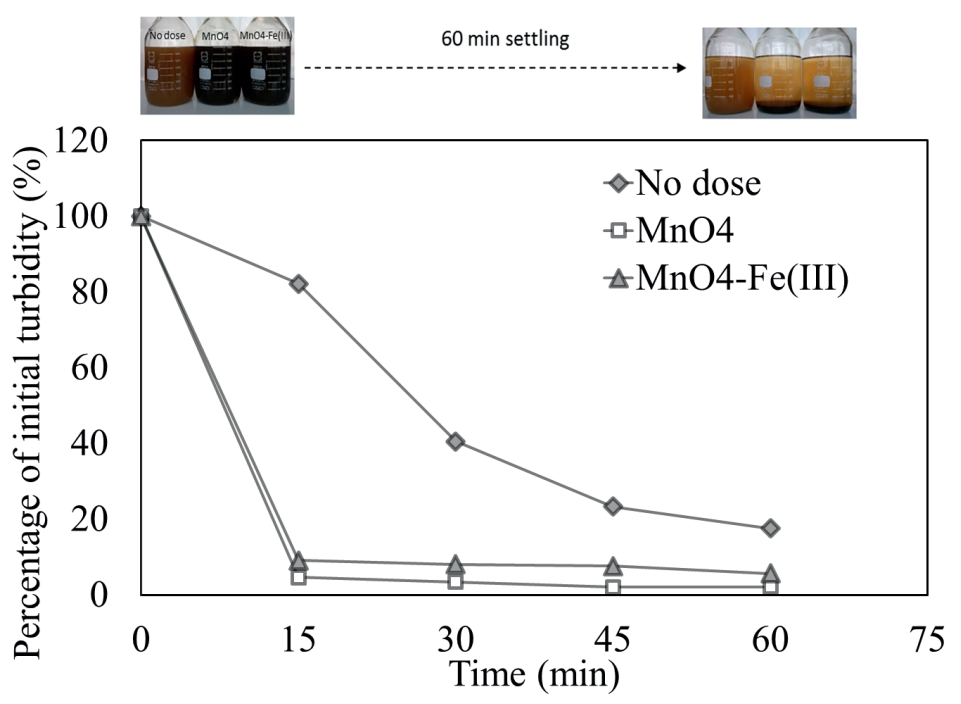

Figure 2.7 Decrease in backwash water turbidity as a function of time. Photos on top show backwash water samples at the beginning $(t=0)$ and end $(t=60 \mathrm{~min})$ of the settling test.

\subsubsection{Characterization of backwash water solids}

Fig 2.8 shows the Fe-K edge XANES and EXAFS spectra of the backwash solids collected from the full scale filter. It can be observed that the position of the absorption edge in the XANES spectra (Fig 2.8a) of the sample with no dose and with $\mathrm{MnO}_{4}$ - dose were similar and matched the absorption edge of the lepidocrocite and ferrihydrite XANES spectrum. This result shows that the Fe in both samples was primarily present as $\mathrm{Fe}(\mathrm{III})$. The oscillations in the post-edge region of the XANES spectra were similar for both the samples, but showed a slight shoulder (highlighted by the arrows in Fig 2.8a) near the absorption maximum. This oscillation was more pronounced than in the ferrihydrite and lepidocrocite XANES spectra.

The Fe K-edge EXAFS spectra (Fig 2.8b) of the samples showed a roughly symmetric first oscillation from 3.5 to $4.5 \AA^{-1}$, a major fingerprint of poorly-crystalline $\mathrm{Fe}(\mathrm{III})$ precipitates. The first oscillation of the samples matches both the 2-line ferrihydrite reference spectrum and the silicate-rich hydrous ferric oxide (Si-HFO) reference spectrum. These two reference spectra represent poorly-ordered Fe(III)-precipitate phases that form via rapid oxidation of $\mathrm{Fe}(\mathrm{II})$ or polymerization of $\mathrm{Fe}(\mathrm{III})$ salts in the presence of strongly-sorbing oxyanions (e.g. silicate, phosphate) and have been characterized previously (Van Genuchten et al. 2014b). In addition, the small beat near $5.0-5.2 \AA^{-1}$ in the ferrihydrite EXAFS spectrum, which is due to the cornersharing Fe polyhedra, was weakened or absent in the spectra of both the backwash 

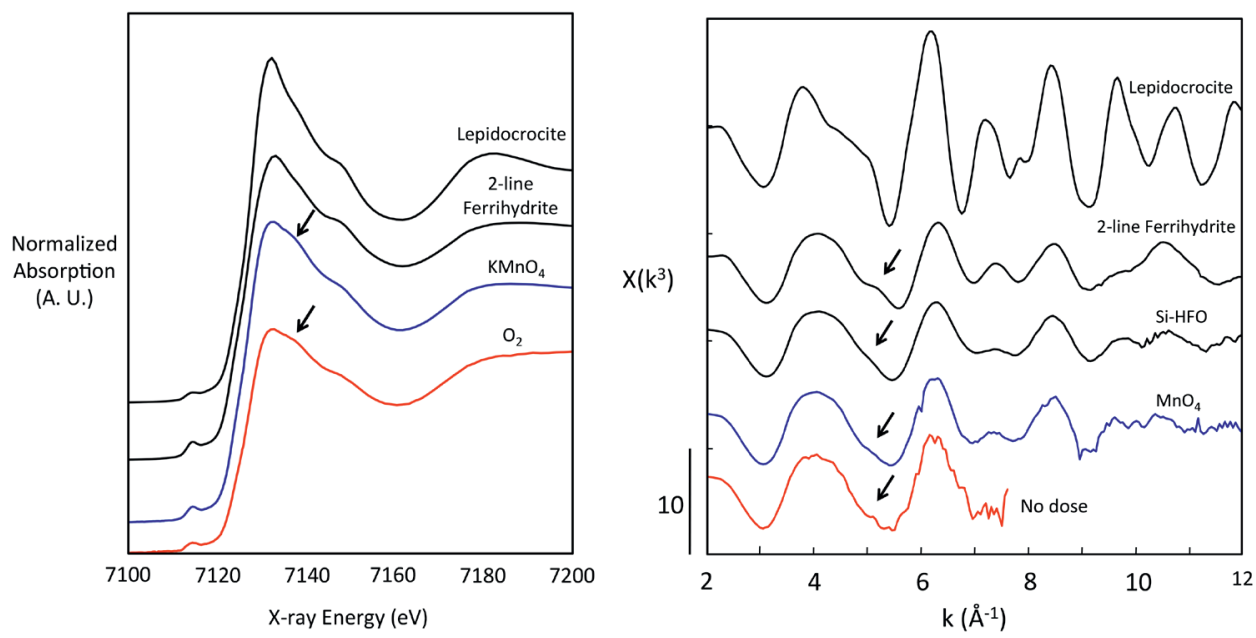

Figure 2.8 (A) Fe K-edge XANES and (B) EXAFS spectra. Samples without dose (red) and with $\mathrm{MnO}_{4}$ (blue).

solids samples. The weakened feature indicative of corner-sharing Fe polyhedral in the backwash samples can be explained by the presence of silica in water during $\mathrm{Fe}(\mathrm{III})$ precipitation (Van Genuchten et al. 2014b). Finally, the peak near $6.2 \AA^{-1}$ was reduced in the backwash solids and the oscillations at $\mathrm{k}>9 \AA^{-1}$ in the $\mathrm{MnO}_{4}^{-}$sample were broadened relative to lepidocrocite. Therefore, the XAS data showed that $\mathrm{Fe}$ in both the backwash solid samples was present as poorly-crystalline $\mathrm{Fe}(\mathrm{III})$ precipitates with structures that have slightly less polyhedral connectivity than ferrihydrite, regardless of the presence or absence of $\mathrm{MnO}_{4}^{-}$.

The XRD data (Fig 2.9) of both the backwash solids samples were similar and showed only the broad peaks indicative of poorly crystalline hydrous ferric oxide. This result was consistent with the XAS data. Although Mn was present in the samples (much higher concentration in $\mathrm{MnO}_{4}^{-}$dosed sample, $\mathrm{Mn}: \mathrm{Fe}>0.3 \mathrm{~g}: \mathrm{g}$, see Table S2.1), no evidence for any crystalline Mn oxides was observed in the XRD patterns. This result suggests that $\mathrm{Mn}$ in the solid phase was present as a nanocrystalline solid, such as poorly-ordered birnessite, or perhaps was incorporated into the structure of the nanocrystalline hydrous ferric oxide, which has been observed previously during the co-precipitation of $\mathrm{Mn}$ with $\mathrm{Fe}(\mathrm{III})$ precipitates (Ebinger and Schulze 1989, Van Genuchten and Pena 2017b). Although neither of these possible Mn coordination environments would produce strong Bragg diffraction peaks, which is consistent with our XRD data, we note that identifying the exact Mn speciation in the solid phase requires additional structural information. Because we observed 
that $\mathrm{MnO}_{4}$ - dosing alters substantially the settling characteristics of the backwash solids, and that $\mathrm{MnO}_{4}$ - dosing did not impact solid phase Fe speciation, it is likely that Mn speciation plays a critical role in determining the macroscopic properties of the backwashed solids. Therefore, further investigation to elucidate the mechanism of $\mathrm{Mn}$ incorporation in the flocs, and the subsequent impact on floc size, density, filterability and settling is required.

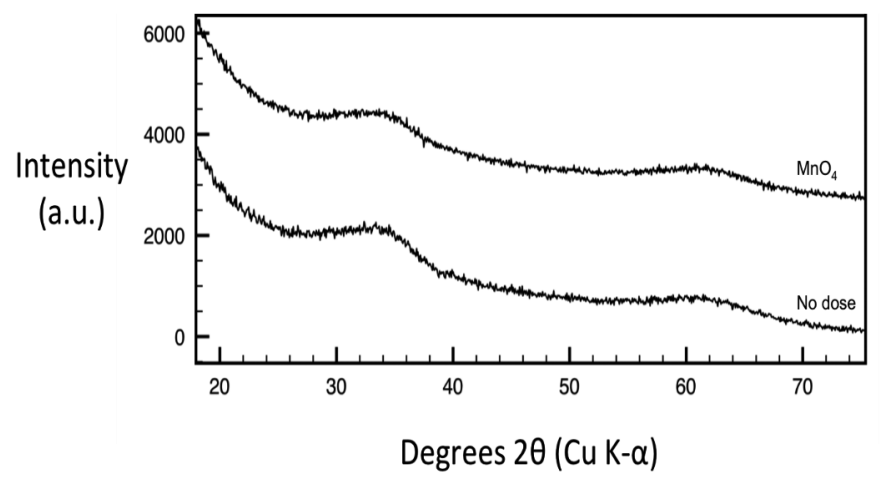

Figure 2.9 X-ray diffraction patterns of the rapid sand filter backwash solids.

\subsection{CONCLUSIONS}

This study concludes that $\mathrm{MnO}_{4}^{-}-\mathrm{Fe}(\mathrm{III})$ dosing is an effective technique to improve As(III) removal at groundwater treatment facilities that typically use aeration - rapid sand filtration for drinking water production. At WTP Dorst, a typical groundwater treatment facility in the Netherlands, drinking water As concentrations of $<1 \mu \mathrm{g} / \mathrm{L}$ were achieved with $1.2 \mathrm{mg} / \mathrm{L} \mathrm{MnO}_{4}^{-}$and $1.8 \mathrm{mg} / \mathrm{L} \mathrm{Fe}(\mathrm{III})$, based on the outcomes of systematic batch and pilot study. The optimized combination of $\mathrm{MnO}_{4}^{-}$and $\mathrm{Fe}$ (III) doses did not decrease the removal efficiency of $\mathrm{Fe}(\mathrm{II}), \mathrm{Mn}(\mathrm{II})$ and $\mathrm{NH}_{4}^{+}$, although the removal patterns of $\mathrm{Fe}(\mathrm{II})$ and $\mathrm{Mn}$ (II) were altered. In the absence of $\mathrm{MnO}_{4}^{-}$$\mathrm{Fe}$ (III) dose, a significant part of $\mathrm{Fe}$ precipitation and the complete precipitation of $\mathrm{Mn}$ occurred in the filter bed whereby with $\mathrm{MnO}_{4}^{-}-\mathrm{Fe}$ (III) dosing, both $\mathrm{Fe}$ and Mn were completely precipitated in the supernatant, before entering the filter bed, and resulted in a shortening of the filter run time. The dosing of $\mathrm{MnO}_{4}^{-}-\mathrm{Fe}(\mathrm{III})$ improved the settling rate of backwash solids, which was not attributed to changes in molecular-scale structure of Fe-precipitates that form during treatment, but to the increased Mn concentration in the backwash solids. 


\section{Acknowledgements}

This research is supported by the TKI Water Technology Programme of the Dutch Government and companies including Brabant Water, Evides Dunea, Aqua Minerals, Carus and Maltha group. AA wants to thank Doris van Halem, Jink Gude and Luuk Rietveld at Sanitary Engineering Dept. of Technical University of Delft for their valuable input during the project. The authors acknowledge the comments from both the anonymous reviewers which improved the paper substantially.

\section{SUPPLEMENTARY INFORMATION}

Table S2.1. Unfiltered and $0.45 \mu \mathrm{m}$ filtered Fe and Mn concentration in the backwash water samples

\begin{tabular}{lllll}
\hline Setting & $\begin{array}{l}\text { Fe } \\
\text { (unfiltered) }\end{array}$ & $\begin{array}{l}\mathbf{F e}(\mathbf{0 . 4 5} \boldsymbol{\mu m} \\
\text { filtered) }\end{array}$ & $\begin{array}{l}\text { Mn } \\
\text { (unfiltered) }\end{array}$ & $\begin{array}{l}\text { Mn } \\
(\mathbf{0 . 4 5} \boldsymbol{\mu m} \text { filtered) }\end{array}$ \\
\hline & $\mathrm{mg} / \mathrm{L}$ & $\mathrm{mg} / \mathrm{L}$ & $\mathrm{mg} / \mathrm{L}$ & $\mathrm{mg} / \mathrm{L}$ \\
No dose & 127.1 & 0.6 & 0.50 & 0.02 \\
$\mathrm{MnO}_{4}^{-}$ & 119.1 & 0.14 & 51.9 & 0.06 \\
$\mathrm{MnO}_{4}^{-}-\mathrm{Fe}(\mathrm{III})$ & 111.5 & 0.16 & 38.1 & 0.05 \\
\hline
\end{tabular}




\section{REFERENCES}

Ahmad, A., Kools, S., Schriks, M., Stuyfzand, P., \& Hofs, B. (2015). Arsenic and chromium concentrations and their speciation in groundwater resources and drinking water supply in the Netherlands. KWR BTO Report 2015.017. Nieuwegein, the Netherlands

Bhattacharya, P., Frisbie, S. H., Smith, E., Naidu, R., Jacks, G., \& Sarkar, B. (2002). Arsenic in the Environment: A Global Perspective. In B. Sarkar (Ed.), Handbook of Heavy Metals in the Environment (pp. 145-215). Taylor \& Francis Inc. New York, USA

Bhattacharya, P., Welch, A. H., Stollenwerk, K. G., McLaughlin, M. J., Bundschuh, J., \& Panaullah, G. (2007). Arsenic in the environment: Biology and Chemistry. Science of the Total Environment, 379(2), 109-120. doi:https://doi.org/10.1016/j.scitotenv.2007.02.037

Bissen, M., \& Frimmel, F. H. (2003). Arsenic - A review. Part II: Oxidation of arsenic and its removal in water treatment. Acta hydrochimica et hydrobiologica, 31(2), 97-107. doi:10.1002/ aheh. 200300485

Borba, R. P., Figueiredo, B. R., \& Matschullat, J. (2003). Geochemical distribution of arsenic in waters, sediments and weathered gold mineralized rocks from Iron Quadrangle, Brazil. Environmental Geology, 44(1), 39-52

Bordoloi, S., Nath, S. K., Gogoi, S., \& Dutta, R. K. (2013). Arsenic and iron removal from groundwater by oxidation-coagulation at optimized $\mathrm{pH}$ : Laboratory and field studies. Journal of Hazardous Materials, 260, 618-626. doi:https://doi.org/10.1016/j.jhazmat.2013.06.017

Borho, M., \& Wilderer, P. (1996). Optimized removal of arsenate(III) by adaptation of oxidation and precipitation processes to the filtration step. Water Science and Technology, 34(9), 25-31.

Bruins, J. H., Petrusevski, B., Slokar, Y. M., Kruithof, J. C., \& Kennedy, M. D. (2015). Manganese removal from groundwater: Characterization of filter media coating. Desalination and Water Treatment, 55(7), 1851-1863. doi:10.1080/19443994.2014.927802

Bundschuh, J., Maity, J. P., Mushtaq, S., Vithanage, M., Seneweera, S., Schneider, J., . . Chen, C. Y. (2017). Medical geology in the framework of the sustainable development goals. Science of the Total Environment, 581-582, 87-104. doi:10.1016/j.scitotenv.2016.11.208

Clifford, D. A., Ceber, L., \& Chow, S. (1983). Separation of arsenic III and arsenic V by ion Exchange. Paper presented at the AWWA Water Quality Technology Conference, Denver, Colorado

Cornell, R. M., \& Schwertmann, U. (2003). The Iron Oxides: Structure, Properties, Reactions, Occurances and Uses: WILEY-VCH Verlag GmbH \& Co.

De Moel, P. J., Verberk, J. Q. J. C., \& van Dijk, J. C. (2006). Drinking Water: Principles and Practices. Delft, the Netherlands

De Vet, W. (2011). Biological drinking water treatment of anaerobic groundwater in trickling filters. $\mathrm{PhD}$ thesis at Technical University of Delft. Delft, the Netherlands

Diem, D., \& Stumm, W. (1984). Is dissolved $\mathrm{Mn}^{+2}$ being oxidized by O2 in absence of Mn-bacteria and surface catalysts? Geochimica et Cosmochimica Acta, 48, 1571-1573

Dixit, S., \& Hering, J. G. (2003). Comparison of arsenic(V) and arsenic(III) sorption onto iron oxide minerals: Implications for arsenic mobility. Environmental Science and Technology, 37(18), 4182-4189. doi:10.1021/es030309t

Driehaus, W., Seith, R., \& Jekel, M. (1995). Oxidation of arsenate(III) with manganese oxides in water treatment. Water Research, 29(1), 297-305.

Ebinger, M. H., \& Schulze, D. G. (1989). Mn-Substituted Goethite and Fe-Substituted Groutite Synthesized at Acid pH. Clays and clay minerals, 37(2), 151-156. doi:10.1346/ CCMN.1989.0370206

Edwards, M. (1994). Chemistry of arsenic removal during coagulation and Fe-Mn oxidation. American Water Works Association, 64-78. 
Ferguson, J. F., \& Gavis, J. (1972). A review of the arsenic cycle in natural waters. Water Research, 6(11), 1259-1274. doi:http://dx.doi.org/10.1016/0043-1354(72)90052-8

Frank, P., \& Clifford, D. (1986). Arsenic(III) oxidation and removal from drinking water. USEPA Report EPA/600/2-86/021

Ghurye, G., \& Clifford, D. A. (2001). Laboratory Study on the Oxidation of Arsenic III to As V. USEPA Report EPA/600/R-01/021

Guan, X., Ma, J., Dong, H., \& Jiang, L. (2009). Removal of arsenic from water: Effect of calcium ions on As(III) removal in the $\mathrm{KMnO}_{4}-\mathrm{Fe}(\mathrm{II})$ process. Water Research, 43(20), 5119-5128. doi:http://dx.doi.org/10.1016/j.watres.2008.12.054

Gude, J. C. J., Rietveld, L. C., \& van Halem, D. (2016). Fate of low arsenic concentrations during full-scale aeration and rapid filtration. Water Research, 88, 566-574. doi:10.1016/j. watres.2015.10.034

Gude, J. C. J., Rietveld, L. C., \& van Halem, D. (2017). As(III) oxidation by MnO2 during groundwater treatment. Water Research, 111, 41-51. doi:10.1016/j.watres.2016.12.041

Gunduz, O., Simsek, C., \& Hasozbek, A. (2010). Arsenic pollution in the groundwater of Simav Plain, Turkey: Its impact on water quality and human health. Water, Air, and Soil Pollution, 205(1-4), 43-62. doi:10.1007/s11270-009-0055-3

Hering, J. G., Chen, P.-Y., Wilkie, J. A., Elimelech, M., \& Liang, S. (1996). Arsenic removal by ferric chloride. American Water Works Association, 88(4), 155-167.

Hsu, J. C., Lin, C. J., Liao, C. H., \& Chen, S. T. (2008). Removal of As(V) and As(III) by reclaimed iron-oxide coated sands. Journal of Hazardous Materials, 153(1-2), 817-826. doi:10.1016/j. jhazmat.2007.09.031

Jain, C. K., \& Ali, I. (2000). Arsenic: Occurrence, toxicity and speciation techniques. Water Research, 34(17), 4304-4312. doi:10.1016/S0043-1354(00)00182-2

Jessen, S., Larsen, F., Koch, C. B., \& Arvin, E. (2005). Sorption and Desorption of Arsenic to Ferrihydrite in a Sand Filter. Environmental Science \& Technology, 39(20), 8045-8051. doi:10.1021/es050692x

Katsoyiannis, I. A., Zikoudi, A., \& Hug, S. J. (2008). Arsenic removal from groundwaters containing iron, ammonium, manganese and phosphate: A case study from a treatment unit in northern Greece. Desalination, 224(1-3), 330-339. doi:10.1016/j.desal.2007.06.014

Kim, M.-J., \& Nriagu, J. (2000). Oxidation of arsenite in groundwater using ozone and oxygen. Science of the Total Environment, 247(1), 71-79. doi:https://doi.org/10.1016/S0048-9697(99)00470-2

Kozisek, F. (2017). Regulatory aspects of Arsenic in drinking water. In P. Bhattacharya, D. A. Polya, $\&$ D. Jovanovic (Eds.), Best Practice Guide on the Control of Arsenic in Drinking Water. IWA Publishing. London, UK

Lakshmanan, D., Clifford, D., \& Samanta, G. (2008). Arsenic Removal by Coagulation with Aluminum, Iron, Titanium, and Zirconium. American Water Works Association, 100(2), 76-88

Lihua, S., Ruiping, L., Shengji, X., Yanling, Y., \& Guibai, L. (2009). Enhanced As(III) removal with permanganate oxidation, ferric chloride precipitation and sand filtration as pretreatment of ultrafiltration. Desalination, 243(1), 122-131. doi:http://dx.doi.org/10.1016/j. desal.2008.04.019

Lytle, D. A., Chen, A. S., Sorg, T. J., Phillips, S., \& French, K. (2007). Microbial As(III) oxidation in water treatment plant filters. American Water Works Association, 99(12), 72-86

Lytle, D. A., Sorg, T. J., \& Snoeyink, V. L. (2005). Optimizing arsenic removal during iron removal: Theoretical and practical considerations. Journal of Water Supply: Research and Technology AQUA, 54(8), 545-560

MacDonald, A. M., Bonsor, H. C., Ahmed, K. M., Burgess, W. G., Basharat, M., Calow, R. C., . . Yadav, S. K. (2016). Groundwater quality and depletion in the Indo-Gangetic Basin mapped from in situ observations. Nature Geoscience, 9(10), 762-766. doi:10.1038/ngeo2791 
Marszałek, H., \& Wąsik, M. (2000). Influence of arsenic-bearing gold deposits on water quality in Zloty Stok mining area (SW Poland). Environmental Geology, 39(8), 888-892. doi:10.1007/ s002549900036

McCarty, K. M., Hanh, H. T., \& Kim, K. W. (2011). Arsenic geochemistry and human health in South East Asia. Rev Environ Health, 26(1), 71-78

McNeill, L. S., \& Edwards, M. (1995). Soluble arsenic removal at water treatment plants. American Water Works Association, 87(4), 105-113

Murcott, S. (2012). Arsenic Contamination in the World. IWA Publishing. London, UK

Naujokas, M. F., Anderson, B., Ahsan, H., Aposhian, H. V., Graziano, J. H., Thompson, C., \& Suk, W. A. (2013). The broad scope of health effects from chronic arsenic exposure: update on a worldwide public health problem. Environ Health Perspect, 121(3), 295-302. doi:10.1289/ ehp. 1205875

Nriagu, J. O., Bhattacharya, P., Mukherjee, A. B., Bundschuh, J., Zevenhoven, R., Loeppert, R. H. (2007). Arsenic in soil and groundwater: an introduction. In P. Bhattacharya, A. B. Mukherjee, J. Bundschuh, R. Zevenhoven \& R. H. Loeppert (Eds.), Arsenic in soil and groundwater environment: Biogeochemical interactions, health effects and remediation, trace metals and other contaminants in the environment (Vol. 9, pp. 3-60). Amsterdam, the Netherlands

Pierce, M. L., \& Moore, C. B. (1982). Adsorption of arsenite and arsenate on amorphous iron hydroxide. Water Research, 16(7), 1247-1253. doi:10.1016/0043-1354(82)90143-9

Pontius, F. W., Brown, K. G., \& Chen, C.-J. (1994). Health Implications of Arsenic in Drinking Water. American Water Works Association, 86(9), 52-63

Qiao, J., Jiang, Z., Sun, B., Sun, Y., Wang, Q., \& Guan, X. (2012). Arsenate and arsenite removal by $\mathrm{FeCl} 3$ : Effects of $\mathrm{pH}, \mathrm{As} / \mathrm{Fe}$ ratio, initial As concentration and co-existing solutes. Separation and Purification Technology, 92, 106-114. doi:10.1016/j.seppur.2012.03.023

Raven, K. P., Jain, A., \& Loeppert, R. H. (1998). Arsenite and arsenate adsorption on ferrihydrite: Kinetics, equilibrium, and adsorption envelopes. Environmental Science and Technology, 32(3), 344-349. doi:10.1021/es970421p

Roberts, L. C., Hug, S. J., Ruettimann, T., Billah, M. M., Khan, A. W., \& Rahman, M. T. (2004). Arsenic Removal with Iron(II) and Iron(III) in Waters with High Silicate and Phosphate Concentrations. Environmental Science \& Technology, 38(1), 307-315. doi:10.1021/es0343205

Schmidt, C. W. (2014). Low-Dose Arsenic: In Search of a Risk Threshold. Environ Health Perspect, 122(5), A131-134.

Schuhmacher-Wolz, U., Dieter, H. H., Klein, D., \& Schneider, K. (2009). Oral exposure to inorganic arsenic: evaluation of its carcinogenic and non-carcinogenic effects. Critical reviews in toxicology, 39(4), 271-298.

Smedley, P. L., \& Kinniburgh, D. G. (2002). A review of the source, behaviour and distribution of arsenic in natural waters. Applied Geochemistry, 17(5), 517-568. doi:10.1016/s0883-2927(02)00018-5

Smeets, P., Medema, G., \& Dijk, J. (2009). The Dutch secret: How to provide safe drinking water without chlorine in the Netherlands. Drinking water and Engineering Science, 2, 1-14

Smith, A. H., Hopenhayn-Rich, C., Bates, M. N., Goeden, H. M., Hertz-Picciotto, I., Duggan, H. M., ... Smith, M. T. (1992). Cancer risks from arsenic in drinking water. Environ Health Perspect, 97, 259-267.

Sorlini, S., \& Gialdini, F. (2010). Conventional oxidation treatments for the removal of arsenic with chlorine dioxide, hypochlorite, potassium permanganate and monochloramine. Water Research, 44(19), 5653-5659. doi:10.1016/j.watres.2010.06.032

Sorlini, S., Gialdini, F., \& Collivignarelli, M. C. (2014). Survey on full-scale drinking water treatment plants for arsenic removal in Italy. Water Practice and Technology, 9(1), 42-51.

Stuyfzand, P., van Rossum, P., \& Mendizabal, I. (2008). Does arsenic, in groundwaters of the compound Rhine-Meuse-Scheldt-Eems delta, menace drinking water supply in the Netherlands? In T. 
Appelo (Ed.), Arsenic in groundwater - A world problem (pp. 102-125). Netherlands National Committee of the IAH. Utrecht, the Netherlands

Su, C., \& Puls, R. W. (2001). Arsenate and Arsenite Removal by Zerovalent Iron: Effects of Phosphate, Silicate, Carbonate, Borate, Sulfate, Chromate, Molybdate, and Nitrate, Relative to Chloride. Environ. Sci. Technol., 35(22), 4562-4568. doi:10.1021/es010768z

Vahter, M. (2008). Health effects of early life exposure to arsenic. Basic and Clinical Pharmacology and Toxicology, 102(2), 204-211. doi:10.1111/j.1742-7843.2007.00168.x

Vahter, M., Gardner, R., Ahmed, S., Kippler, M., Hamadani, J. D., Tofail, F., \& Raqib, R. (2012). Effects of early-life arsenic exposure on child health and development. In: J.C. Ng, B.N. Noller, R. Naidu, J. Bundschuh \& P. Bhattacharya (eds.) Understanding the Geological and Medical Interface of Arsenic, As 2012. CRC Press/Taylor and Francis (ISBN-13: 978-0-415-63763-3), pp. 173-174.

Van Beek, C. G. E. M., Hiemstra, T., Hofs, B., Bederlof, M. M., van Paassen, J. A. M., \& Reijnen, G. K. (2012). Homogeneous, heterogeneous and biological oxidation of iron(II) in rapid sand filtration. Journal of Water Supply: Research and Technology—AQUA, 61(1), 1-2012

Van der Wens, P., Baken, K., Schriks, M., 2016. Arsenic at low concentrations in Dutch drinking water: assessment of removal costs and health benefits. In: Bhattacharya, P., et al., (Eds.), Arsenic Research and Global Sustainability: Proceedings of the Sixth International Congress on Arsenic in the Environment (As2016), June 19-23, 2016, Stockholm, Sweden, CRC Press, pp. 563-564

Van Genuchten, C. M., \& Pena, J. (2017). Mn(II) Oxidation in Fenton and Fenton Type Systems: Identification of Reaction Efficiency and Reaction Products. Environ. Sci. Technol., 51(5), 2982-2991. doi:10.1021/acs.est.6b05584

Van Genuchten, C. M., Pena, J., Amrose S, E., \& Gadgil, A. J. (2014). Structure of Fe(III) precipitates genberated by the electrolytric dissolution of $\mathrm{Fe}(0)$ in the presence of groundwater ions. Geochimica et Cosmochimica Acta, 127, 285-304

Von Gunten, U. (2003). Ozonation of drinking water: Part II. Disinfection and by-product formation in presence of bromide, iodide or chlorine. Water Research, 37(7), 1469-1487. doi:10.1016/ S0043-1354(02)00458-X

Vries, D., Bertelkamp, C., Schoonenberg Kegel, F., Hofs, B., Dusseldorp, J., Bruins, J. H., . . van den Akker, B. (2017). Iron and manganese removal: Recent advances in modelling treatment efficiency by rapid sand filtration. Water Research, 109, 35-45. doi:10.1016/j.watres.2016.11.032

Wang, S., \& Mulligan, C. N. (2006). Occurrence of arsenic contamination in Canada: Sources, behavior and distribution. Science of the Total Environment, 366, $701-721$

WHO. (2011). Arsenic in Drinking-water: Background document for development of WHO Guidelines for Drinking-water Quality (pp. 16). WHO Press. Geneva, Switzerland

Wilkie, J. A., \& Hering, J. G. (1996). Adsorption of arsenic onto hydrous ferric oxide: Effects of adsorbate/adsorbent ratios and co-occurring solutes. Colloids and Surfaces A: Physicochemical and Engineering Aspects, 107, 97-110. doi:10.1016/0927-7757(95)03368-8

Woo, N. C., \& Choi, M. C. (2001). Arsenic and metal contamination of water resources from mining wastes in korea. Environmental Geology, 40(3), 305-311. doi:10.1007/s002540000161

Youngran, J., Fan, M., Van Leeuwen, J., \& Belczyk, J. F. (2007). Effect of competing solutes on $\operatorname{arsenic}(\mathrm{V})$ adsorption using iron and aluminum oxides. Journal of Environmental Sciences, 19(8), 910-919. doi:http://dx.doi.org/10.1016/S1001-0742(07)60151-X 



\section{Chapter 3}

\section{Characteristics of iron and manganese bearing precipitates generated by $\mathrm{Fe}(\mathrm{II})$ and $\mathrm{Mn}(\mathrm{II})$ co-oxidation with $\mathrm{O}_{2}, \mathrm{MnO}_{4}$ and $\mathrm{HOCl}$ in the presence of groundwater ions}

This chapter has been published as:

Ahmad, A., van der Wal, A., Bhattacharya, P., \& Van Genuchten, C. M. (2019). Characteristics of $\mathrm{Fe}$ and $\mathrm{Mn}$ bearing precipitates generated by $\mathrm{Fe}(\mathrm{II})$ and $\mathrm{Mn}(\mathrm{II})$ co-oxidation with $\mathrm{O}_{2}, \mathrm{MnO}_{4}$ and $\mathrm{HOCl}$ in the presence of groundwater ions. Water Research, 161, 505-516. 


\section{ABSTRACT}

In this work, we combined macroscopic measurements of precipitate aggregation and chemical composition ( $\mathrm{Mn} / \mathrm{Fe}$ solids ratio) with X-ray absorption spectroscopy to investigate the solids formed by co-oxidation of $\mathrm{Fe}(\mathrm{II})$ and $\mathrm{Mn}$ (II) with $\mathrm{O}_{2}, \mathrm{MnO}_{4}$, and $\mathrm{HOCl}$ in the presence of groundwater ions. In the absence of the strongly sorbing oxyanions, phosphate $(\mathrm{P})$ and silicate $(\mathrm{Si})$, and calcium $(\mathrm{Ca}), \mathrm{O}_{2}$ and $\mathrm{HOCl}$ produced suspensions that aggregated rapidly, whereas co-oxidation of $\mathrm{Fe}(\mathrm{II})$ and $\mathrm{Mn}$ (II) by $\mathrm{MnO}_{4}$ generated colloidally stable suspensions. The aggregation of all suspensions decreased in $\mathrm{P}$ and $\mathrm{Si}$ solutions, but Ca counteracted these oxyanion effects. The speciation of oxidized Fe and $\mathrm{Mn}$ in the absence of $\mathrm{P}$ and $\mathrm{Si}$ also depended on the oxidant, with $\mathrm{O}_{2}$ producing $\mathrm{Mn}(\mathrm{III})$-incorporated lepidocrocite $(\mathrm{Mn} / \mathrm{Fe}=0.01$ to $0.02 \mathrm{~mol} / \mathrm{mol}$ ), $\mathrm{HOCl}$ producing $\mathrm{Mn}$ (III)-incorporated hydrous ferric oxide (HFO) $(\mathrm{Mn} / \mathrm{Fe}=0.08 \mathrm{~mol} / \mathrm{mol})$, and $\mathrm{MnO}_{4}$ producing poorly-ordered $\mathrm{MnO}_{2}$ and $\mathrm{HFO}$ $(\mathrm{Mn} / \mathrm{Fe}>0.5 \mathrm{~mol} / \mathrm{mol})$. In general, the presence of $\mathrm{P}$ and $\mathrm{Si}$ decreased the crystallinity of the $\mathrm{Fe}(\mathrm{III})$ phase and increased the $\mathrm{Mn} / \mathrm{Fe}$ solids ratio, which was found by $\mathrm{Mn}$ $\mathrm{K}$-edge XAS analysis to be due to an increase in surface-bound $\mathrm{Mn}(\mathrm{II})$. By contrast, Ca decreased the $\mathrm{Mn} / \mathrm{Fe}$ solids ratio and decreased the fraction of $\mathrm{Mn}$ (II) associated with the solids, suggesting that $\mathrm{Ca}$ and $\mathrm{Mn}$ (II) compete for sorption sites. Based on these results, we discuss strategies to optimize the design (i.e. filter bed operation and chemical dosing) of water treatment plants that aim to remove $\mathrm{Fe}(\mathrm{II})$ and $\mathrm{Mn}$ (II) by co-oxidation. 


\section{$3.1 \quad$ INTRODUCTION}

Groundwater is treated to remove dissolved iron (Fe(II)) and manganese $(\mathrm{Mn}(\mathrm{II}))$ to avoid sedimentation in distribution pipelines and discoloration of treated water (Vries et al. 2017). Typical schemes at groundwater treatment plants consist of aeration followed by rapid sand filtration (De Moel et al. 2006). Aeration saturates the groundwater with dissolved oxygen $\left(\mathrm{O}_{2}\right)$, which facilitates oxidation and precipitation of Fe and Mn solids. The Fe and Mn bearing precipitates accumulate in filters until backwashing is applied to dislodge the solids from the filtration media. While $\mathrm{O}_{2}$ is often capable of oxidizing $\mathrm{Fe}(\mathrm{II})$ on the time scale of typical groundwater treatment, $\mathrm{O}_{2}$ alone is ineffective at oxidizing $\mathrm{Mn}(\mathrm{II})$ to $\mathrm{Mn}(\mathrm{III}, \mathrm{IV})$ and $\mathrm{As}(\mathrm{III})$ to As $(V)$, the more easily removed arsenic species (Diem and Stumm 1984, Gude et al. 2016, Van Beek et al. 2012). To rapidly oxidize $\mathrm{Mn}(\mathrm{II})$ and As(III) at water treatment plants, stronger chemical oxidants, such $\mathrm{NaOCl}$ or $\mathrm{KMnO}_{4}$, can be used (Ahmad et al. 2018, Sorlini and Gialdini 2010). Strong oxidants are also used when high concentrations of $\mathrm{Fe}(\mathrm{II})$ are present in groundwater and rapid oxidation is desired (Allard et al. 2013, Knocke et al. 1991).

Although chemical oxidants (i.e. $\mathrm{NaOCl}$ and $\mathrm{KMnO}_{4}$ ) can improve co-oxidative removal of $\mathrm{Fe}(\mathrm{II}), \mathrm{Mn}$ (II) and $\mathrm{As}(\mathrm{III})$, little is known about how different oxidants impact key properties of the solid end-products, including the structure and composition. Previous work has shown that the Fe(II) and $\mathrm{Mn}$ (II) oxidation rates alter the structure of the solid phase. For example, poorly-ordered Fe(III) precipitates result from rapid $\mathrm{Fe}$ (II) oxidation by $\mathrm{H}_{2} \mathrm{O}_{2}$ and moderately crystalline lepidocrocite forms from slower $\mathrm{Fe}(\mathrm{II})$ oxidation by $\mathrm{O}_{2}$ (Van Genuchten and Pena 2017a, Voegelin et al. 2010). These differences in crystallinity are important because poorly-ordered Fe(III) (oxyhydr)oxides have a higher specific surface area than crystalline solids, which would increase sorption of ions (e.g. As) per mass of Fe added. Similarly, poorly-ordered $\mathrm{Mn}(\mathrm{IV})$ oxides are favoured when microorganisms oxidize $\mathrm{Mn}(\mathrm{II})$ rapidly, whereas $\mathrm{Mn}$ (III) oxides can form from slow, surface-catalyzed $\mathrm{Mn}$ (II) oxidation by $\mathrm{O}_{2}$ (Lan et al. 2017, Tebo et al. 2005). However, the co-occurrence of $\mathrm{Fe}(\mathrm{II})$ and $\mathrm{Mn}(\mathrm{II})$, which is common in groundwater (McArthur et al. 2012), can alter the pathways of co-oxidation since strong Fenton-type oxidants generated from $\mathrm{Fe}(\mathrm{II})$ oxidation can react rapidly with reduced species, including $\mathrm{Mn}$ (II) (Hug and Leupin 2003, Van Genuchten and Pena 2017a). In addition to the type of chemical oxidant, the structure of Fe and Mn bearing solids can also be altered by the presence of common groundwater ions, such as silicate $(\mathrm{Si})$, phosphate $(\mathrm{P}), \mathrm{As}$, and calcium $(\mathrm{Ca})$. By binding strongly to precipitate surfaces, $\mathrm{P}$ and $\mathrm{Si}$ oxyanions can inhibit crystal growth, leading to poorly-ordered solids (Kaegi et al. 2010, Senn et al. 2017). Moreover, Si and P oxyanions can decrease the particle surface charge, which 
strongly influences particle aggregation and sedimentation efficiency (Sposito 2008), whereas $\mathrm{Ca}$ can counteract the effects of $\mathrm{P}$ and Si. Since the sorption reactivity and colloidal stability of Fe and $\mathrm{Mn}$ precipitates depend strongly on their structure and composition, it is critical to investigate how structural properties of the precipitates are altered by oxidant type and solution composition.

In this work, we combine macroscopic measurements of aggregation and sedimentation (i.e. turbidity and filterability) with $\mathrm{Fe}$ and $\mathrm{Mn} \mathrm{K}$-edge X-ray absorption spectroscopy to investigate the solids formed by $\mathrm{Fe}(\mathrm{II})$ and $\mathrm{Mn}(\mathrm{II})$ cooxidation with $\mathrm{O}_{2}, \mathrm{MnO}_{4}$, and $\mathrm{HOCl}$. We perform batch $\mathrm{Fe}(\mathrm{II})$ and $\mathrm{Mn}(\mathrm{II})$ cooxidation experiments in solutions with systematically varied concentrations of As, $\mathrm{P}$, $\mathrm{Si}$, and $\mathrm{Ca}$. We focus primarily on characterizing the speciation of $\mathrm{Fe}$ and $\mathrm{Mn}$ in this work, but note that the redox and sorption behavior of As in identical experiments will be reported in a follow-up study. The knowledge generated in our investigation is critical to select the most effective oxidant in groundwater treatment, considering the co-removal of $\mathrm{Fe}(\mathrm{II}), \mathrm{Mn}(\mathrm{II})$ and $\mathrm{As}(\mathrm{III})$ and the aggregation properties of the end-products.

\subsection{MATERIALS AND METHODS}

\subsubsection{Chemicals}

All chemicals were reagent grade. The stock solutions for $\mathrm{Fe}(\mathrm{II}), \mathrm{Mn}(\mathrm{II})$ and $\mathrm{HOCl}$ were prepared by dissolving $24.9 \mathrm{~g} / \mathrm{L} \mathrm{FeSO}_{4} \cdot 7 \mathrm{H}_{2} \mathrm{O}$ (Boom BV), $1.8 \mathrm{~g} / \mathrm{L} \mathrm{MnCl}_{2}$ (Merck) and $4.66 \mathrm{~g} / \mathrm{L} \mathrm{NaOCl}$ (Acors Organics) in $100 \mathrm{~mL}$ oxygen-free ultrapure water $(18.2 \mathrm{M} \Omega \mathrm{cm}$, Purelab Chorus: Veolia Water). The stock solutions for $\mathrm{Si}$, $\mathrm{HCO}_{3}, \mathrm{NaCl}$ and $\mathrm{MnO}_{4}$ were prepared by dissolving $75.7 \mathrm{~g} / \mathrm{L} \mathrm{Na} \mathrm{SiO}_{3} \cdot 5 \mathrm{H}_{2} \mathrm{O}$ (Aldrich'), $0.87 \mathrm{~g} / \mathrm{L} \mathrm{NaHCO}_{3}$ (J.T. Baker), $0.26 \mathrm{~g} / \mathrm{L} \mathrm{NaCl}$ (J.T. Baker) and 6.3

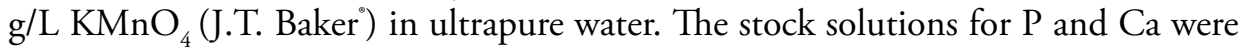
obtained by dissolving $1.11 \mathrm{~g} / \mathrm{L} \mathrm{NaH}_{2} \mathrm{PO}_{4} \cdot \mathrm{H}_{2} \mathrm{O}$ (J.T. Baker) and $138.5 \mathrm{~g} / \mathrm{L} \mathrm{CaCl}_{2}$ (J.T. Baker) in $0.1 \mathrm{M} \mathrm{HCl}$. For As(III) addition, a certified solution $(1000 \mathrm{mg}$ $\mathrm{As}(\mathrm{III}) / \mathrm{L}$, Inorganic ventures ${ }^{\circ}$ ) set in $\mathrm{HCl}$ matrix was used without any dilution. The concentration of the As(III) stock was $1000 \mathrm{mg} / \mathrm{L}$. For $\mathrm{pH}$ control during the experiments, $0.1 \mathrm{M} \mathrm{NaOH}$ and $0.1 \mathrm{M} \mathrm{HCl}$ solutions were used.

\subsubsection{Oxidation and precipitation experiments}

Experiments were performed with a $5 \mathrm{~L}$ glass reactor connected to a controller (ez-Control, Applikon Biotechnology) for adjusting, maintaining and logging (BioXpertV2 software) reaction parameters, including the $\mathrm{pH}$, temperature, oxidant supply and stirring speed (Fig 3.1). The experiments were carried out at $\mathrm{pH} 7.5$ 
and $20^{\circ} \mathrm{C}$, with stirring set to $100 \mathrm{rpm}$. Fe(II) and $\mathrm{Mn}$ (II) oxidation was initiated by dosing $\mathrm{O}_{2}, \mathrm{KMnO}_{4}$ or $\mathrm{NaOCl}$ to anaerobic solutions that initially contained $\mathrm{Fe}(\mathrm{II}), \mathrm{Mn}(\mathrm{II}), \mathrm{As}(\mathrm{III}), \mathrm{Si}, \mathrm{P}$ and $\mathrm{Ca}$ in different concentrations (Table 3.1). The range of ionic compositions studied in this work was derived from an analysis of groundwater quality in the Netherlands (Ahmad et al. 2015). For each oxidant, the initial solutions in the reference experiments (herein referred to as Ref) contained 90 $\mu \mathrm{M} \mathrm{Fe}(\mathrm{II})(5.0 \mathrm{mg} / \mathrm{L}), 9.0 \mu \mathrm{M} \mathrm{Mn}(\mathrm{II})(0.5 \mathrm{mg} / \mathrm{L})$ and $0.7 \mu \mathrm{M} \mathrm{As}(\mathrm{III})(0.05 \mathrm{mg} / \mathrm{L})$ without Si, P and Ca. In Mn18 experiments, the initial solution contained $18 \mu \mathrm{M}$ $\mathrm{Mn}$ instead of $9 \mu \mathrm{M} \mathrm{Mn}$. The rest of the experiments are identified by the ions added in $\mu \mathrm{M}$ to the Ref solution (i.e. Si150 consists of $150 \mu \mathrm{M} \mathrm{Si}, 90 \mu \mathrm{M}$ Fe(II), $9.0 \mu \mathrm{M}$ $\mathrm{Mn}(\mathrm{II})$ and $0.7 \mu \mathrm{M}$ As(III)). All solutions also contained $2.5 \mathrm{mM} \mathrm{NaHCO}_{3}$ and 0.6 $\mathrm{mM} \mathrm{NaCl}$ to provide alkalinity and ionic strength.

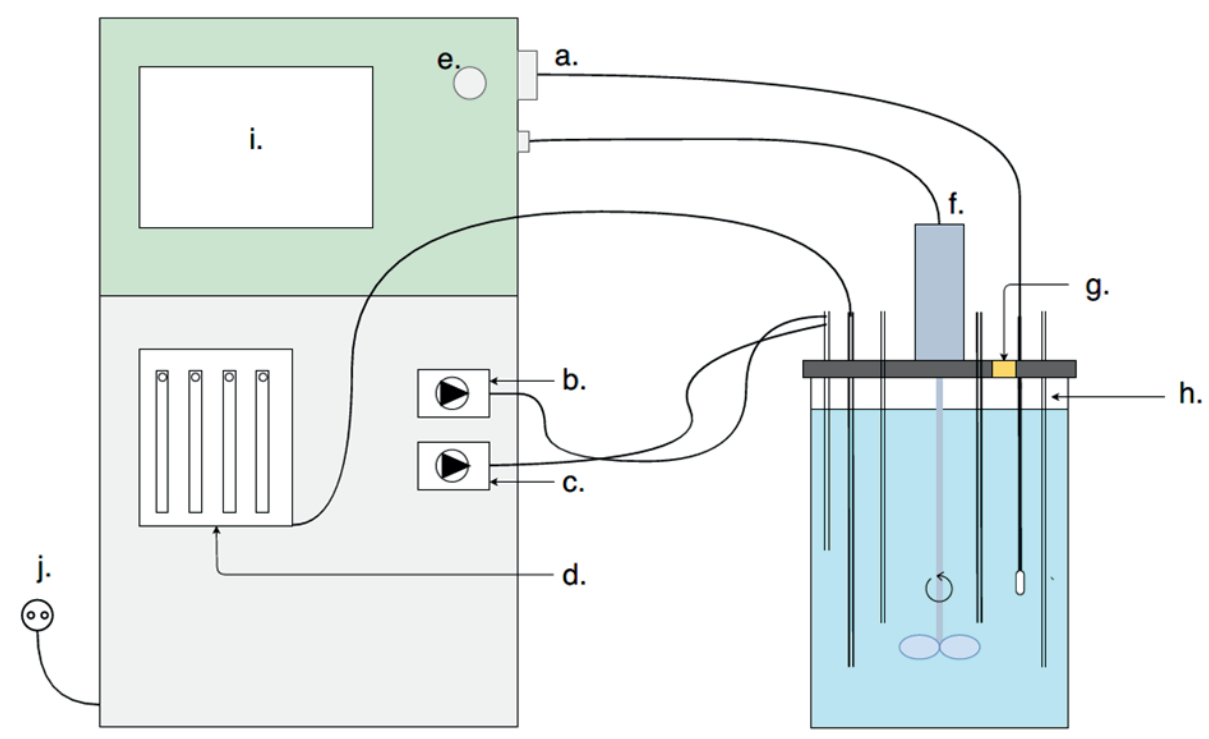

Figure 3.1 A schematic overview of the assembly used in precipitation and settling experiments. a. data logger ( $\mathrm{pH}$. temperature. dissolved oxygen); b. acid pump; c. alkali pump; d. nitrogen and air supply; e. on/off; f. stirrer; g. chemical injection port; h. sampling port; i. controller display; j. power supply.

For the $\mathrm{O}_{2}$ experiments, the initial solutions were bubbled with air to reach saturation $\left(\approx 9 \mathrm{mg} \mathrm{O}_{2} / \mathrm{L}\right)$. For $\mathrm{MnO}_{4}$ and $\mathrm{HOCl}$ systems, the doses of the $\mathrm{KMnO}_{4}$ and $\mathrm{NaOCl}$ stocks were based on the combined stoichiometric demand of $\mathrm{Fe}(\mathrm{II})$, $\mathrm{Mn}(\mathrm{II})$ and $\mathrm{As}(\mathrm{III})$ oxidation to produce $\mathrm{Fe}(\mathrm{III}), \mathrm{Mn}(\mathrm{IV})$ and $\mathrm{As}(\mathrm{V})$, respectively 
(chemical reactions are provided in the supplementary data) (Ghurye and Clifford 2001).

The experimental procedure included: (i) preparation of the initial solutions in the reaction vessel under anaerobic conditions, (ii) dosing the oxidant $\left(\mathrm{O}_{2}, \mathrm{MnO}_{4}\right.$ or $\mathrm{HOCl}$ ) and allowing for oxidation and precipitation while stirring at $100 \mathrm{rpm}$ and (iii) collection of suspension samples $30 \mathrm{~min}$ after oxidant addition, which were filtered over $0.45 \mu \mathrm{m}$ filters and stored for subsequent analysis. A 30 min reaction interval was selected based on PHREEQC simulations showing complete $\mathrm{Fe}(\mathrm{II})$ oxidation in the $\mathrm{O}_{2}$ system in $30 \mathrm{~min}$ (Fig S3.1). Samples for aqueous and total Fe and $\mathrm{Mn}$ were collected in $100 \mathrm{~mL}$ plastic bottles that contained $0.5 \mathrm{~mL}$ of $65 \%$ $\mathrm{HNO}_{3}$ and were stored at $4{ }^{\circ} \mathrm{C}$ until analysis by Inductively Coupled Plasma Mass Spectrometry (ICP-MS) (Thermo Scientific XSERIES 2 ICP-MS, Thermo Fisher Scientific, Breda, The Netherlands) at Aqualab Zuid B.V. in The Netherlands. The removal of $\mathrm{Mn}$ and $\mathrm{Fe}$ and the $\mathrm{Mn} / \mathrm{Fe}$ solid ratios $(\mathrm{mol} / \mathrm{mol})$ were determined from the difference between the $\mathrm{Fe}$ and $\mathrm{Mn}$ concentrations of the initial and final filtered solutions. Solids generated in each experiment were also collected and reserved for XAS analysis.

\subsubsection{Settling experiments}

The aggregation and settling characteristics of the particles were studied by measuring the turbidity of the suspensions as a function of time using a 2100Q Portable Turbidimeter, Hach ${ }^{\circ}$ USA. Following the addition of oxidant and $30 \mathrm{~min}$ of mixing, the turbidity of the suspension was measured by removing an aliquot $5 \mathrm{~cm}$ below the water surface during mixing. After the initial turbidity measurement, the stirring was stopped and the suspension was allowed to settle by gravity. A second turbidity measurement was made after $1 \mathrm{~h}$ of settling by removing another aliquot $5 \mathrm{~cm}$ below the water surface. The turbidity measurement vessel was rinsed twice with ultrapure water and oxalic acid ( $\mathrm{pH} 1-3)$ between measurements.

\subsubsection{X-ray absorption spectroscopy}

\subsubsection{Data collection}

$\mathrm{X}$-ray absorption spectra at the $\mathrm{Fe}$ and $\mathrm{Mn} \mathrm{K}$-edges were collected at room temperature at beamline 4-1 of the Stanford Synchrotron Radiation Lightsource (SSRL) and the DUBBLE beamline (BM-26a) of the European Synchrotron Radiation Facility (ESRF). The design of the DUBBLE beamline is described by Borsboom et al., (1998) and Nikitenko et al., (2008). Fe K-edge XAS data were recorded in transmission mode out to $k$ of $13 \AA^{-1}$. Mn K-edge XAS data were collected in transmission and fluorescence modes out to $k$ of $12 \AA^{-1}$, with spectra of superior data quality selected for subsequent analysis. $\mathrm{Fe}(0)$ or $\mathrm{Mn}(0)$ foils were used to calibrate the beam at 

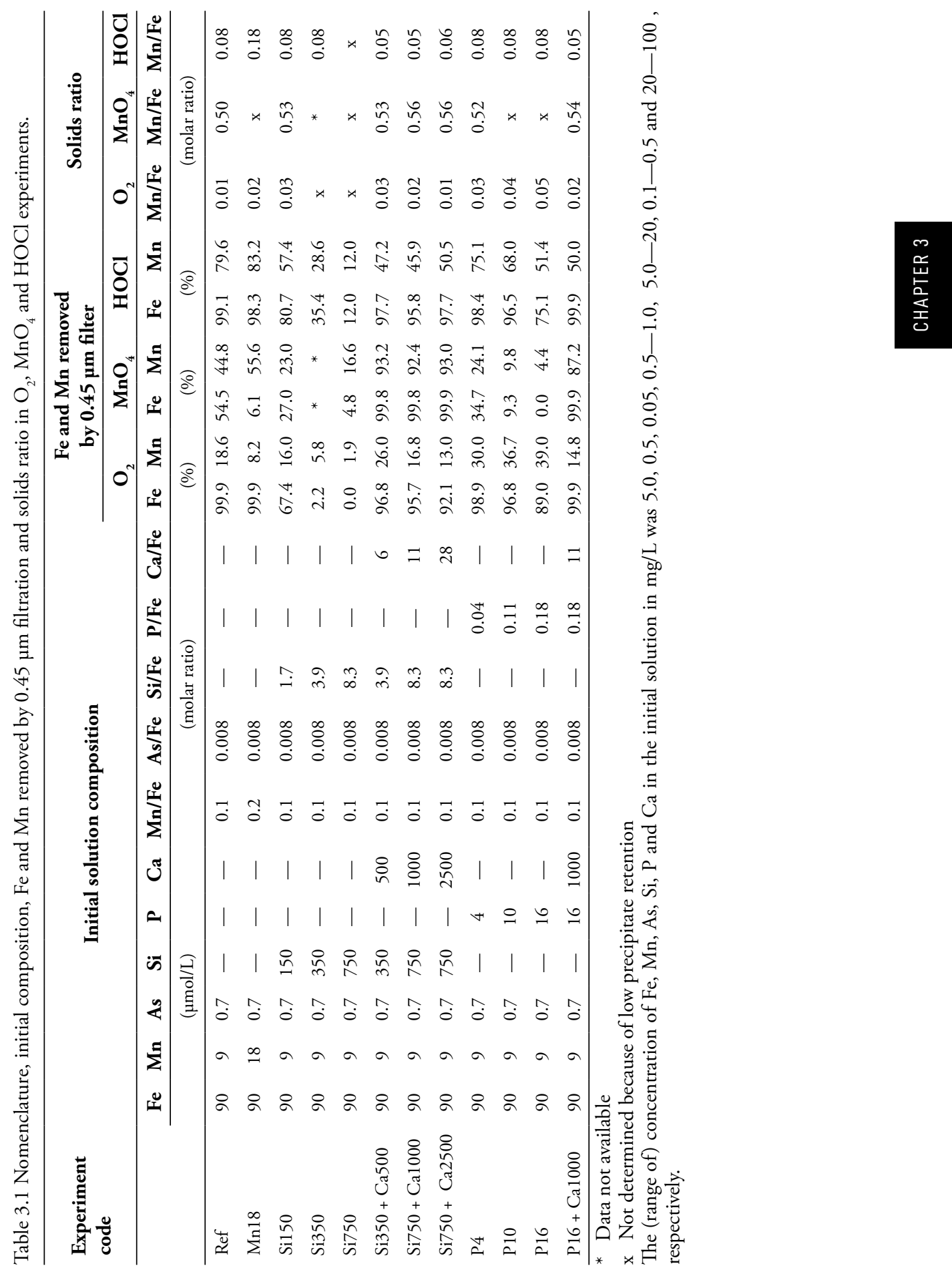
$7112 \mathrm{eV}$ or $6539 \mathrm{eV}$, respectively. Spectra were aligned, averaged and backgroundsubtracted using SixPack software (Webb 2005) following standard methods described previously (Van Genuchten et al. 2012a). The $\mathrm{k}^{3}$-weighted EXAFS spectra $\left(\chi(\mathrm{k}) \mathrm{k}^{3}\right)$ were Fourier-transformed using a Kaiser-Bessel window with dk of $3 \AA^{-1}$ typically over the $k$-range $2-12 \AA^{-1}$ for the Fe spectra and $2-10.5 \AA^{-1}$ for the Mn spectra. Further details of the data collection are given in the Supplementary Data.

\subsubsection{Data Analysis}

The Fe K-edge EXAFS spectra were analyzed by principal component analysis (PCA) and linear combination fits (LCFs). For the PCA, the ITFA program suite (Rossberg et al. 2003, Scheinost et al. 2006) was used to determine the number of independent components that reproduced the major variance of the data set based on minimizing the indicator (IND) function. The LCFs were performed with the SixPack software (Webb 2005) using the EXAFS spectra of Fe(III)-bearing standard minerals. Details on the synthesis of these standards (e.g. lepidocrocite, 2-line ferrihydrite, oxyanionrich hydrous ferric oxide) are reported elsewhere (Van Genuchten et al. 2018a, Van Genuchten et al. 2014b) The fit-derived fractions of the standards in each sample were normalized to one.

The Mn K-edge XANES spectra were analyzed by LCFs to determine the fraction of solid-associated $\mathrm{Mn}(\mathrm{II}), \mathrm{Mn}(\mathrm{III})$, and $\mathrm{Mn}(\mathrm{IV})$. SixPack software was used to perform the LCFs on the normalized XANES spectra, with a fit range of 6530 to $6590 \mathrm{eV}$. The Mn K-edge EXAFS spectra of representative samples were analyzed by shell-by-shell fits. Since the presence of multiple Mn oxidation states in a single sample complicates the interpretation of shell-by-shell fits, we applied this approach on samples that were determined by XANES LCFs to consist of primarily a single oxidation state (i.e. $\mathrm{Mn}(\mathrm{II}), \mathrm{Mn}(\mathrm{III})$, or $\mathrm{Mn}(\mathrm{IV})$ ). Theoretical curve fits were performed in $R+\Delta R$-space $(\AA)$ using the SixPack software with algorithms based on the IFEFFIT library (Newville 2001). Single scattering paths (Mn-O, Mn-Mn) were derived from the structure of birnessite $\left(\mathrm{MnO}_{2}\right)$ (Lanson et al. 2002), with theoretical phase and amplitude functions calculated using FEFF6 (Rehr et al. 1992). Because $\mathrm{Mn}$ and Fe have similar atomic numbers, these backscattering atoms cannot be distinguished in shell-by-shell fits. Consequently, the second shell fitting results for the $\mathrm{Mn}$ data are reported as $\mathrm{CN}_{\mathrm{Mn}-\mathrm{Mn} / \mathrm{Fe}}$ and $\mathrm{R}_{\mathrm{Mn}-\mathrm{Mn} / \mathrm{Fe}}$. The goodness-of-fit was assessed based on the R-factor, which is the mean square difference between the fit and the data on a point-by-point basis: $\mathrm{R}=\Sigma_{\mathrm{i}}\left(\mathrm{data}_{\mathrm{i}}-\mathrm{fit}_{\mathrm{i}}\right)^{2} / \sum_{\mathrm{i}}\left(\mathrm{data}_{\mathrm{i}}\right)^{2}$. A reasonable fit is considered to yield an R-factor less than 0.05 (Kelly et al. 2008). A similar shellby-shell fitting approach was followed for select Fe spectra. Further details regarding the XANES and EXAFS analyses are reporting in the Supplementary Data. 


\subsection{RESULTS}

\subsubsection{Macroscopic precipitate properties}

\subsubsection{Settling and filterability}

In the $\mathrm{O}_{2}$ system, the Ref and Mn18 experiments had an initial turbidity of $\approx 8$ NTU (Fig 3.2) and a similarly low final turbidity of $<3$ NTU $(\approx 70 \%$ turbidity decrease), which indicates rapid flocculation and sedimentation. These particles were highly filterable ( $>99 \%$ ) by $0.45 \mu \mathrm{m}$ filters (pore size used to approximate filterable particles in rapid sand filters). The addition of 150 to $750 \mu \mathrm{M}$ Si decreased the initial turbidity from 6 to 2 NTU, resulting in translucent light yellow suspensions that were colloidally stable (i.e. no difference in initial and final turbidity, Fig 3.2A, and low filterability, Table 3.1). The addition of $\mathrm{Ca}$ to the 350 and $750 \mu \mathrm{M} \mathrm{Si}$ solutions increased the initial turbidity to match the Ref $\mathrm{O}_{2}$ sample, but the final turbidity was higher than the Ref $\mathrm{O}_{2}$ sample. In the P series, 4 and $10 \mu \mathrm{M}$ P did not alter significantly the initial or final turbidity relative to the Ref $\mathrm{O}_{2}$ sample and the precipitates settled effectively ( $\approx 65 \%$ turbidity decrease). However, the $16 \mu \mathrm{M}$ $\mathrm{P}$ experiment resulted in a colloidally stable suspension. When $1000 \mu \mathrm{M} \mathrm{Ca}$ was added to the $16 \mu \mathrm{M} P$ solution, the suspension had the highest initial turbidity in the $\mathrm{O}_{2}$ experiments (14 NTU), with effective turbidity reduction (70\%) and good filterability (>99\% Fe removed, Table 3.1).

The settling behavior and filterability of the precipitates formed in the $\mathrm{MnO}_{4}$ system (Fig 3.2B, Table 3.1) differed considerably from those in the $\mathrm{O}_{2}$ system. The darker Ref and Mn18 suspensions formed in the $\mathrm{MnO}_{4}$ system were colloidally stable, having initial and final turbidity $>5.5 \mathrm{NTU}$, which contrasts the rapid settling of the Ref $\mathrm{O}_{2}$ sample. The 150 to $750 \mu \mathrm{M}$ Si samples in the $\mathrm{MnO}_{4}$ system were also colloidally stable, but the initial turbidity was slightly lower than the Ref $\mathrm{MnO}_{4}$ sample. The addition of $\mathrm{Ca}$ to the $\mathrm{Si}$ solutions produced cloudy suspensions that settled more effectively ( $\approx 60 \%$ turbidity decrease) than the $\mathrm{Ca}+\mathrm{Si}$ samples in the $\mathrm{O}_{2}$ system. The 4, 10 and $16 \mu \mathrm{M}$ P samples in the $\mathrm{MnO}_{4}$ system were all colloidally stable (turbidity $=3$ to 5 NTU) with low filterability (Table 3.1). Similar to the $\mathrm{O}_{2}$ system, $\mathrm{P} 16+\mathrm{Ca} 1000$ sample in the $\mathrm{MnO}_{4}$ system had an higher initial turbidity $(\approx 8 \mathrm{NTU})$ and improved particle settling $(70 \%$ turbidity reduction) and filterability (>99\% Fe removed).

In the $\mathrm{HOCl}$ system (Fig 3.2C), the initial turbidity of all suspensions $(<4$ NTU) was systematically lower than the $\mathrm{O}_{2}$ or $\mathrm{MnO}_{4}$ systems. The Ref and Mn18 $\mathrm{HOCl}$ suspensions were light yellow with visible flocs that settled quickly and were effectively filtered ( $\approx 90 \%)$, despite their low initial turbidity. The 150 to $750 \mu \mathrm{M}$ Si samples were colloidally stable, similar to the $\mathrm{O}_{2}$ and $\mathrm{MnO}_{4}$ systems. When $\mathrm{Ca}$ was added to the Si solutions, turbidity removal improved (20\%), but was lower than the 
Ref $\mathrm{HOCl}$ sample. The $\mathrm{HOCl}$ experiments in $\mathrm{P}$ solutions resembled the $\mathrm{O}_{2}$ system more than the $\mathrm{MnO}_{4}$ system, with $46 \%$ and $41 \%$ decreases in turbidity for $\mathrm{P} 4$ and P10 samples, but only $8 \%$ for the P16 sample. The impact of Ca in P solutions was similar in all $\mathrm{HOCl}, \mathrm{O}_{2}$ and $\mathrm{MnO}_{4}$ systems, with the $\mathrm{P} 16+\mathrm{Ca} 1000$ sample displaying increased aggregation and sedimentation ( $40 \%$ turbidity decrease).
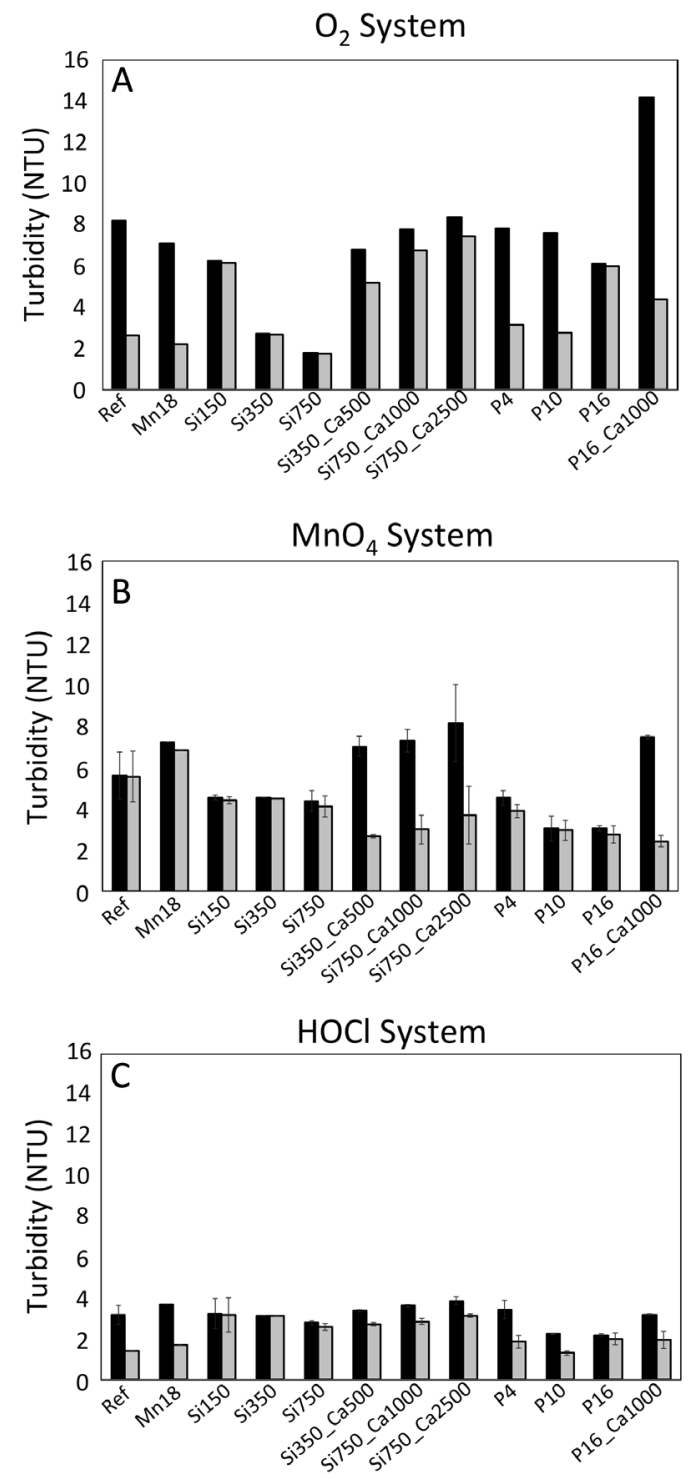

Figure 3.2 Initial and final turbidity as function of the oxidant used and solution composition. A. $\mathrm{O}_{2}$ system, B. $\mathrm{MnO}_{4}$ system, C. $\mathrm{HOCl}$ system. 


\subsection{2 $\mathrm{Mn} / \mathrm{Fe}$ solid ratios}

In the $\mathrm{O}_{2}$ system, the precipitate $\mathrm{Mn} / \mathrm{Fe}$ ratio content was low $(\leq 0.05)$ and varied with solution composition. The $\mathrm{Mn} / \mathrm{Fe}$ ratio of the Ref experiment was $0.01 \mathrm{~mol} /$ mol, which doubled to $0.02 \mathrm{~mol} / \mathrm{mol}$ in the Mn18 experiment, matching the doubled initial Mn concentration. The presence of Si and P increased the precipitate Mn content, with the Si150 and P16 samples having solids ratios of $0.03 \mathrm{~mol} / \mathrm{mol}$ and $0.05 \mathrm{~mol} / \mathrm{mol}$, respecitvely. By contrast, $\mathrm{Ca}$ addition decreased the $\mathrm{Mn} / \mathrm{Fe}$ ratio. The precipitate $\mathrm{Mn}$ content was only $0.02 \mathrm{~mol} / \mathrm{mol}$ in the $\mathrm{P} 16+\mathrm{Ca} 1000$ sample.

In $\mathrm{MnO}_{4}$ system the $\mathrm{Mn} / \mathrm{Fe}$ ratio ranged from 0.5 to 0.55 , with no significant trends in the presence of $\mathrm{Si}, \mathrm{P}$ and $\mathrm{Ca}$. The higher $\mathrm{Mn} / \mathrm{Fe}$ ratio relative to the $\mathrm{O}_{2}$ and $\mathrm{HOCl}$ systems is attributed to the dosing of $\mathrm{MnO}_{4}$, which increased the total $\mathrm{Mn}$ concentration.

In the $\mathrm{HOCl}$ system, the precipitate $\mathrm{Mn} / \mathrm{Fe}$ ratio was higher than in the $\mathrm{O}_{2}$ system, indicating more effective Mn uptake. The Mn/Fe ratio of the Ref and Mn18 experiments was 0.08 and $0.18 \mathrm{~mol} / \mathrm{mol}$, which was near the total $\mathrm{Mn} / \mathrm{Fe}$ ratio dosed into solution. The presence of $\mathrm{Si}$ and $\mathrm{P}$ did not impact significantly the $\mathrm{Mn} / \mathrm{Fe}$ ratio in the $\mathrm{HOCl}$ system (Table 3.1 ), with $\mathrm{Mn} / \mathrm{Fe}$ ratios of $\approx 0.08 \mathrm{~mol} / \mathrm{mol}$ for the $\mathrm{Si} 350$ and P16 samples. However, $\mathrm{Ca}$ addition decreased Mn uptake, leading to an $\mathrm{Mn} / \mathrm{Fe}$ solids ratio of $0.05 \mathrm{~mol} / \mathrm{mol}$ for the Si350+Ca500 and P16+Ca1000 samples.

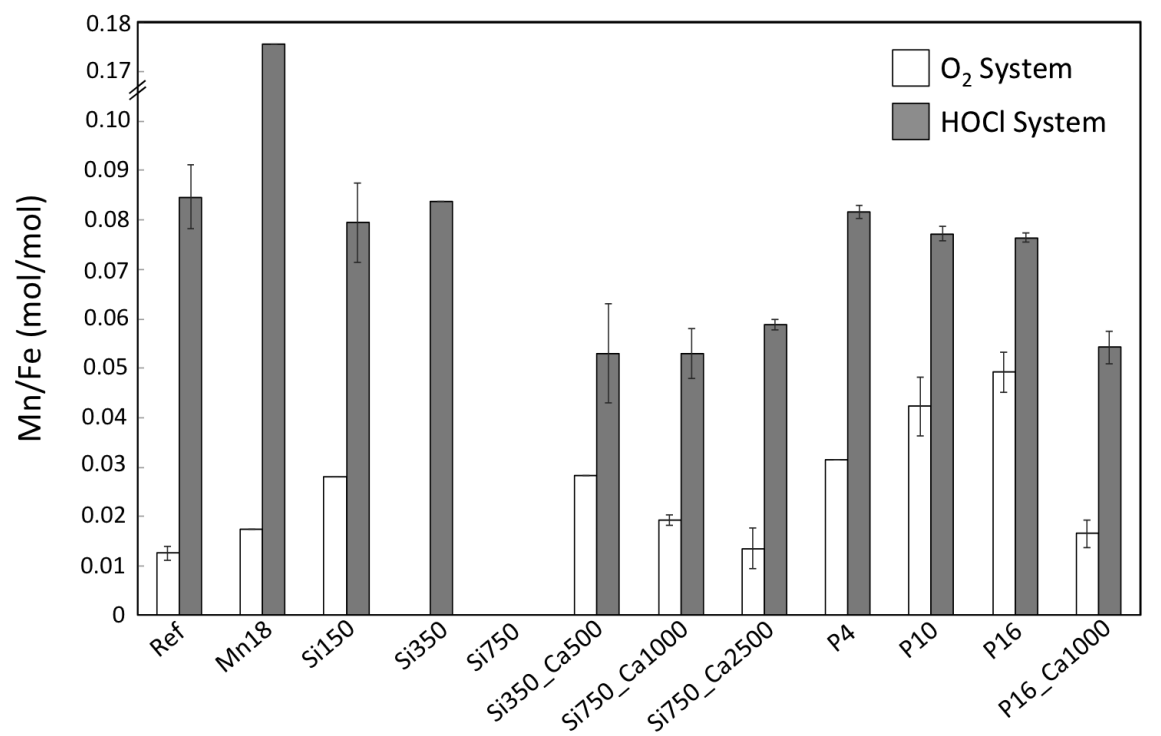

Figure 3.3 Precipitate $\mathrm{Mn} / \mathrm{Fe}$ ratio ( $\mathrm{mol} / \mathrm{mol})$. Samples without data were colloidally stable and could not to be separated with $0.45 \mu \mathrm{m}$ filters. The $\mathrm{Mn} / \mathrm{Fe}$ ratio was between 0.5 and 0.55 for all the samples in $\mathrm{MnO}_{4}$ system and is thus not given. Note the break in the y-axis from 0.10 to $0.17 \mathrm{~mol} / \mathrm{mol}$. 


\subsubsection{Fe K-edge EXAFS spectroscopy}

Principal component analysis (PCA) of the Fe K-edge EXAFS spectra of the entire data set $\left(\mathrm{O}_{2}, \mathrm{MnO}_{4}\right.$, and $\mathrm{HOCl}$ systems) revealed a significant decrease in the indicator function (Fig S3.2) with three independent components and a gradual plateau in the indicator function with increasing components. Based on the PCA results and the experimental conditions, we used three Fe(III) (oxyhydr)oxide standards in the linear combination fits (LCFs) of the experimental spectra: lepidocrocite $(\gamma$-FeOOH), 2-line ferrihydrite (2LFh), and an oxyanion-rich hydrous ferric oxide (oxy-HFO) that was produced by $\mathrm{Fe}(\mathrm{II})$ oxidation in the presence of $\mathrm{P}$ and that contains no FeFe corner-sharing bonds (Van Genuchten et al. 2014b). The LCF output is overlain to the data in Fig 3.4 and results of the LCFs of the experimental spectra using lepidocrocite, 2LFh, and oxy-HFO are given Fig 3.5.

The Ref and Mn18 experiments in the $\mathrm{O}_{2}$ system consisted of dominantly lepidocrocite $(>85 \%)$. The minor fraction $(<15 \%)$ of oxy-HFO determined in the LCFs of these samples likely arises from subtle differences in the structure of the lepidocrocite standard and the type of lepidocrocite formed in the experiments (Van Genuchten et al. 2014b, Voegelin et al. 2010). Lepidocrocite formation was largely inhibited in the presence of $\mathrm{Si}$, with the LCFs of all $\mathrm{Si}$ series samples returning fractions of 15 to $26 \%$ oxy-HFO and 72 to $82 \%$ 2LFh without clear trends in the fractions oxy-HFO and $2 \mathrm{LFh}$ with increasing $\mathrm{Si}$ or presence of $\mathrm{Ca}$. In the $\mathrm{P}$ experiments, the LCFs indicated the formation of lepidocrocite, but its fraction depended on the P concentration (i.e. P/Fe ratio). Increasing P from 4 to $16 \mu \mathrm{M}$ decreased the lepidocrocite fraction from 64 to $27 \%$, which was balanced by an increase in oxy-HFO from 16 to $37 \%$ (the $2 \mathrm{LFh}$ fraction was stable at $\approx 30 \%$ ). The addition of $\mathrm{Ca}$ to the $\mathrm{P} 16$ solution increased the lepidocrocite fraction from 27 to $55 \%$ at the expense of oxy-HFO and 2LFh. This impact of $\mathrm{Ca}$ on the $\mathrm{Fe}$ (II) oxidation products in the $\mathrm{P}$ solutions is consistent with the sequential formation of Ca- and P-rich Fe(III) polymers (Voegelin et al. 2010) which remove P from solution with $\mathrm{P} / \mathrm{Fe}$ ratios near 1 , followed by lepidocrocite formation with excess $\mathrm{Fe}$ (II) after $\mathrm{P}$ is removed from solution.

In contrast to the $\mathrm{O}_{2}$ experiments, no sample in the $\mathrm{MnO}_{4}$ system consisted of lepidocrocite, regardless of solution composition. The LCFs indicated poorlyordered $\mathrm{Fe}$ (III) precipitates formed in $\mathrm{MnO}_{4}$ experiments, which had average structures consistent with mixtures of $2 \mathrm{LFh}$ and oxy-HFO (30 to 73\% oxy-HFO, 25 to $69 \%$ 2LFh). Increasing the Si concentration from 150 to $750 \mu \mathrm{M}$ increased the fraction of oxy-HFO from 32 to $60 \%$, with $2 \mathrm{LFh}$ making up the remainder. The $\mathrm{Fe}(\mathrm{III})$ precipitates formed from $\mathrm{Fe}(\mathrm{II})$ oxidation by $\mathrm{MnO}_{4}$ in $\mathrm{P}_{\text {solutions were }}$ similar to those in Si solutions, with the LCFs yielding mixtures of 2LFh and oxy$\mathrm{HFO}$ without clear trends in the presence of $\mathrm{Ca}$. 
In the $\mathrm{HOCl}$ system, lepidocrocite was not detected in any sample. The LCFs of the Ref sample yielded 53\% oxy-HFO and 40\% 2LFh, whereas the Mn18 sample consisted of 40\% oxy-HFO and 54\% 2LFh. Although P and Si increased the fraction of poorly-ordered $\mathrm{Fe}(\mathrm{III})$ precipitates in the $\mathrm{O}_{2}$ system, the analogous trend was not observed in the HOCl system. No trends in the fractions of 2LFh and oxy-rich HFO with increasing $\mathrm{Si}$ or $\mathrm{P}$ were observed in the $\mathrm{HOCl}$ samples. Comparing the LCFs across all oxidants (i.e. $\mathrm{O}_{2}, \mathrm{MnO}_{4}$, and $\mathrm{HOCl}$ ) reveals that $\mathrm{Si}$ and $\mathrm{P}$ impacted $\mathrm{Fe}$ (III) speciation in the $\mathrm{O}_{2}$ experiments more than in $\mathrm{MnO}_{4}$ and $\mathrm{HOCl}$ experiments.
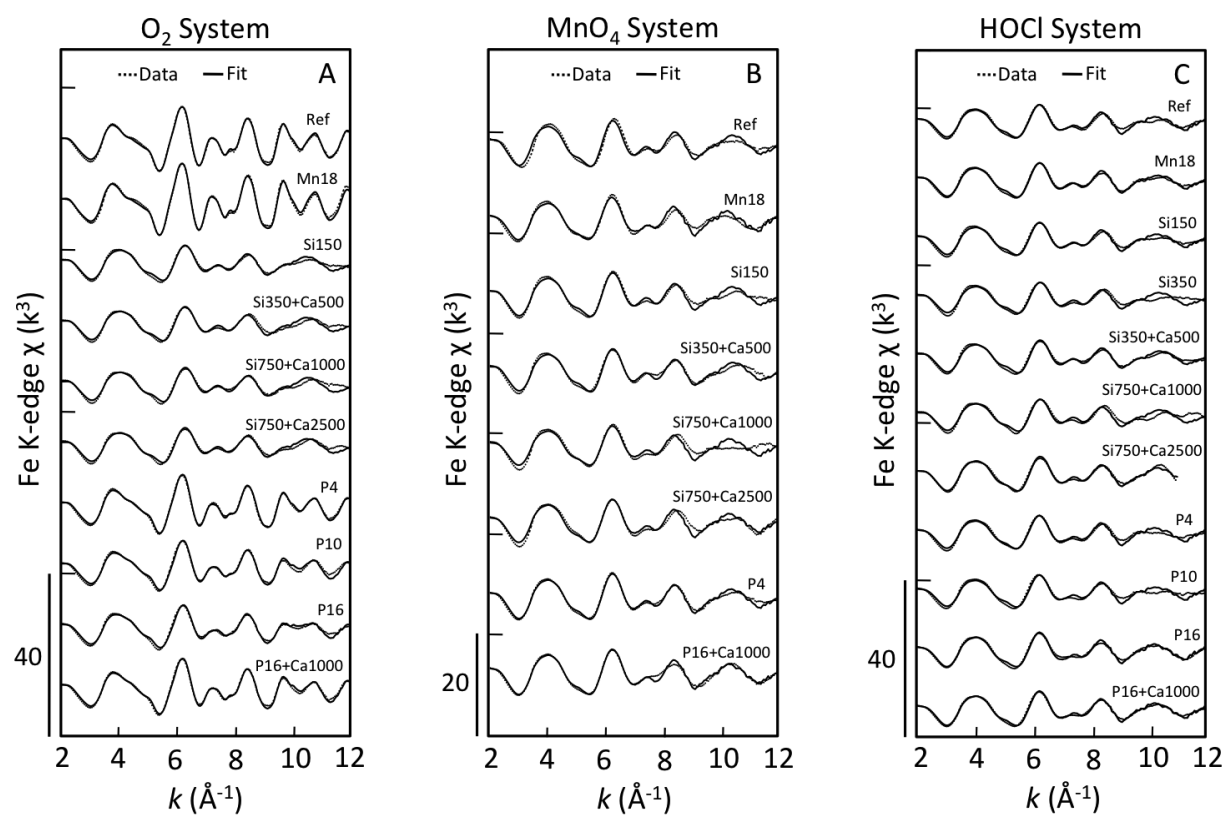

Figure 3.4 Fe K-edge EXAFS spectra of precipitate samples (dotted lines) and output of linear combination fits (solid lines) using lepidocrocite, 2-line ferrihydrite, and oxyanion-rich hydrous ferric oxide.

\subsubsection{Mn K-edge XANES spectroscopy}

The Mn K-edge XANES LCFs of the Ref $\mathrm{O}_{2}$ sample (Fig 3.6, Table 3.2) indicated that $\mathrm{Mn}(\mathrm{III})$ was the dominant species $(96 \pm 3 \%)$ in the solids, consistent with the absorption maximum near $6556 \mathrm{eV}$. However, the Si150 sample displayed an absorption maximum at lower X-ray energy $(6552 \mathrm{eV})$ and the LCFs indicated $\mathrm{Mn}(\mathrm{II})$ was the dominant species $(\mathrm{Mn}(\mathrm{II})=75 \pm 2 \%, \mathrm{Mn}(\mathrm{III})=26 \pm 4 \%)$. The trend in increased $\mathrm{Mn}$ (II) in the presence of oxyanions was also observed in the P16 experiment, which consisted of $85 \pm 3 \% \mathrm{Mn}(\mathrm{II})$, with $\mathrm{Mn}$ (III) making up 
the remainder. When $\mathrm{Ca}$ was added to the P16 electrolyte, the LCFs indicated a significant decrease in solid-associated $\mathrm{Mn}$ (II) $(52 \pm 3 \%)$ and an increase in $\mathrm{Mn}$ (III) $(45 \pm 5 \%)$. The presence of $\mathrm{Mn}(\mathrm{IV})$ was not supported by the LCFs of any $\mathrm{O}_{2}$ samples.

The XANES spectra of the $\mathrm{MnO}_{4}$ samples were largely independent of solution chemistry, with $>98 \% \mathrm{Mn}(\mathrm{IV})$ detected by the LCFs in all samples (absorption maximum near $6558 \mathrm{eV}$ ). While the LCFs returned a small fraction of $\mathrm{Mn}$ (III) in some samples $(<20 \%)$, the standard deviation was nearly as high as the fit-derived value (Table 3.2). No clear trends in the Mn oxidation state with $\mathrm{Si}$, $\mathrm{P}$, or Ca were detected in the LCFs of the $\mathrm{MnO}_{4}$ samples. The presence of residual, unreacted $\mathrm{Mn}(\mathrm{VII})$, which has a prominent pre-edge peak near $6541 \mathrm{eV}$, was not supported by the XANES spectra.

Co-oxidation of $\mathrm{Fe}(\mathrm{II})$ and $\mathrm{Mn}$ (II) by $\mathrm{HOCl}$ produced primarily $\mathrm{Mn}(\mathrm{III})$ in the Ref and Mn1 8 samples, with a slight increase in the Mn(IV) fraction from $15 \pm 10 \%$ in the Ref sample to $23 \pm 11 \%$ in the Mn18 sample. The LCFs of the Si 150 sample indicated that $\mathrm{Mn}(\mathrm{III})$ remained the dominant solid-phase $\mathrm{Mn}$ species (>85\%). At $\mathrm{P}$ concentrations of 4 and $16 \mu \mathrm{M}$, the solid-phase $\mathrm{Mn}(\mathrm{II})$ fraction increased from $9 \pm 5$ to $41 \pm 4 \%$. When $\mathrm{Ca}$ was added to the $\mathrm{P} 16$ solution, the solid-phase $\mathrm{Mn}$ (II) fraction decreased from $41 \pm 4$ to $14 \pm 5 \%$. A similar decrease in $\mathrm{Mn}$ (II) fraction in favor of $\mathrm{Mn}(\mathrm{III})$ was observed in the $\mathrm{O}_{2}$ experiments when Ca was added to the P16 solution.

\subsubsection{Mn K-edge EXAFS spectroscopy}

\subsubsection{1 $\mathrm{O}_{2}$ experiments}

In Fig 3.7, the Mn K-edge EXAFS spectra of samples produced in the $\mathrm{O}_{2}, \mathrm{MnO}_{4}$, and $\mathrm{HOCl}$ experiments are shown alongside the spectra of $\mathrm{Mn}$ standards. The Ref $\mathrm{O}_{2}$ sample, which was found by the LCFs to be dominantly $\mathrm{Mn}$ (III), differed relative to the other spectra in Fig 3.7, including the aqueous $\mathrm{Mn}(\mathrm{II})$, bixbyite $\left(\alpha-\mathrm{Mn}_{2} \mathrm{O}_{3}\right)$ and $\delta-\mathrm{MnO}_{2}$ standards. In particular, the first oscillation from 3 to $5.5 \AA^{-1}$ became a doublet, which is not present in other $\mathrm{Mn}$ (III)-bearing material (e.g. groutite, manganite, feitnechtite) (Manceau et al. 2012b). Furthermore, the next major peaks at 6.2 and $7.5 \AA^{1}$ in the Ref $\mathrm{O}_{2}$ sample are out of phase with the standards, which suggests a unique $\mathrm{Mn}$ coordination environment. In the presence of $\mathrm{P}$ and $\mathrm{Si}$, the EXAFS oscillations for the $\mathrm{O}_{2}$ samples match more closely those of aqueous $\mathrm{Mn}$ (II), which is consistent with the XANES-derived predominance of $\mathrm{Mn}(\mathrm{II})$ in these samples.

Shell-by-shell fits of the Fourier-transformed Mn K-edge EXAFS spectrum of the Ref $\mathrm{O}_{2}$ sample (Fig 3.8, Table 3.3) returned an Mn-O interatomic distance $\left(\mathrm{R}_{\mathrm{Mn}-\mathrm{O}}\right)$ of $1.93 \pm 0.02 \AA$ and an $\mathrm{Mn}-\mathrm{O}$ coordination number $\left(\mathrm{CN}_{\mathrm{Mn}-\mathrm{O}}\right)$ of $1.9 \pm 0.5$, which is lower than the theoretical CN of 6 for octahedrally coordinated $\mathrm{Mn}(\mathrm{III})$. These 

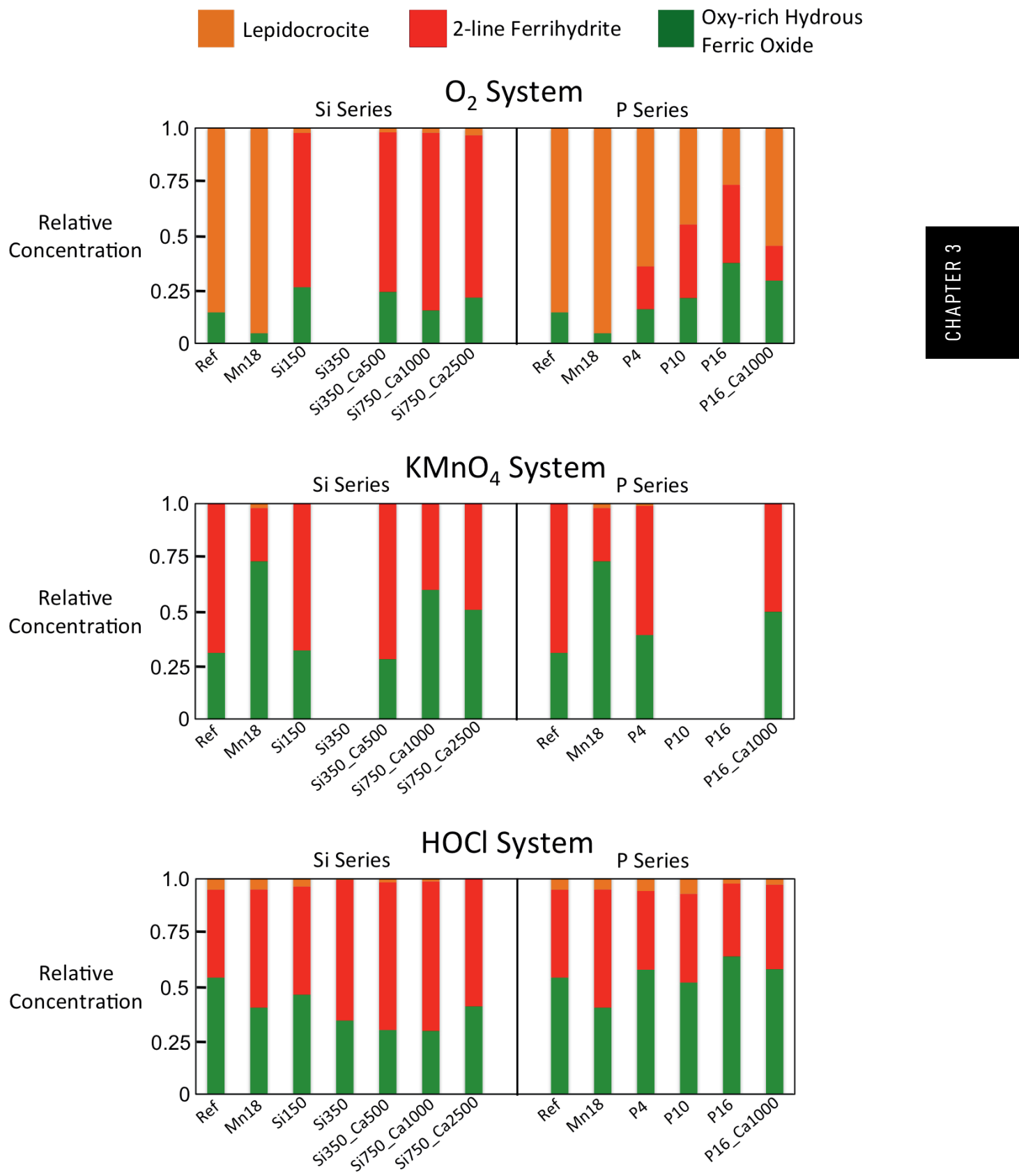

Figure 3.6 Mn K-edge XANES spectra for precipitate samples formed in the $\mathrm{O}_{2}$ (left panel), $\mathrm{MnO}_{4}$ (middle panel) and $\mathrm{HOCl}$ (right panel) experiments. The experimental data is plotted below $\mathrm{Mn}$ (II), $\mathrm{Mn}(\mathrm{III})$, and $\mathrm{Mn}(\mathrm{IV})$ standards. 
Table 3.2 Summary of XANES LCF Results.

\begin{tabular}{|c|c|c|c|c|}
\hline Oxidant & Experiment Code & $\% \mathrm{Mn}^{2+}$ & $\% \mathrm{Mn}^{3+}$ & $\% \mathbf{M n}^{4+}$ \\
\hline \multirow{5}{*}{$\mathrm{O}_{2}$ System } & Ref & $<1$ & $96 \pm 3$ & $<1$ \\
\hline & Si 150 & $75 \pm 2$ & $26 \pm 4$ & $<1$ \\
\hline & $\mathrm{Si} 750+\mathrm{Ca} 1000$ & $65 \pm 3$ & $35 \pm 5$ & $<1$ \\
\hline & P16 & $85 \pm 3$ & $20 \pm 4$ & $<1$ \\
\hline & $\mathrm{P} 16+\mathrm{Ca} 1000$ & $52 \pm 3$ & $45 \pm 5$ & $<1$ \\
\hline \multirow{8}{*}{$\mathrm{MnO}_{4}$ System } & Ref & $<1$ & $8 \pm 8$ & $106 \pm 15$ \\
\hline & Mn18 & $<1$ & $6 \pm 7$ & $109 \pm 15$ \\
\hline & Si 150 & $<1$ & $7 \pm 8$ & $105 \pm 14$ \\
\hline & $\mathrm{Si} 350+\mathrm{Ca} 500$ & $<1$ & $8 \pm 9$ & $108 \pm 14$ \\
\hline & Si750 + Ca1000 & $<1$ & $16 \pm 6$ & $99 \pm 16$ \\
\hline & $\mathrm{Si} 750+\mathrm{Ca} 2500$ & $<1$ & $17 \pm 8$ & $102 \pm 14$ \\
\hline & P4 & $<1$ & $10 \pm 7$ & $104 \pm 15$ \\
\hline & $\mathrm{P} 16+\mathrm{Ca} 1000$ & $<1$ & $13 \pm 6$ & $98 \pm 15$ \\
\hline \multirow{8}{*}{ HOCl System } & Ref & $5 \pm 4$ & $84 \pm 16$ & $15 \pm 10$ \\
\hline & Mn18 & $<1$ & $79 \pm 15$ & $23 \pm 11$ \\
\hline & Si150 & $11 \pm 5$ & $85 \pm 18$ & $10 \pm 11$ \\
\hline & $\mathrm{Si} 750+\mathrm{Ca} 1000$ & $33 \pm 8$ & $85 \pm 12$ & $<1$ \\
\hline & $\mathrm{Si} 750+\mathrm{Ca} 2500$ & $27 \pm 6$ & $95 \pm 11$ & $<1$ \\
\hline & $\mathrm{P} 4$ & $9 \pm 5$ & $87 \pm 18$ & $11 \pm 12$ \\
\hline & P16 & $41 \pm 4$ & $63 \pm 11$ & $3 \pm 4$ \\
\hline & $\mathrm{P} 16+\mathrm{Ca} 1000$ & $14 \pm 5$ & $88 \pm 18$ & $10 \pm 11$ \\
\hline
\end{tabular}

fit-derived $\mathrm{R}_{\mathrm{Mn}-\mathrm{O}}$ and $\mathrm{CN}_{\mathrm{Mn}-\mathrm{O}}$ values matched the first shell fits of bixbyite $\left(\mathrm{R}_{\mathrm{Mn}-\mathrm{O}}=\right.$ $\left.1.92 \pm 0.02 \AA, \mathrm{CN}_{\mathrm{Mn}-\mathrm{O}}=2.4 \pm 0.5\right)$ and are consistent Jahn-Teller distorted Mn(III) octahedra. Fits of the second shell of the Ref $\mathrm{O}_{2}$ sample resulted in a $\mathrm{CN}_{\mathrm{Mn}-\mathrm{Mn} / \mathrm{Fe}}=$ $2.8 \pm 1.1$ and $\mathrm{R}_{\mathrm{Mn}-\mathrm{Mn} / \mathrm{Fe}}=3.04 \pm 0.02 \AA$. This $\mathrm{R}_{\mathrm{Mn}-\mathrm{Mn} / \mathrm{Fe}}$ is significantly shorter than the edge-sharing $\mathrm{Mn}-\mathrm{Mn}$ bond in bixbyite (Table 3.3) and longer than the edge-sharing $\mathrm{Mn}-\mathrm{Mn}$ bond in groutite (Wyckoff 1963). However, the fit-derived $\mathrm{R}_{\mathrm{Mn}-\mathrm{Mn} / \mathrm{Fe}}$ value for this sample is in good agreement with the edge-sharing Fe-Fe bond length in the $\mathrm{Fe}(\mathrm{III})$ precipitates that formed in this sample (i.e. lepidocrocite, $\mathrm{R}_{\mathrm{Fe}-\mathrm{Fe}}=3.07 \pm 0.01$ A, Table S3.1). 


\subsubsection{2 $\mathrm{MnO}_{4}$ experiments}

The Mn K-edge EXAFS spectra of $\mathrm{MnO}_{4}$ samples were similar regardless solution composition, with all samples resembling the EXAFS spectrum of the $\delta-\mathrm{MnO}_{2}$ standard. All experimental EXAFS spectra contained the characteristic staircase feature from 4 to $6 \AA^{-1}$ indicative of $\mathrm{MnO}_{2}$ minerals (Manceau et al. 2012b), which implies that $\mathrm{Mn}(\mathrm{II})$ and $\mathrm{Fe}(\mathrm{II})$ co-oxidation by $\mathrm{MnO}_{4}$ in a variety of solutions leads to solid-phase $\mathrm{Mn}$ in a $\mathrm{MnO}_{2}$-like bonding environment.

Shell-by-shell fits of the Ref $\mathrm{MnO}_{4}$ sample, which contained $<10 \% \mathrm{Mn}(\mathrm{III})$ (Table 3.2), indicated a Mn-O coordination shell of $\mathrm{CN}_{\mathrm{Mn}-\mathrm{O}}=5.2 \pm 0.9$ and $\mathrm{R}_{\mathrm{Mn}-\mathrm{O}}$ $=1.91 \pm 0.01 \AA$. These fit-derived values are in excellent agreement with the first shell fits of the $\delta-\mathrm{MnO}_{2}$ standard (Table 3.3) and are representative of $\mathrm{Mn}(\mathrm{IV})$ in octahedral coordination. The second shell fit of the $\mathrm{Ref} \mathrm{MnO}_{4}$ sample returned values of $\mathrm{CN}_{\mathrm{Mn}-\mathrm{Mn} / \mathrm{Fe}}=3.2 \pm 0.4$ and $\mathrm{R}_{\mathrm{Mn}-\mathrm{Mn} / \mathrm{Fe}}=2.89 \pm 0.01 \AA$, which also matches the fits $\delta-\mathrm{MnO}_{2}$ standard (Table 3.3) and is consistent with edge-sharing $\mathrm{MnO}_{6}$ octahedra. Furthermore, this fit-derived $\mathrm{R}_{\mathrm{Mn}-\mathrm{Mn} / \mathrm{Fe}}$ value is considerably shorter than the fitderived $\mathrm{R}_{\mathrm{Mn}-\mathrm{Mn} \text {-Fe }}$ of the $\mathrm{Ref}_{2}$ sample and is also shorter than the edge-sharing $\mathrm{Fe}-\mathrm{Fe}$ bond in $\mathrm{Fe}$ (III) (oxyhydr)oxide minerals (Manceau and Combes 1988). Interestingly, the shell-by-shell fits of the Ref $\mathrm{MnO}_{4}$ sample and the $\mathrm{MnO}_{4}$ sample generated in the highest oxyanion solution (i.e. Si750+Ca2500) were identical within fit-derived standard errors (Table 3.3). This result suggests that oxyanions do not modify the structure of $\mathrm{MnO}_{2}$ solids as much as $\mathrm{Fe}(\mathrm{III})$ precipitates, which is attributed to the lower affinity of oxyanions for $\mathrm{MnO}_{2}$ surfaces than $\mathrm{Fe}(\mathrm{III})$ (oxyhydr) oxides (Van Genuchten and Peña 2016a).

\subsubsection{3 $\mathrm{HOCl}$ experiments}

The EXAFS spectra of the Ref and Mn18 samples in the HOCl system, which consisted of primarily $\mathrm{Mn}(\mathrm{III})$ (Table 3.3), were nearly identical. Both Ref and Mn18 spectra displayed a split oscillation from 3 to $5 \AA^{-1}$, which is similar to that of the Ref $\mathrm{O}_{2}$ sample, but the split in this oscillation was less prominent in the $\mathrm{HOCl}$ samples. The Ref and $\mathrm{Mn} 18 \mathrm{HOCl}$ samples also exhibited an asymmetric oscillation near 6.5 $\AA^{-1}$ that was less pronounced or absent from the EXAFS spectra of other samples and standards (Fig 3.7). In the presence of $\mathrm{P}$ and $\mathrm{Si}$, some features in the EXAFS spectra changed, including the disappearance of the assymetric oscillation near $6.5 \AA$, but the first oscillation from 3 to $5 \AA^{-1}$ was still split. The similarity of key EXAFS features across all $\mathrm{HOCl}$ samples regardless of the presence (e.g. Si150, P4) or absence (Ref, Mn18) of oxyanions is consistent with the XANES LCFs, which identified Mn(III) as the predominant $\mathrm{Mn}$ oxidation state in all $\mathrm{HOCl}$ samples (Table 3.2).

Shell-by-shell fits of the Fourier-transformed EXAFS spectrum of the Ref $\mathrm{HOCl}$ sample (Table 3.3) revealed a first shell Mn-O coordination environment similar 
to the Ref $\mathrm{O}_{2}$ sample, with $\mathrm{CN}_{\mathrm{Mn}-\mathrm{O}}=2.4 \pm 0.4$ and $\mathrm{R}_{\mathrm{Mn}-\mathrm{O}}=1.91 \pm 0.01 \AA$, which is consistent with Jahn-Teller distorted Mn(III) octahedra. Fits of the second shell of the Ref $\mathrm{HOCl}$ sample returned values of $1.7 \pm 0.4$ for $\mathrm{CN}_{\mathrm{Mn}-\mathrm{Mn} / \mathrm{Fe}}$ and $3.01 \pm 0.02 \AA$ for $\mathrm{R}_{\mathrm{Mn}-\mathrm{Mn} / \mathrm{Fe}}$. Similar to the $\mathrm{O}_{2}$ system, the second shell fits of the Ref $\mathrm{HOCl}$ sample produced a $\mathrm{R}_{\mathrm{Mn}-\mathrm{Mn} / \mathrm{Fe}}$ value that is shorter than the edge-sharing Mn-Mn bond in $\mathrm{Mn}(\mathrm{III})$-bearing minerals. However, the $\mathrm{R}_{\mathrm{Mn}-\mathrm{Mn} / \mathrm{Fe}}$ for the $\mathrm{HOCl}$ sample is in good agreement with the $\mathrm{Fe}-\mathrm{Fe}$ bond length for edge-sharing $\mathrm{FeO}_{6}$ octahedra in $\mathrm{Fe}$ (III) precipitates that formed in this sample (i.e. hydrous ferric oxide, $\mathrm{R}_{\mathrm{Fe}-\mathrm{Fe}}=3.05 \pm 0.01$ A, Table S3.1).
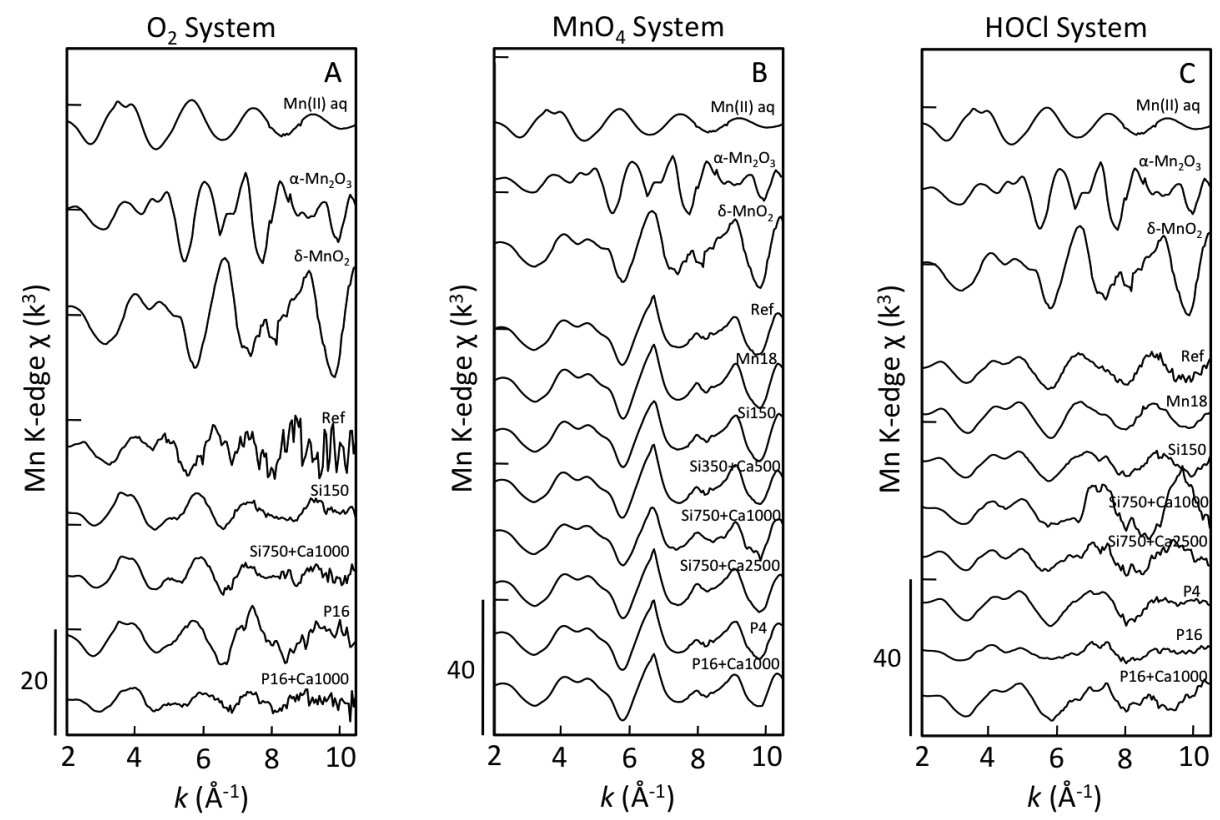

Figure 3.7 Mn K-edge EXAFS spectra for precipitate samples formed in the $\mathrm{O}_{2}$ (left panel), $\mathrm{MnO}_{4}$ (middle panel) and $\mathrm{HOCl}$ (right panel) experiments. The experimental data is plotted below $\mathrm{Mn}$ (II), $\mathrm{Mn}(\mathrm{III})$, and $\mathrm{Mn}(\mathrm{IV})$ standards. 

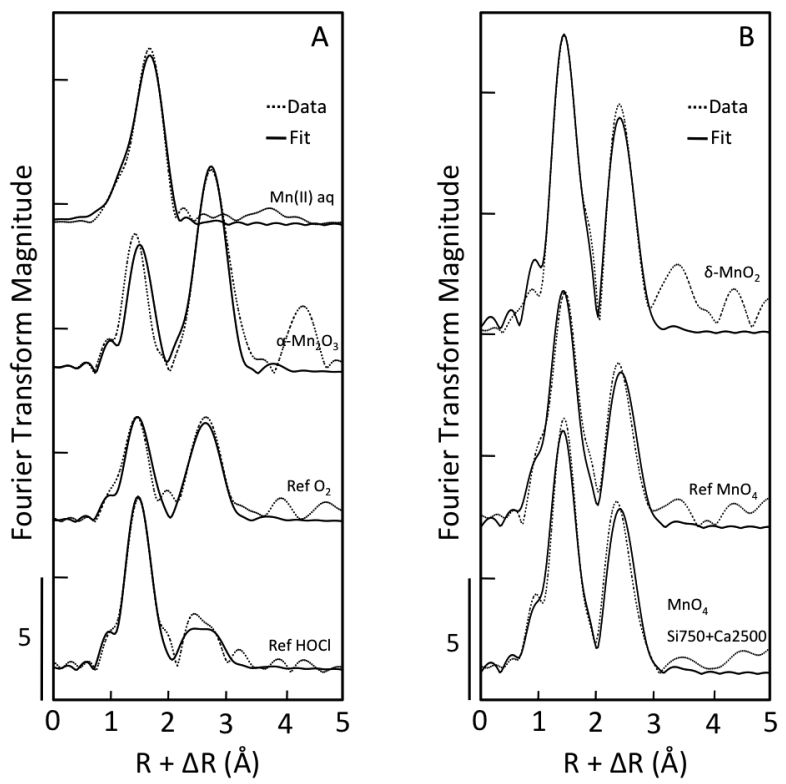

Figure 3.8 Fourier-transformed Mn K-edge EXAFS spectra of precipitate samples (dotted lines) overlain to the output of shell-by-shell fits.

\subsection{DISCUSSION}

\subsubsection{Effect of oxidant and solution chemistry on $\mathrm{Fe}(\mathrm{III})$ speciation and particle aggregation}

\subsubsection{1 $\mathrm{Fe}(\mathrm{II})$ oxidation in $\mathrm{O}_{2}, \mathrm{MnO}_{4}$, and $\mathrm{HOCl}$ Ref experiments}

Comparison of the Ref experiments across all oxidants shows that $\mathrm{Fe}(\mathrm{II})$ and $\mathrm{Mn}$ (II) co-oxidation by $\mathrm{O}_{2}$ and $\mathrm{HOCl}$ produced suspensions that aggregated rapidly and that can be separated by gravitational settling or filtering easily, whereas the $\mathrm{MnO}_{4}$ Ref experiment generated a colloidally stable suspension. However, Fe(III) speciation differed between $\mathrm{RefO}_{2}$ and Ref $\mathrm{HOCl}$ experiments, with $\mathrm{O}_{2}$ producing lepidocrocite and both $\mathrm{HOCl}$ and $\mathrm{MnO}_{4}$ producing poorly-crystalline $\mathrm{Fe}(\mathrm{III})$ precipitates. These differences in aggregation and $\mathrm{Fe}(\mathrm{III})$ speciation with oxidant can be explained by the different $\mathrm{Fe}(\mathrm{II})$ reaction rates with $\mathrm{O}_{2}, \mathrm{HOCl}$, and $\mathrm{MnO}_{4}$ and the different endproducts of each reaction. The $\mathrm{Fe}(\mathrm{II})$ oxidation rate by $\mathrm{O}_{2}$ depends strongly on $\mathrm{pH}$ (Van Beek et al. 2016, Van Beek et al. 2012, Vries et al. 2017), but at circumneutral $\mathrm{pH}$ is orders of magnitude lower than $\mathrm{HOCl}$ and $\mathrm{MnO}_{4}$ (Ghurye and Clifford 2001, Knocke et al. 1991, Stumm and Morgan 1996). Although our experiments were designed to allow for complete $\mathrm{Fe}(\mathrm{II})$ oxidation in the $\mathrm{O}_{2}$ experiments, $\mathrm{Fe}$ (II) reactions with $\mathrm{O}_{2}$ are not instantaneous, which ensures that freshly-oxidized 
Table 3.3 Summary of Shell Fits of Mn-bearing Standards and Precipitate Samples.

\begin{tabular}{|c|c|c|c|c|c|c|}
\hline $\begin{array}{l}\text { Experiment } \\
\text { Code }\end{array}$ & $\begin{array}{l}\text { Atomic } \\
\text { Pairs } \\
\end{array}$ & $\mathrm{CN}$ & $\mathbf{R}(\AA ̊)$ & $\sigma^{2}\left(\AA^{2}\right)$ & $\Delta \mathrm{E}_{0}(\mathrm{eV})$ & R-Factor \\
\hline $\begin{array}{l}\text { Aqueous } \\
\mathrm{Mn}(\mathrm{II})\end{array}$ & $\mathrm{Mn}-\mathrm{O}$ & $7.0(0.6)$ & $2.18(0.01)$ & $0.010(0.001)$ & $-11.0(1.0)$ & 0.015 \\
\hline \multirow{3}{*}{$\mathrm{a}-\mathrm{Mn}_{2} \mathrm{O}_{3}$} & $\mathrm{Mn}-\mathrm{O}$ & $2.4(0.7)$ & $1.92(0.02)$ & $0.004(0.002)$ & $-16.7(1.8)$ & 0.041 \\
\hline & Mn-Mn1 & $4.8(2.3)$ & $3.10(0.03)$ & $0.009(0.004)$ & & \\
\hline & Mn-Mn2 & $3.4(1.7)$ & $3.53(0.04)$ & $\sigma^{2}(\mathrm{Mn}-\mathrm{Mn} 1)$ & & \\
\hline \multirow{2}{*}{$\delta-\mathrm{MnO}_{2}$} & $\mathrm{Mn}-\mathrm{O}$ & $4.4(1.0)$ & $1.90(0.01)$ & $0.001(0.001)$ & $-17.6(2.7)$ & 0.047 \\
\hline & $\mathrm{Mn}-\mathrm{Mn}$ & $4.3(0.6)$ & $2.88(0.02)$ & 0.007 & & \\
\hline \multirow{2}{*}{$\mathrm{RefO}_{2}$} & $\mathrm{Mn}-\mathrm{O}$ & $1.9(0.5)$ & $1.93(0.02)$ & $0.004(0.003)$ & $-11.4(3.0)$ & 0.067 \\
\hline & $\mathrm{Mn}-\mathrm{Mn} / \mathrm{Fe}$ & $2.8(1.1)$ & $3.04(0.02)$ & $0.009(0.003)$ & & \\
\hline \multirow{2}{*}{ Ref $\mathrm{HOCl}$} & $\mathrm{Mn}-\mathrm{O}$ & $2.4(0.4)$ & $1.91(0.01)$ & $0.002(0.001)$ & $-10.0(2.1)$ & 0.032 \\
\hline & $\mathrm{Mn}-\mathrm{Mn} / \mathrm{Fe}$ & $1.7(0.4)$ & $3.01(0.02)$ & 0.01 & & \\
\hline \multirow{2}{*}{ Ref $\mathrm{MnO}_{4}$} & $\mathrm{Mn}-\mathrm{O}$ & $5.2(0.9)$ & $1.91(0.01)$ & $0.005(0.002)$ & $-16.7(2.1)$ & 0.031 \\
\hline & $\mathrm{Mn}-\mathrm{Mn} / \mathrm{Fe}$ & $3.2(0.4)$ & $2.89(0.01)$ & 0.007 & & \\
\hline \multirow{2}{*}{$\begin{array}{l}\mathrm{MnO}_{4} \\
\mathrm{Si} 750+\mathrm{Ca} 1000\end{array}$} & $\mathrm{Mn}-\mathrm{O}$ & $4.9(0.7)$ & $1.90(0.01)$ & $0.004(0.001)$ & $-17.3(1.7)$ & 0.020 \\
\hline & $\mathrm{Mn}-\mathrm{Mn} / \mathrm{Fe}$ & $3.3(0.3)$ & $2.87(0.01)$ & 0.007 & & \\
\hline
\end{tabular}

$\mathrm{CN}$ represents the coordination number. $\mathrm{R}$ the interatomic distance. $\sigma 2$ the mean squared atomic displacement and $\Delta \mathrm{E}_{0}$ represents the change in threshold energy. The passive electron reduction factor. $\mathrm{SO}^{2}$. was fixed at 0.7 . Fitting parameters allowed to float are accompanied by fit-determined standard errors in parenthesis. while constrained parameters appear without a parenthesis. All fits were carried out from 1 to $3.5 \AA$ in $R+\Delta R$-space. The number of independent point $\left(\mathrm{N}_{\mathrm{IDP}}\right)$ in the fits was 13.4 and the number of variables $\left(\mathrm{N}_{\mathrm{Var}}\right)$ was 4 to 9 . 
$\mathrm{Fe}(\mathrm{III})$ precursors form in the presence of Fe(II). Aqueous Fe(II) catalyzes the rapid transformation of poorly-ordered Fe(III) precipitates into lepidocrocite, which was the dominant $\mathrm{Fe}$ (III) phase of the Ref $\mathrm{O}_{2}$ experiment (Pedersen et al. 2005). By contrast, the reaction rate of $\mathrm{HOCl}$ and $\mathrm{MnO}_{4}$ with $\mathrm{Fe}(\mathrm{II})$ is high enough that aqueous $\mathrm{Fe}$ (II) is too unstable to catalyze the transformation of freshly-formed Fe(III) to lepidocrocite, leading to the persistence of poorly-ordered $\mathrm{Fe}$ (III) precipitates. Although $\mathrm{Fe}(\mathrm{III})$ speciation was similar in the Ref $\mathrm{HOCl}$ and $\mathrm{MnO}_{4}$ experiments, the Ref $\mathrm{MnO}_{4}$ solids contained a major fraction of $\mathrm{MnO}_{2}$ that did not form in the $\mathrm{O}_{2}$ and $\mathrm{HOCl}$ experiments. The presence of $\mathrm{MnO}_{2}$ likely enhances the colloidal stability of the $\mathrm{MnO}_{4}$ samples because of the much lower point of zero charge of $\mathrm{MnO}_{2}(\approx 2-3)$ compared to lepidocrocite and poorly-ordered $\mathrm{Fe}(\mathrm{III})$ precipitates $(\approx 7-8)$ (Sposito 2008). At circumneutral $\mathrm{pH}$, suspensions containing $\mathrm{MnO}_{2}$ will have a strong negative charge, preventing aggregation, whereas suspensions of Fe(III) precipitates will be near the optimum $\mathrm{pH}$ to induce aggregation (Sposito 2008).

\subsubsection{Impact of ionic composition}

Solution chemistry was found to alter both the suspension stability and Fe(III) speciation, with different impacts depending on the $\mathrm{Fe}(\mathrm{II})$ oxidant and ionic composition. The $\mathrm{Fe}(\mathrm{III})$ speciation in the $\mathrm{O}_{2}$ samples was impacted the most by solution composition, but similar trends were observed in the $\mathrm{MnO}_{4}$ and $\mathrm{HOCl}$ experiments. The presence of oxyanions in the $\mathrm{O}_{2}$ samples decreased particle aggregation and resulted in a transition from lepidocrocite to poorly-ordered Fe(III) precipitates. Oxyanions, such as Si and P, bind strongly to Fe(III) precipitate surfaces during Fe(III) polymerization, which modifies two key properties of the suspension. First, by binding strongly to crystal growth sites on the Fe(III) precipitate surface, oxyanions inhibit the formation of crystalline Fe(III) minerals (i.e. lepidocrocite), leading to the persistence of poorly-ordered Fe(III) precipitates with a large specific surface area (Van Genuchten et al. 2014b, Voegelin et al. 2010). Second, sorption of oxyanions leads to negatively charged Fe(III) precipitate surfaces, even in the case of $\mathrm{Si}$, which is uncharged in solution circumneutral pH (Delaire et al. 2016, Kanematsu et al. 2013a). Therefore, oxyanion sorption generates particles with highly negative surface charge that are less likely to aggregate. Both consequences of co-occurring oxyanions during $\mathrm{Fe}(\mathrm{III})$ precipitation (i.e. changes in suspension aggregation and $\mathrm{Fe}(\mathrm{III})$ speciation) were observed in the $\mathrm{O}_{2}$ experiments. These effects were less pronounced in the $\mathrm{MnO}_{4}$ experiments since the Ref $\mathrm{MnO}_{4}$ suspension was already colloidally stable and consisted of poorly-ordered Fe(III) precipitates even in the absence of Si and P.

The presence of $\mathrm{Ca}$ can counteract some of the oxyanion effects, particularly with respect to particle surface charge. Ca addition enhanced aggregation (i.e. settling and 
filterability) in nearly every $\mathrm{O}_{2}, \mathrm{HOCl}$ and $\mathrm{MnO}_{4}$ experiment, with stronger impact in $\mathrm{P}$ solutions than $\mathrm{Si}$. The pronounced impact of $\mathrm{Ca}$ in $\mathrm{P}$ solutions is attributed to the formation of Ca-O-P linkages during $\mathrm{Fe}(\mathrm{III})$ polymerization that enhance particle aggregation by neutralizing more effectively the negative surface charge of P-rich Fe(III) precipitates (Senn et al. 2015, Van Genuchten et al. 2014a, Voegelin et al. 2010). The presence of $\mathrm{Ca}$ was also important to enhancing the aggregation of $\mathrm{MnO}_{4}$ suspensions, which is explained by positively charged Ca neutralizing the negatively charged $\mathrm{MnO}_{2}$ produced in the $\mathrm{MnO}_{4}$ experiments.

\subsubsection{Behavior of $\mathrm{Mn}$ (II) during co-oxidation with $\mathrm{Fe}(\mathrm{II})$}

\subsubsection{1 $\mathrm{Mn}(\mathrm{II})$ removal in $\mathrm{O}_{2}, \mathrm{MnO}_{4}$, and $\mathrm{HOCl}$ Ref experiments}

A visual representation of the structure and composition of the solids formed in the Ref experiments is given in Fig 3.9. The $\mathrm{Ref}_{2}, \mathrm{MnO}_{4}$ and $\mathrm{HOCl}$ experiments were performed in solutions with the least ionic complexity and form the baseline for comparing $\mathrm{Mn}(\mathrm{II})$ removal in the simulated groundwater solutions. In the Ref $\mathrm{O}_{2}$ experiment, the $\mathrm{Mn} / \mathrm{Fe}$ solids ratio was $\approx 0.01 \mathrm{~mol} / \mathrm{mol}$ (i.e. $\approx 10 \% \mathrm{Mn}$ (II) removal) and the XANES LCFs indicated solid-phase Mn was dominantly Mn(III). Shell-by-shell fits of the Ref $\mathrm{O}_{2}$ sample were consistent with a first shell $\mathrm{Mn}(\mathrm{III})-\mathrm{O}$ coordination environment and a second shell that consisted of $\mathrm{Mn}-\mathrm{Mn} / \mathrm{Fe}$ atomic pairs at $\mathrm{R}=3.04 \pm 0.02 \AA$. This $\mathrm{R}$-value matches that of edge-sharing $\mathrm{FeO}_{6}$ octahedra in the $\mathrm{Fe}(\mathrm{III})$ precipitates formed in this sample (Table S3.1). Therefore, $\mathrm{Mn}$ (II) removal in the Ref $\mathrm{O}_{2}$ experiment likely occurs via $\mathrm{Mn}$ (II) oxidation to $\mathrm{Mn}$ (III) by the reactive Fenton-type oxidants produced during $\mathrm{Fe}(\mathrm{II})$ oxidation by $\mathrm{O}_{2}\left({ }^{*} \mathrm{O}_{2}{ }^{-}\right.$, $\mathrm{Fe}(\mathrm{IV})$ ) and subsequent (partial) incorporation into the resulting Fe(III) precipitate. This $\mathrm{Mn}$ (II) removal mechanism has been observed in experiments that dosed $\mathrm{Fe}(\mathrm{II})$ slowly by $\mathrm{Fe}(0)$ electrolysis into air-saturated solutions of $\mathrm{Mn}$ (II), allowing $\mathrm{Fe}(\mathrm{II})$ and $\mathrm{Mn}$ (II) co-oxidize by $\mathrm{O}_{2}$ (Van Genuchten and Pena 2017a).

The Ref $\mathrm{MnO}_{4}$ experiment had a high $\mathrm{Mn} / \mathrm{Fe}$ solids ratio of $>0.5 \mathrm{~mol} / \mathrm{mol}$, which matches the total $\mathrm{Mn} / \mathrm{Fe}$ ratio dosed into the initial solution. The XANES LCFs of the Ref $\mathrm{MnO}_{4}$ sample indicated $\mathrm{Mn}$ was present as $\mathrm{Mn}(\mathrm{IV})$. The line shape and position of the Mn K-edge EXAFS spectrum and the shell-by-shell fitting output of the $\mathrm{Ref} \mathrm{MnO}_{4}$ sample indicated an $\mathrm{Mn}$ coordination environment similar to the $\delta-\mathrm{MnO}_{2}$ standard. The formation of nanoscale $\mathrm{MnO}_{2}$ by reaction of $\mathrm{Mn}(\mathrm{II})$ and $\mathrm{MnO}_{4}$ has been well documented in many studies (Knocke et al. 1991, Lee et al. 2011) and our results suggest that the presence of $\mathrm{Fe}(\mathrm{II})$ and other background ions in the Ref $\mathrm{MnO}_{4}$ experiment did not alter this reaction pathway.

Effective removal of approximately $80 \%$ of the initial $\mathrm{Mn}$ (II) was observed in the Ref $\mathrm{HOCl}$, leading to an $\mathrm{Mn} / \mathrm{Fe}$ solids ratio of $\approx 0.08 \mathrm{~mol} / \mathrm{mol}$, which was significantly higher than the Ref $\mathrm{O}_{2}$ sample. The XANES LCFs of the Ref $\mathrm{HOCl}$ 
sample indicated that solid-phase $\mathrm{Mn}$ was dominantly $\mathrm{Mn}(\mathrm{III})$. Similar to the $\mathrm{O}_{2}$ system, the shell-by-shell fits of the Ref $\mathrm{HOCl}$ sample were consistent with a first shell $\mathrm{Mn}(\mathrm{III})-\mathrm{O}$ coordination environment and second shell that consisted of $\mathrm{Mn}-\mathrm{Mn} / \mathrm{Fe}$ atomic pairs at an $\mathrm{R}$-value $(3.01 \pm 0.02 \AA$ ) that is not found in $\mathrm{Mn}(\mathrm{III})$ (oxyhydr)oxide minerals. However, this R-value is similar to that of the edge-sharing Fe octahedra in the Fe(III) precipitates that formed in this sample $(3.05 \pm 0.01 \AA$, Table S3.1). Therefore, we propose that $\mathrm{Mn}(\mathrm{II})$ removal in the Ref $\mathrm{HOCl}$ experiment proceeds by a single electron transfer from $\mathrm{Mn}(\mathrm{II})$ to $\mathrm{Mn}$ (III), with $\mathrm{Mn}$ (III) stabilized by co-precipitating $\mathrm{Fe}(\mathrm{III})$ (oxyhydr)oxides. While a similar $\mathrm{Mn}(\mathrm{II})$ removal pathway has been documented for $\mathrm{Mn}(\mathrm{II})$ and $\mathrm{Fe}(\mathrm{II})$ co-oxidation by $\mathrm{H}_{2} \mathrm{O}_{2}$, this pathway is inconsistent with previous research investigating $\mathrm{Mn}$ (II) removal by chlorination, which report the formation of $\mathrm{Mn}$ (IV) species (Allard et al. 2013, Hao et al. 1991). In our experiments, the precipitation of Fe(III) during $\mathrm{Mn}$ (II) oxidation likely stabilizes the initial $\mathrm{Mn}$ (III) product by incorporation into the solid phase, which prevents subsequent $\mathrm{Mn}(\mathrm{III})$ oxidation to $\mathrm{Mn}(\mathrm{IV})$.

\subsubsection{Impact of ionic composition}

A visual representation of the impact of oxyanions and bivalent cations on the structure and composition of the precipitates formed by $\mathrm{Fe}(\mathrm{II})$ and $\mathrm{Mn}(\mathrm{II})$ cooxidation is given in Fig 3.9. Solution composition modified the uptake and removal mechanism of $\mathrm{Mn}(\mathrm{II})$ in many experiments, with the most pronounced impacts in the $\mathrm{O}_{2}$ and $\mathrm{HOCl}$ systems. Based on the XANES LCFs and Mn K-edge EXAFS spectra, $\mathrm{Mn}$ (II) was removed by reaction with $\mathrm{MnO}_{4}$ to form nanoscale $\mathrm{MnO}_{2}$ in every experiment in the $\mathrm{MnO}_{4}$ system, regardless of solution composition. However, in the $\mathrm{O}_{2}$ and $\mathrm{HOCl}$ experiments, $\mathrm{Si}$ and $\mathrm{P}$ increased the fraction of solid-phase $\mathrm{Mn}(\mathrm{II})$. For example, whereas $<5 \% \mathrm{Mn}(\mathrm{II})$ was present in the $\mathrm{Ref} \mathrm{O}_{2}$ and $\mathrm{HOCl}$ samples, the $\mathrm{P} 16$ samples in the $\mathrm{O}_{2}$ and $\mathrm{HOCl}$ systems consisted of $85 \pm 3$ and $41 \pm 4 \% \mathrm{Mn}(\mathrm{II})$, respectively. The impact of Si was weaker than P, but still increased the $\mathrm{Mn}(\mathrm{II})$ fraction in the Si150 sample in the $\mathrm{O}_{2}$ system to $75 \pm 2 \%$. Furthermore, the increased fraction of sorbed $\mathrm{Mn}(\mathrm{II})$ in the $\mathrm{O}_{2}$ experiments coincided with an increase in $\mathrm{Mn} / \mathrm{Fe}$ solids ratio, particularly in the $\mathrm{P}$ experiment $\left(\mathrm{Mn} / \mathrm{Fe}_{\mathrm{Ref}}=0.01\right.$ $\mathrm{mol} / \mathrm{mol}, \mathrm{Mn} / \mathrm{Fe}_{\mathrm{P} 16}=0.05 \mathrm{~mol} / \mathrm{mol}$ ). These results indicate that $\mathrm{P}$, and Si to a lesser extent, can enhance $\mathrm{Mn}(\mathrm{II})$ sorption when $\mathrm{Mn}(\mathrm{II})$ oxidation is incomplete. The enhanced $\mathrm{Mn}(\mathrm{II})$ removal in the presence of oxyanions can be explained by the interaction between positively charged $\mathrm{Mn}(\mathrm{II})$ and negatively charged surfaces of oxyanion-rich Fe(III) precipitates. The more pronounced impact of P relative to Si could arise from direct $\mathrm{Mn}(\mathrm{II})-\mathrm{O}-\mathrm{P}$ bonding on the $\mathrm{Fe}(\mathrm{III})$ precipitate surface (i.e. ternary complexes), analogous to $\mathrm{Ca}-\mathrm{O}-\mathrm{P}$ linkages.

In contrast to the effect of oxyanions, the presence of $\mathrm{Ca}$ in $\mathrm{Si}$ and $\mathrm{P}$ solutions systematically decreased the fraction of solid-phase $\mathrm{Mn}(\mathrm{II})$ in both $\mathrm{O}_{2}$ and $\mathrm{HOCl}$ 

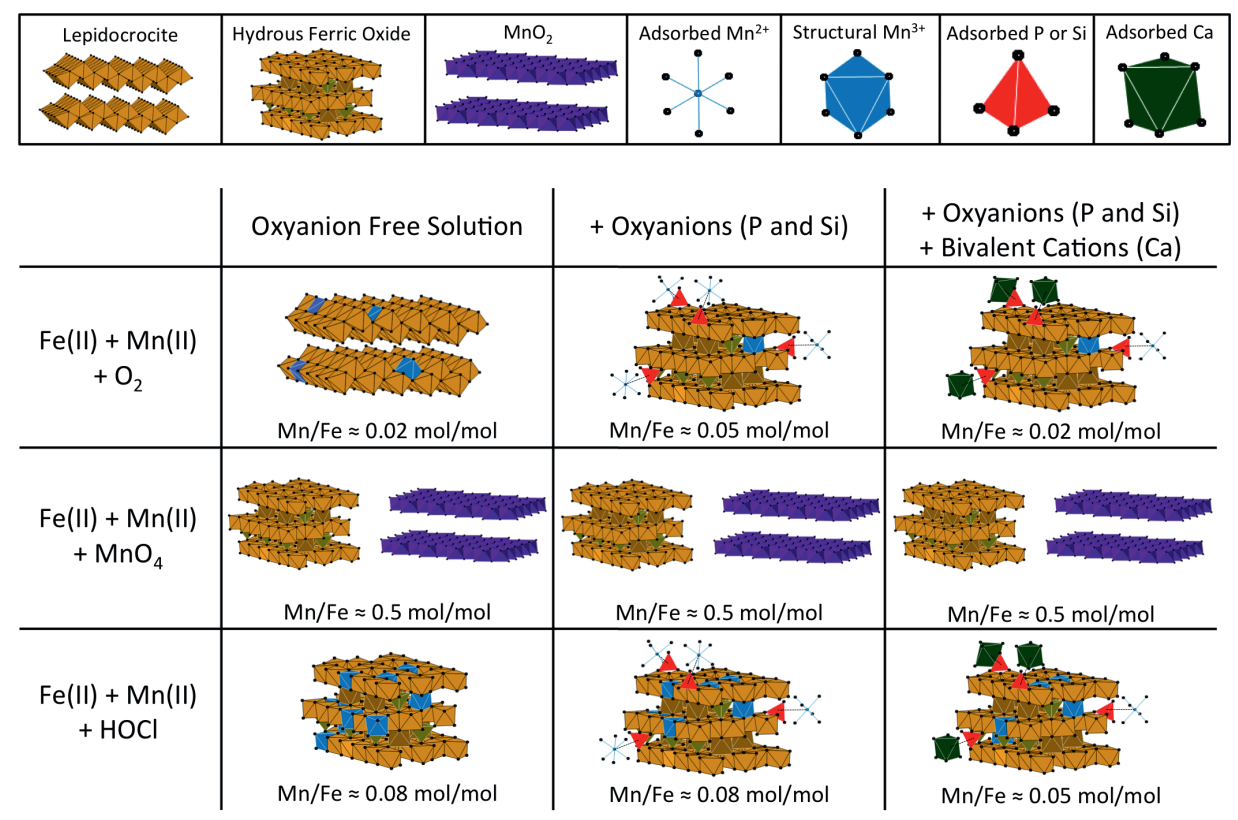

Figure 3.9. Visual representations and $\mathrm{Mn} / \mathrm{Fe}$ ratios of the experimental solids derived from the wet chemical measurements and XAS analyses. We expect that sorbed $\mathrm{Mn}$ (II) increased in the oxyanion experiments due to $\mathrm{Mn}(\mathrm{II})$ interactions with $\mathrm{P}$ and Si bound to the $\mathrm{Fe}(\mathrm{III})$ precipitate. We did not include $\mathrm{P}$ or $\mathrm{Si}$ oxyanions bound to the $\mathrm{Fe}(\mathrm{III})$ precipitates in the $\mathrm{MnO}_{4}$ panels since $\mathrm{Mn}$ (II) was not detected in these samples.

experiments. The impact of $\mathrm{Ca}$ was most pronounced in the P16 solutions, with decreases in the $\mathrm{Mn}$ (II) fraction from $85 \pm 3$ to $20 \pm 4 \%$ in the $\mathrm{O}_{2}$ system and from $41 \pm 4$ and $14 \pm 5 \%$ in the $\mathrm{HOCl}$ system. The Ca-induced decrease in sorbed $\mathrm{Mn}$ (II) was coupled to a decrease in the $\mathrm{Mn} / \mathrm{Fe}$ solids ratio (Fig 3.3), which suggests that $\mathrm{Ca}$ can compete effectively with $\mathrm{Mn}$ (II) for sorption sites, especially in the case of P-rich $\mathrm{Fe}(\mathrm{III})$ precipitates. This conclusion is consistent with the similar ionic potential (charge/ionic radius) of $\mathrm{Mn}(\mathrm{II})\left(\mathrm{IP}_{\mathrm{Mn}(\mathrm{II})} \approx 24\right)$ and $\mathrm{Ca}\left(\mathrm{IP}_{\mathrm{Ca}} \approx 20\right)$ ions, which suggests similar sorption reactivity between $\mathrm{Mn}(\mathrm{II})$ and $\mathrm{Ca}$.

\subsection{CONCLUSIONS AND IMPLICATIONS FOR WATER TREATMENT}

We found that the composition of water and the identity of the oxidant strongly determines the macroscopic and molecular-scale characteristics of $\mathrm{Fe}$ and $\mathrm{Mn}$ bearing precipitates generated by $\mathrm{Fe}(\mathrm{II})$ and $\mathrm{Mn}(\mathrm{II})$ co-oxidation. The higher $\mathrm{Mn}$ / 
Fe ratio of the precipitates produced with $\mathrm{MnO}_{4}$ or $\mathrm{HOCl}$ indicates that the $\mathrm{Mn}$ removal mechanism will differ between the typical aeration-rapid sand filtration type groundwater treatment systems that rely on bacteria and surface catalysts for $\mathrm{Mn}$ (II) removal (Bruins et al. 2015) and the ones that use strong oxidants such as $\mathrm{KMnO}_{4}$ and $\mathrm{NaOCl}$. In the prior case, $\mathrm{Mn}$ removal will take place deeper in the filter bed, whereas $\mathrm{Mn}$ is expected to precipitate in the supernatant storage with $\mathrm{KMnO}_{4}$ and $\mathrm{NaOCl}$, resulting in accumulation of $\mathrm{Mn}$ bearing solids in the top sand filter layer.

Our study shows that the addition of Ca counteracts the negative effect of oxyanions and enhances the settling and filterability of Fe and Mn bearing precipitates. Thus, water treatment utilities that plan to implement softening at Fe/Mn removal plants should consider placing softening reactors after Fe/Mn removal to avoid colloidally stable suspensions arising from solutions low in bivalent cations. If colloidally stable suspensions are unavoidable, low pressure membrane systems (microfiltration/ ultrafiltration) may replace rapid sand filters for effective removal of colloidal precipitates, but the fouling of membranes will be a critical issue. Precipitates can foul the membranes in different ways, depending on particle size. Particle sizes larger than the membrane pores will deposit on membrane surfaces, resulting in cake layer formation, which is often easily reversible (Floris et al. 2016). However, smaller particles can deposit in the membrane internal structure, resulting in undesirable pore entrapment and pore narrowing, which severely decreases the flux over time (irreversible fouling).

With respect to contaminant removal during treatment, the formation of $\mathrm{MnO}_{2}$ by $\mathrm{MnO}_{4}$ addition should not be overlooked. The characterization data in the $\mathrm{MnO}_{4}$ experiments indicated that the $\mathrm{Mn}$ solids were structurally similar to $\delta-\mathrm{MnO}_{2}$, a nanoscale $\mathrm{MnO}_{2}$ mineral. These types of $\mathrm{Mn}(\mathrm{IV})$ oxides have remarkable reactivity with respect to sorption of a wide variety of toxic heavy metals (e.g. $\mathrm{Cd}(\mathrm{II}), \mathrm{Pb}(\mathrm{II})$, $\mathrm{Cu}(\mathrm{II}), \mathrm{Ni}(\mathrm{II})$ ) (Peńa et al. 2015, Pena et al. 2010, Villalobos 2015). For example, the $\mathrm{Pb} / \mathrm{Mn}$ solids ratio for $\delta-\mathrm{MnO}_{2}$ can reach $0.4 \mathrm{~mol} / \mathrm{mol}$ (Villalobos et al. 2005), which is partly due to highly reactive $\mathrm{Mn}(\mathrm{IV})$ vacancies in $\mathrm{MnO}_{2}$ sheets (Lanson et al. 2002). In our study, $\mathrm{MnO}_{4}$ was investigated primarily because it improves the kinetics of $\mathrm{Fe}(\mathrm{II}), \mathrm{Mn}(\mathrm{II})$ and $\mathrm{As}(\mathrm{III})$ oxidation. However, our results suggest that $\mathrm{Fe}(\mathrm{II})$ oxidation by $\mathrm{MnO}_{4}$ and the production of mixtures of $\mathrm{Fe}(\mathrm{III})$ and $\mathrm{MnO}_{2}$ would be ideal for concurrent treatment of As(III) and heavy metals. This result is particularly important for the co-removal of $\mathrm{As}(\mathrm{III})$ and $\mathrm{Cd}(\mathrm{II})$, which can often occur simultaneously in polluted environments (Perera et al. 2016), since Cd(II) removal by $\mathrm{Fe}(\mathrm{III})$ precipitates is much less effective than $\mathrm{MnO}_{2}$ (Van Genuchten and Peña 2016b). 


\section{Acknowledgement}

This research is co-financed with PPS-funding from the Topconsortia for Knowledge \& Innovation (TKI's) of the Ministry of Economic Affairs and Climate. AA acknowledges support from Evides Waterbedrijf. CMvG acknowledges funding from a NWO Veni grant. The authors want to thank Luuk de Waal of KWR, Simon Mueller of Evides and Martijn Eikelboom of Wageningen University for their support during the experiments. We thank Ryan Davis at SSRL and Dipanjan Banerjee at ESRF for assistance during XAS data collection. Use of SSRL, SLAC National Accelerator Laboratory, was supported by the U.S. Department of Energy, Office of Science, Basic Energy Sciences, under Contract No. DE-AC02-76SF00515.

\section{SUPPLEMENTARY INFORMATION}

1. Oxidation reactions of $\mathrm{Fe}(\mathrm{II}), \mathrm{Mn}(\mathrm{II})$ and $\mathrm{As}(\mathrm{III})$ with $\mathrm{O}_{2}, \mathrm{MnO}_{4}$ and $\mathrm{HOCl}$ (Ghurye and Clifford 2001)

$\mathrm{Fe}(\mathrm{II})$ oxidation with $\mathrm{O}_{2}, \mathrm{MnO}_{4}$ and $\mathrm{HOCl}$

$\mathrm{O}_{2}+4 \mathrm{Fe}^{2+}+4 \mathrm{H}^{+} \rightarrow 4 \mathrm{Fe}^{3+}+2 \mathrm{H}_{2} \mathrm{O}$

$\mathrm{MnO}_{4}^{-}+5 \mathrm{Fe}^{2+}+8 \mathrm{H}^{+} \rightarrow \mathrm{Mn}^{2+}+5 \mathrm{Fe}^{3+}+4 \mathrm{H}_{2} \mathrm{O}$

$\mathrm{HOCl}+2 \mathrm{Fe}^{2+}+5 \mathrm{H}_{2} \mathrm{O} \rightarrow \mathrm{Cl}^{-}+2 \mathrm{Fe}(\mathrm{OH})_{3}+5 \mathrm{H}^{+}$

$\mathrm{Mn}(\mathrm{II})$ oxidation with $\mathrm{O}_{2}, \mathrm{MnO}_{4}$ and $\mathrm{HOCl}$

$$
\begin{aligned}
& \mathrm{O}_{2}+2 \mathrm{Mn}^{2+}+2 \mathrm{H}_{2} \mathrm{O} \rightarrow 2 \mathrm{MnO}_{2}+4 \mathrm{H}^{+} \\
& 2 \mathrm{MnO}_{4}^{-}+3 \mathrm{Mn}^{2+}+2 \mathrm{H}_{2} \mathrm{O} \rightarrow 5 \mathrm{MnO}_{2}+4 \mathrm{H}^{+} \\
& \mathrm{HOCl}+\mathrm{Mn}^{2+}+\mathrm{H}_{2} \mathrm{O} \rightarrow \mathrm{MnO}_{2}+\mathrm{Cl}^{-}+3 \mathrm{H}^{+}
\end{aligned}
$$

As(III) oxidation with $\mathrm{O}_{2}, \mathrm{MnO}_{4}$ and $\mathrm{HOCl}$

$2 \mathrm{H}_{3} \mathrm{AsO}_{3}+2 \mathrm{O}_{2}+4 \mathrm{H}^{+} \rightarrow 2 \mathrm{H}_{3} \mathrm{AsO}_{4}+2 \mathrm{H}_{2} \mathrm{O}$

$5 \mathrm{H}_{3} \mathrm{AsO}_{3}+2 \mathrm{MnO}_{4}^{-}+6 \mathrm{H}^{+} \rightarrow 5 \mathrm{H}_{3} \mathrm{AsO}_{4}+2 \mathrm{Mn}^{2+}+3 \mathrm{H}_{2} \mathrm{O}$

$\mathrm{HOCl}+\mathrm{H}_{3} \mathrm{AsO}_{3} \rightarrow \mathrm{H}_{2} \mathrm{AsO}_{4}^{-}+2 \mathrm{H}^{+}+\mathrm{Cl}^{-}$ 


\section{X-ray absorption spectroscopy sample preparation and data collection}

Solids for X-ray absorption spectroscopy (XAS) analysis were collected from the precipitation experiments on $0.45 \mu \mathrm{m}$ filters and encapsulated in Kapton tape while the filter was wet. The amount of solid material trapped on the filter was selected to optimize Fe K-edge XAS measurements in transmission mode i.e. the total absorption from the entire sample was less than 2.5 absorption lengths, while the absorption of Fe was 1.0 absorption length. Fe and Mn K-edge XAS data were collected at room temperature at beamline 4-1 of the Stanford Synchrotron Radiation Lightsource (SSRL) and the DUBBLE beamline (BM-26a) of the European Synchrotron Radiation Facility (ESRF). Transmission measurements were made using ion chambers for measurements of $\mathrm{I}_{0}\left(40 \% \mathrm{~N}_{2}, 60 \% \mathrm{He}\right)$ and $\mathrm{I}_{\mathrm{t}}(20 \% \mathrm{Ar}, 80 \% \mathrm{He})$, whereas a 9-element solid state Ge detector was used for fluorescence measurements. The vertical and horizontal dimensions of the X-ray beam during the measurement were 0.5 to $1 \mathrm{~mm}$ and $3 \mathrm{~mm}$, respectively. Harmonic rejection mirrors were used to remove second-order harmonics or the X-ray beam was detuned $40 \%$. The XANES region was measured with $0.35 \mathrm{eV}$ steps, whereas step sizes of $0.05 \AA^{-1}$ were used for the EXAFS region. Two to 8 scans were collected for each sample and beam damage was not observed in replicate scans for any sample.

\section{Fe K-edge EXAFS analysis}

The Fe K-edge EXAFS spectra of select samples and reference material was analyzed by shell-by-shell fits. Theoretical curve fits were performed in $R+\Delta R$-space $(\AA)$ using SixPack software, which is built on algorithms derived from the IFEFFIT library (Newville 2001). Scattering paths used in the fits were derived from the structure of goethite (Gualtieri and Venturelli 1999). Fits were typically performed by varying the coordination number $(C N)$, change in threshold energy $\left(\Delta E_{0}\right)$, interatomic distance $(R)$ and the mean squared displacement parameter $\left(\sigma^{2}\right)$ for each path in the fit. For several of the samples, the $\sigma^{2}$ for the first and second shell Fe-Fe paths were constrained to 0.01 to reduce the high fit-derived standard error on $\mathrm{CN}$ and $\sigma^{2}$ produced in preliminary fits. The passive electron reduction factor $\left(S_{0}^{2}\right)$ was set to 0.8 . The goodness of fit was determined using the R-factor.

\section{Mn K-edge XANES analysis}

The Mn K-edge XANES spectra of experimental samples were analyzed by LCFs to determine the fraction of solid-associated $\mathrm{Mn}(\mathrm{II}), \mathrm{Mn}(\mathrm{III})$, and $\mathrm{Mn}(\mathrm{IV})$. SixPack software was used to perform the LCFs on the normalized XANES spectra, with a fit range of 6530 to $6590 \mathrm{eV}$. Following previous approaches (Manceau et al. 2012a), negative fit-derived fractions were not permitted in the fit. Since the selection of particular $\mathrm{Mn}(\mathrm{II}), \mathrm{Mn}(\mathrm{III})$, and $\mathrm{Mn}(\mathrm{IV})$ standards used in the LCFs 
can impact the fit-derived $\mathrm{Mn}(\mathrm{II}), \mathrm{Mn}(\mathrm{III})$, and $\mathrm{Mn}(\mathrm{IV})$ fractions (Manceau et al. 2012a), we adopted a previous approach where several LCFs were performed for each experimental sample using different combinations of 5 different Mn-bearing standards (Van Genuchten and Pena 2017a). The standard XANES spectra used in the LCFs were aqueous $\mathrm{Mn}(\mathrm{II})$, bixbyite $\left(\alpha-\mathrm{Mn}_{2} \mathrm{O}_{3}\right)$, manganite $(\gamma-\mathrm{MnOOH})$, $\delta$ - $\mathrm{MnO}_{2}$, and ramsdellite $\left(\beta-\mathrm{MnO}_{2}\right)$, which were collected as part of previous studies or were obtained from X-ray absorption spectra databases (Manceau et al. 2012a, Van Genuchten and Pena 2017a). Four LCFs were performed and the fraction of $\mathrm{Mn}(\mathrm{II}), \mathrm{Mn}(\mathrm{III})$, and $\mathrm{Mn}(\mathrm{IV})$ for each experimental sample was calculated by taking the average and standard deviation of the four LCFs.

\section{Mn K-edge EXAFS analysis}

The Mn K-edge EXAFS spectra of select samples and standards were analyzed by shell-by-shell fits. Theoretical curve fits were performed in $R+\Delta R$-space ( $\mathrm{A})$ using the SixPack software with algorithms based on the IFEFFIT library (Newville 2001). Single scattering paths ( $\mathrm{Mn}-\mathrm{O}, \mathrm{Mn}-\mathrm{Mn} / \mathrm{Fe}$ ) were derived from the structure of birnessite $\left(\mathrm{MnO}_{2}\right)$ (Lanson et al. 2002), with theoretical phase and amplitude functions calculated using FEFF6 (Rehr et al. 1992). Fits were performed by varying $C N, \Delta E_{0}, R$, and $\sigma^{2}$. The passive electron reduction factor was set to 0.7 . In preliminary fits, the fit-derived uncertainties on $\mathrm{CN}$ and $\sigma^{2}$ were large due to their high correlation. Therefore, we constrained the $\sigma^{2}$ value in the fits of some experimental samples and standards, which is a common shell-by-shell fitting approach for nanoscale metal oxides (Mikutta et al. 2010). 


\section{SUPPLEMENTARY INFORMATION}

\section{Iron oxidation for different oxidation}

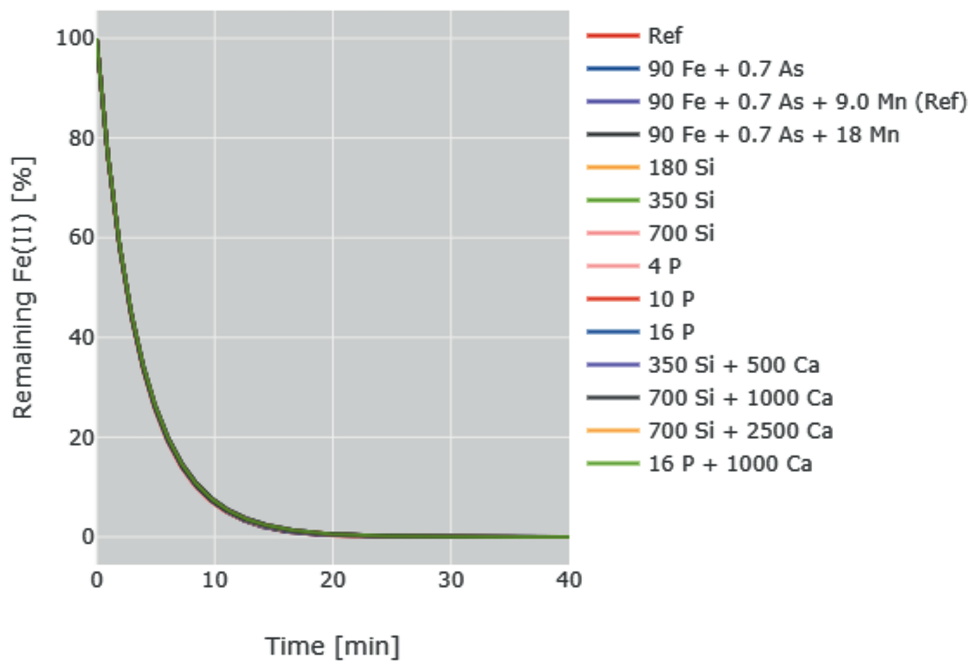

Figure S3.1 PHREEQC simulations of $\mathrm{Fe}(\mathrm{II})$ oxidation by $\mathrm{O}_{2}$ as a function of the ionic composition of initial solutions studied in $\mathrm{Fe}(\mathrm{II})$ and $\mathrm{Mn}$ (II) co-oxidation experiments.

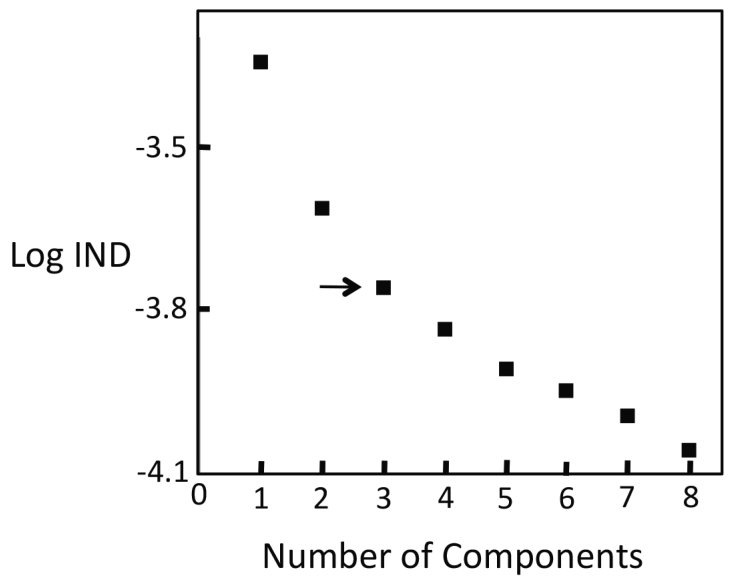

Figure S3.2. Results of the principal component analysis of the Fe K-edge EXAFS spectra. The indicator function (IND) decreases with increasing number of principal components. The arrow highlights the number of principal components used in the LCFs. 

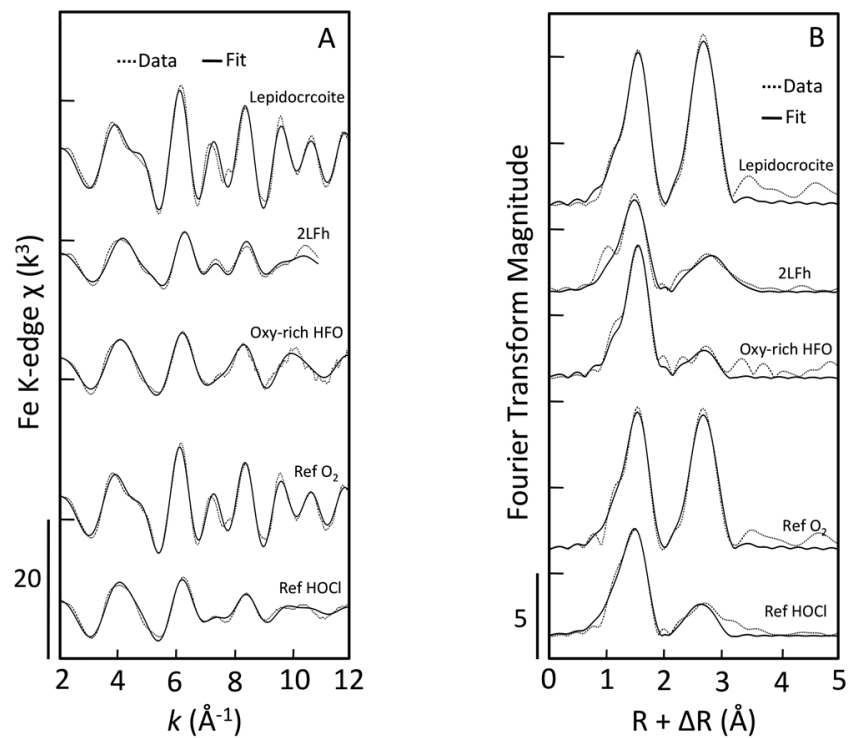

Figure S3.3 Fe K-edge EXAFS spectra and Fourier transforms of Fe-bearing standards and precipitate samples formed in the $\mathrm{O}_{2}$ and $\mathrm{HOCl}$ experiments. The output of shell-by-shell fits (solid lines) is overlain to the data (dotted lines). 
Table S3.1. Summary of Fe Shell Fits of Fe-bearing References and Precipitate Samples.

\begin{tabular}{|c|c|c|c|c|c|c|}
\hline Sample & $\begin{array}{l}\text { Atomic } \\
\text { Pairs }\end{array}$ & $\mathrm{CN}$ & $\mathbf{R}(\AA)$ & $\sigma^{2}\left(\AA^{2}\right)$ & $\Delta \mathrm{E}_{0}(\mathrm{eV})$ & R-Factor \\
\hline \multirow{2}{*}{$\gamma$-FeOOH } & $\mathrm{Fe}-\mathrm{O}$ & $6.2(0.8)$ & $2.01(0.01)$ & $0.007(0.001)$ & $-3.0(1.0)$ & 0.021 \\
\hline & $\mathrm{Fe}-\mathrm{Fe}$ & $6.5(0.9)$ & $3.07(0.01)$ & $0.007(0.001)$ & & \\
\hline \multirow{3}{*}{$2 \mathrm{LFh}$} & $\mathrm{Fe}-\mathrm{O}$ & $4.1(0.7)$ & $1.97(0.01)$ & $0.008(0.002)$ & $-2.6(2.0)$ & 0.044 \\
\hline & $\mathrm{Fe}-\mathrm{Fe} 1$ & $1.7(0.5)$ & $3.04(0.02)$ & 0.01 & & \\
\hline & $\mathrm{Fe}-\mathrm{Fe} 2$ & $1.8(0.7)$ & $3.46(0.03)$ & 0.01 & & \\
\hline \multirow{2}{*}{$\begin{array}{l}\text { Oxy-rich } \\
\text { HFO }\end{array}$} & $\mathrm{Fe}-\mathrm{O}$ & $4.4(0.5)$ & $2.00(0.01)$ & $0.005(0.001)$ & $-2.1(1.3)$ & 0.035 \\
\hline & $\mathrm{Fe}-\mathrm{Fe}$ & $1.6(0.4)$ & $3.06(0.02)$ & 0.01 & & \\
\hline \multirow{2}{*}{$\operatorname{RefO} \mathrm{O}_{2}$} & $\mathrm{Fe}-\mathrm{O}$ & $6.3(0.7)$ & $2.01(0.01)$ & $0.008(0.001)$ & $-3.1(0.9)$ & 0.017 \\
\hline & $\mathrm{Fe}-\mathrm{Fe}$ & $5.7(0.8)$ & $3.07(0.01)$ & $0.007(0.001)$ & & \\
\hline \multirow{2}{*}{ Ref $\mathrm{HOCl}$} & $\mathrm{Fe}-\mathrm{O}$ & $6.2(0.7)$ & $1.98(0.01)$ & $0.011(0.001)$ & $-3.9(1.3)$ & 0.031 \\
\hline & $\mathrm{Fe}-\mathrm{Fe}$ & $2.0(0.3)$ & $3.05(0.01)$ & 0.01 & & \\
\hline
\end{tabular}

$\overline{\mathrm{CN}}$ represents the coordination number. $\mathrm{R}$ the interatomic distance. $\sigma^{2}$ the mean squared atomic displacement and $\Delta \mathrm{E}_{0}$ represents the change in threshold energy. The passive electron reduction factor. $\mathrm{S}_{0}{ }^{2}$, was fixed at 0.8 . Fitting parameters allowed to float are accompanied by fit-determined standard errors in parenthesis, whereas constrained parameters appear without a parenthesis. 


\section{REFERENCES}

Ahmad, A., Cornelissen, E., van de Wetering, S., van Dijk, T., Van Genuchten, C., Bundschuh, J., van der Wal, A., Bhattacharya, P. (2018). Arsenite removal in groundwater treatment plants by sequential Permanganate - Ferric treatment. Journal of Water Process Engineering, 26, 221-229. doi:https://doi.org/10.1016/j.jwpe.2018.10.014

Ahmad, A., Kools, S., Schriks, M., Stuyfzand, P., \& Hofs, B. (2015). Arsenic and chromium concentrations and their speciation in groundwater resources and drinking water supply in the Netherlands. KWR BTO Report 2015.017. Nieuwegein, the Netherlands

Allard, S., Fouché, L., Dick, J., Heitz, A., \& von Gunten, U. (2013). Oxidation of Manganese(II) during Chlorination: Role of Bromide. Environmental Science \& Technology, 47(15), 87168723

Borsboom, M., Bras, W., Cerjak, I., Detollenaere, D., van Loon, D., Goedtkindt, P., . . Vlieg, E. (1998). The Dutch-Belgian beamline at the ESRF. Journal of Synchrotron Radiation, 5, 518520. doi:10.1107/S0909049597013484

Bruins, J. H., Petrusevski, B., Slokar, Y. M., Kruithof, J. C., \& Kennedy, M. D. (2015). Manganese removal from groundwater: Characterization of filter media coating. Desalination and Water Treatment, 55(7), 1851-1863. doi:10.1080/19443994.2014.927802

De Moel, P. J., Verberk, J. Q. J. C., \& van Dijk, J. C. (2006). Drinking Water: Principles and Practices. Delft, the Netherlands.

Delaire, C., Van Genuchten, C., Amrose, S., \& Gadgil, A. (2016). Bacteria attenuation by iron electrocoagulation governed by interactions between bacterial phosphate groups and $\mathrm{Fe}(\mathrm{III})$ precipitates. Water Research, 103, 74-82. doi:10.1016/j.watres.2016.07.020

Diem, D., \& Stumm, W. (1984). Is dissolved $\mathrm{Mn}^{+2}$ being oxidized by O2 in absence of Mn-bacteria and surface catalysts? Geochimica et Cosmochimica Acta, 48, 1571-1573.

Floris, R., Nijmeijer, K., \& Cornelissen, E. R. (2016). Removal of Aqueous nC60 Fullerene from Water by Low Pressure Membrane Filtration. Water Research, 91, 115-125.

Ghurye, G., \& Clifford, D. A. (2001). Laboratory Study on the Oxidation of Arsenic III to As V. USEPA Report EPA/600/R-01/021

Gualtieri, A., \& Venturelli, P. (1999). In situ study of the goethite-hematite phase transformation by real time synchrotron powder diffraction. American Mineralogist, 84, 895-904.

Gude, J. C. J., Rietveld, L. C., \& van Halem, D. (2016). Fate of low arsenic concentrations during full-scale aeration and rapid filtration. Water Research, 88, 566-574. doi:10.1016/j. watres.2015.10.034

Hao, O., P. Davis, A., \& H. Chang, P. (1991). Kinetics of Manganese(II) Oxidation with Chlorine. Journal of Environmental Engineering, 117(3)

Hug, S. J., \& Leupin, O. (2003). Iron-Catalyzed Oxidation of Arsenic(III) by Oxygen and by Hydrogen Peroxide: pH-Dependent Formation of Oxidants in the Fenton Reaction. Environmental Science \& Technology, 37(12), 2734-2742. doi:10.1021/es026208x

Kaegi, R., Voegelin, A., Folini, D., \& Hug, S. J. (2010). Effect of phosphate, silicate, and Ca on the morphology, structure and elemental composition of $\mathrm{Fe}(\mathrm{III})$-precipitates formed in aerated $\mathrm{Fe}(\mathrm{II})$ and As(III) containing water. Geochimica et Cosmochimica Acta, 74(20), 5798-5816. doi:10.1016/j.gca.2010.07.017

Kanematsu, M., Young, T., Fukushi, K., Green, P., \& Darby, J. (2013). Arsenic(III, V) adsorption on a goethite-based adsorbent in the presence of major co-existing ions: Modeling competitive adsorption consistent with spectroscopic and molecular evidence. Geochimica Et Cosmochimica Acta, 106, 404-428. doi:10.1016/j.gca.2012.09.055

Kelly, S. D., Hesterberg, D., \& Ravel, B. (2008). Analysis of soils and minerals using X-ray absorption 
spectroscopy. In Kelly, S.D., Hesterberg, D., \& Ravel, B. (Eds.) Methods of Soil Analysis. Part 5. Mineralogical Methods. SSA Book Series No.5.

Knocke, W. R., Van Benschoten, J. E., Kearney, M. J., Soborski, A. W., \& Reckhow, D. A. (1991). Kinetics of Manganese and Iron Oxidation by Potassium Permanganate and Chlorine Dioxide. AWWA, 83(6), 80-87.

Lan, S., Wang, X., Xiang, Q., Yin, H., Tan, W., Qiu, G., . . Feng, X. (2017). Mechanisms of Mn(II) catalytic oxidation on ferrihydrite surfaces and the formation of manganese (oxyhydr)oxides. Geochimica et Cosmochimica Acta, 211, 79-96

Lanson, B., Drits, V., Feng, Q., \& Manceau, A. (2002). Structure of synthetic Na-birnessite: Evidence for a triclinic one-layer unit cell. American Mineralogist, 87(11-12), 1662-1671.

Lee, G., Song, K., \& Bae, J. (2011). Permanganate oxidation of arsenic (III): Reaction stoichiometry and the characterization of solid product. Geochimica et Cosmochimica Acta, 75(17), 47134727

Manceau, A., \& Combes, J. M. (1988). Structure of Mn and Fe oxides and oxyhydroxides: A topological approach by EXAFS. Physics and Chemistry of Minerals, 15(3), 283-295. doi:10.1007/ BF00307518

Manceau, A., Marcus, M., \& Grangeon, S. (2012). Determination of Mn valence states in mixed-valent manganates by XANES spectroscopy. American Mineralogist, 97(5-6), 816-827. doi:10.2138/ am.2012.3903

McArthur, J. M., Sikdar, P. K., Nath, B., Grassineau, N., Marshall, J. D., \& Banerjee, D. M. (2012). Sedimentological Control on Mn, and Other Trace Elements, In Groundwater of the Bengal Delta. Environmental Science \& Technology, 46(2), 669-676. doi:10.1021/es202673n

Mikutta, C., Frommer, J., Voegelin, A., Kaegi, R., \& Kretzschmar, R. (2010). Effect of citrate on the local Fe coordination in ferrihydrite, arsenate binding, and ternary arsenate complex formation. Geochimica et Cosmochimica Acta, 5574-5592. doi:10.1016/j.gca.2010.06.024

Newville, M. (2001). IFEFFIT: interactive XAFS analysis and FEFF fitting. Journal of Synchrotron Radiation, 8, 322-324.

Nikitenko, S., Beale, A., van der Eerden, A., Jacques, S., Leynaud, O., O’Brien, M., . . Bras, W. (2008). Implementation of a combined SAXS/WAXS/QEXAFS set-up for time-resolved in situ experiments. Journal of Synchrotron Radiation, 15, 632-640. doi:10.1107/S0909049508023327

Pedersen, H. D., Postma, D., Jakobsen, R., \& Larsen, O. (2005). Fast transformation of iron oxyhydroxides by the catalytic action of aqueous Fe(II). Geochimica et Cosmochimica Acta, 69(16), 3967-3977. doi:https://doi.org/10.1016/j.gca.2005.03.016

Peña, J., Bargar, J. R., \& Sposito, G. (2015). Copper sorption by the edge surface of synthetic birnessite nanoparticles. Chemical Geology. 395, 196-207

Pena, J., Kwon, K., Refson, K., Bargar, J., \& Sposito, G. (2010). Mechanisms of nickel sorption by a bacteriogenic birnessite. Geochimica Et Cosmochimica Acta, 74(11), 3076-3089. doi:10.1016/j. gca.2010.02.035

Perera, P. A. C. T., Sundarabarathy, T. V., Sivananthawerl, T., Kodithuwakku, S. P., \& Edirisinghe, U. (2016). Arsenic and Cadmium Contamination in Water, Sediments and Fish is a Consequence of Paddy Cultivation: Evidence of River Pollution in Sri Lanka. Achievements in the Life Sciences, 10(2), 144-160. doi:https://doi.org/10.1016/j.als.2016.11.002

Rehr, J., Albers, R., \& Zabinsky, S. (1992). High-order multiple-scattering calculations of X-ray absorption fine structure. Physical Review Letters, 69(23), 3397-3400

Rossberg, A., Reich, T., \& Bernhard, G. (2003). Complexation of uranium(VI) with protocatechuic acid - application of iterative transformation factor analysis to EXAFS spectroscopy. Analytical and Bioanalytical Chemistry, 376(5), 631-638. doi:10.1007/s00216-003-1963-5

Scheinost, A., Rossberg, A., Vantelon, D., Xifra, I., Kretzschmar, R., Leuz, A., . . Johnson, C. (2006). Quantitative antimony speciation in shooting-range soils by EXAFS spectroscopy. Geochimica 
Et Cosmochimica Acta, 70(13), 3299-3312. doi:10.1016/j.gca.2006.03.020

Senn, A.-C., Hug, S. J., Kaegi, R., Hering, J. G., \& Voegelin, A. (2017). Arsenate co-precipitation with $\mathrm{Fe}(\mathrm{II})$ oxidation products and retention or release during precipitate aging. Water Research. doi:https://doi.org/10.1016/j.watres.2017.12.038

Senn, A.-C., Kaegi, R., Hug, S. J., Hering, J. G., Mangold, S., \& Voegelin, A. (2015). Composition and structure of $\mathrm{Fe}(\mathrm{III})$-precipitates formed by $\mathrm{Fe}(\mathrm{II})$ oxidation in water at near-neutral $\mathrm{pH}$ : Interdependent effects of phosphate, silicate and Ca. Geochimica et Cosmochimica Acta, 162, 220-246. doi:https://doi.org/10.1016/j.gca.2015.04.032

Sorlini, S., \& Gialdini, F. (2010). Conventional oxidation treatments for the removal of arsenic with chlorine dioxide, hypochlorite, potassium permanganate and monochloramine. Water Research, 44(19), 5653-5659. doi:10.1016/j.watres.2010.06.032

Sposito, G. (2008). The Chemistry of Soils. Oxford University Press. New York, USA

Stumm, W., \& Morgan, J. J. (1996). Aquatic Chemistry, Chemical Equilibria and Rates in Natural Waters (Vol. 3rd Edition). John Wiley \& Sons, Inc. New York, USA

Tebo, B. M., Johnson, H. A., McCarthy, J. K., \& Templeton, A. S. (2005). Geomicrobiology of manganese(II) oxidation. Trends in Microbiology, 13(9), 421-428. doi:https://doi.org/10.1016/j. tim.2005.07.009

Van Beek, C. G. E. M., Dusseldorp, J., Joris, K., Huysman, K., Leijssen, H., Schoonenberg Kegel, F., . . Hofs, B. (2016). Contributions of homogeneous, heterogeneous and biological iron(II) oxidation in aeration and rapid sand filtration (RSF) in field sites. Journal of Water Supply: Research and Technology—AQUA, 65(3), 195-207.

Van Beek, C. G. E. M., Hiemstra, T., Hofs, B., Bederlof, M. M., van Paassen, J. A. M., \& Reijnen, G. K. (2012). Homogeneous, heterogeneous and biological oxidation of iron(II) in rapid sand filtration. Journal of Water Supply: Research and Technology—AQUA, 61(1), 1-2012.

Van Genuchten, C., Addy, S., Pena, J., \& Gadgil, A. (2012). Removing arsenic from synthetic groundwater with iron electrocoagulation: An Fe and As K-edge EXAFS study. Environmental Science \&amp; Technology, 46(2), 986-994. doi:10.1021/es201913a

Van Genuchten, C., Behrends, T., Kraal, P., Stipp, S., \& Dideriksen, K. (2018). Controls on the formation of $\mathrm{Fe}(\mathrm{II}, \mathrm{III})$ (hydr)oxides by $\mathrm{Fe}(0)$ electrolysis. Electrochimica Acta, 286, 324-338. doi:10.1016/j.electacta.2018.08.031

Van Genuchten, C., \& Pena, J. (2017). Mn(II) Oxidation in Fenton and Fenton Type Systems: Identification of Reaction Efficiency and Reaction Products. Environmental Science \& Technology, 51(5), 2982-2991. doi:10.1021/acs.est.6b05584

Van Genuchten, C. M., Gadgil, A. J., \& Peña, J. (2014). Fe(III) Nucleation in the Presence of Bivalent Cations and Oxyanions Leads to Subnanoscale $7 \AA$ Polymers. Environmental Science \& Technology, 48(20), 11828-11836. doi:10.1021/es503281a

Van Genuchten, C. M., \& Peña, J. (2016a). Antimonate and arsenate speciation on reactive soil minerals studied by differential pair distribution function analysis. Chemical Geology, 429, 1-9. doi:https://doi.org/10.1016/j.chemgeo.2016.03.001

Van Genuchten, C. M., \& Peña, J. (2016b). Sorption selectivity of birnessite particle edges: a d-PDF analysis of $\mathrm{Cd}(\mathrm{ii})$ and $\mathrm{Pb}(\mathrm{ii})$ sorption by $\delta-\mathrm{MnO}_{2}$ and ferrihydrite. Environmental Science: Processes \& Impacts, 18(8), 1030-1041. doi:10.1039/C6EM00136J

Van Genuchten, C. M., Pena, J., Amrose S, E., \& Gadgil, A. J. (2014). Structure of Fe(III) precipitates genberated by the electrolytric dissolution of $\mathrm{Fe}(0)$ in the presence of groundwater ions. Geochimica et Cosmochimica Acta, 127, 285-304.

Villalobos, M. (2015). The Role of Surface Edge Sites in Metal(loid) Sorption to Poorly-Crystalline Birnessites. In X. Feng, W. Li, M. Zhu, \& D. Sparks (Eds.), Advances in the Environmental Biogeochemistry of Manganese Oxides: American Chemical Society.

Villalobos, M., Bargar, J., \& Sposito, G. (2005). Mechanisms of Pb(II) sorption on a biogenic manganese 
oxide. Environmental Science \& Technology, 39(2), 569-576. doi:10.1021/es049434a|10.1021/ es049434s

Voegelin, A., Kaegi, R., Frommer, J., Vantelon, D., \& Hug, S. J. (2010). Effect of phosphate, silicate, and $\mathrm{Ca}$ on $\mathrm{Fe}(\mathrm{III})$-precipitates formed in aerated $\mathrm{Fe}(\mathrm{II})$ - and $\mathrm{As}(\mathrm{III})$-containing water studied by X-ray absorption spectroscopy. Geochimica et Cosmochimica Acta, 74(1), 164-186. doi:https:// doi.org/10.1016/j.gca.2009.09.020

Vries, D., Bertelkamp, C., Schoonenberg Kegel, F., Hofs, B., Dusseldorp, J., Bruins, J. H., . . van den Akker, B. (2017). Iron and manganese removal: Recent advances in modelling treatment efficiency by rapid sand filtration. Water Research, 109, 35-45. doi:10.1016/j.watres.2016.11.032

Webb, S. (2005). SIXPACK: a graphical user interface for XAS analysis using IFEFFIT. Physica Scripta, T115, 1011-1014.

Wyckoff, R. W. G. (1963). Crystal Structures: Wiley. New York, USA 



\section{Chapter 4}

\section{Mobility and redox transformation of arsenic during treatment of artificially recharged groundwater for drinking water production}

This chapter has been published as:

Ahmad, A. Heijnen, L., de Waal, L., Battaglia-Brunet, F., Oorthuizen, W., Pieterse, B., Bhattacharya, P. van der Wal, A. (2020). Mobility and redox transformation of arsenic during treatment of artificially recharged groundwater for drinking water production. Water Research, 115826. 


\section{ABSTRACT}

In this study we investigate opportunities for reducing arsenic (As) to very low levels, below $1 \mu \mathrm{g} / \mathrm{L}$ in produced drinking water from artificially infiltrated groundwater. We observe that rapid sand filtration is the most important treatment step for the oxidation and removal of As at water treatment plants which use artificially recharged groundwater as source. Removal of As is mainly due to As co-precipitation with $\mathrm{Fe}$ (III)(oxyhydr)oxides, which shows higher efficiency in rapid sand filter beds compared to aeration and supernatant storage. This is due to an accelerated oxidation of As(III) to As(V) in the filter bed which may be caused by the manganese oxides and/or As(III) oxidizing bacteria, as both are found in the coating of rapid sand filter media grains by chemical analysis and taxonomic profiling of the bacterial communities. Arsenic removal does not take place in treatment steps such as granular activated carbon filtration, ultrafiltration or slow sand filtration, due to a lack of hydrolyzing iron in their influent and a lack of adsorption affinity between As and the filtration surfaces. Further, we found that As reduction to below $1 \mu \mathrm{g} / \mathrm{L}$ can be effectively achieved at water treatment plants either by treating the influent of rapid sand filters by dosing potassium permanganate in combination with ferric chloride or by treating the effluent of rapid sand filters with ferric chloride dosing only. Finally, we observe that reducing the $\mathrm{pH}$ is an effective measure for increasing As co-precipitation with Fe(III)(oxyhydr)oxides, but only when the oxidized arsenic, $\mathrm{As}(\mathrm{V})$, is the predominant species in water. 


\subsection{INTRODUCTION}

Artificial recharge of groundwater with surface water is a widely used approach for drinking water production. Infiltration of the surface water into underground aquifers often leads to an improved chemical and/or microbiological quality (De Moel et al. 2006). After retention in the underground aquifers, the infiltrated water is recovered and further purified at water treatment plants (WTPs) to meet drinking water quality criteria before supply to consumer houses. Arsenic (As) concentrations in surface water are generally low (Smedley and Kinniburgh 2002), however, high concentrations of As can be introduced into the recharged water from aquifer matrix (Dillon et al. 2019, Fakhreddine et al. 2015). In the Netherlands, trace-level release of As into the recharged water in coastal dunes has been observed which results in elevated As levels in the recovered water (Ahmad et al. 2015, Stuyfzand et al. 2008). Although the As levels in the recovered water are well below the WHO guideline of $10 \mu \mathrm{g} / \mathrm{L}$, recent studies indicate that human health might be affected by As concentrations below the WHO guideline of $10 \mu \mathrm{g} / \mathrm{L}$ (Ahmad and Bhattacharya 2019, Kozisek 2017, Saint-Jacques et al. 2018, Schmidt 2014). Therefore, as a precautionary measure, Dutch drinking water sector aims to supply drinking water with $<1 \mu \mathrm{g} / \mathrm{L}$ As (Ahmad et al. 2020, Van der Wens et al. 2016).

The removal of As from natural anaerobic groundwater, in addition to $\mathrm{Fe}(\mathrm{II}), \mathrm{Mn}$ (II) and $\mathrm{NH}_{4}^{+}$removal, has been extensively investigated in previous studies (Ahmad et al. 2018, Gude et al. 2016, Jessen et al. 2005, Lytle et al. 2007, Lytle et al. 2005). The treatment of natural groundwater is generally simple, consisting of aeration followed by rapid sand filtration whereby As is mainly removed by co-precipitation with $\mathrm{Fe}(\mathrm{III})$ (oxyhydr)oxides which are formed due to oxidation of native $\mathrm{Fe}(\mathrm{II})$ and subsequent hydrolysis (Gude et al. 2016, McNeill and Edwards 1995). The treatment of artificially recharged water, on the other hand, often requires more treatment steps than that of natural groundwater. For example, granular activated carbon (GAC) filtration is often used to remove color, improve the taste of the water and additional disinfection steps may be required to achieve microbiological stability of water (e.g. by ultrafiltration (UF) or ultraviolet (UV) treatment). A complete understanding of the fate of As at low levels during the treatment of artificially recharged dune-water is not yet fully obtained. Nevertheless, this knowledge is required to identify the water quality and operational parameters that can improve As removal at dune-water treatment plants in order to achieve very low As concentration $(<1 \mu \mathrm{g} / \mathrm{L})$ in drinking water. In this study, we develop a detailed understanding of As removal during dunewater treatment and investigate opportunities to reduce As levels in the recharged water to even lower levels below $1 \mu \mathrm{g} / \mathrm{L}$ in produced drinking water. 


\subsection{MATERIALS AND METHODS}

\subsubsection{Water treatment plants}

Two water treatment plants (WTPs) in the Netherlands, Ouddorp (WTP 1) and Katwijk (WTP 2), which rely on artificially recharged dune-water for drinking water production were chosen for this study. For both WTPs, the treatment schemes are shown in Fig 4.1, the influent and effluent quality in Table 4.1 and design and operational details in Table 4.2.
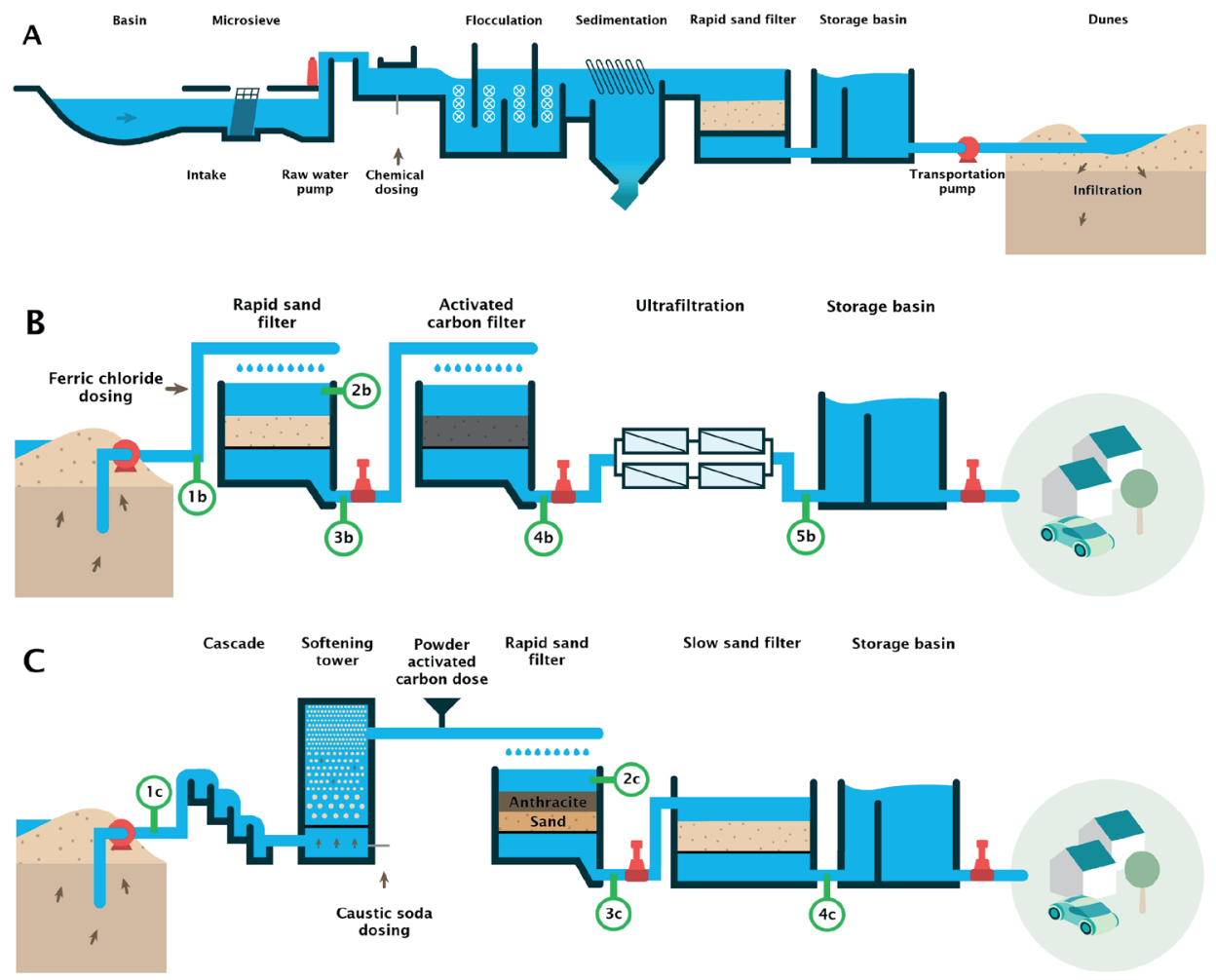

Figure 4.1 Process schemes of (A) general pre-treatment of surface water before dune infiltration applicable to both WTPs. (B) Dune-water treatment at WTP 1. (C) Dune-water treatment at WTP 2. Markings $1 \mathrm{~b}-5 \mathrm{~b}$ and $1 \mathrm{c}-4 \mathrm{c}$ indicate sampling points at WTP 1 and WTP 2 respectively. 


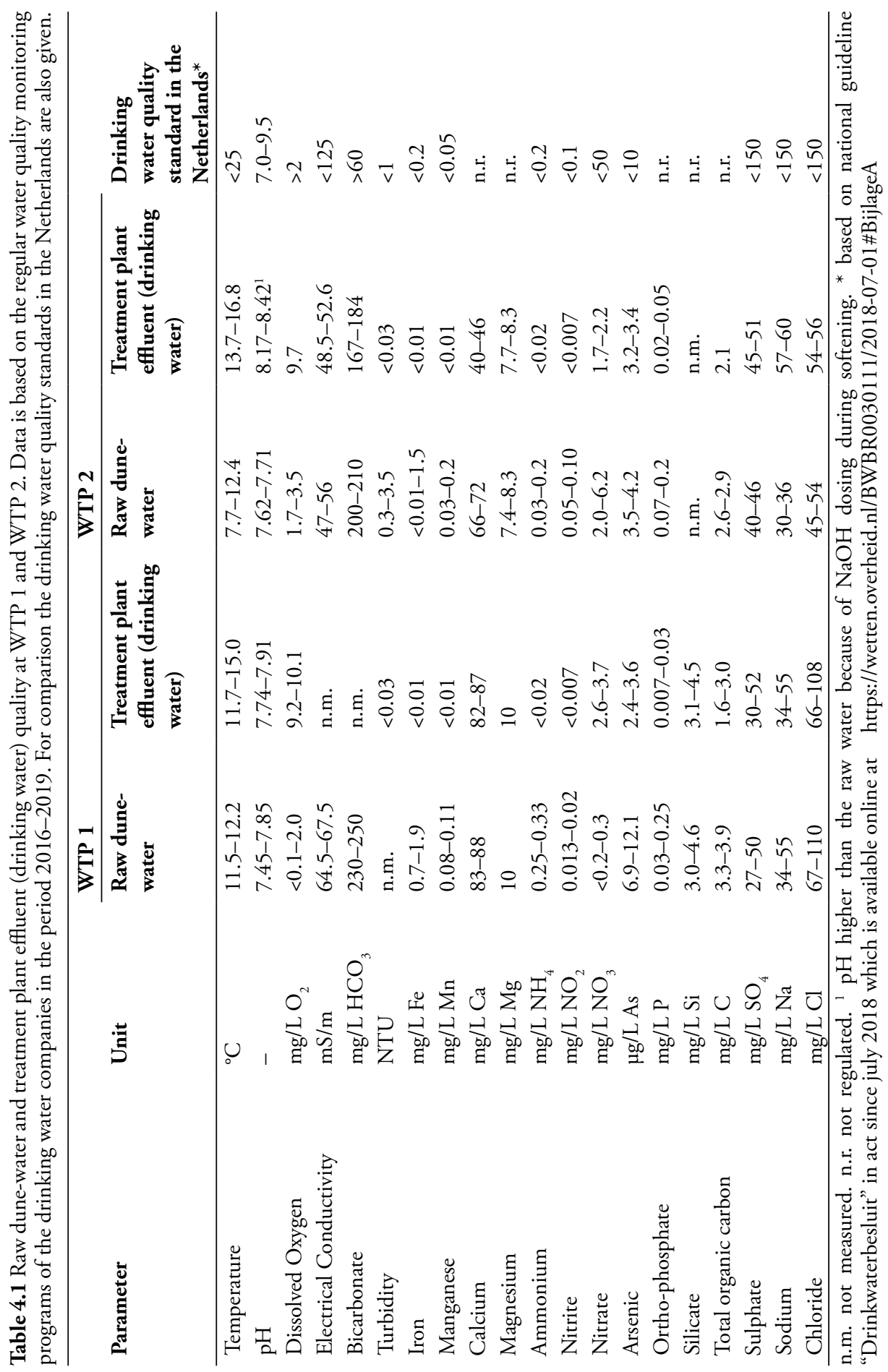


Table 4.2 Process details of WTP 1 and WTP 2. Abbreviations are as follows. RSF: Rapid Sand Filter HRT: Hydraulic Residence Time. GAC: Granular Activated Carbon filter, PAC: Powdered Activated Carbon, UF: Ultrafiltration, SSF: Slow Sand Filter.

\begin{tabular}{|c|c|c|}
\hline & WTP 1 & WTP 2 \\
\hline \multicolumn{3}{|l|}{ Pre-treatment } \\
\hline Surface water source & Rhine-Meuse estuary & River Meuse \\
\hline $\begin{array}{l}\text { Treatment before } \\
\text { dune infiltration }\end{array}$ & $\begin{array}{l}\text { Coagulation-Flocculation-Rapid } \\
\text { sand filtration }\end{array}$ & $\begin{array}{l}\text { Coagulation-Flocculation-Rapid } \\
\text { sand filtration }\end{array}$ \\
\hline Dune storage & 30 days & 60 days \\
\hline \multicolumn{3}{|l|}{ Post-treatment } \\
\hline Dune-water abstraction & $4.8 \mathrm{Mm}^{3} /$ year & $24.8 \mathrm{Mm}^{3} /$ year \\
\hline Aeration & Spray & Cascade \\
\hline Rapid sand filtration & $\begin{array}{l}\text { - Single media RSF with } \\
\text { silica sand } \\
(\mathrm{h}=1.4 \mathrm{~m} ; \mathrm{d}=2.0-3.8 \mathrm{~mm}) \\
\text { - Supernatant level: } 0.35 \mathrm{~m} \\
\text { - HRT of supernatant: } 11 \mathrm{~min} \\
\text { - Filtration velocity: } 2 \mathrm{~m} / \mathrm{h} \\
\text { - HRT in filter bed: } 17 \mathrm{~min} \\
\text { - Filter run time: } 3-4 \text { days }\end{array}$ & $\begin{array}{l}\text { - Double media RSF; } \\
\text { top layer anthracite } \\
\left(\mathrm{h}_{1}=0.5 \mathrm{~m} ; \mathrm{d}_{1}=1.7-2.8 \mathrm{~mm}\right)+ \\
\text { bottom silica sand }\left(\mathrm{h}_{2}=1.0 \mathrm{~m} \text {; }\right. \\
\left.\mathrm{d}_{2}=0.8-1.3 \mathrm{~mm}\right) \\
\text { - Supernatant level: } 1.0 \mathrm{~m} \\
\text { - HRT of supernatant: } 21 \mathrm{~min} \\
\text { - Filtration velocity: } 4 \mathrm{~m} / \mathrm{h} \\
\text { - HRT in filter bed: } 10 \mathrm{~min} \\
\text { - Filter run time: } 7 \text { days }\end{array}$ \\
\hline $\begin{array}{l}\text { Activated carbon } \\
\text { treatment }\end{array}$ & $\begin{array}{l}\text { - GAC filter with media. } \\
\text { Filtrasorb F300 Chemviron } \\
\text { Carbon in Belgium } \\
\text { (h=2.0 m; d=1.5-1.7 mm) } \\
\text { - Supernatant level: } 0.30 \mathrm{~m} \\
\text { - Filtration velocity: } 2.5 \mathrm{~m} / \mathrm{h} \\
\text { - Filter run time Run time: } 10 \\
\text { days }\end{array}$ & $\begin{array}{l}\text { - PAC dosing }(2 \mathrm{mg} / \mathrm{L}) \text { in the feed } \\
\text { of rapid sand filters. NORIT } \\
\text { SA SUPER (Cabot Norit } \\
\text { Netherlands B.V.) }\end{array}$ \\
\hline Polishing filter & $\begin{array}{l}\text { - UF (pore size } 20 \mathrm{~nm} \text { ). } \\
\text { Norit X-flow } \mathrm{S}-225 \\
\text { - Flux } 55 \mathrm{~L} / \mathrm{m}^{2} . \mathrm{h} \text {; Recovery }>98 \% \\
\text { - Operational transmembrane } \\
\text { pressure (TMP) }=0.2 \text { bar } \\
\text { - Hydraulic backwash after } 180 \\
\text { min }\end{array}$ & $\begin{array}{l}\text { - SSF with silica sand } \\
\text { (h=1.0 m; d=0.3-1.2 mm). } \\
\text { - Supernatant level: } 1 \mathrm{~m} \\
\text { - Filtration velocity: } 0.3 \mathrm{~m} / \mathrm{h} \\
\text { - Filter surface is scrapped } 10 \mathrm{~cm} \\
\text { and replenished after every } 2 \\
\text { years }\end{array}$ \\
\hline
\end{tabular}

\subsubsection{Sampling campaigns}

\subsubsection{Water samples}

To understand the removal of As, sampling campaigns were carried out at both WTPs which included collection of water samples before and after each treatment step and 
analysis of the samples for a range of water quality parameters (Table 4.3 and Fig 4.1). Approximately $24 \mathrm{~h}$ before sampling, rotation of the dune-water abstraction wells was stopped and the filters were backwashed to ensure a stable water quality during the sampling campaign. For sampling, each sampling point was flushed for at least $5 \mathrm{~min}$ and subsequently $2 \mathrm{~L}$ of water was collected in an acid-washed glass beaker. From that primary $2 \mathrm{~L}$ sample volume, $200 \mathrm{~mL}$ of water was directly preserved for analysis and another $200 \mathrm{~mL}$ was filtered through $0.45 \mu \mathrm{m}$ filters before preservation (see section 4.2 .7 for conservation and analysis details). The residual sample volume $(1.6 \mathrm{~L})$ was used for the measurements of $\mathrm{pH}$, temperature and dissolved oxygen. For the sampling of dune-water, care was taken to avoid aeration of the samples during collection. The pore water over the height of the rapid sand filters (RSFs) was sampled using the available sampling points (at least $10 \mathrm{~cm}$ apart) in the full-scale filters at an approximate flow rate of $50 \mathrm{~mL} / \mathrm{min}$.

\subsubsection{Sampling of rapid sand filter material}

To determine the chemical composition of the coating on the RSF media, microbial community analysis and to perform batch experiments aimed to gain insights into As adsorption, filter material from the full-scale RSFs of both WTPs were analyzed. For these purposes, approximately $5 \mathrm{~kg}$ of the filter material from the upper $10 \mathrm{~cm}$ of each filter bed was collected with a stainless steel spade directly after backwash and stored in a closed bucket.

\subsubsection{Batch experiments}

A number of batch experiments with influent, supernatant and effluent water of the RSFs were performed to elucidate the effect of different water quality and operational parameters on As removal. Approximately $10 \mathrm{~min}$ before each batch experiment, $20 \mathrm{~L}$ of water was collected from the relevant sample point in the full-scale WTP using a jerry can (Fig 4.1). Further details about the experiments are provided in the following sections.

\subsubsection{Supernatant water experiments}

Arsenic removal as a function of residence time in RSF supernatant was studied with supernatant water samples from both WTPs using a standard jar test apparatus which has been described previously (Ahmad et al. 2018). The supernatant water sample was poured in 4 jars ( $2 \mathrm{~L}$ each jar) of the jar test apparatus. This was considered $t=0$, i.e. start of the experiment. Unfiltered and $0.45 \mu \mathrm{m}$ filtered samples of the initial solution were collected and preserved for analysis. These jars were then stirred at 100 RPM for $60 \mathrm{~min}$. Unfiltered and $0.45 \mu \mathrm{m}$ filtered samples were collected at $\mathrm{t}=15$, 30,45 and 60 min using a sterile syringe while the jars were continuously mixed. Collection of the 60 min samples marked the end of the jar test. 


\subsubsection{Experiments with influent and effluent of rapid sand filters}

To investigate options to achieve a reduction in As concentration to $<1 \mu \mathrm{g} / \mathrm{L}$, batch experiments were performed with the influent and effluent of RSFs. In the experiments with the RSF influent, the impact of different Fe(III) doses (achieved by $\mathrm{FeCl}_{3}$ dosing) alone or after potassium permanganate $\left(\mathrm{KMnO}_{4}\right)$ pre-treatment $(0.5$

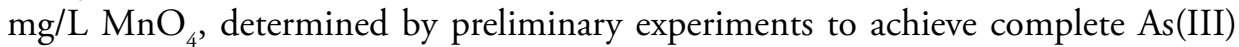
oxidation in all cases) was studied. For the RSF effluent, we investigated only the effect of different Fe(III) doses because of the absence of As(III) in RSF effluent. To investigate the effect of $\mathrm{pH}$ on As removal, experiments were performed at natural $\mathrm{pH}$ (pH 7.8 for WTP 1 and $\mathrm{pH} 8.2$ for WTP 2) and at an experimentally lowered $\mathrm{pH}$ of 7.0 (achieved by $\mathrm{HCl}$ dosing).

First of all, the jars were filled with the influent or the effluent of the RSFs from both WTPs. Subsequently, a predetermined aliquot of $\mathrm{KMnO}_{4}$ and/or $\mathrm{FeCl}_{3}$ was dosed in each jar while the solutions were mixed at $100 \mathrm{RPM}$. In the $\mathrm{KMnO}_{4}-\mathrm{FeCl}_{3}$ dosing experiments, the interval between $\mathrm{KMnO}_{4}$ and $\mathrm{FeCl}_{3}$ doses was kept constant at $2 \mathrm{~min}$. This interval was chosen to ensure that complete oxidation of As(III) to $\mathrm{As}(\mathrm{V})$ had occurred before the Fe(III) dosing (Ahmad et al. 2018). For the pH adjustment, $0.1 \mathrm{M} \mathrm{HCl}$ or $0.1 \mathrm{M} \mathrm{NaOH}$ was used before the addition of $\mathrm{KMnO}_{4}$ and/or $\mathrm{FeCl}_{3}$. Finally, unfiltered and $0.45 \mu \mathrm{m}$ filtered water samples were collected from the jars at $\mathrm{t}=30 \mathrm{~min}$ using a sterile syringe while the jars were continuously mixed. The samples were analyzed for As and Fe concentrations.

\subsubsection{Experiments with rapid sand filter material}

Adsorption and desorption of As by RSF media was studied as a function of $\mathrm{pH}$ (7.0-9.0), As concentration and As speciation. The RSF effluent of each WTP was used as the initial solution in the experiments with RSF media of that WTP. Before experiments, the filter media samples were washed at least 5 times with ultrapure water to remove loose precipitates and afterwards air dried for $24 \mathrm{~h}$ at room temperature. The solid-solution ratio used in the batch experiments was $250 \mathrm{~g} / \mathrm{L}$. All the suspensions were agitated by back-and-forth strokes at a rate of $120 \mathrm{~min}^{-1}$. Sample aliquots of $100 \mathrm{~mL}$ were collected using a sterile syringe with a $30 \mathrm{~cm}$ Teflon tube on the tip were taken at $\mathrm{t}=0$, i.e. directly after solid addition and intermittently until $\mathrm{t}=24 \mathrm{~h}$.

\subsubsection{Chemical characterization of rapid sand filter material}

The RSF media grains from both WTPs were characterized for the chemical composition of the coating to investigate As(III) oxidation in RSFs. For each sample, the coating of $4.0 \mathrm{~g}$ of the filter material was dissolved in $50 \mathrm{~mL}$ ultrapure water and $6.3 \mathrm{~mL}$ concentrated $\mathrm{HNO}_{3}(65 \%)$ followed by heating the suspension at $105^{\circ} \mathrm{C}$ for 
$24 \mathrm{~h}$. After cooling down the solution was filtered through Whatman 589/1 paper filter and analyzed for the elemental composition.

\subsubsection{Microbial community analysis on rapid sand filter material}

To further investigate As(III) oxidation in RSFs, insights into the microbial community in RSFs were obtained by DNA extraction and 16S rRNA taxonomic profiling using next generation sequencing (NGS). To perform the analysis, $40 \mathrm{~mL}$ of ultrapure water (Invitrogen, ThermoFisher scientific) was added to $7.0 \mathrm{~g}$ of freshly collected filter material from each WTP. High energy sonication was used to release the biomass from the filter material as described previously (Magic-Knezev and van der Kooij 2004). The suspended biomass was subsequently concentrated on polycarbonate tracketched membrane filters having a pore size of $0.2 \mu \mathrm{m}$ (Sartorius). The PowerBiofilm Kit (Qiagen) was used for DNA extraction using the protocol described by the manufacturer. The V4 variable region of the $16 \mathrm{~S}$ rRNA genes was amplified using the 515F-806R primer pair. Amplicons were barcoded and the size and concentration was checked on an Agilent Bioanalyser. DNA concentrations were determined using the Qubit fluorescent measurement (Fisher Scientific). Equimolar amplicon concentrations were pooled and sequenced using the Miseq v2 (2x $250 \mathrm{bp}$ ) reagents (Illumina) on an Illumina MiSeq platform. Subsequent processing of sequence data was performed using the MOTHUR pipeline (Schloss et al. 2009). In short, raw paired end sequence reads were assembled, aligned against the Silva alignment db (version 132; (Quast et al. 2013)) and potential chimeric sequences were removed. Finally, Operational Taxonomic Units (OTUs) with 97\% sequence identity were predicted and taxonomic identification of the OTUs until genus-level depth was performed against the Silva taxonomic database, only prokaryote OTUs were retained.

\subsubsection{Chemicals and other apparatus}

All chemicals were reagent grade. $\mathrm{KMnO}_{4}$ was dosed using a $0.03 \mathrm{M} \mathrm{KMnO}_{4}(3.6$ $\mathrm{g} / \mathrm{L} \mathrm{MnO}_{4}$ ) stock solution. It was prepared by dissolving $948 \mathrm{mg}$ of solid $\mathrm{KMnO}_{4}$ (Cairox ${ }^{\circledR}$, Carus Corporation) in $200 \mathrm{~mL}$ ultrapure water directly before the start of batch experiments. $\mathrm{A} \mathrm{FeCl}_{3}$ solution $(2.0 \mathrm{~g} \mathrm{Fe}(\mathrm{III}) / \mathrm{L})$ was used to dose $\mathrm{Fe}(\mathrm{III})$ in water. It was prepared by dissolving $1936 \mathrm{mg}$ solid $\mathrm{FeCl}_{3} \cdot 6 \mathrm{H}_{2} \mathrm{O}$ (J.T. Baker ${ }^{\oplus}$ ) in 200 $\mathrm{mL}$ ultrapure water directly before the start of the batch experiments. For As(III) and As $(\mathrm{V})$ spike, certified solutions (1000 mg As(III) and As(V)/L, Inorganic ventures ${ }^{\oplus}$ ) set in $\mathrm{HCl}$ and $\mathrm{H}_{2} \mathrm{O}$ matrices respectively were used without any dilution. For $\mathrm{pH}$ control during the experiments, $0.1 \mathrm{M} \mathrm{NaOH}$ and $0.1 \mathrm{M} \mathrm{HCl}$ solutions were used. The PP/PE $50 \mathrm{~mL}$ sterile syringes (Sigma-Aldrich) were used for the filtration of water samples. To obtain $0.45 \mu \mathrm{m}$ filtered samples, GE's GD/XP disposable syringe filters were used. 


\subsubsection{Conservation and analysis of water samples}

The determination of arsenic (As), iron (Fe), manganese ( $\mathrm{Mn})$, phosphate $(\mathrm{P})$, calcium $(\mathrm{Ca})$, magnesium $(\mathrm{Mg})$ and silicate $(\mathrm{Si})$ concentrations was carried out by Inductively Coupled Plasma Mass Spectrometry (ICP-MS) (XSERIES 2, Thermo Fisher Scientific). These samples were preserved immediately after sampling by adding $250 \mu \mathrm{L}$ of $10 \%$ ultra-pure nitric acid $\left(\mathrm{HNO}_{3}\right)$. The total organic carbon (TOC) samples were measured by high temperature combustion and infrared detection. After collection the TOC samples were conserved with $0.18 \mathrm{~mL}$ of 9.1 $\mathrm{M} \mathrm{H}_{2} \mathrm{SO}_{4}(59 \% \mathrm{w} / \mathrm{w})$ added in $100 \mathrm{~mL}$ sample. The samples for As speciation were conserved with $2 \mathrm{~mL}$ of $125 \mathrm{mM}$ EDTA added to $100 \mathrm{~mL}$ of the water sample. The As speciation was determined by $\mathrm{IC}-\mathrm{ICP}-\mathrm{MS}$. The $\mathrm{NH}_{4}^{+}$was analysed by a discrete analyser spectrophotometry (Aquakem 250, Thermo Scientific). All samples were stored at $4^{\circ} \mathrm{C}$ before analysis.

\subsection{RESULTS AND DISCUSSION}

\subsubsection{Arsenic removal during dune-water treatment}

Table 4.3 presents results of the sampling campaigns that were carried out at WTP 1 and WTP 2 to gain insights into As removal during dune-water treatment. A fraction of As and Fe concentrations in raw dune-water was removed by $0.45 \mu \mathrm{m}$ filtration at both WTPs which shows that some portion of As and Fe is already co-precipitated in the raw dune-water at both WTPs. During treatment of dune-water, As removal is strongly correlated with Fe removal at both WTPs, attributed to further coprecipitation of As with Fe(III) (oxyhydr)oxides that are formed due to the (oxidative) hydrolysis of natural and dosed Fe in water (latter only at WTP 1). At WTP 1, the effluent of RSF is treated by GAC filtration and UF (Fig 4.1B) and at WTP 2 the effluent of RSF is treated by SSF to produce drinking water (Fig 4.1C). We observe that the As concentrations in RSF effluent were not reduced further by any of these treatment steps (Table 4.3). This can be attributed to the absence of As adsorbing Fe(III)(oxyhydr)oxides in the RSF effluent at both WTPs and low adsorption affinity between $\mathrm{As}(\mathrm{V})$ (the predominant As species in RSF effluent) and the negatively charged surfaces of activated carbon media (Newcombe et al. 1993), UF membranes (Floris et al. 2016, Li et al. 2011) and SSF media (Śmiech et al. 2018).

Complete Mn removal is observed in the RSF bed at both WTPs (Table 4.3). The direct oxidation of $\mathrm{Mn}(\mathrm{II})$ to form solid $\mathrm{MnO}_{\mathrm{x}}$ with oxygen in the relevant $\mathrm{pH}$ range is a kinetically slow process and can explain the occurrence of dissolved $\mathrm{Mn}$ in the supernatant storage at both WTPs (Diem and Stumm 1984, Knocke et al. 1991, Søgaard and Madsen 2013, Van Benschoten et al. 1992). The Mn removal in RSFs 
is attributed to bacteria and surface catalysts on the filter media grains which are known to mediate the $\mathrm{Mn}$ (II) transformation to insoluble $\mathrm{MnO}_{\mathrm{x}}$ (Bruins et al. 2015, Katsoyiannis et al. 2008). The removal of $\mathrm{NH}_{4}^{+}$at both WTPs also occurs in the filter bed, attributed to the biological oxidation (nitrification) executed by different bacterial species in the filter bed (De Moel et al. 2006, De Vet 2011).

Arsenic in the raw dune-water at both WTPs occurs as a combination of As(III) and $\mathrm{As}(\mathrm{V})$ (Table 4.1). No significant differences are observed between the concentrations of aqueous As(III) in the raw dune-water and RSF supernatant at both WTPs. This shows that aeration is not effective in As(III) oxidation to $\mathrm{As}(\mathrm{V})$. Similar slow oxidation kinetics of As(III) in oxygen systems has been observed in previous studies (Frank and Clifford 1986, Ghurye and Clifford 2001).

Irrespective of As speciation in the RSF influent, $\mathrm{As}(\mathrm{V})$ is the predominant species of residual As in the effluent of RSFs at both WTPs which can be attributed to oxidation of aqueous As(III) in RSFs. At WTP 1, the difference between aqueous As and Fe concentrations in the supernatant and the RSF effluent indicates an uptake of $9.7 \mu \mathrm{g}$ As per mg of the precipitated Fe during rapid sand filtration. This is much higher than the As uptake by $\mathrm{Fe}(\mathrm{III})$ precipitates during aeration and supernatant storage (1.3 $\mu \mathrm{g}$ As per $\mathrm{mg} \mathrm{Fe}$ ). The higher As uptake by $\mathrm{Fe}(\mathrm{III})$ precipitates in the filter bed can be explained by the oxidation of aqueous As(III) due to either $\mathrm{MnO}_{\mathrm{x}}$ and/or As-oxidizing bacteria which have been observed both on RSF media grains (see section3.2, 3.3 and 3.4 for further discussion). At WTP 2, As concentration in the effluent of RSF is similar to the aqueous As in the supernatant. This can be explained by the fact that in the supernatant of WTP 2 Fe is already precipitated and therefore further $\mathrm{Fe}(\mathrm{III})$ (oxyhydr)oxide precipitation and corresponding As coprecipitation is not possible in RSF bed at WTP 2. Thus, it can be concluded that a higher As co-precipitation efficiency is achieved when a higher proportion of $\mathrm{Fe}$ is precipitated in RSF bed where at the same time As(III) is oxidized into As(V).

In summary, the sampling campaigns reveal that during dune-water treatment rapid sand filtration is the most important treatment step for the oxidation and removal of As. The efficiency of As co-precipitation with Fe(III)(oxyhydr)oxides is higher in RSF bed compared to aeration and supernatant storage, because of the rapid oxidation of $\mathrm{As}(\mathrm{III})$ to $\mathrm{As}(\mathrm{V})$ in the RSF bed. Therefore As removal can be increased by ensuring that more of the Fe is precipitated in the RSF bed. After the RSF no further As removal is observed due to the low affinity between $\mathrm{As}(\mathrm{V})$ and the negatively charged filtration surfaces of subsequent treatment steps.

\subsubsection{Oxidation and removal of arsenic over filter bed height}

The oxidation and removal of As during rapid sand filtration was further studied by collecting pore water samples over the RSF beds at both WTPs. The results show 


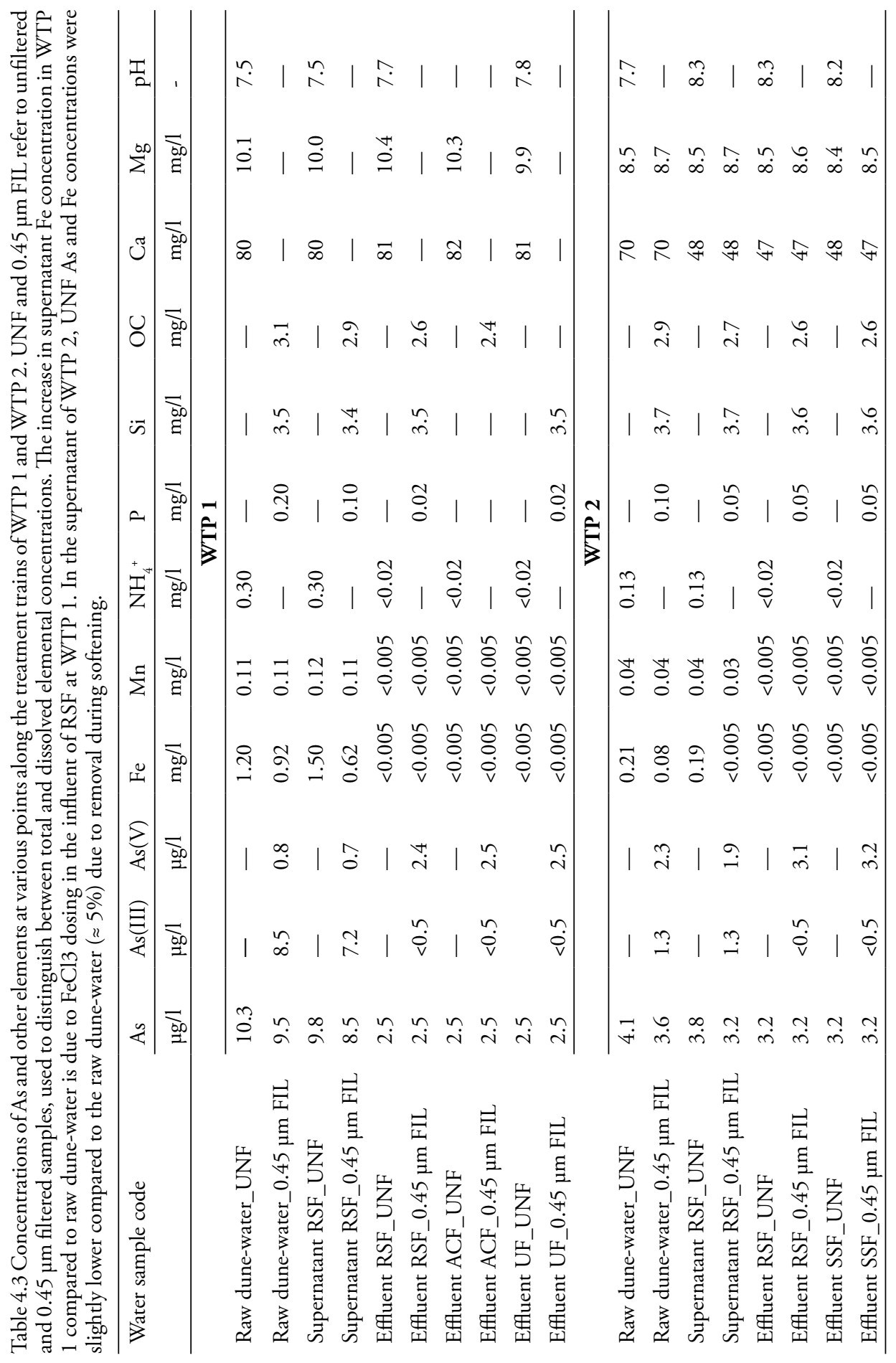


that removal of As, $\mathrm{Fe}, \mathrm{Mn}$ and $\mathrm{NH}_{4}^{+}$predominantly occurs in the upper region (0.5 $\mathrm{m}$ and $0.7 \mathrm{~m}$ for WTP 1 and WTP 2 respectively) of the filter bed at both WTPs (Fig 4.2A and Fig 4.2D). Simultaneously, the oxidation of dissolved As(III) into $\mathrm{As}(\mathrm{V})$ also occurs in the upper $(\sim 0.7 \mathrm{~m})$ region of RSFs (Fig 4.2C and Fig 4.2F). Nevertheless, clear differences are a observed between WTP 1 and WTP 2 for As and Fe co-precipitation profiles. At WTP 1, As and Fe co-precipitation increases with filter depth until $0.5 \mathrm{~m}$ below the filter bed surface, due to the fact that no further $\mathrm{Fe}(\mathrm{III}$ )(oxyhydr)oxides were formed below $0.5 \mathrm{~m}$ onto which As could adsorb (Fig 4.2B). On the other hand, at WTP 2 no further As co-precipitation in the filter bed occurs (Fig 4.2E) because all Fe is already oxidized and precipitated in the supernatant. Thus, though removal and oxidation of As is concentrated in the upper part of the RSFs at both WTPs, As(III) oxidation appears to be independent of Fe oxidation and precipitation.
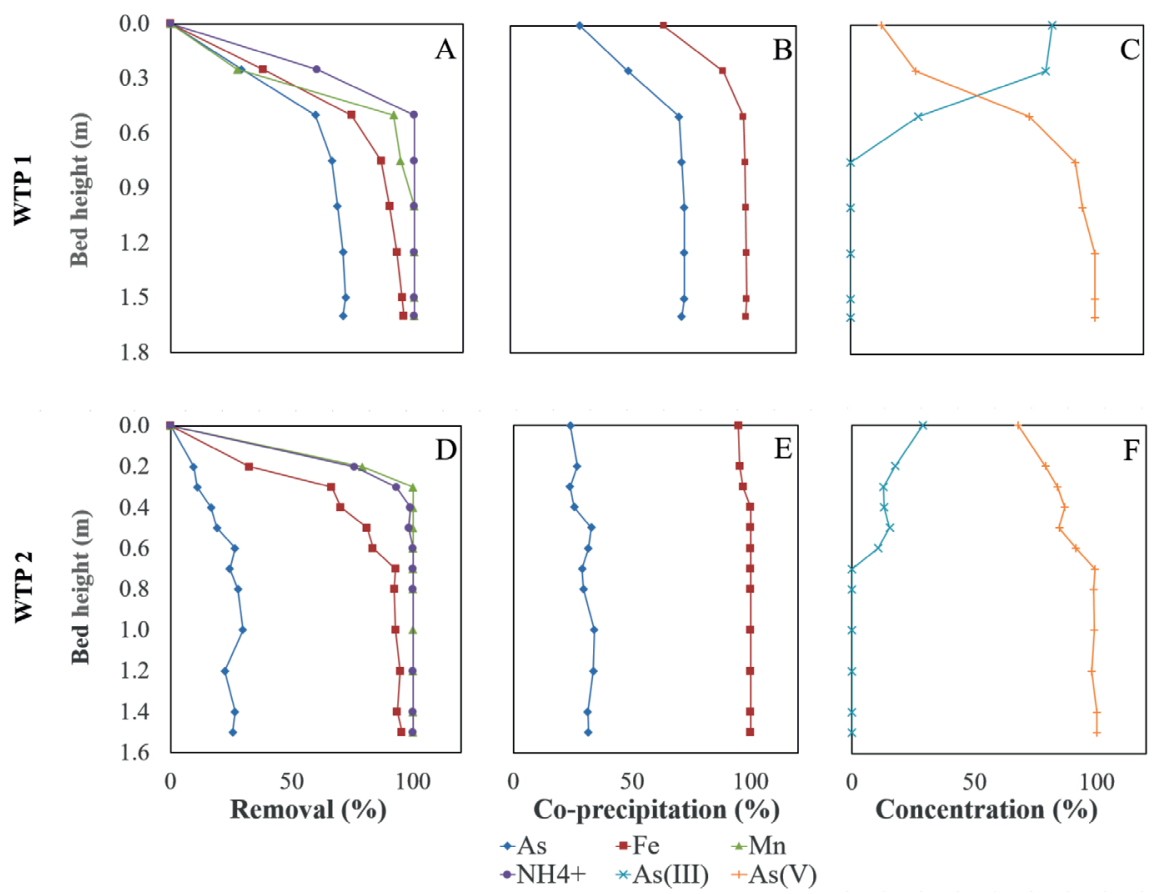

Figure 4.2 Removal of total As, Fe, $\mathrm{Mn}$ and $\mathrm{NH}_{4}^{+}$over rapid sand filter bed height at (A) WTP 1 and (D) WTP 2. Dissolved As(III) and As(V) over rapid sand filter bed height at (C) WTP 1 and (F) WTP 2. To calculate \% of co-precipitated As (or Fe), we first subtracted the dissolved As (or Fe) concentration at each sampling point from the total As (or Fe) concentration in the RSF influent and then we divided this quantity by the total As (or Fe) concentration in the RSF influent. 


\subsubsection{Rapid sand filter media surface coating}

The RSF media at both WTPs have been used for over a decade. To further understand the mechanism of As(III) oxidation in RSFs, the brown-black filter media coating was analyzed to determine the chemical composition (Fig 4.3 and Table 4.4). Besides other elements such as $\mathrm{Ca}, \mathrm{Mg}, \mathrm{Si}, \mathrm{P}$ and As, significant concentrations of Fe and $\mathrm{Mn}$ are found in the coating of both filter media (Table 4.4, Fig S4.1), indicating the presence of Fe and Mn oxides in the filter material coating (Bruins et al. 2015, Gude et al. 2016, 2017, Jessen et al. 2005, Sharma 2001). While the oxidation of As(III) by Fe(III) oxides is known to be slow (Oscarson et al. 1981), the $\mathrm{MnO}_{\mathrm{x}}$ on the filter media grains can rapidly oxidize As(III) into As(V) (Driehaus et al. 1995, Gude et al. 2017, Lafferty et al. 2010, Moore et al. 1990, Oscarson et al. 1983) and therefore the $\mathrm{MnO}_{\mathrm{x}}$ may be responsible for the observed rapid oxidation of As(III) in the RSFs. However, several recent studies argue that As(III) oxidation in RSFs is microbiologically mediated (Crognale et al. 2019, Gude et al. 2018b, c). Therefore, microbial communities in RSFs of both WTPs were analyzed to investigate the presence of As-oxidizing bacteria.
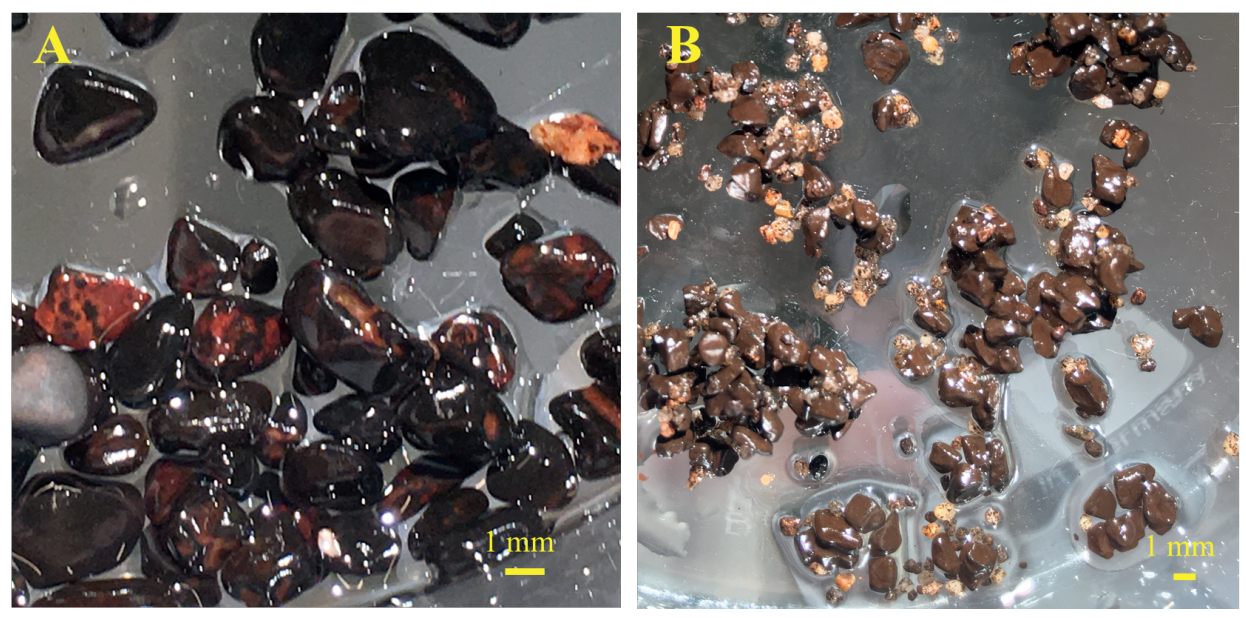

Figure 4.3 Images of rapid sand filter media grains obtained from (A) WTP 1 and (B) WTP 2. Both filter media have been used for over a decade.

\subsubsection{Taxonomic community profiling of $16 \mathrm{~S}$ rRA sequences}

Taxonomic profiling of the bacterial communities was performed on the filter media grains obtained from both WTPs. The overview of the relative proportions of the different bacterial taxa at family and genus level in the microbial communities (Fig 4.4) shows only minor differences between the duplicate samples from the WTPs, 
Table 4.4 Elemental composition of rapid sand filter media coating in $\mathrm{g} / \mathrm{kg} \mathrm{ds}$ (ds: dry solid). The numbers in brackets represent the relative abundance in \%.

\begin{tabular}{lll}
\hline \multirow{2}{*}{ Element } & Filter media grains WTP 1 & Filter media grains WTP 2 \\
\cline { 2 - 3 } & $\mathrm{g} / \mathrm{kg} \mathrm{ds}(\%)$ & $\mathrm{g} / \mathrm{kg} \mathrm{ds}(\%)$ \\
\hline Arsenic $(\mathrm{As})$ & $0.2(<1)$ & $0.004(<1)$ \\
Calcium $(\mathrm{Ca})$ & $29.7(12)$ & $105(84)$ \\
Iron $(\mathrm{Fe})$ & $109(44)$ & $8.0(6)$ \\
Magnesium $(\mathrm{Mg})$ & $5.8(2)$ & $1.6(1)$ \\
Manganese $(\mathrm{Mn})$ & $85.8(34)$ & $6.9(6)$ \\
Silica (Si) & $8.4(3)$ & $2.8(2)$ \\
Phosphorous $(\mathrm{P})$ & $8.4(3)$ & $0.7(<1)$ \\
\hline
\end{tabular}

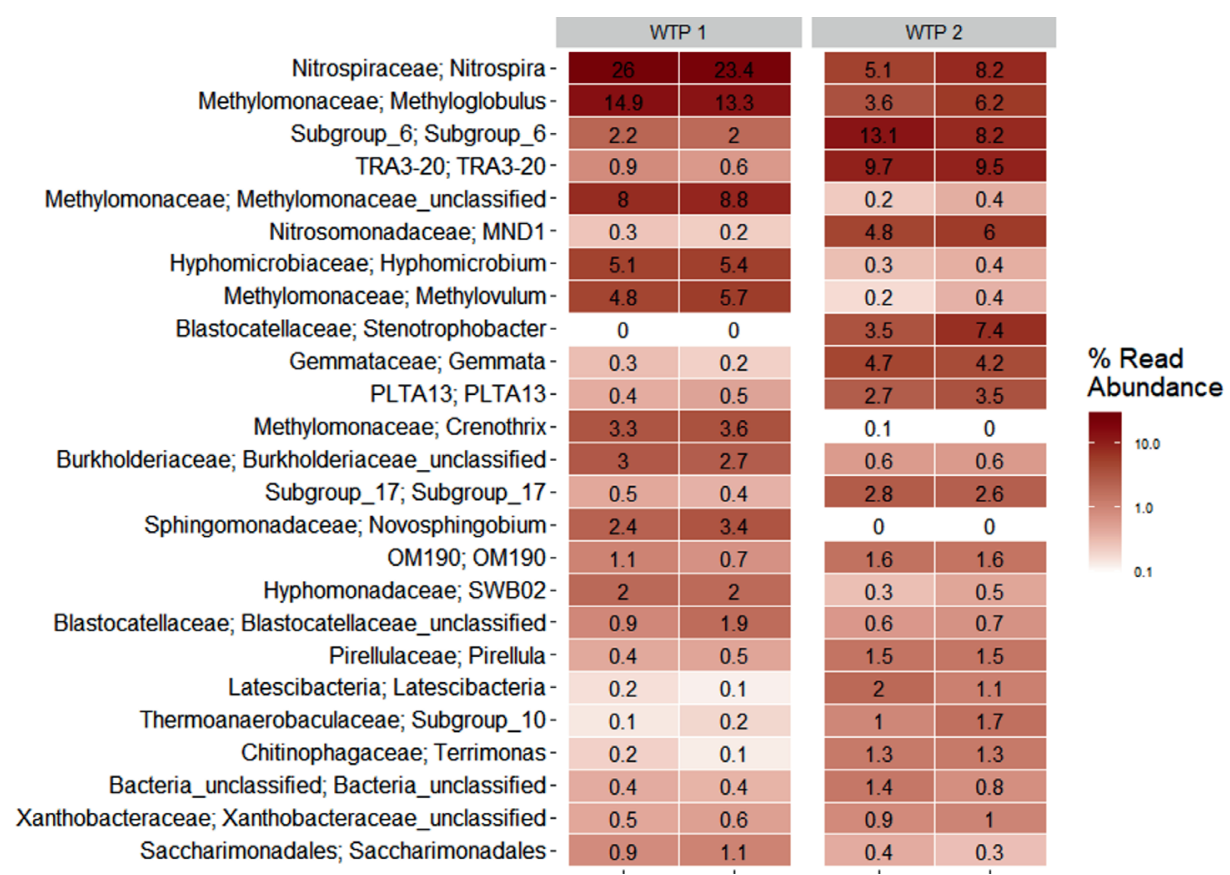

Figure 4.4 Relative abundance of the 25 most abundant bacterial taxa in in the microbial communities of duplicate samples from the WTP 1 and WTP 2 rapid sand filters. The names of the taxa are shown at family and genus level (from left to right separated with semi-colons).

demonstrating limited experimental variation and indicating that representative samples were analyzed. Family level taxonomic profiling indicates that, though much less abundant than the other genera like Nitrospira or Methyloglobulus, bacterial 
sequences related to Xanthobacteraceae and Burkholderiaceae are present on both the filter media. Some strains in these bacterial families carry aioA genes encoding for As(III) oxidase and are thus able to rapidly oxidize As(III) (Heinrich-Salmeron et al. 2011). Therefore, we hypothesize that As(III) oxidation in rapid sand filters during dune-water treatment is biologically mediated by As(III) oxidizing bacteria.

\subsubsection{Arsenic adsorption onto rapid sand filter material}

The chemical characterization of filter media coating (Table 4.4) shows that Fe(III) (oxyhydr)oxides are present on filter media grains which may contribute to As removal in RSFs. To investigate this we performed batch experiments with RSF media and RSF effluent samples of both WTPs under different conditions of $\mathrm{pH}$, initial As concentration and As speciation. The adsorption-desorption distribution coefficient $\left(\mathrm{K}_{\mathrm{d}}\right)$ under different conditions is presented in Fig 4.5 and Fig 4.6. We observe that at natural $\mathrm{pH}$ and As concentrations, $\mathrm{K}_{\mathrm{d}}$ value after a long equilibration time of 1440 $\min (24 \mathrm{~h})$ is very low $\left(\mathrm{K}_{\mathrm{d}} \approx 0\right)$ for both WTPs (Fig 4.5A and Fig 4.5B), indicating absence of any adsorption of As onto RSF media coating even after a prolonged contact of $24 \mathrm{~h}$ (the contact time in RSFs is $17 \mathrm{~min}$ and $10 \mathrm{~min}$ for WTP 1 and WTP 2 respectively, Table 4.2). These results show that the adsorption sites on the $\mathrm{Fe}(\mathrm{III}$ )(oxyhydr)oxides present in filter media coating are already in equilibrium with the As concentration in water and therefore no further As adsorption takes place. Moreover, this result confirms that co-precipitation of As with freshly formed $\mathrm{Fe}$ (III) (oxyhydr)oxides is the main As removal mechanism at both WTPs and filter media coating does not contribute to As removal. At a $\mathrm{pH}$ of 7.0, a positive $\mathrm{K}_{\mathrm{d}}$ is observed for both WTPs, indicating adsorption of As onto the RSF media coating. On the other hand, when $\mathrm{pH}$ is increased to 9.0 , a negative $\mathrm{K}_{\mathrm{d}}$ is observed for both WTPs,

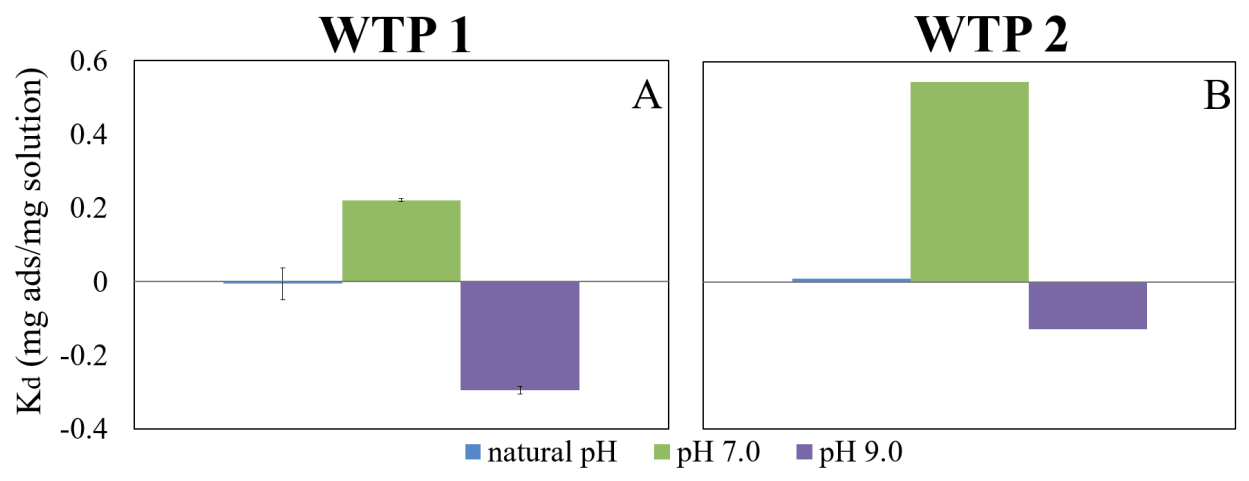

Figure 4.5 Distribution coefficient $\left(\mathrm{K}_{\mathrm{d}}\right)$ at $\mathrm{t}=1440 \mathrm{~min}(24 \mathrm{~h})$ for As adsorption/desorption from RSF effluent to rapid sand filter material of (A) WTP 1 and (B) WTP 2 as a function of $\mathrm{pH}$. natural $\mathrm{pH}$ of RSF effluent for WTP 1 and WTP 2 is 7.8 and 8.2 respectively. 
indicating desorption of As from the RSF media coating. The observed adsorption/ desorption of As as a function of $\mathrm{pH}$ can be explained by the fact that the number of adsorption sites for $\mathrm{As}(\mathrm{V})$ (which is a deprotonated oxyanion) on $\mathrm{Fe}(\mathrm{III})$ (oxyhydr) oxides increases with a decrease in $\mathrm{pH}$ (Dixit and Hering 2003, Kanematsu et al. 2013b, L. Pierce and Moore 1982, Manning et al. 1998, Meng et al. 2000, Qiao et al. 2012, Raven 1998). Thus, from these results it can be concluded that filter media coating does not contribute to As removal and that a reduction in $\mathrm{pH}$ is required to adsorb more As onto the Fe(III) (oxyhydr)oxides.

At natural $\mathrm{pH}$, the adsorption of As onto filter media occurs only in the experiments with higher As concentration (100 $\mu \mathrm{g} / \mathrm{L}$ As(III) or As(V) spike, Fig 4.6A and 4.6B), which can be explained by the fact that the equilibrium loading of an adsorbent increases with an increase in adsorbate/adsorbent ratio until adsorption capacity of the adsorbent is reached (Raven et al. 1998, Wilkie and Hering 1996). We also observe that the adsorption of As is similar when $\mathrm{As}(\mathrm{III})$ or $\mathrm{As}(\mathrm{V})$ is the initial As species (Fig 4.6A and Fig 4.6B). This can be attributed to the oxidation of aqueous As(III) to As(V) before adsorption (Fig S4.2), thus again confirming the accelerating effect of filter media grains on As(III) oxidation.

WTP 1

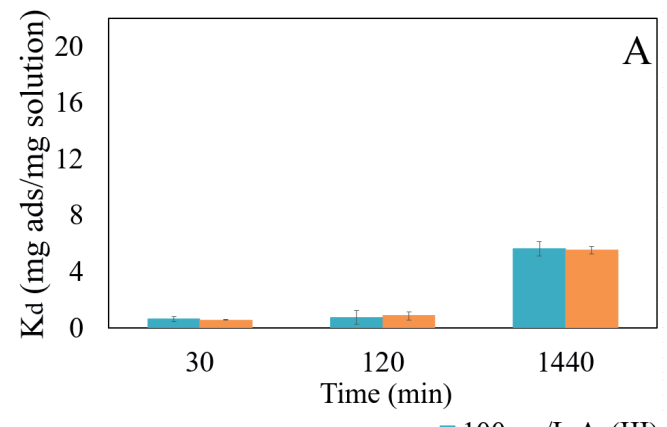

$\because 100 \mu \mathrm{g} / \mathrm{L}$ As(III)
WTP 2

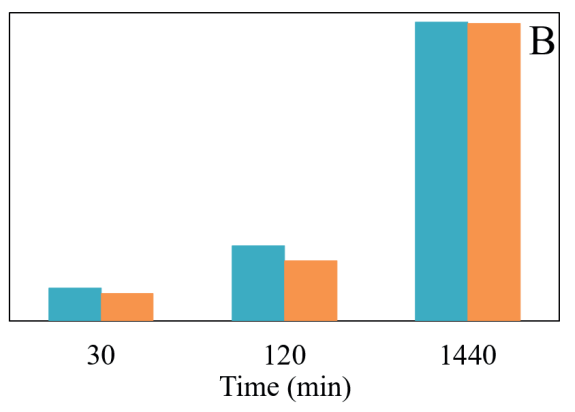

$\square 100 \mu \mathrm{g} / \mathrm{L}$ As(V)

Figure 4.6 Distribution coefficient $\left(\mathrm{K}_{d}\right)$ in function of time for As adsorption/desorption from RSF effluent to rapid sand filter material of (A) WTP 1 and (B) WTP 2 at initial As(III) or As(V) concentration of $100 \mu \mathrm{g} / \mathrm{L}$. The natural $\mathrm{pH}$ of the RSF effluent from WTP 1 and WTP 2 is 7.8 and 8.2 respectively. 


\subsubsection{Impact of extended residence time in supernatant}

Jar tests were performed with the supernatant water samples from the RSFs of both WTPs to investigate whether increasing residence time of water in the supernatant storage could increase As removal. For WTP 1 , As and Fe removal is $\approx 30 \%$ and $\approx$ $70 \%$ respectively at $\mathrm{t}=0$ (Fig $4.7 \mathrm{~A}, \mathrm{t}=0$ refers to the occasion of supernatant sample collection which corresponds to the residence time in the supernatant (Table 4.2). Arsenic and Fe removal increases to $35 \%$ and $85 \%$ respectively at $\mathrm{t}=15 \mathrm{~min}$ and $40 \%$ and $100 \%$ at $\mathrm{t}=30 \mathrm{~min}$ (Fig 4.7A). No further increase in As removal occurs after 30 min because of the absence of freshly formed additional Fe(III) precipitates. The achieved As removal efficiency in this case is much lower compared to As removal at WTP 1 (40\% compared to 75\%), which can be due to the fact that As(III) was not oxidized in the absence of RSF media (Fig 4.7C). Thus, it can be concluded that the extended residence time in the supernatant storage is ineffective for increasing As removal during dune-water treatment. In contrast to WTP 1, no considerable increase in As removal is observed with extended residence time in jar tests with supernatant water of WTP 2 (Fig 4.7B), which can be attributed to the absence of fresh formation of $\mathrm{Fe}(\mathrm{III})$ precipitates.
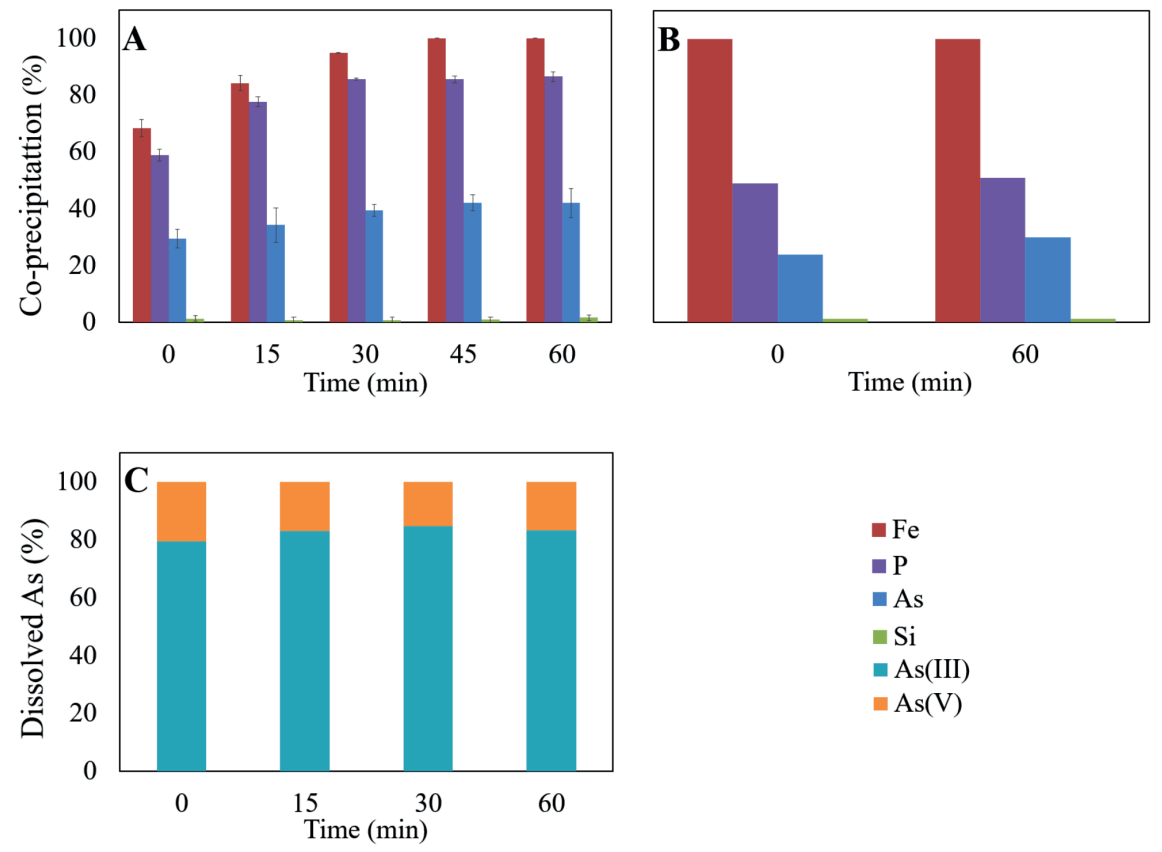

Figure 4.7 Removal of As, Fe, P and Si from the supernatant water by $0.45 \mu \mathrm{m}$ filtration in batch experiments as function of time. (A) WTP 1. (B) WTP 2. (C) the aqueous As speciation in the supernatant water of WTP 1 during the batch experiment. 
We also monitored removal of $\mathrm{P}$ and $\mathrm{Si}$ as a function of extended residence time in the supernatant. The results show that $\mathrm{P}$ is better removed than As, e.g. for WTP 1 removal of $\mathrm{P}$ is $\approx 60 \%$ at $\mathrm{t}=0$ which increases to $75 \%$ and $85 \%$ at $\mathrm{t}=15 \mathrm{~min}$ and 30 min respectively (Fig 4.7A). The relatively lower removal of As compared to $\mathrm{P}$ can be attributed to the lower As concentration in the initial solution and the presence of a major proportion (80-85\%) of aqueous As in the form of As(III) (Fig 4.7C) which is generally outcompeted by $\mathrm{P}$ for the adsorption sites on $\mathrm{Fe}(\mathrm{III})$ precipitates due to lower affinity of As(III) than P (Dixit and Hering 2003, Jain and Loeppert 2000, Stachowicz et al. 2008). The removal of Si remains low ( $<5 \%)$ in all the cases which can be attributed to the uncharged nature of Si species at the given $\mathrm{pH}$ (Kanematsu et al. 2013b, Roberts et al. 2004, Swedlund and Webster 1999).

\subsubsection{Arsenic reduction below $1 \mu \mathrm{g} / \mathrm{L}$ at dune-water treatment plants}

\subsubsection{1 $\mathrm{KMnO}_{4}-\mathrm{FeCl}_{3}$ dosing in $\mathrm{RSF}$ influent}

The sampling campaigns show that As removal during dune-water treatment depends on As speciation, $\mathrm{pH}$ and amount of freshly precipitated Fe(III)(oxyhydr)oxides in water. To explore opportunities for As reduction to very low levels $(<1 \mu \mathrm{g} / \mathrm{L})$, we studied As co-precipitation efficiency in RSF influent as a function of $\mathrm{Fe}$ (III) dosing and $\mathrm{pH}$, with and without pre-treatment with $\mathrm{KMnO}_{4}-$ which is known to rapidly oxidize As(III). At natural pH of RSF influent, the As co-precipitation efficiency increases with Fe(III) dosing for both WTPs (Fig 4.8A and Fig 4.8C), attributed to the availability of a higher amount of $\mathrm{Fe}(\mathrm{III})$ precipitates in water that adsorb more As (Dixit and Hering 2003, Hering et al. 1996a, Qiao et al. 2012, Su and Puls 2001, Wilkie and Hering 1996, Youngran et al. 2007). We further observe that As co-precipitation efficiency corresponding to a residual As concentration of significantly <lower than $1 \mu \mathrm{g} / \mathrm{L}$ is achieved only in case of WTP 2 (at $3 \mathrm{mg} / \mathrm{L}$ $\mathrm{Fe}(\mathrm{III})$ ) and the increase in As co-precipitation is steeper for WTP 2 than WTP 1. This can be explained by the fact that in the RSF influent of WTP 2 the proportion of As $(\mathrm{V})$ is higher than WTP 1 (Table 4.3). Interestingly, in case of WTP 1 when the $\mathrm{pH}$ is lowered to 7.0, the As removal efficiency remains similar to $\mathrm{pH} 7.8$ (Fig $4.8 \mathrm{~A}$ ). Although the amount of precipitated Fe is slightly lower at $\mathrm{pH} 7.0$ compared to results obtained at $\mathrm{pH} 7.8$ (due to the slower oxidation of natural $\mathrm{Fe}(\mathrm{II}$ ) at $\mathrm{pH} 7.0$ (Vries et al. 2017)), we attribute the insignificant impact of $\mathrm{pH}$ on As co-precipitation to the presence of a large proportion of As in the form of As(III) at WTP 1 (Fig S4.3) whose adsorption onto $\mathrm{Fe}(\mathrm{III})$ (oxyhydr)oxides is known to remain unaffected over a pH range of 4-9 (Dixit and Hering 2003, Kanematsu et al. 2013b, Raven 1998, Stachowicz et al. 2006, Stachowicz et al. 2008).

When the co-precipitation of As in RSF influent is studied with $\mathrm{KMnO}_{4}$ pretreatment which facilitates the oxidation of As(III) to As $(\mathrm{V})$, the As removal efficiency 
drastically improves for both WTPs (Fig 4.8B and Fig 4.8D). For WTP 1 (Fig 4.8B), the residual As concentration of $\approx 1 \mu \mathrm{g} / \mathrm{L}(\approx 90 \%)$ is achieved with $\mathrm{Fe}(\mathrm{III})$ dose of only $1.5 \mathrm{mg} / \mathrm{L}$. Similarly for WTP 2 , the residual As concentration of $0.9 \mu \mathrm{g} / \mathrm{L}$ As $(\approx 80 \%$ removal) is achieved with only $0.7 \mathrm{mg} / \mathrm{L} \mathrm{Fe}(\mathrm{III})$ dose (Fig $4.8 \mathrm{D})$. Thus, As reduction to $<1 \mu \mathrm{g} / \mathrm{L}$ can be achieved at a much lower $\mathrm{Fe}(\mathrm{III})$ dose if $\mathrm{KMnO}_{4}$ pretreatment is applied. Oxidizing As(III) to As(V) by dosing a strong oxidant such as $\mathrm{KMnO}_{4}$ has also been previously shown to increase As co-precipitation with $\mathrm{Fe}$ (III) (oxyhydr)oxides (Ahmad et al. 2018, Bissen and Frimmel 2003, Sorlini and Gialdini 2010) because $\mathrm{As}(\mathrm{V})$ adsorbs to Fe(III) precipitates more readily compared to As(III) (Hering et al. 1996a, Hsu et al. 2008, Lakshmanan et al. 2008, Lytle et al. 2005, Qiao et al. 2012). For WTP 1, at the reduced pH 7.0 a residual As concentration of $0.8 \mu \mathrm{g} / \mathrm{L}$ (93\% removal) with $\mathrm{Fe}(\mathrm{III})$ dose of only $0.9 \mathrm{mg} / \mathrm{L}$ is achieved which can be explained by the availability of higher number of adsorption sites for $\mathrm{As}(\mathrm{V})$ of $\mathrm{Fe}(\mathrm{III})$ precipitates at lower $\mathrm{pH}$.
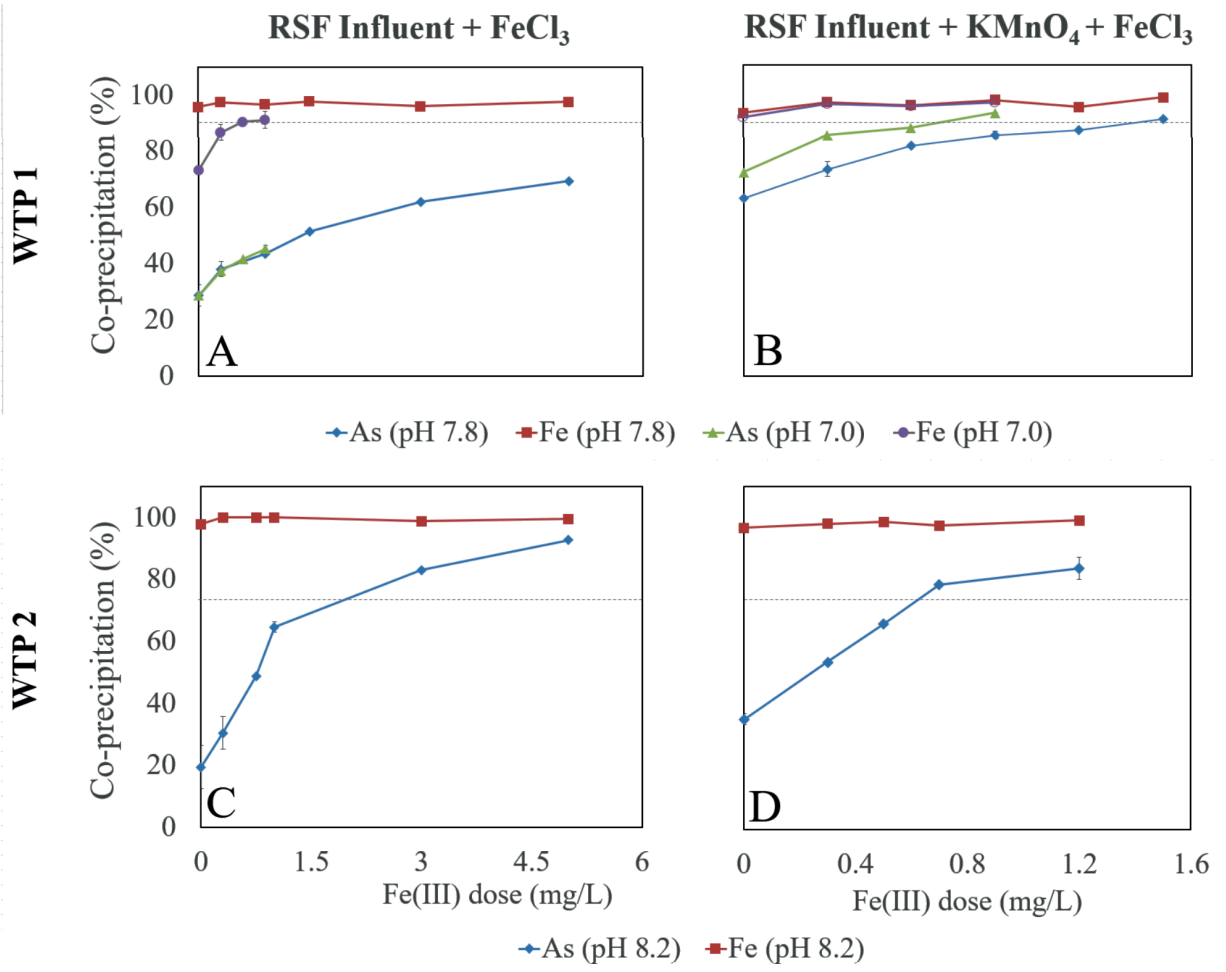

Figure 4.8 Arsenic and Fe removal in batch experiments performed with the influent rapid sand filters at WTP 1 (A and B) and at WTP 2 (C and D). The rapid sand filter influent of WTP 1 and WTP 2 contained 10.8 and $4.1 \mu \mathrm{g} / \mathrm{L}$ As respectively. The dashed line on each figure indicates As removal corresponding to $1 \mu \mathrm{g} / \mathrm{L}$ residual As. 
From these results it can be concluded that the presence of As(III) restricts the efficiency of As co-precipitation with $\mathrm{Fe}(\mathrm{III})$ (oxyhydr)oxides, even with $\mathrm{pH}$ adjustment to lower values. When $\mathrm{As}(\mathrm{III})$ is oxidized to $\mathrm{As}(\mathrm{V})$ by a strong oxidant $\left(\mathrm{KMnO}_{4}\right)$, not only the As uptake by $\mathrm{Fe}(\mathrm{III})$ precipitates increases but also As coprecipitation efficiency can be further increased by lowering the $\mathrm{pH}$. Thus, $\mathrm{KMnO}_{4}-$ $\mathrm{FeCl}_{3}$ dosing in the influent of RSFs is an effective approach for As reduction to $<1$ $\mu \mathrm{g} / \mathrm{L}$.

\subsubsection{2 $\mathrm{FeCl}_{3}$ dosing in $\mathrm{RSF}$ effluent}

The sampling campaigns have revealed that As(III) oxidizes completely into As(V) during rapid sand filtration. We investigated if As reduction to $<1 \mu \mathrm{g} / \mathrm{L}$ can be achieved by $\mathrm{FeCl}_{3}$ dosing in RSF effluent of WTP 1 . The results show that As removal of $\approx 70 \%$ is achieved (reduction from $2.3 \mu \mathrm{g} / \mathrm{L}$ to $0.7 \mu \mathrm{g} / \mathrm{L}$ ) at an $\mathrm{Fe}(\mathrm{III})$ dose of $0.75 \mathrm{mg} / \mathrm{L}$ for WTP 1 (Fig 4.9). Compared to the RSF influent of WTP 1, in which As reduction to $<1 \mu \mathrm{g} / \mathrm{L}$ was not achieved even at an $\mathrm{Fe}(\mathrm{III})$ dose of $5 \mathrm{mg} / \mathrm{L}$ (Fig 4.8A), the As co-precipitation efficiency with Fe(III)(oxyhydr)oxides in RSF effluent is much higher due to the fact that in RSF effluent As is predominantly present in the form of $\mathrm{As}(\mathrm{V})$ which has a higher affinity for $\mathrm{Fe}(\mathrm{III})$ precipitates than $\mathrm{As}(\mathrm{III})$. From this, we conclude that the use of $\mathrm{KMnO}_{4}$ in dune-water treatment can be avoided by treating the RSF effluent by $\mathrm{FeCl}_{3}$ for $\mathrm{As}(\mathrm{V})$ removal instead of treating the RSF influent for $\mathrm{As}(\mathrm{III})$ removal by $\mathrm{KMnO}_{4}-\mathrm{FeCl}_{3}$ dosing.

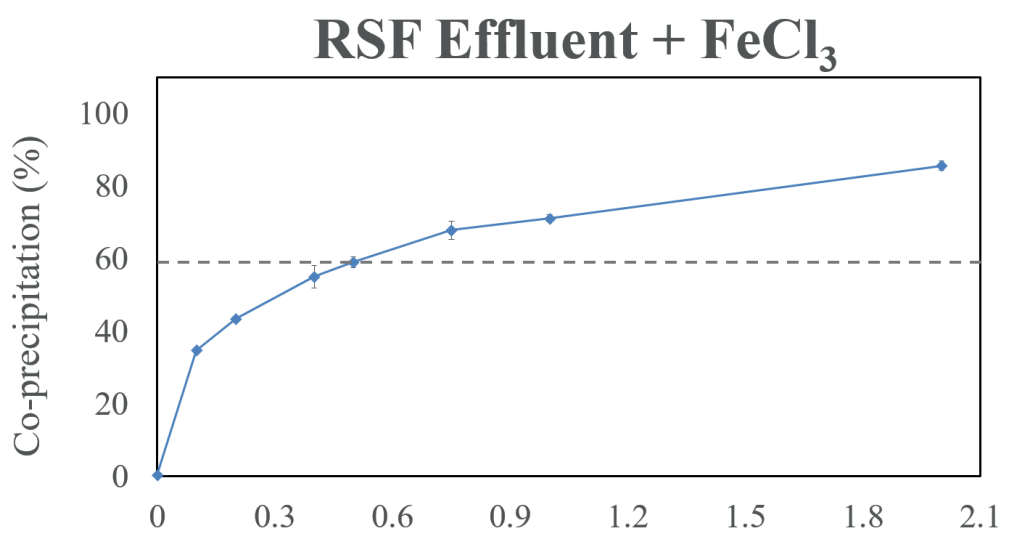

Figure 4.9 Arsenic in batch experiments performed with the effluent of rapid sand filters at WTP 1. The rapid sand filter effluent of WTP 1 contained $2.3 \mu \mathrm{g} / \mathrm{L}$ As respectively. The dashed line indicates \% As removal corresponding to $1 \mu \mathrm{g} / \mathrm{L}$ residual As. 


\subsection{CONCLUSIONS AND IMPLICATIONS FOR WATER TREATMENT}

From this study we conclude that rapid sand filtration is the most important treatment step for oxidation and removal of As during treatment of artificially recharged groundwater. Removal of As is mainly due to As co-precipitation with $\mathrm{Fe}$ (III)(oxyhydr)oxides and the efficiency of As co-precipitation with Fe(III) (oxyhydr) oxides is much higher in rapid sand filter beds compared to the preceding aeration and supernatant storage steps. This is due to an accelerated oxidation of As(III) to $\mathrm{As}(\mathrm{V})$ in the filter beds which may be caused by the manganese oxides and/or As(III) oxidizing bacteria, as both exist in the coating of rapid sand filter media grains. While more research is needed to unravel the actual As(III) oxidation mechanism, we conclude that a higher As co-precipitation efficiency can be achieved during rapid sand filtration by allowing precipitation of $\mathrm{Fe}$ (III) (oxyhydr)oxides to take place inside rapid sand filter bed. Arsenic removal does not take place in treatment steps such as granular activated carbon filtration, ultrafiltration or slow sand filtration, due to a lack of hydrolyzing Fe in their influent and a lack of adsorption affinity between As and the filtration surfaces.

In this study we also investigated opportunities to reduce As levels in produced drinking water. We conclude that As reduction to very low levels $(<1 \mu \mathrm{g} / \mathrm{L})$ at dune-water treatment plants can be achieved either by treating the influent or the effluent of rapid sand filters. Oxidizing As(III) in the rapid sand filter influent by a strong oxidant, $\mathrm{KMnO}_{4}$, results in a significant increase in the amount of As coprecipitated with $\mathrm{Fe}$ and therefore leads to a reduction in the amount of $\mathrm{Fe}$ (III) coagulant required to reduce As to $<1 \mu \mathrm{g} / \mathrm{L}$. On the other hand, the occurrence of As in the form of $\mathrm{As}(\mathrm{V})$ in the RSF effluent can eliminate the need to dose $\mathrm{KMnO}_{4}$ and As reduction to $<1 \mu \mathrm{g} / \mathrm{L}$ can be achieved by low $\mathrm{FeCl}_{3}$ dosing alone. Based on these results, treating the RSF effluent for As removal is expected to be more cost-effective than treating the RSF influent.

We also found in this study that a slight $\mathrm{pH}$ reduction is an effective approach to improve $\mathrm{As}(\mathrm{V})$ co-precipitation with $\mathrm{Fe}(\mathrm{III})$ (oxyhydr)oxides, but it is relatively ineffective for As(III) co-precipitation. Therefore, we suggest $\mathrm{pH}$ reduction only when $\mathrm{As}(\mathrm{V})$ is the predominant As species, e.g. in rapid sand filter influent which has been pre-treated with $\mathrm{KMnO}_{4}$ or in rapid sand filter effluent.

\section{Acknowledgments}

This research is co-financed with PPS-funding from the Topconsortia for Knowledge \& Innovation (TKI's) of the Ministry of Economic Affairs and Climate. AA acknowledges financial support from Evides Waterbedrijf and research support from Evides colleagues including Anthonie Hogendoorn, Peter Vollaard, Bas Schaaf, Bas Hofs, Anna Jeworrek and David de Ridder. The authors want to thank Martijn Eikelboom of Wageningen University, for his support during the sampling campaigns. 


\section{SUPPLEMENTARY INFORMATION}
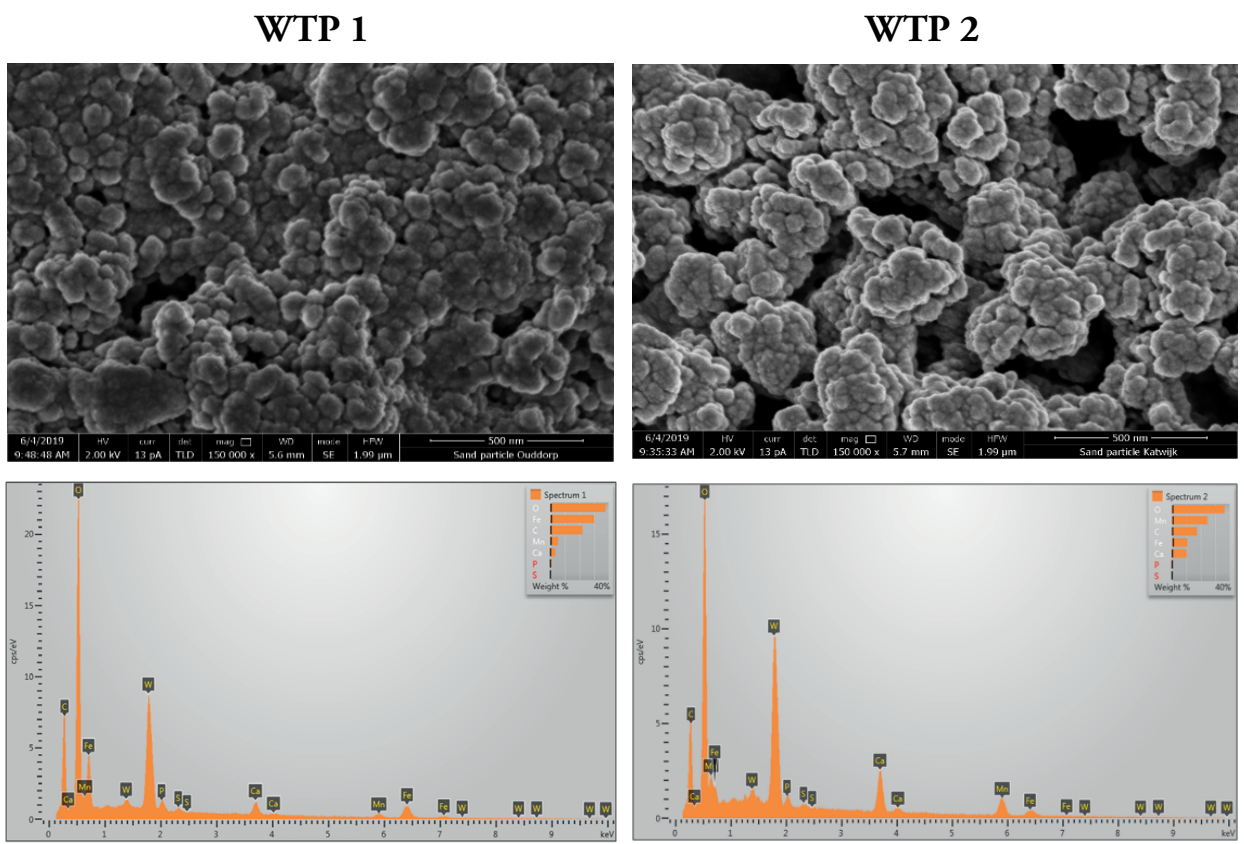

Figure S4.1 SEM-EDX analysis of the surface of RSF media grain. Fe and Mn are clearly detected by EDX in the coating of media from both WTPs. A high degree of surface roughness is observed for both the materials when analyzed with SEM, as well as cracks in the surface coating. Similar physical characteristics of the surface of the RSF media collected from full-scale WTPs were also observed by Jessen et al. (2005) and Sharma (2001). The surface morphologies nevertheless are quite distinct, with the surface relatively smooth and less porous for WTP 1 than WTP 2. Moreover, the surface coating on both the materials consists of agglomerated spherical phases.
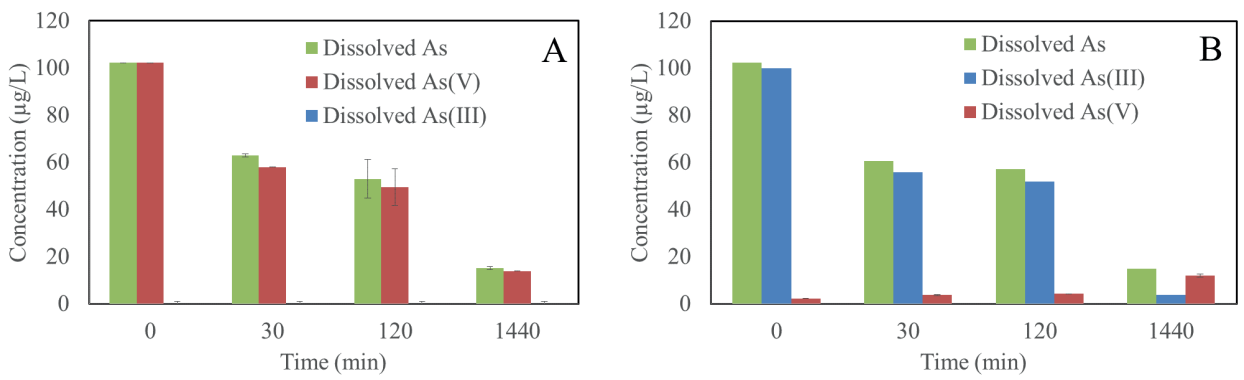

Figure S4.2 Aqueous As species in function of time during batch experiments with WTP 1 filter media and rapid sand filter effluent with (A) $100 \mu \mathrm{g} / \mathrm{L}$ As(V) spike and (B) $100 \mu \mathrm{g} / \mathrm{L}$ As(III) spike. 


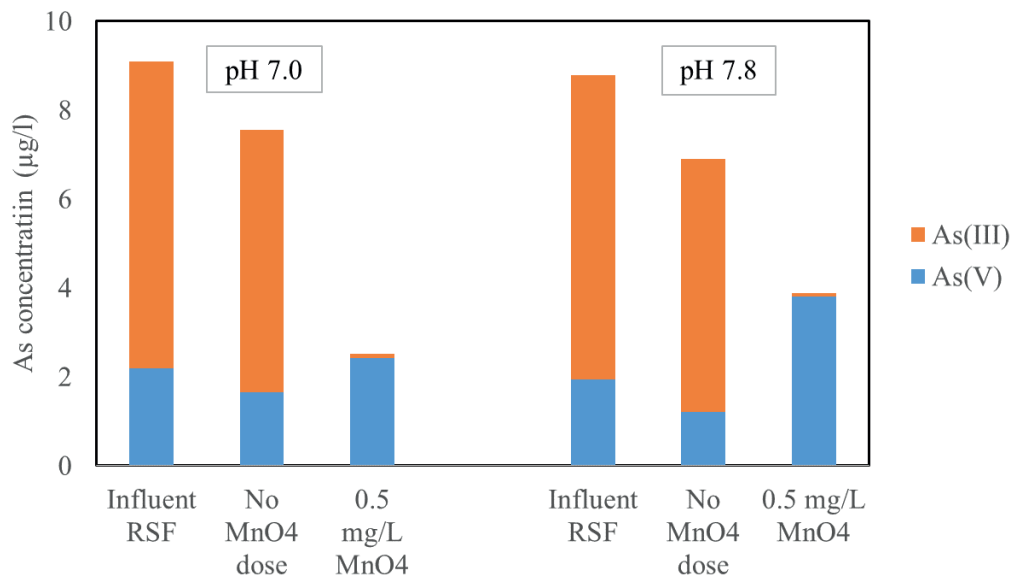

Figure S4.3 Arsenic speciation in the influent of rapid sand filters at WTP 1, without or with treatment with $\mathrm{KMnO}_{4}$. 


\section{REFERENCES}

Ahmad, A., \& Bhattacharya, P. (2019). Arsenic in Drinking Water: Is $10 \mu \mathrm{g} / \mathrm{L}$ a Safe Limit? Current Pollution Report, 5, 1-3. doi:10.1007/s40726-019-0102-7

Ahmad, A., Cornelissen, E., van de Wetering, S., van Dijk, T., Van Genuchten, C., Bundschuh, J., van der Wal, A., Bhattacharya, P. (2018). Arsenite removal in groundwater treatment plants by sequential Permanganate - Ferric treatment. Journal of Water Process Engineering, 26, 221-229. doi:https://doi.org/10.1016/j.jwpe.2018.10.014

Ahmad, A., Kools, S., Schriks, M., Stuyfzand, P., \& Hofs, B. (2015). Arsenic and chromium concentrations and their speciation in groundwater resources and drinking water supply in the Netherlands. KWR BTO Report 2015.017. Nieuwegein, the Netherlands

Ahmad, A., van der Wens, P., Baken, K., de Waal, L., Bhattacharya, P., \& Stuyfzand, P. (2020). Arsenic reduction to $<1 \mu \mathrm{g} / \mathrm{L}$ in Dutch drinking water. Environ Int, 134, 105253. doi:https://doi. org/10.1016/j.envint.2019.105253

Bissen, M., \& Frimmel, F. H. (2003). Arsenic - A review. Part II: Oxidation of arsenic and its removal in water treatment. Acta hydrochimica et hydrobiologica, 31(2), 97-107. doi:10.1002/ aheh.200300485

Bruins, J. H., Petrusevski, B., Slokar, Y. M., Kruithof, J. C., \& Kennedy, M. D. (2015). Manganese removal from groundwater: Characterization of filter media coating. Desalination and Water Treatment, 55(7), 1851-1863. doi:10.1080/19443994.2014.927802

Crognale, S., Casentini, B., Amalfitano, S., Fazi, S., Petruccioli, M., \& Rossetti, S. (2019). Biological As(III) oxidation in biofilters by using native groundwater microorganisms. Sci Total Environ, 651(Pt 1), 93-102. doi:10.1016/j.scitotenv.2018.09.176

De Moel, P. J., Verberk, J. Q. J. C., \& van Dijk, J. C. (2006). Drinking Water: Principles and Practices. Delft, the Netherlands

De Vet, W. (2011). Biological drinking water treatment of anaerobic groundwater in trickling filters. $\mathrm{PhD}$ thesis at Technical University of Delft. Delft, the Netherlands

Diem, D., \& Stumm, W. (1984). Is dissolved $\mathrm{Mn}_{+2}$ being oxidized by O2 in absence of Mn-bacteria and surface catalysts? Geochimica et Cosmochimica Acta, 48, 1571-1573.

Dillon, P., Stuyfzand, P., Grischek, T., Lluria, M., Pyne, R. D. G., Jain, R. C., . . Sapiano, M. (2019). Sixty years of global progress in managed aquifer recharge. Hydrogeology Journal, 27(1), 1-30. doi: $10.1007 / \mathrm{s} 10040-018-1841-\mathrm{z}$

Dixit, S., \& Hering, J. G. (2003). Comparison of arsenic(V) and arsenic(III) sorption onto iron oxide minerals: Implications for arsenic mobility. Environmental Science and Technology, 37(18), 4182-4189. doi:10.1021/es030309t

Driehaus, W., Seith, R., \& Jekel, M. (1995). Oxidation of arsenate(III) with manganese oxides in water treatment. Water Research, 29(1), 297-305

Fakhreddine, S., Dittmar, J., Phipps, D., Dadakis, J., \& Fendorf, S. (2015). Geochemical Triggers of Arsenic Mobilization during Managed Aquifer Recharge. Environmental Science \& Technology, 49(13), 7802-7809. doi:10.1021/acs.est.5b01140

Floris, R., Nijmeijer, K., \& Cornelissen, E. R. (2016). Removal of Aqueous nC60 Fullerene from Water by Low Pressure Membrane Filtration. Water Research, 91, 115-125.

Frank, P., \& Clifford, D. (1986). Arsenic(III) oxidation and removal from drinking water. USEPA Report EPA/600/2-86/021

Ghurye, G., \& Clifford, D. A. (2001). Laboratory Study on the Oxidation of Arsenic III to As V. USEPA Report EPA/600/R-01/021

Gude, J. C. J., Rietveld, L. C., \& van Halem, D. (2016). Fate of low arsenic concentrations during full-scale aeration and rapid filtration. Water Research, 88, 566-574. doi:10.1016/j. 
watres.2015.10.034

Gude, J. C. J., Rietveld, L. C., \& van Halem, D. (2017). As(III) oxidation by MnO2 during groundwater treatment. Water Research, 111, 41-51. doi:10.1016/j.watres.2016.12.041

Gude, J. C. J., Rietveld, L. C., \& van Halem, D. (2018a). As(III) removal in rapid filters: Effect of pH, $\mathrm{Fe}(\mathrm{II}) / \mathrm{Fe}(\mathrm{III})$, filtration velocity and media size. Water Research, 147, 342-349. doi:https://doi. org/10.1016/j.watres.2018.10.005

Gude, J. C. J., Rietveld, L. C., \& van Halem, D. (2018b). Biological As(III) oxidation in rapid sand filters. Journal of Water Process Engineering, 21, 107-115. doi:https://doi.org/10.1016/j. jwpe.2017.12.003

Heinrich-Salmeron, A., Cordi, A., Brochier-Armanet, C., Halter, D., Pagnout, C., Abbaszadehfard, E., . . . Arsène-Ploetze, F. (2011). Unsuspected diversity of arsenite-oxidizing bacteria as revealed by widespread distribution of the aoxB gene in prokaryotes. Applied and environmental microbiology, 77(13), 4685-4692. doi:10.1128/AEM.02884-10

Hering, J. G., Chen, P.-Y., Wilkie, J. A., Elimelech, M., \& Liang, S. (1996). Arsenic removal by ferric chloride. American Water Works Association, 88(4), 155-167.

Hsu, J. C., Lin, C. J., Liao, C. H., \& Chen, S. T. (2008). Removal of As(V) and As(III) by reclaimed iron-oxide coated sands. Journal of Hazardous Materials, 153(1-2), 817-826. doi:10.1016/j. jhazmat.2007.09.031

Jain, A., \& Loeppert, R. H. (2000). Effect of competing anions on the adsorption of arsenate and arsenite by ferrihydrite. Journal of Environmental Quality, 29(5), 1422-1430.

Jessen, S., Larsen, F., Koch, C. B., \& Arvin, E. (2005). Sorption and Desorption of Arsenic to Ferrihydrite in a Sand Filter. Environmental Science \& Technology, 39(20), 8045-8051. doi:10.1021/es050692x

Kanematsu, M., Young, T. M., Fukushi, K., Green, P. G., \& Darby, J. L. (2013). Arsenic(III, V) adsorption on a goethite-based adsorbent in the presence of major co-existing ions: Modeling competitive adsorption consistent with spectroscopic and molecular evidence. Geochimica et Cosmochimica Acta, 106, 404-428. doi:https://doi.org/10.1016/j.gca.2012.09.055

Katsoyiannis, I. A., Zikoudi, A., \& Hug, S. J. (2008). Arsenic removal from groundwaters containing iron, ammonium, manganese and phosphate: A case study from a treatment unit in northern Greece. Desalination, 224(1-3), 330-339. doi:10.1016/j.desal.2007.06.014

Knocke, W. R., Van Benschoten, J. E., Kearney, M. J., Soborski, A. W., \& Reckhow, D. A. (1991). Kinetics of Manganese and Iron Oxidation by Potassium Permanganate and Chlorine Dioxide. AWWA, 83(6), 80-87.

Kozisek, F. (2017). Regulatory aspects of Arsenic in drinking water. In P. Bhattacharya, D. A. Polya, \& D. Jovanovic (Eds.), Best Practice Guide on the Control of Arsenic in Drinking Water. . London, UK: IWA Publishing.

Pierce, M.L., \& Moore, C. (1982). Adsorption of As(III) and As(V) on amorphous iron hydroxide. Water Research, 16, 1247-1253. doi:10.1016/0043-1354(82)90143-9

Lafferty, B. J., Ginder-Vogel, M., Zhu, M., Livi, K. J. T., \& Sparks, D. L. (2010). Arsenite Oxidation by a Poorly Crystalline Manganese-Oxide. 2. Results from X-ray Absorption Spectroscopy and X-ray Diffraction. Environmental Science \& Technology, 44(22), 8467-8472. doi:10.1021/ es102016c

Lakshmanan, D., Clifford, D., \& Samanta, G. (2008). Arsenic Removal by Coagulation with Aluminum, Iron, Titanium, and Zirconium. American Water Works Association, 100(2), 76-88.

Li, S., Heijman, S., Q J C Verberk, J., Le-Clech, P., Lu, J., Kemperman, A., . . Dijk, J. (2011). Fouling control mechanisms of demineralized water backwash: Reduction of charge screening and calcium bridging effects (Vol. 45).

Lytle, D. A., Chen, A. S., Sorg, T. J., Phillips, S., \& French, K. (2007). Microbial As(III) oxidation in water treatment plant filters. American Water Works Association, 99(12), 72-86. 
Lytle, D. A., Sorg, T. J., \& Snoeyink, V. L. (2005). Optimizing arsenic removal during iron removal: Theoretical and practical considerations. Journal of Water Supply: Research and Technology AQUA, 54(8), 545-560.

Magic-Knezev, A., \& van der Kooij, D. (2004). Optimisation and significance of ATP analysis for measuring active biomass in granular activated carbon filters used in water treatment. Water Res, 38(18), 3971-3979. doi:10.1016/j.watres.2004.06.017

S0043-1354(04)00346-X [pii]

Manning, B. A., Fendorf, S. E., \& Goldberg, S. (1998). Surface Structures and Stability of Arsenic(III) on Goethite: Spectroscopic Evidence for Inner-Sphere Complexes. Environmental Science \& Technology, 32(16), 2383-2388. doi:10.1021/es9802201

McNeill, L. S., \& Edwards, M. (1995). Soluble arsenic removal at water treatment plants. American Water Works Association, 87(4), 105-113.

Meng, X., Bang, S., \& Korfiatis, G. P. (2000). Effects of silicate, sulfate, and carbonate on arsenic removal by ferric chloride. Water Research, 34(4), 1255-1261. doi:10.1016/s0043-1354(99)00272-9

Moore, J. N., Walker, J. R., \& Hayes, T. H. (1990). Reaction scheme for the oxidation of As(III) to As $(\mathrm{V})$ by birnessite. The Clay Minerals Society, 38(5), 549-555.

Newcombe, G., Hayes, R., \& Drikas, M. (1993). Granular activated carbon: Importance of surface properties in the adsorption of naturally occurring organics. Colloids and Surfaces A: Physicochemical and Engineering Aspects, 78, 65-71. doi:https://doi.org/10.1016/09277757(93)80311-2

Oscarson, D. W., Huang, P. M., Defosse, C., \& Herbillon, A. (1981). Oxidative power of Mn(IV) and $\mathrm{Fe}(\mathrm{III})$ oxides with respect to As(III) in terrestrial and aquatic environments. Nature, 291(5810), 50-51. doi:10.1038/291050a 0

Oscarson, D. W., Huang, P. M., Liaw, W. K., \& Hammer, U. T. (1983). Kinetics of Oxidation of Arsenite by Various Manganese Dioxides1. Soil Science Society of America Journal, 47, 644-648. doi:10.2136/sssaj1983.03615995004700040007x

Qiao, J., Jiang, Z., Sun, B., Sun, Y., Wang, Q., \& Guan, X. (2012). Arsenate and arsenite removal by $\mathrm{FeCl} 3$ : Effects of $\mathrm{pH}, \mathrm{As} / \mathrm{Fe}$ ratio, initial As concentration and co-existing solutes. Separation and Purification Technology, 92, 106-114. doi:10.1016/j.seppur.2012.03.023

Quast, C., Pruesse, E., Yilmaz, P., Gerken, J., Schweer, T., Yarza, P., . . Glockner, F. O. (2013). The SILVA ribosomal RNA gene database project: improved data processing and web-based tools. Nucleic Acids Res, 41(Database issue), D590-596. doi:10.1093/nar/gks1219

Raven, K. P., Jain, A., \& Loeppert, R. H. (1998). Arsenite and arsenate adsorption on ferrihydrite: Kinetics, equilibrium, and adsorption envelopes. Environmental Science and Technology, 32(3), 344-349. doi:10.1021/es970421p

Roberts, L. C., Hug, S. J., Ruettimann, T., Billah, M. M., Khan, A. W., \& Rahman, M. T. (2004). Arsenic Removal with Iron(II) and Iron(III) in Waters with High Silicate and Phosphate Concentrations. Environmental Science \& Technology, 38(1), 307-315. doi:10.1021/es0343205

Saint-Jacques, N., Brown, P., Nauta, L., Boxall, J., Parker, L., \& Dummer, T. J. B. (2018). Estimating the risk of bladder and kidney cancer from exposure to low-levels of arsenic in drinking water, Nova Scotia, Canada. Environ Int, 110, 95-104. doi:https://doi.org/10.1016/j.envint.2017.10.014

Schloss, P. D., Westcott, S. L., Ryabin, T., Hall, J. R., Hartmann, M., Hollister, E. B., . . W Weber, C. F. (2009). Introducing mothur: open-source, platform-independent, community-supported software for describing and comparing microbial communities. Appl Environ Microbiol, 75(23), 7537-7541. doi:10.1128/aem.01541-09

Schmidt, C. W. (2014). Low-Dose Arsenic: In Search of a Risk Threshold. Environ Health Perspect, 122(5), A131-134.

Sharma, S. K. (2001). Adsorptive Iron Removal from Groundwater. PhD thesis at Wageningen University. Wageningen, the Netherlands. 
Smedley, P. L., \& Kinniburgh, D. G. (2002). A review of the source, behaviour and distribution of arsenic in natural waters. Applied Geochemistry, 17(5), 517-568. doi:10.1016/s0883-2927(02)00018-5

Śmiech, K. M., Tolsma, A., Kovács, T., Dalbosco, V., Yasadi, K., Groendijk, L., \& Agostinho, L. L. F. (2018). Comparing Mixed-Media and Conventional Slow-Sand Filters for Arsenic Removal from Groundwater. Water, 10(2), 119.

Søgaard, E. G., \& Madsen, H. T. (2013). Groundwater Chemistry and Treatment: Application to Danish Waterworks, Water Treatment, . In Elshorbagy, W., \& Chowdhury, R.K. (Eds.) Water Treatment. IntechOpen. doi: 10.5772/54166

Sorlini, S., \& Gialdini, F. (2010). Conventional oxidation treatments for the removal of arsenic with chlorine dioxide, hypochlorite, potassium permanganate and monochloramine. Water Research, 44(19), 5653-5659. doi:10.1016/j.watres.2010.06.032

Stachowicz, M., Hiemstra, T., \& van Riemsdijk, W. H. (2006). Surface speciation of As(III) and As(V) in relation to charge distribution. Journal of Colloid and Interface Science, 302(1), 62-75. doi:https://doi.org/10.1016/j.jcis.2006.06.030

Stachowicz, M., Hiemstra, T., \& van Riemsdijk, W. H. (2008). Multi-competitive interaction of $\mathrm{As}(\mathrm{III})$ and $\mathrm{As}(\mathrm{V})$ oxyanions with $\mathrm{Ca}(2+), \mathrm{Mg}(2+), \mathrm{PO}(3-)(4)$, and $\mathrm{CO}(2-)(3)$ ions on goethite. J Colloid Interface Sci, 320(2), 400-414. doi:10.1016/j.jcis.2008.01.007

Stuyfzand, P., van Rossum, P., \& Mendizabal, I. (2008). Does arsenic, in groundwaters of the compound Rhine-Meuse-Scheldt-Eems delta, menace drinking water supply in the Netherlands? In T. Appelo (Ed.), Arsenic in groundwater - A world problem (pp. 102-125). Netherlands National Committee of the IAH. Utrecht, the Netherlands

Su, C., \& Puls, R. W. (2001). Arsenate and Arsenite Removal by Zerovalent Iron: Effects of Phosphate, Silicate, Carbonate, Borate, Sulfate, Chromate, Molybdate, and Nitrate, Relative to Chloride. Environ. Sci. Technol., 35(22), 4562-4568. doi:10.1021/es010768z

Swedlund, P. J., \& Webster, J. G. (1999). Adsorption and polymerisation of silicic acid on ferrihydrite, and its effect on arsenic adsorption. Water Research, 33(16), 3413-3422. doi:10.1016/S00431354(99)00055-X

Van Benschoten, J. E., Lin, W., \& Knocke, W. R. (1992). Kinetic modeling of manganese(II) oxidation by chlorine dioxide and potassium permanganate. Environmental Science \& Technology, 26(7), 1327-1333. doi:10.1021/es00031a008

Van der Wens, P., Baken, K., Schriks, M., 2016. Arsenic at low concentrations in Dutch drinking water: assessment of removal costs and health benefits. In: Bhattacharya, P., et al., (Eds.), Arsenic Research and Global Sustainability: Proceedings of the Sixth International Congress on Arsenic in the Environment (As2016), June 19-23, 2016, Stockholm, Sweden, CRC Press, pp. 563-564

Vries, D., Bertelkamp, C., Schoonenberg Kegel, F., Hofs, B., Dusseldorp, J., Bruins, J. H., . . . van den Akker, B. (2017). Iron and manganese removal: Recent advances in modelling treatment efficiency by rapid sand filtration. Water Research, 109, 35-45. doi:10.1016/j.watres.2016.11.032

Wilkie, J. A., \& Hering, J. G. (1996). Adsorption of arsenic onto hydrous ferric oxide: effects of adsorbate/adsorbent ratios and co-occurring solutes. Colloids and Surfaces A: Physicochemical and Engineering Aspects, 107, 97-110. doi:http://dx.doi.org/10.1016/0927-7757(95)03368-8

Youngran, J., Fan, M., Van Leeuwen, J., \& Belczyk, J. F. (2007). Effect of competing solutes on $\operatorname{arsenic}(\mathrm{V})$ adsorption using iron and aluminum oxides. Journal of Environmental Sciences, 19(8), 910-919. doi:http://dx.doi.org/10.1016/S1001-0742(07)60151-X 



\section{Chapter 5}

\section{Impact of phosphate, silicate and natural organic matter on the size of Fe(III) precipitates and arsenate co-precipitation efficiency in calcium containing water}

This chapter has been published as:

Ahmad, A., Rutten, S., Eikelboom, M., de Waal, L., Bruning, H., Bhattacharya, P., \& van der Wal, A. (2020). Impact of phosphate, silicate and natural organic matter on the size of $\mathrm{Fe}$ (III) precipitates and arsenate co-precipitation efficiency in calcium containing water. Separation and Purification Technology, 235, 116117. 


\section{ABSTRACT}

Removal of arsenic (As) from water by co-precipitation with Fe(III) (oxyhydr)oxides is a widely used technique in water treatment. Nevertheless, As removal efficiency appears to be sensitive to the composition of the water matrix. The aim of this study was to gain a deeper understanding of the independent and combined effects of silicate $(\mathrm{Si})$, phosphate $(\mathrm{P})$, natural organic matter $(\mathrm{NOM})$ and calcium $(\mathrm{Ca})$ on arsenate $[\mathrm{As}(\mathrm{V})]$ co-precipitation efficiency and the size of $\mathrm{Fe}(\mathrm{III})$ precipitates. We found that, in complex solutions containing multiple solutes and high levels of $\mathrm{Ca}$, (variations in) Si and $\mathrm{P}$ concentrations reduce $\mathrm{As}(\mathrm{V})$ removal to some extent, mainly due to a decreased adsorption of $A s(\mathrm{~V})$ onto $\mathrm{Fe}(\mathrm{III})$ precipitates. On the other hand, NOM concentrations reduced $\mathrm{As}(\mathrm{V})$ removal to a much greater extent, due to possible formation of mobile Fe(III)-NOM complexes that were difficult to remove by filtration. These findings have a great significance for predicting $A s(V)$ removal as a function of seasonal and process-related water quality changes at water treatment plants. 


\subsection{INTRODUCTION}

The co-precipitation of arsenic (As) with in situ produced Fe(III)(oxyhydr)oxides is a widely used As removal technique in water treatment (Fuller et al. 1993, Roberts et al. 2004, Van Genuchten et al. 2012b). Typically, an Fe(III) coagulant such as ferric chloride $\left(\mathrm{FeCl}_{3}\right)$ is dosed which, in contact with water, undergoes hydrolysis to form $\mathrm{Fe}$ (III)(oxyhydr) oxide precipitates. Arsenic adsorbs onto the surface of the Fe(III) precipitates, at an early stage of the precipitate growth (Hering et al. 1996a, Jain et al. 1999, Qiao et al. 2012, Van Genuchten et al. 2012b, Waychunas et al. 1993). The As bearing Fe(III) precipitates (i.e. co-precipitated As and Fe(III)) can be removed from water in a downstream granular media filter or e.g. with low-pressure membranes (Choi and Dempsey 2004, Jessen et al. 2005). At pH relevant to most natural waters (6.5-8.5), As $(\mathrm{V})$ is negatively charged and therefore exhibits a higher affinity for the surface of Fe(III) precipitates than As(III) which is uncharged (Hering et al. 1996a, Lakshmanan et al. 2008, Smedley and Kinniburgh 2002). Therefore, in order to effectively remove As from ground water, oxidizing As(III) to As(V) e.g. by adding potassium permanganate $\left(\mathrm{KMnO}_{4}\right)$ before co-precipitation with $\mathrm{Fe}(\mathrm{III})$ (oxyhydr) oxides has previously been suggested (Ahmad et al. 2018, Guan et al. 2009a, Guan et al. 2009b, Sorlini and Gialdini 2010). Recent studies have shown that As(III) also oxidizes rapidly to $\mathrm{As}(\mathrm{V})$ during rapid sand filtration (RSF), a treatment step commonly used at water treatment plants (Ahmad et al. 2018, Gude et al. 2018a, Gude et al. 2016). Thus, the use of $\mathrm{KMnO}_{4}$ in water treatment can be avoided by treating the RSF effluent for As $(\mathrm{V})$ removal instead of treating the raw groundwater for As(III) removal.

The removal efficiency of $\mathrm{As}(\mathrm{V})$ with $\mathrm{Fe}(\mathrm{III})$ based co-precipitation is sensitive to the ionic composition of water (Davis and Edwards 2017, Dong et al. 2011, Guan et al. 2009a, Guan et al. 2009b, Kanematsu et al. 2010, 2013b, Qiao et al. 2012). The most abundant oxyanions that may impact $\mathrm{As}(\mathrm{V})$ removal are silicate (i.e. $\mathrm{H}_{4} \mathrm{SiO}_{4}$ ) and phosphate (i.e. $\mathrm{H}_{2} \mathrm{PO}_{4}^{-}$or $\mathrm{HPO}_{4}^{2-}$ ), denoted further as $\mathrm{Si}$ and $\mathrm{P}$ respectively (Meng et al. 2000, Van Genuchten et al. 2012b, Van Genuchten et al. 2014b). Moreover, natural organic matter (NOM), especially humic substances (HS), can adversely affect As(V) removal (Davis and Edwards 2017, Sharma et al. 2010, Weng et al. 2009). These inorganic and organic solutes can modify the structure, composition and identity of the Fe(III) precipitates, thereby affecting their size and As(V) uptake behaviour (Sposito 2008, Van Genuchten et al. 2014b). Moreover, these solutes compete with $\mathrm{As}(\mathrm{V})$ for adsorption sites on Fe(III) precipitates (Chen et al. 2014, Dixit and Hering 2003, Hering et al. 1996a, Meng et al. 2000, Su and Puls 2001, Weng et al. 2009, Wilkie and Hering 1996, Youngran et al. 2007). On the other hand, natural waters often contain calcium ions $(\mathrm{Ca})$ which can increase As $(\mathrm{V})$ 
removal during $\mathrm{Fe}$ (III) based co-precipitation. It has been shown that $\mathrm{Ca}$ increases the size of Fe(III) precipitates (Ahmad et al. 2019b) and also results in an increased uptake of $\mathrm{As}(\mathrm{V})$ by $\mathrm{Fe}(\mathrm{III})$ precipitates. Several mechanisms have been proposed to explain these observations, such as neutralization of the $\mathrm{Fe}(\mathrm{III})$ precipitate surface charge by Ca (Wilkie and Hering 1996), suppression of electrostatic repulsion (Masue et al. 2007) and the formation of ternary complexes between $\mathrm{Fe}(\mathrm{III}), \mathrm{As}(\mathrm{V})$ and Ca (Kanematsu et al. 2013b, Van Genuchten et al. 2014a).

So far, most of the available studies have focused on the interactions between $\mathrm{As}(\mathrm{V})$ and $\mathrm{Fe}(\mathrm{III})$ precipitates in simple solutions (Laky and Licskó 2011, Weng et al. 2008, Weng et al. 2009), whereas systematic studies providing understanding of the $\mathrm{As}(\mathrm{V})-\mathrm{Fe}(\mathrm{III})$ interactions in complex multi-solute solutions are lacking. In this study, we aim to provide more insights into the independent and combined effects of $\mathrm{Si}, \mathrm{P}, \mathrm{NOM}$ and $\mathrm{Ca}$ on $\mathrm{As}(\mathrm{V})$ co-precipitation efficiency and the size of formed $\mathrm{Fe}(\mathrm{III})$ precipitates.

\subsection{MATERIALS AND METHODS}

\subsubsection{Chemicals and stock solutions}

All chemicals were reagent grade and used without any purification. The stock solutions of $1.4 \mathrm{~g} / \mathrm{L} \mathrm{FeCl}_{3}, 92.9 \mathrm{~g} / \mathrm{L} \mathrm{NaHCO} 3,15 \mathrm{~g} / \mathrm{L} \mathrm{NaCl}$, and $30.2 \mathrm{~g} / \mathrm{L} \mathrm{Na}_{2} \mathrm{SiO}_{3}$ were prepared by dissolving the required amounts of $\mathrm{FeCl}_{3} \cdot 6 \mathrm{H}_{2} \mathrm{O}$ (CAS: 10025-771, 97\% purity, J.T Baker The Netherlands), $\mathrm{NaHCO}_{3}$ (CAS: 144-55-8, >99\% purity, J.T Baker The Netherlands), NaCl (CAS: 7647-14-5, 99\% purity, J. T Baker The Netherlands) and $\mathrm{Na}_{2} \mathrm{SiO}_{3} \cdot 5 \mathrm{H}_{2} \mathrm{O}$ (CAS: 10213-79-3, 99\% purity, Sigma-Aldrich) respectively in ultrapure water (Mill-Q, produced by purifying distilled water with a Purelab Chorus provided by Veolia). The stock solutions of $73.8 \mathrm{~g} / \mathrm{L} \mathrm{CaCl}_{2}, 39.2$ $\mathrm{g} / \mathrm{L} \mathrm{MgCl}_{2}$ and $0.45 \mathrm{~g} / \mathrm{L} \mathrm{NaH}_{2} \mathrm{PO}_{4}$ were prepared by dissolving $\mathrm{CaCl}_{2}$ anhydrous (CAS: 10043-52-4, 96\% purity, J. T Baker), $\mathrm{MgCl}_{2} \cdot 6 \mathrm{H}_{2} \mathrm{O}$ (CAS: 7791-18-6, 99\% purity, Boom B.V.) and $\mathrm{NaH}_{2} \mathrm{PO}_{4} \cdot \mathrm{H}_{2} \mathrm{O}$ (CAS: 10049-21-5, >98\% purity, J.T Baker) respectively in $0.1 \mathrm{M} \mathrm{HCl}$. The NOM stock solution of $2.4 \mathrm{~g} \mathrm{DOC} / \mathrm{L}$ was prepared by diluting a primary stock (HumVi, Vitens, The Netherlands, $117.4 \mathrm{~g}$ DOC/L) that contained ca. 75\% HS (LC-OCD results given in Table S5.1). Arsenate was dosed using a stock solution of $1.0 \mathrm{~g} / \mathrm{l} \mathrm{As}_{2} \mathrm{O}_{5}$ (CAS: 12044-50-7, 99\% purity, Inorganic Ventures). $\mathrm{pH}$ was adjusted with $0.1 \mathrm{M} \mathrm{HCl}$ or $0.1 \mathrm{M} \mathrm{NaOH}$.

\subsubsection{Composition of initial solutions}

The experiments were performed with synthetic solutions and real RSF effluent collected from WTP Ouddorp (Table 5.1). The ionic composition of the synthetic 
initial solutions in the experiments (Table 5.1) was based on the yearly variation recorded in the quality of RSF effluent at the WTP (Table S5.2). The synthetic initial solution in the reference experiment contained $0.07 \mu \mathrm{M} \mathrm{As}(\mathrm{V})$ and $2000 \mu \mathrm{M} \mathrm{Ca}$, without Si, P and NOM. The rest of the experiments are identified by the ions added in $\mu \mathrm{M}$ to the reference solution (i.e. $70 \mathrm{Si}$ consists of $70 \mu \mathrm{M} \mathrm{Si}, 0.07 \mu \mathrm{M}$ As(III) and $2000 \mu \mathrm{M} \mathrm{Ca}$ ). All the synthetic initial solutions also contained $4.1 \mathrm{mM} \mathrm{NaHCO}_{3}$ and $0.6 \mathrm{mM} \mathrm{NaCl}$ to provide alkalinity and ionic strength.

The experiments with the RSF effluent were performed with and without pretreatment with anion exchange (AEX) or cation exchange (CEX). The objective of the AEX or CEX pre-treatment was to remove the naturally present anions or cations from the RSF effluent before use as initial solution in the experiments, to determine the impact of natural anions or cations on $\mathrm{Fe}(\mathrm{III})$ precipitation and $\mathrm{As}(\mathrm{V})$ removal. The AEX was performed with Amberlite IRA-400 chloride form resin (CAS: 6017739-1) and the CEX was carried out with Amberlite IR120 $\mathrm{N}^{+}$form (CAS: 6844133-8), both were obtained from Sigma Aldrich, Zwijndrecht, The Netherlands. Each IEX treatment was performed in a glass column with a contact time of $1 \mathrm{~min}$ and bed volumes of $78 \mathrm{~cm}^{3}$. The RSF effluent based initial solutions were spiked with As $(V)$ to achieve As concentration of $0.07 \mu \mathrm{mol} / \mathrm{L}$ (i.e. similar As concentration as synthetic initial solutions). The AEX effluent samples were dosed with $\mathrm{NaHCO}_{3}$ to compensate for the loss of $\mathrm{HCO}_{3}$ during AEX.

\subsubsection{Co-precipitation experiments}

The experiments were performed with a $5 \mathrm{~L}$ glass reactor connected to a controller (ez-Control, Applikon Biotechnology) for adjusting, maintaining and logging (BioXpertV2 software) reaction parameters, including the $\mathrm{pH}$, temperature, oxidant supply and stirring speed (Fig 5.1). The reactor was connected to a Mastersizer 2000 (Malvern Instruments, UK). The experiments were carried out at $\mathrm{pH} 7.5$ and $20^{\circ} \mathrm{C}$, with stirring set to $100 \mathrm{rpm}$. The experimental procedure included: (i) preparation of the initial solutions in the reaction vessel and collection of solution samples for control, (ii) dosing the $\mathrm{FeCl}_{3}$ stock to result in $\mathrm{Fe}(\mathrm{III})$ concentration of $5 \mu \mathrm{mol} / \mathrm{L}$ and allowing the hydrolysis and precipitation of Fe(III) to take place while the suspension was stirred at $100 \mathrm{rpm}$ and (iii) collection of suspension samples after 1 and 60 min of $\mathrm{FeCl}_{3}$ addition, which were filtered over $0.45 \mu \mathrm{m}$ filters to determine the removal of $\mathrm{Fe}$ (III) precipitates. The samples were preserved for subsequent analysis. The unfiltered samples without conservation were collected for zeta-potential measurements.

For the filtration of samples Spartan ${ }^{\mathrm{TM}} 30 / 0.45 \mathrm{RC} 0.45 \mu \mathrm{m}$ syringe filters (GE Healthcare, Buckinghamshire, UK) were used. Samples for Fe, As, Si, Ca and P were conserved by addition of $50 \mu \mathrm{L} 60 \% \mathrm{HNO}_{3}$ solution to $50 \mathrm{~mL}$ of sample and stored 
at $4{ }^{\circ} \mathrm{C}$. The removal of As and Fe were determined from the difference between the measured values of the initial solution and final filtered solution. Samples for DOC analysis were conserved by adding $200 \mu \mathrm{L} 40 \% \mathrm{HCl}$ solution to $100 \mathrm{ml}$ of sample which was closed off airtight and stored at $4{ }^{\circ} \mathrm{C}$.

Table 5.1 Nomenclature and composition of the initial solutions used in the co-precipitation experiments. In all the initial solutions the concentration of $\mathrm{Fe}(\mathrm{III})$ was $5 \mu \mathrm{mol} / \mathrm{L}, \mathrm{As}(\mathrm{V})$ was 0.07 $\mu \mathrm{mol} / \mathrm{L}(\mathrm{As} / \mathrm{Fe}=0.014)$ and $\mathrm{HCO}_{3}$ was $4100 \mu \mathrm{mol} / \mathrm{L}$. The concentration of $\mathrm{Ca}$ was $2000 \mu \mathrm{mol} / \mathrm{L}$ in all the synthetic initial solutions $(\mathrm{Ca} / \mathrm{Fe}=400)$. In RSF effluent the concentration of $\mathrm{Ca}$ was $2200 \mu \mathrm{mol} / \mathrm{L}$ $(\mathrm{Ca} / \mathrm{Fe}=440)$, which was reduced to $<1 \mu \mathrm{mol} / \mathrm{L}$ after CIEX treatment.

\begin{tabular}{|c|c|c|c|c|c|c|}
\hline \multirow[t]{2}{*}{ Experiment code } & $\mathrm{Si}$ & $\mathbf{P}$ & DOC & $\mathrm{Si} / \mathrm{Fe}$ & $\mathrm{P} / \mathrm{Fe}$ & $\mathrm{DOC} / \mathrm{Fe}$ \\
\hline & \multicolumn{3}{|c|}{$\mu \mathrm{mol} / \mathrm{L}$} & \multicolumn{3}{|c|}{$\mathrm{mol} / \mathrm{mol}$} \\
\hline Reference (Ref) & - & - & - & - & - & - \\
\hline Si70 & 70 & - & - & 14 & - & - \\
\hline Si 140 & 140 & - & - & 28 & - & - \\
\hline Si 280 & 280 & - & - & 56 & - & - \\
\hline P1.3 & - & 1.3 & - & - & 0.26 & - \\
\hline P2.5 & - & 2.5 & - & - & 0.5 & - \\
\hline P3.3 & - & 3.3 & - & - & 0.66 & - \\
\hline DOC165 & - & - & 165 & - & - & 33 \\
\hline DOC330 & - & - & 330 & - & - & 66 \\
\hline DOC500 & - & - & 500 & - & - & 100 \\
\hline $\mathrm{Si} 0+\mathrm{P} 1.3+\mathrm{DOC} 165$ & - & 1.3 & 165 & - & 0.26 & 33 \\
\hline Si $140+P 1.3+$ DOC165 & 140 & 1.3 & 165 & 28 & 0.26 & 33 \\
\hline Si $280+P 1.3+$ DOC165 & 280 & 1.3 & 165 & 56 & 0.26 & 33 \\
\hline $\mathrm{Si} 140+\mathrm{P} 2.5+\mathrm{DOC} 165$ & 140 & 2.5 & 165 & 28 & 0.5 & 33 \\
\hline Si $140+$ P3.3 + DOC165 & 140 & 3.3 & 165 & 28 & 0.66 & 33 \\
\hline Si $140+\mathrm{P} 1.3+\mathrm{DOC} 330$ & 140 & 1.3 & 330 & 28 & 0.26 & 66 \\
\hline Si $140+$ P1.3 + DOC500 & 140 & 1.3 & 500 & 28 & 0.26 & 100 \\
\hline Effluent $\mathrm{RSF}^{+}$ & 153 & 1.5 & 172 & 31 & 0.3 & 34 \\
\hline Effluent RSF after CIEX ${ }^{+}$ & 159 & 1.5 & 175 & 32 & 0.3 & 35 \\
\hline Effluent RSF after AIEX $^{+*}$ & 160 & $\mathrm{BDL}$ & 59 & 32 & - & 12 \\
\hline
\end{tabular}

${ }^{*} \mathrm{HCO}_{3}$ was compensated after the AIEX treatment. ${ }^{+} \mathrm{As}(\mathrm{V})$ was spiked using a stock solution. BDL: below detection limit $(<0.2 \mu \mathrm{mol} / \mathrm{L})$ 


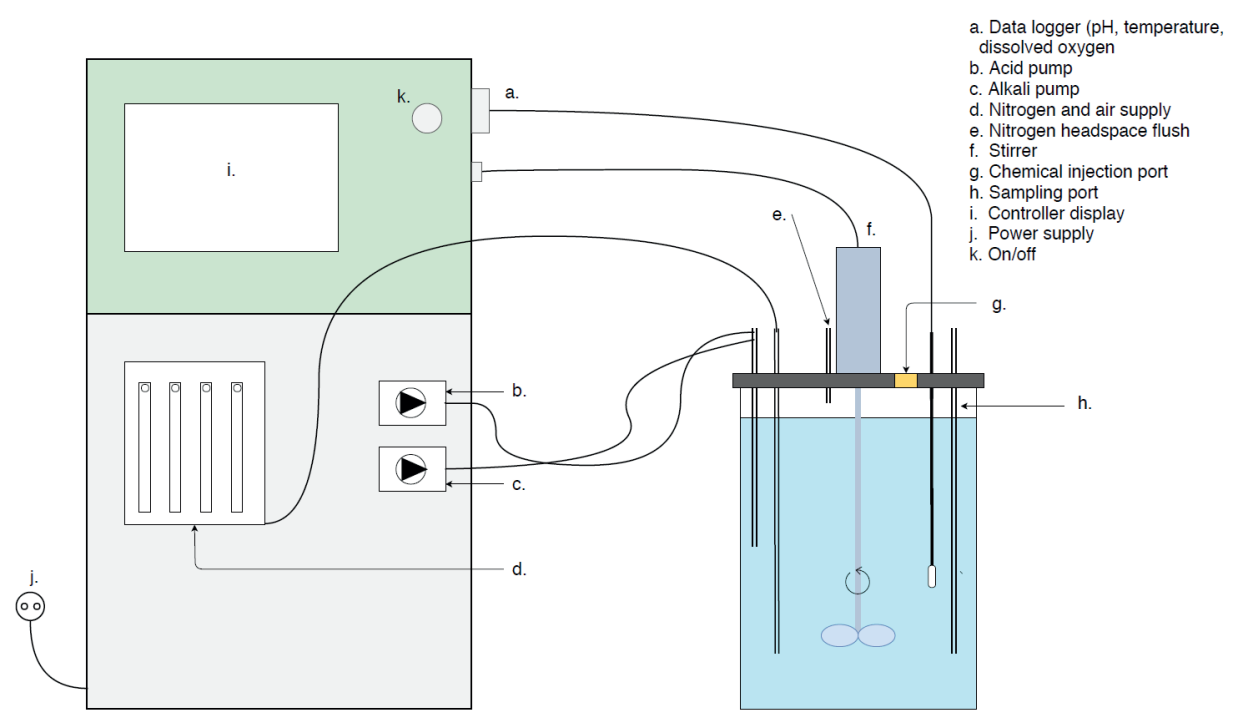

Figure 5.1 A schematic overview of the laboratory setup.

\subsubsection{Wet analysis}

Arsenic, Fe, $\mathrm{Ca}, \mathrm{Si}, \mathrm{P}$ were measured in water samples by Inductively Coupled Plasma Mass Spectrometry (ICP-MS) (XSERIES 2, Thermo Fisher Scientific, The Netherlands). The analysis of DOC in water samples was carried out with a Shimadzu TOC- $\mathrm{V}_{\mathrm{CPH}}$ total organic carbon analyzer (Shimadzu Benelux, 's-Hertogenbosch, The Netherlands). Bicarbonate was analyzed by titration (HI-3811, Hanna Instruments).

\subsubsection{Particle characterization}

The size distribution of the Fe(III) precipitates was determined by Multiple Light Scattering (MLS) using the Mastersizer 2000 (Malvern Instruments, UK). The Mastersizer was connected to the co-precipitation reactor and the suspension was fed to the Mastersizer at a constant flow of $216 \mathrm{~mL} / \mathrm{min}$ through a masterflex easy-load II peristaltic pump combination (Metrohm Nederland B.V. The Netherlands). Malvern instruments mastersizer 2000 software v5.61 recorded the particle size distribution every 20 seconds for $5 \mathrm{~min}$. The Zetasizer Nano-ZS (Malvern Instruments) was used for the determination of electrophoretic mobility and the calculated zeta-potential of the particles in a sub-set of samples collected after 60 min of $\mathrm{FeCl}_{3}$ dosing. Each sample was equilibrated at $20{ }^{\circ} \mathrm{C}$ for 300 seconds prior to measurement which were obtained in duplicate. The measurement cell (cuvette) was rinsed with ethanol and demineralized water and dried between the measurements. 


\subsection{RESULTS AND DISCUSSION}

\subsubsection{Size distribution and filterability of $\mathrm{Fe}(\mathrm{III})$ precipitates}

\subsubsection{Impact of independent $\mathrm{Si}, \mathrm{P}$ and NOM addition}

The particle size distribution and the removal efficiency of Fe(III) precipitates by $0.45 \mu \mathrm{m}$ filters as a function of the composition of initial solution are given in Fig 5.2 and Fig 5.3 respectively. For the reference experiment, (initial solution free of $\mathrm{Si}, \mathrm{P}$ and NOM), the particles were in the range of $5-180 \mu \mathrm{m}$ with the mode of the distribution $\left(\mathrm{d}_{\mathrm{m}}\right.$, the most commonly occurring particle diameter) at $70 \mu \mathrm{m}$. The precipitates in both $1 \mathrm{~min}$ and $60 \mathrm{~min}$ samples were completely removed $(\approx 100 \%$ removal) by $0.45 \mu \mathrm{m}$ filtration, indicating a rapid growth of $\mathrm{Fe}(\mathrm{III})$ precipitates within the first minute. When different concentrations of Si or P were added, the size distribution of the precipitates was not significantly affected, although a slightly lower $\mathrm{d}_{\mathrm{m}}(\approx 50 \mu \mathrm{m})$ was noted for the highest Si and P additions (i.e. $280 \mathrm{Si} \mu \mathrm{M}$ and $3.3 \mu \mathrm{M}$ P) compared to the reference $\left(\mathrm{d}_{\mathrm{m}} \approx 70 \mu \mathrm{m}\right)$. Nevertheless, the precipitates were completely removed by $0.45 \mu \mathrm{m}$ filtration in all the samples, indicating yet effective and rapid Fe(III) precipitate growth. Silicate and P oxyanions bind to the surface of Fe(III) precipitates and result in colloidally stable suspensions (Doelsch et al. 2000, Rose et al. 1996). On the other hand, it has been shown that in the presence of $\mathrm{Ca}$ the electrostatic repulsion between the particles is reduced, which can result in coagulation/destabilization of colloidal Fe(III) precipitates. For example, Mayer and Jarrell (1996) reported an improved flocculation, settling and filtration of $\mathrm{Fe}(\mathrm{III})$ precipitates in a solution where the molar $\mathrm{Si} / \mathrm{Fe}$ and $\mathrm{Ca} / \mathrm{Fe}$ ratio was 4.5 and $20(\mathrm{Ca} / \mathrm{Si}=0.2)$. In our study, however, the molar $\mathrm{Ca} / \mathrm{Si}$ ratio was much higher $(\mathrm{Ca} /$ $\mathrm{Si}=7-28)$ than in the study of Mayer and Jarrell (1996). Similarly, Van Genuchten et al. (2014b), in their co-precipitation experiments, noticed a stabilization of $\mathrm{Fe}(\mathrm{III})$ suspensions at molar $\mathrm{P} / \mathrm{Fe}$ ratio of 0.3 and destabilization of the colloids was observed when $\mathrm{Ca}$ was present at $\mathrm{Ca} / \mathrm{Fe}=2.0(\mathrm{Ca} / \mathrm{P}=6.7)$. In our study the molar $\mathrm{Ca} / \mathrm{P}$ was 570-1300, thus much higher than Van Genuchten et al. (2014b). From this we conclude that in our study the large size and highly efficient removal of the $\mathrm{Fe}(\mathrm{III})$ precipitates by $0.45 \mu \mathrm{m}$ filtration with the independent additions of Si and P was due to the presence of high Ca concentration in water (Table 5.1).

Unlike the Si and P additions, the independent NOM addition altered the particle size distribution significantly (Fig 5.2). The particle size distribution was bimodal for 330 and $500 \mu \mathrm{M}$ DOC additions, consisting of a larger contribution from particles in the non-colloidal size range (i.e. $\geq 1 \mu \mathrm{m}$ ) and a relatively small contribution in the colloidal range $(<1 \mu \mathrm{m})$ for each case (please note that the precipitate size distribution was not measured for $165 \mu \mathrm{M}$ DOC addition). Moreover, Fe(III) removal by 0.45 $\mu \mathrm{m}$ filtration was significantly reduced (e.g. with the additions of 165, 330 and 500 
$\mu \mathrm{M}$ DOC, Fe(III) removal after 60 min was $\approx 40,30$ and $20 \%$ respectively, Fig 5.3). These observations are in agreement with several previous studies which also report a similar reduction in the removal of Fe(III) in the presence NOM. The suppression of Fe(III) removal by filtration has been attributed to formation of soluble Fe(III)NOM complexes, as well as formation of Fe(III)-NOM and Fe(III) (oxyhydr)oxideNOM colloids (Davis and Edwards 2017, Kim et al. 2015, Sharma et al. 2010). These different Fe(III)-NOM complexes, which can be soluble and/or colloidal, are not removed from water by $0.45 \mu \mathrm{m}$ filtration due to their small size. Although the exact mechanism for the decreased Fe(III) removal in the presence of NOM in our study is not clarified, it is proposed that the mobility of Fe(III) was attributed to the formation of soluble and colloidal Fe(III)-NOM complexes.

To study further the precipitate aggregation, we characterized the particles from a subset of experiments by zeta-potential measurements. The zeta-potential of the reference sample was low $(-2.6 \mathrm{mV}$, Table 5.2) and no considerable decrease was observed with the addition of $3.3 \mu \mathrm{MP}(-2.8 \mathrm{mV})$. This is in agreement with the yet effective aggregation of $\mathrm{Fe}(\mathrm{III})$ precipitates with the independent $\mathrm{P}$ addition, similar to the reference. In the presence of $165 \mu \mathrm{M}$ DOC the zeta-potential decreased somewhat $(-11.1 \mathrm{mV})$, which is in agreement with the restricted growth of the precipitates in the presence of $165 \mu \mathrm{M}$ DOC, due to electrostatic repulsion between the $\mathrm{Fe}(\mathrm{III})$ particles.

\subsubsection{Impact of combined $\mathrm{Si}, \mathrm{P}$ and $\mathrm{NOM}$ addition}

In experiments where $\mathrm{P}$ and NOM were present with and without $\mathrm{Si}$, the $\mathrm{Fe}$ (III) particles were smaller than in the reference (Fig 5.2). Moreover, the removal of Fe(III) precipitates by $0.45 \mu \mathrm{m}$ filtration was lower than the reference $(\leq 80 \%$ compared to $100 \%$ ) (Fig 5.3). Minor changes in the precipitate size were observed with the variation in solution composition. For example, in the absence of Si when $1.3 \mu \mathrm{M} \mathrm{P}$ was present with $165 \mu \mathrm{M}$ DOC, particles in the range of $1.4-70 \mu \mathrm{m}$ were observed with $\mathrm{d}_{\mathrm{m}}$ of $\approx 20 \mu \mathrm{m}$. The addition of 140 to $280 \mu \mathrm{M}$ Si in this solution resulted in a very slight decrease in the removal of Fe(III) precipitates by $0.45 \mu \mathrm{m}$ filtration $(\approx 10 \%)$. Moreover, the precipitate size range was similar to the solution that did not contain Si (i.e. $1.3 \mu \mathrm{M} \mathrm{P}$ and $165 \mu \mathrm{M}$ DOC). Similarly, the precipitate size distribution and the removal efficiency of Fe(III) was not significantly affected in the experiments where the concentration of $\mathrm{P}$ was increased from 1.3 to $3.3 \mu \mathrm{M}$, keeping $\mathrm{Si}$ and DOC fixed at 140 and $165 \mu \mathrm{M}$ respectively. Thus, the studied variations in Si and $\mathrm{P}$ concentrations with fixed concentrations of NOM and $\mathrm{Ca}$ in water, did not severely impact the size of $\mathrm{Fe}(\mathrm{III})$ precipitates.

Compared to when only NOM (165 $\mu \mathrm{M}$ DOC) was present, the Fe(III) removal by $0.45 \mu \mathrm{m}$ filtration was higher when NOM was present with P and Si (Fig 5.3). 

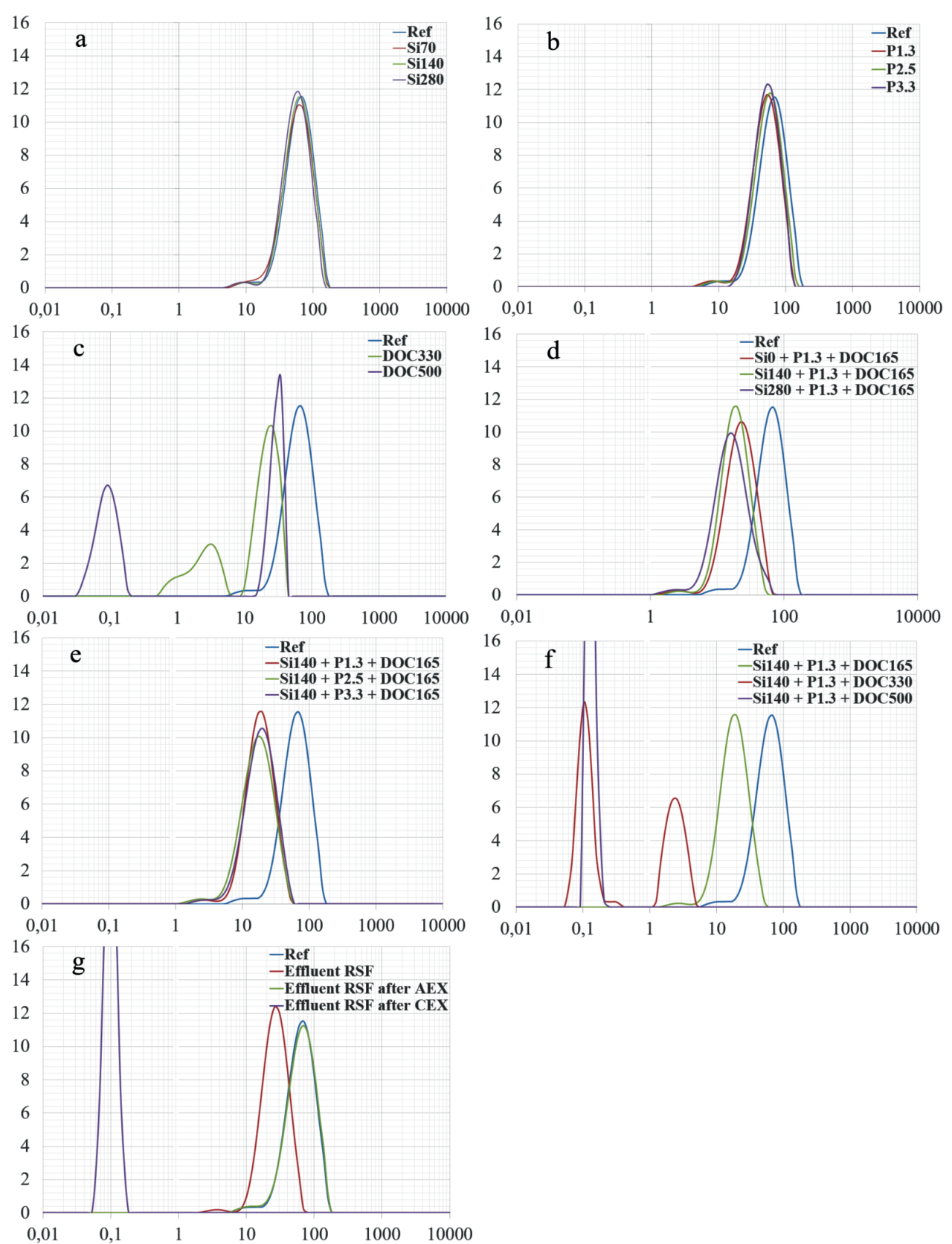

Figure 5.2 Independent and combined effects of silicate, phosphate and natural organic matter on $\mathrm{Fe}(\mathrm{III})$ precipitate size. X-axis: particle size $(\mu \mathrm{m})$. Y-axis: abundance (\%). Ref refers to the reference experiment performed in the absence of $\mathrm{Si}, \mathrm{P}$ and NOM. In (Figure 5.2f \& $5.2 \mathrm{~g}$ ) complete $\mathrm{Y}$-axis is not shown. In Figure 5.2f the abundance peak of $S i 140+P 1.3+D O C 500$ is at $35.4 \%$. In Figure $5.2 \mathrm{~g}$ the abundance peak of Effluent RSF after CEX is at $25.5 \%$. 
Also, the zeta-potential with the independent NOM addition was $-11.1 \mathrm{mV}$, which was lower relative to the experiments in which NOM was present with Si and P (Table 5.2). The higher zeta-potential obviously is in agreement with the large size and higher removal of Fe(III) precipitates in the complex NOM bearing solutions (Fig 5.2 and Fig 5.3). However, the exact mechanism responsible for the higher zetapotential when NOM co-occurred with $\mathrm{Si}$ and P is not clarified. Nevertheless, we note that the interactions between NOM and Fe(III) in the absence and presence of $\mathrm{P}$ and Si appear to follow different mechanisms.

When the concentration of NOM was increased (from 165 to $330 \mu \mathrm{M}$ DOC), keeping Si and P (140 and $1.3 \mu \mathrm{M}$ respectively) fixed, the Fe(III) removal by 0.45 $\mu \mathrm{m}$ filtration was reduced significantly. A further increase in NOM concentration (to $500 \mu \mathrm{M}$ DOC) resulted in no Fe(III) removal (Fig 5.3). This increasing mobility of $\mathrm{Fe}(\mathrm{III})$ may be attributed to the formation of soluble and colloidal Fe(III) - NOM complexes that were not removed with the $0.45 \mu \mathrm{m}$ membrane filters. The presence of colloidal particles is also confirmed with the particle size distribution measurements (Fig 5.2). However, the identity of the particles (Fe(III)-NOM or Fe(III)(oxyhydr) oxide-NOM colloids) was not investigated. Moreover, the properties of the soluble fraction of Fe(III)-NOM complexes remain unclear. Nevertheless, our results indicate that the variations in NOM concentrations, in solution with fixed concentrations of $\mathrm{Si}, \mathrm{P}$ and $\mathrm{Ca}$ exhibit a strong impact on the size of Fe(III) precipitates and their removal.

\subsubsection{Impact of removing anions and cations from RSF effluent}

In the RSF effluent, the $\mathrm{Fe}(\mathrm{III})$ precipitate size ranged from $2-80 \mu \mathrm{m}$ with the $\mathrm{d}_{\mathrm{m}}$ at $25 \mu \mathrm{m}$ (Fig 5.2). The Fe(III) precipitates were effectively removed ( $\approx 95 \%$ removal) by $0.45 \mu \mathrm{m}$ filtration in both $1 \mathrm{~min}$ and $60 \mathrm{~min}$ samples (Fig 5.3). The removal of $\mathrm{Fe}(\mathrm{III})$ precipitates in the RSF effluent was slightly higher than the synthetic solutions that contained Si, P and NOM in comparable concentrations. This can be explained by a higher charge neutralization due to the higher $\mathrm{Ca}$ concentration and an additional presence of $\approx 10 \mathrm{mg} / \mathrm{L}$ magnesium $(\mathrm{Mg})$ in the RSF effluent compared to the synthetic solutions (Table S5.2). When the RSF effluent was pretreated with AEX, P and a major portion of the NOM (negatively charged) was removed from water (Table 5.1). The AEX did not remove $\mathrm{Si}\left(\mathrm{H}_{4} \mathrm{SiO}_{4}\right)$ because it is not disassociated at the given $\mathrm{pH}$ of 7.5 (de Ridder et al. 2018). Interestingly, the precipitate size distribution was quite similar to the reference (i.e. in the absence of $\mathrm{Si}, \mathrm{P}, \mathrm{NOM}$ ) and in solutions where we added $\mathrm{Si}$. The removal efficiency of Fe(III) in the AEX treated RSF effluent was clearly higher than the untreated RSF effluent (Fig 5.3) which can be attributed to a lower charge repulsion between the particles in the absence of surface sorbed (negatively charged) P and NOM ions. 
When the CEX treated RSF effluent, which lacked Ca and Mg ions (Table 5.1), was used as the initial solution in the co-precipitation experiments, the particle size decreased and the removal of $\mathrm{Fe}(\mathrm{III})$ precipitates by $0.45 \mu \mathrm{m}$ filtration strongly depleted ( $\mathrm{Fe}(\mathrm{III})$ removal $<10 \%$ ). It has been shown previously that the presence of cations in solutions result in neutralization of $\mathrm{Fe}(\mathrm{III})$ precipitate surface charge and a lower electrostatic repulsion which promotes growth of $\mathrm{Fe}(\mathrm{III})$ precipitates (Ahmad et al. 2019b, Van Genuchten et al. 2014a, Van Genuchten et al. 2014b). In this study, when $\mathrm{Ca}$ and $\mathrm{Mg}$ were removed from water by CEX, the sorption of Si, P and NOM on Fe(III) precipitate surface resulted in a negatively charged precipitate surface with high electrostatic repulsion which hindered the precipitate growth (de Ridder et al. 2018).

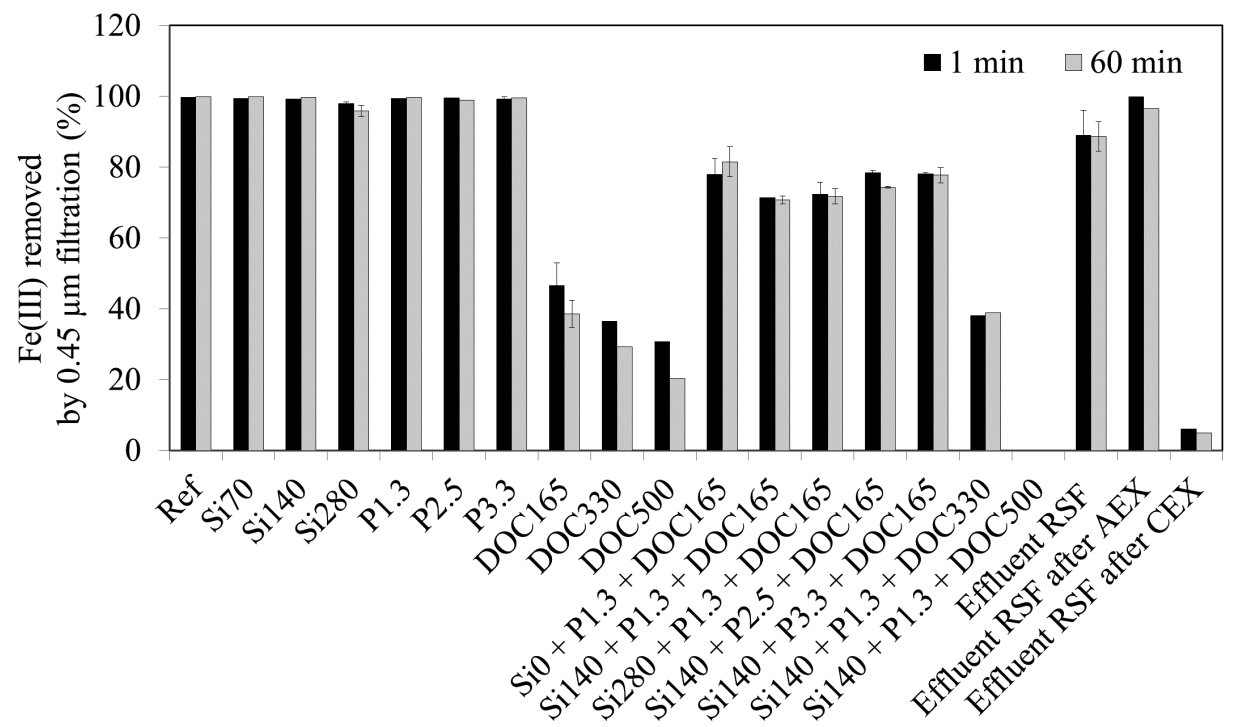

Figure 5.3 Percentage Fe(III) removed by $0.45 \mu \mathrm{m}$ filtration as a function of the composition of the initial solution and time. Ref refers to the reference experiment performed in the absence of Si, P and NOM.

\subsubsection{Arsenic removal}

\subsubsection{Impact of independent $\mathrm{Si}, \mathrm{P}$ and NOM additions}

Arsenate removal was the highest in the reference experiment (i.e. in the absence of $\mathrm{Si}, \mathrm{P}$ and NOM), with As $(\mathrm{V})$ removal efficiency of $65 \%$ and $\approx 90 \%$ after $1 \mathrm{~min}$ and 60 min respectively (Fig 5.4A). This represents a $\approx 75 \%$ of the total $A s(V)$ removed in the first minute, indicating a rapid adsorption of $\mathrm{As}(\mathrm{V})$ to $\mathrm{Fe}(\mathrm{III})$ precipitate 
surfaces. Since $\mathrm{Fe}(\mathrm{III})$ precipitates were completely removed by $0.45 \mu \mathrm{m}$ filtration after both $1 \mathrm{~min}$ and $60 \mathrm{~min}$ (Fig 5.3), the $\approx 25 \%$ increase in As(V) removal in reference experiment was attributed to the diffusion-controlled mass transfer of As to adsorption sites located in the internal porosity of Fe(III) precipitates (Fig 5.4). The similar time-dependent $\mathrm{As}(\mathrm{V})$ adsorption kinetics observed in the presence of $\mathrm{Si}, \mathrm{P}$ and NOM can also be explained by the slow transfer of As towards the internal adsorption sites (Fig 5.4B). The independent additions of Si, P and NOM resulted in a lower $\mathrm{As}(\mathrm{V})$ removal efficiency compared to the reference (Fig 5.4A). The addition of $70 \mu \mathrm{M}$ Si resulted in As(V) removal efficiency of $45 \%$ and $75 \%$ after $1 \mathrm{~min}$ and $60 \mathrm{~min}$, which decreased to $\approx 40 \%$ and $60 \%$ respectively, with the independent addition of the highest concentration of $(280 \mu \mathrm{M} \mathrm{Si})$. The addition of $1.3 \mu \mathrm{M} \mathrm{P}$ resulted in an $\mathrm{As}(\mathrm{V})$ removal efficiency of $25 \%$ and $44 \%$ after $1 \mathrm{~min}$ and $60 \mathrm{~min}$, which decreased to $\approx 20 \%$ and $30 \%$ respectively, with the independent addition of the highest concentration of $\mathrm{P}(3.3 \mu \mathrm{M} \mathrm{P})$. As the removal of Fe(III) precipitates by $0.45 \mu \mathrm{m}$ filtration was (nearly) complete (Fig 5.3), we conclude that the reduced $\mathrm{As}(\mathrm{V})$ removal was due to a reduced adsorption of $\mathrm{As}(\mathrm{V})$ onto the surface of Fe(III) precipitates, similar to the reference (Dixit and Hering 2003, Meng et al. 2000).

Fig $5.4 \mathrm{~B}$ shows that the independent $\mathrm{P}$ additions, though much smaller compared to $\mathrm{Si}$ (Table 5.1), results in a lower As $(\mathrm{V})$ adsorption efficiency than with Si additions. These results can be explained by the $\mathrm{pH}$ dependent affinity of $\mathrm{As}(\mathrm{V}), \mathrm{P}$ and $\mathrm{Si}$ for the adsorption sites on Fe(III) precipitates (Ahmad et al. 2019b, Van Genuchten et al. 2014b, Voegelin et al. 2010) and the concentration differences between Si and $\mathrm{P}$ relative to $\mathrm{As}(\mathrm{V})$. The adsorption of $\mathrm{As}(\mathrm{V}), \mathrm{Si}$ and $\mathrm{P}$ onto the surface of $\mathrm{Fe}(\mathrm{III})$ precipitates is competitive. However, at $\mathrm{pH} 7.5$ (this study), As(V) and P exhibit a similarly high affinity for adsorption sites on Fe(III) precipitates due to their negative charge and similar chemical properties. Silicate, on the other hand, is uncharged at $\mathrm{pH} 7.5$ and the adsorption onto Fe(III) precipitates is much lower than $\mathrm{As}(\mathrm{V})$ and $\mathrm{P}$. Thus, the greater reduction in $\mathrm{As}(\mathrm{V})$ adsorption due to lower $\mathrm{P}$ concentrations than $\mathrm{Si}$ is rationalized.

The As $(\mathrm{V})$ removal efficiency was the lowest with the independent NOM additions. For example, the addition of $165 \mu \mathrm{M}$ DOC resulted in As(V) removal efficiency of $\approx 20 \%$ and $35 \%$ after $1 \mathrm{~min}$ and $60 \mathrm{~min}$, which decreased to $10 \%$ and $15 \%$ respectively with the independent addition of $500 \mu \mathrm{M}$ DOC. The lower As(V) removal efficiency (Fig 5.4A) compared to the reference was due to i) the lower adsorption of $\mathrm{As}(\mathrm{V})$ onto the surface of $\mathrm{Fe}(\mathrm{III})$ precipitates, as reflected in the lower As/Fe solids ratio for NOM additions (Fig 5.4B), and ii) a higher mobility of Fe(III) due to the formation of Fe(III)-NOM complexes that were not removed by $0.45 \mu \mathrm{m}$ filtration (Fig 5.3). With NOM additions, the As/Fe solid ratio was higher than the As/Fe solid ratio with $\mathrm{P}$ additions. This indicates a stronger competition with $\mathrm{As}(\mathrm{V})$ 
for adsorption sites by $\mathrm{P}$ than NOM (Fig 5.4B). Compared to the Si additions, the As/Fe solid ratio was slightly lower in case of NOM additions. This indicates a stronger competition with $\mathrm{As}(\mathrm{V})$ for adsorption sites by NOM than Si (Fig 5.4B). Thus, in the given conditions, $\mathrm{P}$ competed with $\mathrm{As}(\mathrm{V})$ for adsorption sites on $\mathrm{Fe}(\mathrm{III})$ precipitates most strongly and reduced the $\mathrm{As}(\mathrm{V})$ adsorption followed by NOM, whereby $\mathrm{Si}$ showed had the least negative impact on $\mathrm{As}(\mathrm{V})$ adsorption.

From these results it can be concluded that the removal of $A s(V)$ in the presence of $\mathrm{Si}$ and $\mathrm{P}$ was affected mainly because of the reduced adsorption of $\mathrm{As}(\mathrm{V})$, whereas in the presence of NOM a reduced adsorption and a reduced Fe(III) removal both were responsible. Phosphate reduced $\mathrm{As}(\mathrm{V})$ adsorption the most, mainly because of its similar affinity for adsorption sites and higher concentration than $\mathrm{As}(\mathrm{V})$. But, the overall $\operatorname{As}(\mathrm{V})$ removal efficiency was reduced the most with the variations in NOM concentrations, mainly because NOM rendered a large portion of $\mathrm{Fe}(\mathrm{III})$ mobile in the solution.

\subsubsection{Impact of combined $\mathrm{Si}, \mathrm{P}$ and NOM additions}

In the experiments where $165 \mu \mathrm{M}$ DOC was fixed and $\mathrm{P}$ and $\mathrm{Si}$ concentrations were varied, the $A s(V)$ removal efficiency was lower than the reference experiment and the experiments with the corresponding independent $\mathrm{Si}$, P and NOM additions (Fig 5.4A). For example, with $165 \mu \mathrm{M}$ DOC fixed, the addition of $1.3 \mu \mathrm{M} P$ resulted in As $(\mathrm{V})$ removal efficiency of 17 and $32 \%$ after $1 \mathrm{~min}$ and $60 \mathrm{~min}$. This was lower than the $\mathrm{As}(\mathrm{V})$ removal efficiencies observed for the independent $1.3 \mu \mathrm{M} \mathrm{P}(25 \%$ and $44 \%$ after $1 \mathrm{~min}$ and $60 \mathrm{~min}$ ) and $165 \mu \mathrm{M}$ DOC (22\% and 37\% after $1 \mathrm{~min}$ and 60 min) additions. The lower As removal can be attributed to i) a greater competition for the adsorption of $\mathrm{As}(\mathrm{V})$ onto $\mathrm{Fe}(\mathrm{III})$ precipitates due to the presence of multiple inorganic and organic ions, as also confirmed by the lower As/Fe solid ratios, and ii) a NOM-induced higher mobility of Fe(III) (Fig 5.3), as discussed previously.

At fixed $\mathrm{P}$ and NOM concentrations (1.3 $\mu \mathrm{M} \mathrm{P}$ and $165 \mu \mathrm{M}$ DOC), the addition of $\mathrm{Si}$ up to $280 \mu \mathrm{M}$ resulted in only a slight reduction in $\mathrm{As}(\mathrm{V})$ removal efficiency compared to the absence of Si. Similarly, the removal efficiency of $A s(V)$ was reduced only slightly when $\mathrm{P}$ concentrations were increased up to $3.3 \mu \mathrm{M}$ in the presence of 140 and $165 \mu \mathrm{M}$ Si and DOC respectively. The subtle decrease in $\mathrm{As}(\mathrm{V})$ removal was attributed to a stronger competition for $\mathrm{As}(\mathrm{V})$ adsorption onto $\mathrm{Fe}(\mathrm{III})$ precipitates which resulted in a lower As/Fe solid ratio (Fig 5.4B). Arsenate removal efficiency was majorly reduced with an increase in NOM concentration, with $\mathrm{Si}$ and $\mathrm{P}$ also present in water at fixed concentrations. For example, when $500 \mu \mathrm{M}$ DOC was added along with $140 \mu \mathrm{M}$ Si and $1.3 \mu \mathrm{M}$ P, As $(\mathrm{V})$ removal was reduced to zero. The absence of $\mathrm{As}(\mathrm{V})$ removal (Fig 5.4A) was due to formation of $\mathrm{Fe}-\mathrm{NOM}$ complexes that could not be filtered, as discussed previously. 

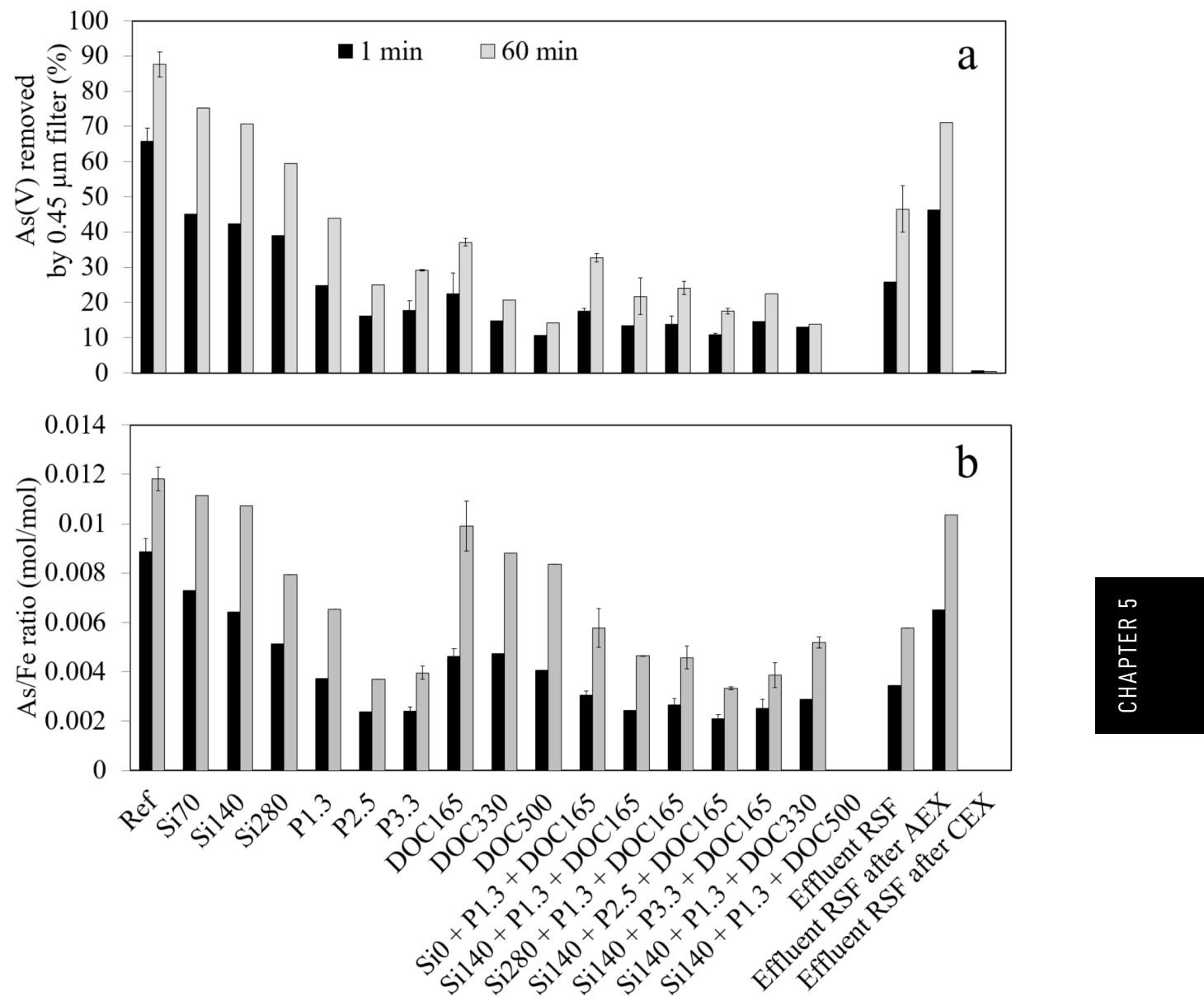

Figure 5.4 (a) Percentage As(V) removed by $0.45 \mu \mathrm{m}$ filtration and (b) As(V) uptake by Fe(III) precipitates as a function of the composition of the initial solution and time. Ref refers to the reference experiment performed in the absence of Si, P and NOM.

Overall, it can be concluded that in complex solutions, containing $\mathrm{Si}, \mathrm{P}, \mathrm{NOM}$ and $\mathrm{Ca}, \mathrm{As}(\mathrm{V})$ removal appears to be most sensitive to variations in NOM concentration, with NOM- Fe(III) complexation a key determinant.

\subsubsection{Impact of removing anions and cations from RSF effluent}

In the RSF effluent, the As $(\mathrm{V})$ removal was lower than the reference experiment, i.e. As $(V)$ removal was $46 \%$ in the RSF effluent compared to $\approx 90 \%$ for the reference solution after $60 \mathrm{~min}$ (Fig 5.4A). The lower As(V) removal in RSF effluent compared to the reference was largely due to competition for $\mathrm{As}(\mathrm{V})$ adsorption from the anions 
such as $\mathrm{Si}, \mathrm{P}$ and NOM. This was also confirmed by pre-treating the RSF effluent by AEX which showed that As $(\mathrm{V})$ removal significantly increased with the removal of $\mathrm{P}$ and NOM (Table 5.1). The removal of Si with AEX treatment was not effective and therefore $\mathrm{Si}$ competed with $\mathrm{As}(\mathrm{V})$ for the adsorption sites, resulting in As/Fe solid ratio that matched the experiments where independent $S i$ additions were investigated (Fig 5.4B).

Arsenate removal was absent when the CEX-pre-treated RSF effluent was used as initial solution. The fact that no removal was observed in the absence of $\mathrm{Ca}$ and $\mathrm{Mg}$ is mainly due to the high mobility of Fe(III), which can be attributed to the highly negative surface of $\mathrm{Fe}(\mathrm{III})$ precipitates that hinders the growth of $\mathrm{Fe}(\mathrm{III})$ precipitates to become larger particles. The mechanistic understanding of how cations like $\mathrm{Ca}$ interact with $\mathrm{Fe}(\mathrm{III})$ precipitates in multi-anionic solutions has been presented in previous studies. It has been reported that when $\mathrm{Ca}$ is present during co-precipitation of $\mathrm{Fe}(\mathrm{III})$ and (oxy)anions such as $\mathrm{Si}, \mathrm{P}, \mathrm{As}(\mathrm{V})$ and $\mathrm{NOM}$, it is incorporated in the structure of the growing $\mathrm{Fe}(\mathrm{III})$ precipitates due to chemical bonding with the surface-sorbed oxyanions (Van Genuchten et al. 2014a). Moreover, Ca interacts electrostatically with the surface of $\mathrm{Fe}(\mathrm{III})$ precipitates. Magnesium ions have also been shown to enhance aggregation of Fe(III) precipitates, but the effect is less pronounced than Ca (Senn et al. 2015, Van Genuchten et al. 2014b).

Table 5.2. The zeta-potential of Fe(III) precipitates in a sub-set of experiments.

\begin{tabular}{lc}
\hline Experiment code & Zeta-potential $[\mathrm{mV}]$ \\
\hline Reference & $-2.6 \pm 0.9$ \\
P3.3 & $-2.8 \pm 0.6$ \\
DOC165 & $-11.1 \pm 1.5$ \\
P1.3 + DOC165 & $-5.5 \pm 1.9$ \\
Si140 + P1.3 + DOC165 & $-5.7 \pm 0.9$ \\
Si280 + P1.3 + DOC165 & $-7.6 \pm 0.2$ \\
Si140 + P2.5 + DOC165 & $-7.1 \pm 0.6$ \\
Si140 + P1.3 + DOC330 & $-13.1 \pm 0.3$ \\
RSF effluent & $-7.0 \pm 1.2$ \\
\hline
\end{tabular}




\subsection{CONCLUSIONS AND IMPLICATIONS FOR WATER TREATMENT}

This study shows that $\mathrm{As}(\mathrm{V})$ removal in $\mathrm{Fe}(\mathrm{III})$ based co-precipitation is sensitive to the composition of water matrix. In complex solutions containing multiple solutes and high levels of $\mathrm{Ca}$, (variations in) $\mathrm{Si}$ and $\mathrm{P}$ concentrations reduce $\mathrm{As}(\mathrm{V})$ removal to some extent, mainly due to a decreased adsorption of $\mathrm{As}(\mathrm{V})$ onto $\mathrm{Fe}(\mathrm{III})$ precipitates. On the other hand, NOM concentrations reduce $\operatorname{As}(\mathrm{V})$ removal quite drastically, which we attribute largely to the formation of soluble and colloidal Fe(III)-NOM complexes.

The findings presented in this study have a great significance for predicting As removal at water treatment plants where water quality changes may take place, e.g. due to seasonal effects. Surface complexation modeling (Dzombak and Morel 1990, Hiemstra and Van Riemsdijk 1999, Kanematsu et al. 2010, 2013b, Stachowicz et al. 2008) is useful in gaining further insights in the As uptake by Fe(III) precipitates, but its application to real water treatment systems is limited. In water treatment plants, the effectiveness of As removal also depends on the separation of $\mathrm{Fe}(\mathrm{III})$ precipitates from water. Calcium effectively counteracts the negative effect of oxyanions and promotes the growth of $\mathrm{Fe}(\mathrm{III})$ precipitates, which can be easily separated from water by gravitation settling and rapid sand filtration. Thus, hardness of water should be carefully considered in designing As removal processes that rely on the co-precipitation of As and Fe. Obviously, effective separation of the colloidal particles can also be achieved by employing low-pressure membrane filtration (MF/ UF) instead of the conventional rapid sand filtration for effective separation of the colloidal particles. Nevertheless, also in this case, the charge and size distribution of $\mathrm{Fe}(\mathrm{III})$ precipitates will remain crucial in determining the membrane fouling mechanisms.

\section{Acknowledgement}

This research is co-financed with PPS-funding from the Topconsortia for Knowledge \& Innovation (TKI's) of the Ministry of Economic Affairs and Climate. AA acknowledges support from Evides Waterbedrijf. The authors want to thank Wolter Siegers of KWR and Peter Vollaard of Evides for their support during the experiments. 


\section{SUPPLEMENTARY INFORMATION}

Table S5.1 NOM characterization of a solution of ultrapure water spiked with NF concentrate to achieve ca. $3 \mathrm{mg} / \mathrm{L}$ DOC, obtained by LC-OCD analysis.

\begin{tabular}{lll}
\hline DOC - Dissolved & $\mu \mathrm{g} / \mathrm{l} \mathrm{C}$ & 3140 \\
DOC - HOC, hydrophobic & $\mu \mathrm{g} / \mathrm{l} \mathrm{C}$ & 451 \\
DOC - CDOC, hydrophilic & $\mu \mathrm{g} / \mathrm{l} \mathrm{C}$ & 2689 \\
CDOC - Bio-polymers & $\mu \mathrm{g} / \mathrm{l} \mathrm{C}$ & 6 \\
CDOC - Bio-polymers - DON & $\mu \mathrm{g} / \mathrm{l} \mathrm{N}$ & 3 \\
CDOC - Bio-polymers - N/C & $\mu \mathrm{g} / \mu \mathrm{g}$ & 0.51 \\
CDOC - Bio-polymers - Proteins & $\%$ & $\mathrm{unknown}$ \\
CDOC - Humic substances (HS) & $\mu \mathrm{g} / \mathrm{l} \mathrm{C}$ & 2370 \\
CDOC - Humic substances - DON & $\mu \mathrm{g} / \mathrm{l} \mathrm{N}$ & 30 \\
CDOC - Humic substances - N/C & $\mu \mathrm{g} / \mu \mathrm{g}$ & 0,01 \\
CDOC - Humic substances - Aromaticity & $\mathrm{L} /\left(\mathrm{mg}{ }^{*} \mathrm{~m}\right)$ & 3,82 \\
CDOC - Humic substances - Mol-Weight & $\mathrm{g} / \mathrm{mol}$ & 749 \\
CDOC - Building Blocks & $\mu \mathrm{g} / \mathrm{l} \mathrm{C}$ & 183 \\
CDOC - LMW acids & $\mu \mathrm{g} / \mathrm{l} \mathrm{C}$ & $<1$ \\
CDOC - LMW Neutrals & $\mu \mathrm{g} / \mathrm{l} \mathrm{C}$ & 130 \\
Inorganic Colloidal (SAC) & $\mathrm{m}-1$ & $<0.01$ \\
SUVA (SAC/DOC) & $\mathrm{L} /\left(\mathrm{mg}{ }^{*} \mathrm{~m}\right)$ & 3.18 \\
\hline
\end{tabular}


Table S5.2 Quality of rapid sand filter effluent collected from WTP Ouddorp in The Netherlands, based on the 2016-18 ( $\mathrm{n}=25)$ data provided by the in charge water company.

\begin{tabular}{|c|c|c|}
\hline Parameter & Unit & RSF effluent Ouddorp \\
\hline Temp & ${ }^{\circ} \mathrm{C}$ & $9.4-16.2$ \\
\hline $\mathrm{pH}$ & & $7.75-7.87$ \\
\hline Dissolved Oxygen & $\mathrm{mg} / \mathrm{L} \mathrm{O}_{2}$ & $6.5-8.0$ \\
\hline Electrical Conductivity & $\mathrm{mS} / \mathrm{m}$ & $55-68$ \\
\hline Bicarbonate & $\mathrm{mg} / \mathrm{L} \mathrm{HCO}_{3}$ & $235-260$ \\
\hline Turbidity & NTU & $0.01-0.03$ \\
\hline Arsenic & $\mu \mathrm{g} / \mathrm{L}$ As & $1.9-3.2$ \\
\hline Iron & $\mathrm{mg} / \mathrm{L} \mathrm{Fe}$ & $<0.01-0.08$ \\
\hline Manganese & $\mathrm{mg} / \mathrm{L} \mathrm{Mn}$ & $<0.01$ \\
\hline Orthophosphate & $\mu \mathrm{g} / \mathrm{L} \mathrm{P}$ & $6.0-120$ \\
\hline Silicate & $\mathrm{mg} / \mathrm{L} \mathrm{Si}$ & $3.0-4.0$ \\
\hline Total organic carbon & $\mathrm{mg} / \mathrm{L} \mathrm{C}$ & $1.5-3.9$ \\
\hline Ammonium & $\mathrm{mg} / \mathrm{L} \mathrm{NH}_{4}$ & $<0.02$ \\
\hline Nitrite & $\mathrm{mg} / \mathrm{L} \mathrm{NO}_{2}$ & $<0.007$ \\
\hline Nitrate & $\mathrm{mg} / \mathrm{L} \mathrm{NO}_{3}$ & $1.4-2.5$ \\
\hline Calcium & $\mathrm{mg} / \mathrm{L} \mathrm{Ca}$ & $77-83$ \\
\hline Magnesium & $\mathrm{mg} / \mathrm{L} \mathrm{Mg}$ & $9.7-10$ \\
\hline Sulphate & $\mathrm{mg} / \mathrm{L} \mathrm{SO}_{4}$ & $30-39$ \\
\hline Sodium & $\mathrm{mg} / \mathrm{L} \mathrm{Na}$ & $34-50$ \\
\hline Chloride & $\mathrm{mg} / \mathrm{L} \mathrm{Cl}$ & $67-94$ \\
\hline
\end{tabular}




\section{REFERENCES}

Ahmad, A., Cornelissen, E., van de Wetering, S., van Dijk, T., Van Genuchten, C., Bundschuh, J., van der Wal, A., Bhattacharya, P. (2018). Arsenite removal in groundwater treatment plants by sequential Permanganate - Ferric treatment. Journal of Water Process Engineering, 26, 221-229. doi:https://doi.org/10.1016/j.jwpe.2018.10.014

Ahmad, A., van der Wal, B., Bhattacharya, P., \& Van Genuchten, C. M. (2019). Characteristics of $\mathrm{Fe}$ and $\mathrm{Mn}$ bearing precipitates generated by $\mathrm{Fe}(\mathrm{II})$ and $\mathrm{Mn}(\mathrm{II})$ co-oxidation with $\mathrm{O}_{2}, \mathrm{MnO}_{4}$ and $\mathrm{HOCl}$ in the presence of groundwater ions. Water Research. doi:https://doi.org/10.1016/j. watres.2019.06.036

Chen, C., Dynes, J. J., Wang, J., Karunakaran, C., \& Sparks, D. L. (2014). Soft X-ray Spectromicroscopy Study of Mineral-Organic Matter Associations in Pasture Soil Clay Fractions. Environmental Science \& Technology, 48(12), 6678-6686. doi:10.1021/es405485a

Choi, K. Y.-j., \& Dempsey, B. A. (2004). In-line coagulation with low-pressure membrane filtration. Water Research, 38(19), 4271-4281. doi:https://doi.org/10.1016/j.watres.2004.08.006

Davis, C. C., \& Edwards, M. (2017). Role of Calcium in the Coagulation of NOM with Ferric Chloride. Environmental Science \& Technology, 51(20), 11652-11659. doi:10.1021/acs.est.7b02038

de Ridder, D. J., van de Wetering, S., van Dijk, T., \& van Halem, D. (2018). Influence of $\mathrm{HPO}_{4}^{2-}$, $\mathrm{H}_{4} \mathrm{SiO}_{4}, \mathrm{Ca}^{2+}, \mathrm{Mg}^{2+}$ on $\mathrm{Fe}$ floc growth and $\mathrm{As}(\mathrm{III})$ removal in aerated, natural groundwater. Journal of Water Process Engineering, 25, 149-156

Dixit, S., \& Hering, J. G. (2003). Comparison of arsenic(V) and arsenic(III) sorption onto iron oxide minerals: Implications for arsenic mobility. Environmental Science and Technology, 37(18), 4182-4189. doi:10.1021/es030309t

Doelsch, E., Rose, J., Masion, A., Bottero, J. Y., Nahon, D., \& Bertsch, P. M. (2000). Speciation and Crystal Chemistry of Iron(III) Chloride Hydrolyzed in the Presence of SiO4 Ligands. 1. An Fe K-Edge EXAFS Study. Langmuir, 16(10), 4726-4731. doi:10.1021/la991378h

Dong, H. R., Guan, X. H., Wang, D. S., \& Ma, J. (2011). Individual and combined influence of calcium and anions on simultaneous removal of chromate and arsenate by $\mathrm{Fe}$ (II) under suboxic conditions. Separation and Purification Technology, 80, 284-292

Dzombak, D. A., \& Morel, F. M. M. (1990). Surface Complexation Modeling: Hydrous Ferric Oxide. New York: John Wiley \& Sons. New York, USA

Fuller, C. C., Davis, J. A., \& Waychunas, G. A. (1993). Surface chemistry of ferrihydrite: Part 2. Kinetics of arsenate adsorption and coprecipitation. Geochimica et Cosmochimica Acta, 57(10), 2271-2282. doi:10.1016/0016-7037(93)90568-H

Guan, X., Dong, H., Ma, J., \& Jiang, L. (2009). Removal of arsenic from water: Effects of competing anions on As(III) removal in KMnO4-Fe(II) process. Water Research, 43(15), 3891-3899. doi:http://dx.doi.org/10.1016/j.watres.2009.06.008

Guan, X., Ma, J., Dong, H., \& Jiang, L. (2009). Removal of arsenic from water: Effect of calcium ions on As(III) removal in the KMnO4-Fe(II) process. Water Research, 43(20), 5119-5128. doi:http://dx.doi.org/10.1016/j.watres.2008.12.054

Gude, J. C. J., Joris, K., Huysman, K., Rietveld, L. C., \& van Halem, D. (2018). Effect of supernatant water level on As removal in biological rapid sand filters. Water Research X, 1, 100013. doi:https://doi.org/10.1016/j.wroa.2018.100013

Gude, J. C. J., Rietveld, L. C., \& van Halem, D. (2016). Fate of low arsenic concentrations during full-scale aeration and rapid filtration. Water Research, 88, 566-574. doi:10.1016/j. watres.2015.10.034

Hering, J. G., Chen, P.-Y., Wilkie, J. A., Elimelech, M., \& Liang, S. (1996). Arsenic removal by ferric chloride. American Water Works Association, 88(4), 155-167 
Hiemstra, T., \& Van Riemsdijk, W. H. (1999). Surface structural ion adsorption modeling of competitive binding of oxyanions by metal (Hydr)oxides. Journal of Colloid and Interface Science, 210(1), 182-193. doi:10.1006/jcis. 1998.5904

Jain, A., Raven, K., \& R.H., L. (1999). Arsenite and Arsenate Adsorption on Ferrihydrite: Surface Charge Reduction and Net OH- Release Stoichiometry. Environmental Science \& Technology, 33(8), 1179-1184

Jessen, S., Larsen, F., Koch, C. B., \& Arvin, E. (2005). Sorption and Desorption of Arsenic to Ferrihydrite in a Sand Filter. Environmental Science \& Technology, 39(20), 8045-8051. doi:10.1021/es050692x

Kanematsu, M., Young, T. M., Fukushi, K., Green, P. G., \& Darby, J. L. (2010). Extended Triple Layer Modeling of Arsenate and Phosphate Adsorption on a Goethite-based Granular Porous Adsorbent. Environmental Science \& Technology, 44(9), 3388-3394. doi:10.1021/es903658h

Kanematsu, M., Young, T. M., Fukushi, K., Green, P. G., \& Darby, J. L. (2013). Arsenic(III, V) adsorption on a goethite-based adsorbent in the presence of major co-existing ions: Modeling competitive adsorption consistent with spectroscopic and molecular evidence. Geochimica et Cosmochimica Acta, 106, 404-428. doi:https://doi.org/10.1016/j.gca.2012.09.055

Kim, E. J., Hwang, B.-R., \& Baek, K. (2015). Effects of natural organic matter on the coprecipitation of arsenic with iron. Environmental Geochemistry and Health, 37(6), 1029-1039. doi:10.1007/ s10653-015-9692-1

Lakshmanan, D., Clifford, D., \& Samanta, G. (2008). Arsenic Removal by Coagulation with Aluminum, Iron, Titanium, and Zirconium. American Water Works Association, 100(2), 76-88.

Laky, D., \& Licskó, I. (2011). Arsenic removal by ferric-chloride coagulation - effect of phosphate, bicarbonate and silicate. Water Science and Technology, 64(5), 1046-1055. doi:10.2166/ wst.2011.419

Masue, Y., Loeppert, R. H., \& Kramer, T. A. (2007). Arsenate and Arsenite Adsorption and Desorption Behavior on Coprecipitated Aluminum:Iron Hydroxides. Environmental Science \& Technology, 41(3), 837-842. doi:10.1021/es061160z

Mayer, T. D., \& Jarrell, W. M. (1996). Formation and stability of iron(II) oxidation products under natural concentrations of dissolved silica. Water Research, 30(5), 1208-1214. doi:https://doi. org/10.1016/0043-1354(95)00265-0

Meng, X., Bang, S., \& Korfiatis, G. P. (2000). Effects of silicate, sulfate, and carbonate on arsenic removal by ferric chloride. Water Research, 34(4), 1255-1261. doi:10.1016/s0043-1354(99)00272-9

Qiao, J., Jiang, Z., Sun, B., Sun, Y., Wang, Q., \& Guan, X. (2012). Arsenate and arsenite removal by $\mathrm{FeCl}_{3}$ : Effects of $\mathrm{pH}, \mathrm{As} / \mathrm{Fe}$ ratio, initial As concentration and co-existing solutes. Separation and Purification Technology, 92, 106-114. doi:10.1016/j.seppur.2012.03.023

Roberts, L. C., Hug, S. J., Ruettimann, T., Billah, M. M., Khan, A. W., \& Rahman, M. T. (2004). Arsenic Removal with Iron(II) and Iron(III) in Waters with High Silicate and Phosphate Concentrations. Environmental Science \& Technology, 38(1), 307-315. doi:10.1021/es0343205

Rose, J., Manceau, A., Bottero, J.-Y., Masion, A., \& Garcia, F. (1996). Nucleation and Growth Mechanisms of Fe Oxyhydroxide in the Presence of PO4 Ions. 1. Fe KEdge EXAFS Study. Langmuir, 12(26), 6701-6707

Senn, A.-C., Kaegi, R., Hug, S. J., Hering, J. G., Mangold, S., \& Voegelin, A. (2015). Composition and structure of $\mathrm{Fe}(\mathrm{III})$-precipitates formed by $\mathrm{Fe}(\mathrm{II})$ oxidation in water at near-neutral $\mathrm{pH}$ : Interdependent effects of phosphate, silicate and Ca. Geochimica et Cosmochimica Acta, 162, 220-246. doi:https://doi.org/10.1016/j.gca.2015.04.032

Sharma, P., Ofner, J., \& Kappler, A. (2010). Formation of Binary and Ternary Colloids and Dissolved Complexes of Organic Matter, Fe and As. Environmental Science \& Technology, 44(12), 44794485. doi:10.1021/es100066s

Smedley, P. L., \& Kinniburgh, D. G. (2002). A review of the source, behaviour and distribution of arsenic 
in natural waters. Applied Geochemistry, 17(5), 517-568. doi:10.1016/s0883-2927(02)00018-5 Sorlini, S., \& Gialdini, F. (2010). Conventional oxidation treatments for the removal of arsenic with chlorine dioxide, hypochlorite, potassium permanganate and monochloramine. Water Research, 44(19), 5653-5659. doi:10.1016/j.watres.2010.06.032

Sposito, G. (2008). The Chemistry of Soils. Oxford University Press. New York, USA

Stachowicz, M., Hiemstra, T., \& van Riemsdijk, W. H. (2008). Multi-competitive interaction of As(III) and $\mathrm{As}(\mathrm{V})$ oxyanions with $\mathrm{Ca}^{2+}, \mathrm{Mg}^{2+}, \mathrm{PO}_{4}^{3-}$, and $\mathrm{CO}_{3}^{2-}$ ions on goethite. J Colloid Interface Sci, 320(2), 400-414. doi:10.1016/j.jcis.2008.01.007

Su, C., \& Puls, R. W. (2001). Arsenate and Arsenite Removal by Zerovalent Iron: Effects of Phosphate, Silicate, Carbonate, Borate, Sulfate, Chromate, Molybdate, and Nitrate, Relative to Chloride. Environ. Sci. Technol., 35(22), 4562-4568. doi:10.1021/es010768z

Van Genuchten, C. M., Addy, S. E. A., Peña, J., \& Gadgil, A. J. (2012). Removing Arsenic from Synthetic Groundwater with Iron Electrocoagulation: An Fe and As K-Edge EXAFS Study. Environmental Science \& Technology, 46(2), 986-994. doi:10.1021/es201913a

Van Genuchten, C. M., Gadgil, A. J., \& Peña, J. (2014). Fe(III) Nucleation in the Presence of Bivalent Cations and Oxyanions Leads to Subnanoscale $7 \AA$ Polymers. Environmental Science \& Technology, 48(20), 11828-11836. doi:10.1021/es503281a

Van Genuchten, C. M., Pena, J., Amrose S, E., \& Gadgil, A. J. (2014). Structure of Fe(III) precipitates genberated by the electrolytric dissolution of $\mathrm{Fe}(0)$ in the presence of groundwater ions. Geochimica et Cosmochimica Acta, 127, 285-304.

Voegelin, A., Kaegi, R., Frommer, J., Vantelon, D., \& Hug, S. J. (2010). Effect of phosphate, silicate, and $\mathrm{Ca}$ on $\mathrm{Fe}(\mathrm{III})$-precipitates formed in aerated Fe(II)- and As(III)-containing water studied by X-ray absorption spectroscopy. Geochimica et Cosmochimica Acta, 74(1), 164-186. doi:https:// doi.org/10.1016/j.gca.2009.09.020

Waychunas, G. A., Rea, B. A., Fuller, C. C., \& Davis, J. A. (1993). Surface chemistry of ferrihydrite: Part 1. EXAFS studies of the geometry of coprecipitated and adsorbed arsenate. Geochimica et Cosmochimica Acta, 57(10), 2251-2269. doi:https://doi.org/10.1016/0016-7037(93)90567-G

Weng, L., Van Riemsdijk, W. H., \& Hiemstra, T. (2008). Humic nanoparticles at the oxide-water interface: Interactions with phosphate ion adsorption. Environmental Science \& Technology, 42(23), 8747-8752. doi:10.1021/es801631d

Weng, L., Van Riemsdijk, W. H., \& Hiemstra, T. (2009). Effects of Fulvic and Humic Acids on Arsenate Adsorption to Goethite: Experiments and Modeling. Environmental Science \& Technology, 43(19), 7198-7204. doi:10.1021/es9000196

Wilkie, J. A., \& Hering, J. G. (1996). Adsorption of arsenic onto hydrous ferric oxide: effects of adsorbate/adsorbent ratios and co-occurring solutes. Colloids and Surfaces A: Physicochemical and Engineering Aspects, 107, 97-110. doi:http://dx.doi.org/10.1016/0927-7757(95)03368-8

Youngran, J., Fan, M., Van Leeuwen, J., \& Belczyk, J. F. (2007). Effect of competing solutes on $\operatorname{arsenic}(\mathrm{V})$ adsorption using iron and aluminum oxides. Journal of Environmental Sciences, 19(8), 910-919. doi:http://dx.doi.org/10.1016/S1001-0742(07)60151-X 



\section{Chapter 6}

\section{Mechanisms of arsenate removal and membrane fouling in ferric based co-precipitation and low pressure membrane filtration systems}

This chapter has been published as:

Ahmad, A. Rutten, S., de Waal, L., Vollaard, P., Van Genuchten, C., Bruning, H., Cornelissen, E., van der Wal, A. (2020). Mechanisms of arsenate removal and membrane fouling in ferric based coprecipitation - low pressure membrane filtration systems. Separation and Purification Technology, 241, 116644. 


\section{ABSTRACT}

Ferric based coprecipitation-low pressure membrane filtration is a promising arsenic (As) removal method, however, membrane fouling mechanisms are not fully understood. In this study we investigated the effect of feed water composition and membrane pore size on As removal and membrane fouling. We observed that As removal efficiency was independent of the membrane pore size because the size of the $\mathrm{Fe}$ (III) particles was larger than the pore size of the membranes, attributed to a high calcium concentration in the feed water. Arsenic coprecipitation with Fe(III) (oxyhydr)oxides rapidly reached equilibrium before membrane filtration, within $1 \mathrm{~min}$. Therefore, As removal efficiency was not improved by increasing residence times before membrane filtration. The removal of As $(\mathrm{V})$ was strongly dependent on feed water composition and a higher $\mathrm{Fe}$ (III) dose was required to reduce As to sub$\mu \mathrm{g} / \mathrm{L}$ levels for feed water having a higher concentration of oxyanions and a lower concentration of cations. Cake-layer formation was observed to be the predominant membrane fouling mechanism. 


\section{$6.1 \quad$ INTRODUCTION}

Arsenic (As) is a well-known human carcinogen, classified in Group 1 by International Agency for Research on Cancer - IARC (Ferreccio et al. 2000, Kapaj et al. 2006, Steinmaus et al. 2010). The WHO guideline for As in drinking water is $10 \mu \mathrm{g} / \mathrm{L}$, however concerns are growing that chronic ingestion of low As concentrations can also adversely affect human health (Ahmad and Bhattacharya 2019, Saint-Jacques et al. 2018). Therefore, certain water treatment companies aim to produce drinking water with As concentrations below $1 \mu \mathrm{g} / \mathrm{L}$ (Ahmad and Bhattacharya 2019, Ahmad et al. 2019c, Van der Wens et al. 2016).

Coprecipitation of arsenate $[\mathrm{As}(\mathrm{V})]$ with $\mathrm{Fe}(\mathrm{III})$ (oxyhydr)oxides is a widely used As removal method (Dixit and Hering 2003, Fuller et al. 1993, Hering et al. 1996a, Qiao et al. 2012, Shi et al. 2018). For arsenite [As(III)], coprecipitation with Fe(III) (oxyhydr)oxides is less effective in the $\mathrm{pH}$ range of most groundwaters because As(III) is uncharged and have a significantly lower affinity for adsorption to $\mathrm{Fe}(\mathrm{III})$ (oxyhydr)oxide surfaces. Typically, a Fe(III) coagulant is dosed in water to produce $\mathrm{Fe}(\mathrm{III})$ (oxyhydr) oxides which adsorb As(V) from water (Hering et al. 1996a, Qiao et al. 2012). The $\mathrm{As}(\mathrm{V})$ bearing $\mathrm{Fe}(\mathrm{III})$ precipitates are subsequently removed in a granular media filter (Gude et al. 2018a, Gude et al. 2016, 2018c, McNeill and Edwards 1995, Ruiping et al. 2009). These precipitates can also be removed by lowpressure membranes like microfiltration (MF) and ultrafiltration (UF), especially when removal of colloidal As bearing Fe(III) particles is to be achieved (Brandhuber and Amy 1998, Choi and Dempsey 2004, Ghurye et al. 2004, Lee et al. 2004, Ruiping et al. 2009, Zouboulis and Katsoyiannis 2002). However, wide-scale application of low-pressure membrane filtration for As removal is restricted, because of a lack of detailed knowledge about membrane fouling due to $\mathrm{Fe}(\mathrm{III})$ particles and operational consequences.

Arsenate coprecipitation efficiency with Fe(III)(oxyhydr)oxides and the size of resulting $\mathrm{Fe}(\mathrm{III})$ particles is dependent on the ionic composition of water (Senn et al. 2018, Voegelin et al. 2010). An overview of possible fouling mechanisms for low pressure membranes is presented in Fig 6.1. It is expected that the Fe(III) particles which are larger than the membrane pores will be deposited on the membrane surface, i.e. form a cake-layer (Fig 6.1A) whereas Fe(III) particles smaller or comparable to the membrane pores will penetrate deeper into membrane structure and cause internal particle deposition (Fig 6.1B). Also, fouling can occur due to adhesion of $\mathrm{Fe}$ (III) particles to the membrane material (Fig 6.1C). To what extent these different $\mathrm{Fe}$ (III) deposits are removed by backwashing is not yet fully understood. This understanding is required to develop advanced membrane cleaning strategies for sustainable membrane operation. 
We have previously shown that As levels much lower than $1 \mu \mathrm{g} / \mathrm{L}$ can be achieved by oxidizing As(III), the predominant As species in anoxic groundwater, by potassium permanganate $\left(\mathrm{KMnO}_{4}\right)$ before co-precipitation with $\mathrm{Fe}(\mathrm{III})$ (oxyhydr) oxides (Ahmad et al. 2018). The use of $\mathrm{KMnO}_{4}$, however, can be avoided by treating the effluents of rapid sand filters (RSFs) which predominantly contain As(V) due to complete As(III) oxidation to As(V) in rapid sand filters (Fig S6.1) (Ahmad et al. 2018, Gude et al. 2018a, Gude et al. 2016). Consequently, the aim of this study is to investigate $\mathrm{As}(\mathrm{V})$ removal efficiency and membrane fouling mechanisms during $\mathrm{Fe}$ (III) based coprecipitation in combination with low-pressure membrane filtration with the objective to achieve an As reduction to below $1 \mu \mathrm{g} / \mathrm{L}$ in RSF effluents.

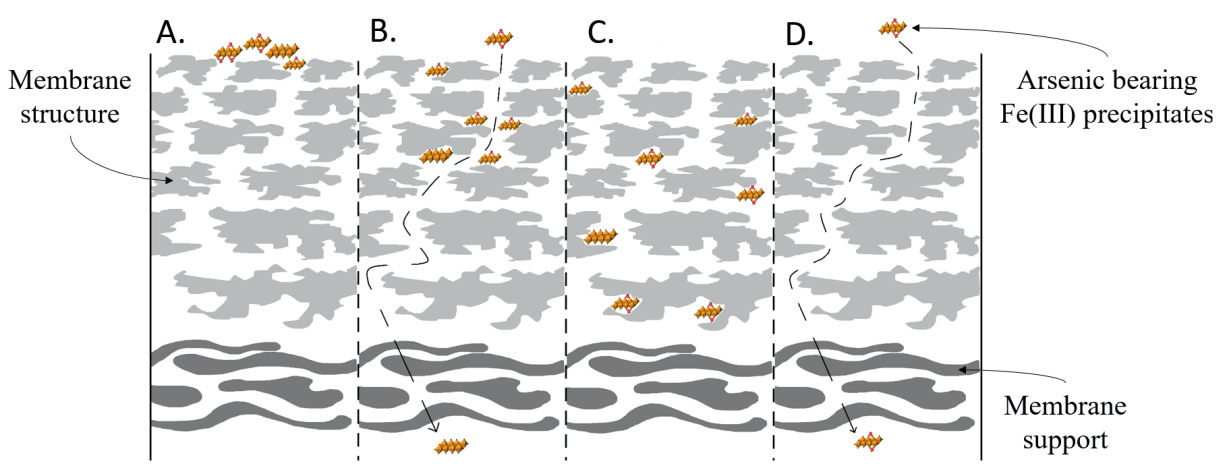

Figure 6.1 Different removal mechanisms for As bearing Fe(III) particles expected for low-pressure membrane filtration. (A) Pore size smaller than Fe(III) particles results in cake layer formation and pore blocking (B) Pore size larger or comparable to Fe(III) particles results in internal deposition. (C) Pore size larger than $\mathrm{Fe}(\mathrm{III})$ particles and adsorption affinity resulting in internal membrane fouling. (D) Pore size larger than $\mathrm{Fe}(\mathrm{III})$ particles without adsorption affinity resulting in transport of particles through the membrane.

\subsection{MATERIALS AND METHODS}

\subsubsection{Feed water}

Ionic composition of water affects both $\mathrm{As}(\mathrm{V})$ adsorption and size of $\mathrm{Fe}(\mathrm{III})$ particles (Ahmad et al. 2019a). Also the size of Fe(III) particles is expected to impact membrane fouling (Fig 6.1). Therefore, we used rapid sand filter effluent samples from two different water treatment plants in the Netherlands (Fig S6.2) which are significantly different in ionic composition (Table 6.1 and Table S6.1). 
Table 6.1 Composition rapid sand filter effluent samples, designated as feed 1 and feed 2, obtained from two water treatment plants in the Netherlands.

\begin{tabular}{llll}
\hline Parameter & Unit & Feed 1 & Feed 2 \\
\hline $\mathrm{pH}$ & - & 7.8 & 8.2 \\
Arsenic & $\mu \mathrm{g} / \mathrm{L} \mathrm{As}$ & 2.3 & 3.3 \\
Iron & $\mu \mathrm{g} / \mathrm{L} \mathrm{Fe}$ & $<10$ & $<10$ \\
Manganese & $\mu \mathrm{g} / \mathrm{L} \mathrm{Mn}$ & $<10$ & $<10$ \\
Ortho-phosphate & $\mu \mathrm{L} / \mathrm{L} \mathrm{P}$ & 8 & 62 \\
Silicate & $\mu \mathrm{g} / \mathrm{L} \mathrm{Si}$ & 3640 & 4585 \\
Dissolved organic carbon & $\mathrm{mg} / \mathrm{L} \mathrm{C}$ & 1.9 & 2.1 \\
Calcium & $\mathrm{mg} / \mathrm{L} \mathrm{Ca}$ & 90 & 48 \\
Magnesium & $\mathrm{mg} / \mathrm{L} \mathrm{Mg}$ & 11 & 8.5 \\
\hline
\end{tabular}

\subsubsection{Membrane and module characteristics}

To investigate the effect of membrane pore size on As removal and membrane fouling, two commercially available hollow fiber membranes (PentairX-Flow, The Netherlands) were used which had different average pore sizes (MF: $200 \mathrm{~nm}$ and UF: $20 \mathrm{~nm}$, Table 6.2). Both types of membranes were made of a similar polymeric polyethersulfone and polyvinylpyrrolidone (PES/PVP) material. Also, both membranes were operated inside-out. Fig 6.2 presents the scanning electron microscope (SEM) images of the inner-surface and the cross-section of the membranes.

Experiments were performed with laboratory scale membrane modules that were made by potting (with an epoxy resin) multiple hollow fibre membranes in a transparent polyvinyl chloride (PVC) tube, as previously described by Floris et al. (2016). The total filtration area for both membranes was $20 \mathrm{~cm}^{2}$, which was realized by installing 2 and 4 hollow fibre membranes for MF and UF respectively.

\subsubsection{Membrane filtration apparatus and filtration procedure}

An automated laboratory scale set-up was used for the experiments (Fig 6.3). The setup consisted of a pulsation-free neMYSIS syringe pump (Cetoni GmbG, Germany) that supplied feed solution to the membrane module at a constant flow of $8.3 \mathrm{~mL} / \mathrm{min}$ (corresponding to the flux of $250 \mathrm{~L} / \mathrm{m}^{2} . \mathrm{h}$ ). A membrane pump (ProMinent $\mathrm{GmbH}$, Heidelberg, Germany) was used for in-line dosing of the $\mathrm{FeCl}_{3}$ stock solution in the feed at a constant flow of $0.3 \mathrm{~mL} / \mathrm{min}$. The concentration of the $\mathrm{FeCl}_{3}$ stock solution was adjusted to change Fe(III) dose in different experiments. The hydraulic residence time (HRT) between the point of Fe(III) dose and membrane filtration was $1 \mathrm{~min}$ in all the experiments except for the study of coprecipitation kinetics where a HRT 
of 5 min was applied. The increased HRT before membrane filtration was achieved by increasing the length of the feed tube. The trans-membrane pressure (TMP) was measured by a sensor (Wika Transmitter 891.13.500) every second and logged using SquirrelView Data Logger (Grant Instruments, Cambridge, UK).

Table 6.2 Membrane and module characteristics. Membranes were supplied by Pentair X-Flow, the Netherlands. Modules were constructed at KWR Water Cycle Research Institute, the Netherlands.

\begin{tabular}{lll}
\hline & UF membrane & MF membrane \\
\hline Commercial identification & UFC M5 & MF02 M2 \\
Membrane process & Ultrafiltration & Microfiltration \\
Membrane material & PES/PVP & PES/PVP \\
Pore size [nm] & 20 & 200 \\
Filtration area $\left[\mathrm{cm}^{2}\right]$ & 20 & 20 \\
No. of fibers per module [-] & 4 & 2 \\
Inner fiber diameter $[\mathrm{mm}]$ & 0.8 & 1.5 \\
Volume/Area ratio $[\mathrm{mm}]$ & 0.2 & 0.4 \\
\hline
\end{tabular}

Each experiment consisted of 6 consecutive filtration (1 hour each) and backwash cycles $(33.3 \mathrm{~mL} / \mathrm{min}, 20 \mathrm{sec}$ each cycle). Ultrapure water was used for backwashing and the backwash flow was provided by a pressurised vessel ( 3 bars) combined with an adjustable flow control. Samples of the feed water, including Fe(III) dosing, were collected directly by opening the valve (point 2 in Fig 6.3). Permeate was sampled from a beaker that collected the entire permeate volume produced during a filtration cycle (point 1 in Fig 6.3), except in the experiments where the effect of successive filtration cycles on $\mathrm{As}(\mathrm{V})$ removal was studied. Backwash samples were collected from a beaker that collected the entire backwash water volume produced during a backwash cycle (point 3 in Fig 6.3).

\subsubsection{Reagents and chemicals}

Ferric chloride was dosed using a stock solution that was prepared by dissolving $\mathrm{FeCl}_{3} \cdot 6 \mathrm{H}_{2} \mathrm{O}$ (CAS: 10025-77-1, 97\% purity, J.T Baker, Deventer, the Netherlands) in $0.5 \mathrm{~L}$ ultrapure water. A stock solution of $1.0 \mathrm{~g} / \mathrm{L} \mathrm{As}_{2} \mathrm{O}_{5}(\mathrm{CAS}: 12044-50-7,99 \%$ purity) obtained from inorganic ventures (Nieuwegein, the Netherlands) was used to spike the water with $A s(V)$. The ultrapure water was obtained by treating distilled water with a Purelab Chorus (Veolia, the Netherlands). 

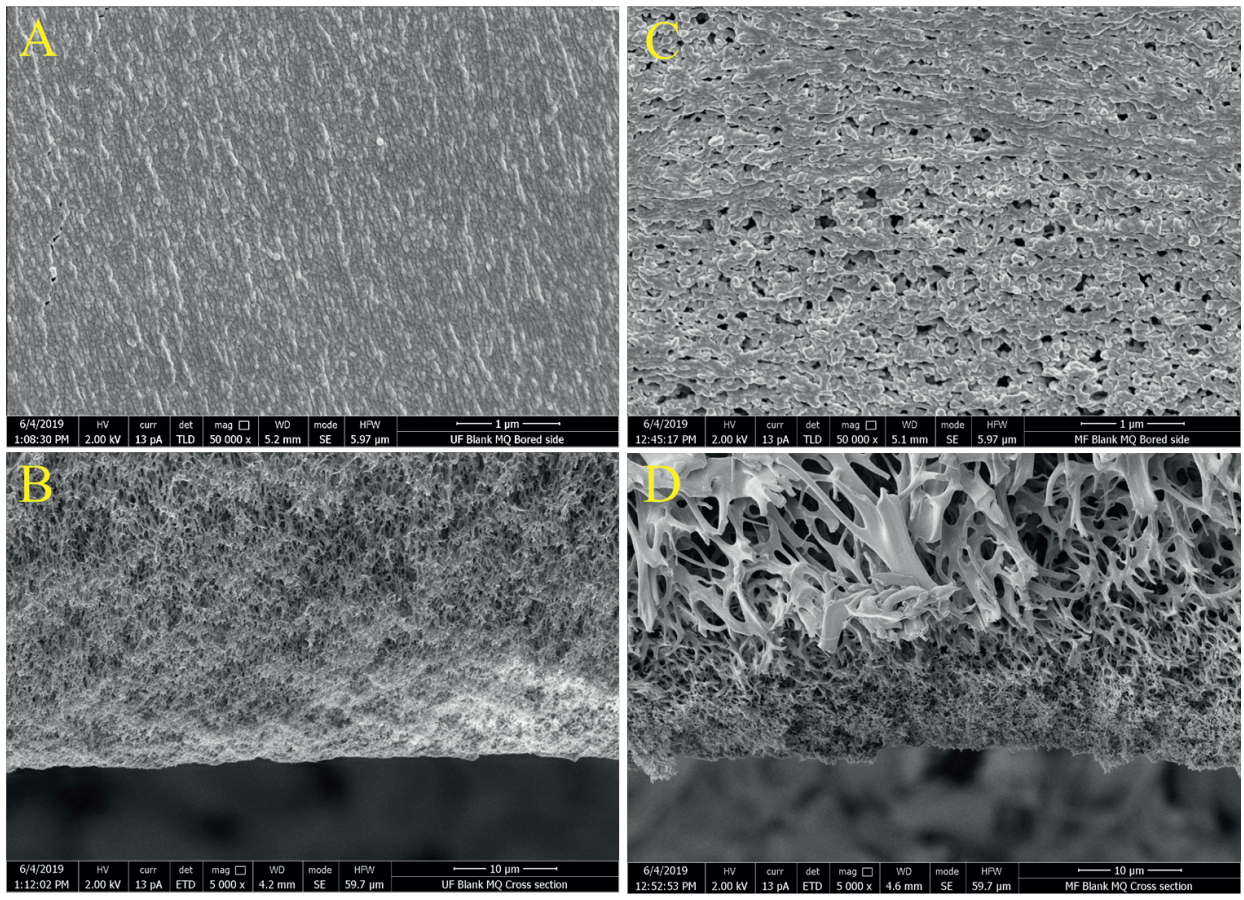

Figure 6.2 The SEM micrographs of the UF and MF membranes. The membranes were pre-conditioned with ultrapure water. (A) and (C) show the inner-surface of the UF and MF respectively and (B) and (D) show the cross-section of the UF and MF respectively.

\subsubsection{Analysis methods for water samples}

Arsenic, $\mathrm{Fe}, \mathrm{Ca}, \mathrm{Mg}$, Si, P were measured by inductively coupled plasma mass spectrometry (ICP-MS) using the Thermo Scientific iCAP TQ (Thermo Fisher Scientific, Breda, the Netherlands). Total organic carbon analysis was carried out with a Shimadzu TOC-V $\mathrm{CPH}_{\mathrm{C}}$ total organic carbon analyser (Shimadzu Benelux, 's-Hertogenbosch, the Netherlands).

\subsubsection{SEM-EDX analysis}

Samples of the fouled UF membranes (membrane after 6 filtration and 5 backwash cycles) and backwashed membranes ( 6 filtration and 6 backwash cycles) were analyzed by SEM to gain further insights into fouling mechanisms. The analysis was carried out at the Wageningen Electron Microscopy Centre at Wageningen University (WUR), using a SEM device (FEI Magellan 400) that was equipped with an Oxford Instruments X-MAX X-ray detector for energy dispersive X-ray (EDX) analysis. The virgin MF and UF membranes were conditioned by ultrapure water 
passage before the SEM analysis. For analysis of each sample, two fragments of the bore side (longitudinal cut) and two fragments of the cross-section (transversal cut) were fixed on a sample holder and coated with tungsten using a Leica SCD 500 sputtercoater.

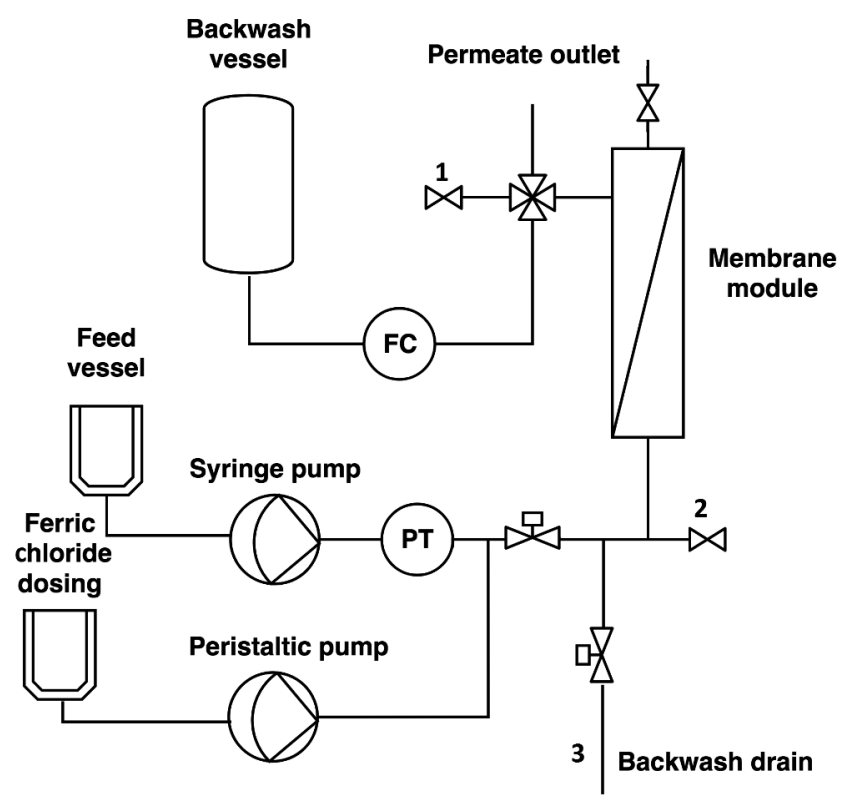

Figure 6.3 Schematic diagram of the experimental setup. Points marked as 1, 2 and 3 indicate permeate, feed and backwash water sampling points, respectively.

\subsubsection{Calculations}

\subsubsection{Rejection efficiency}

The rejection efficiency of a solute (e.g. As and Fe) during filtration is given by

$R_{i}=\left(1-\frac{C_{p}}{C_{f}}\right)_{i} \times 100$

where $\mathrm{R}_{\mathrm{i}}$ is the rejection efficiency of a solute $\mathrm{i}, \mathrm{C}_{\mathrm{p}}$ is the permeate concentration and $\mathrm{C}_{\mathrm{f}}$ is the feed concentration $(\mathrm{mg} / \mathrm{L})$.

\subsubsection{Membrane permeability recovery}

To assess the retention mechanism of Fe(III) particles, the evolution of membrane permeability under different conditions was analyzed. The membrane permeability was calculated according to 


$$
k=\frac{J}{T M P} \quad\left[\mathrm{~L} / \mathrm{m}^{2} \cdot \mathrm{h} \cdot \mathrm{bar}\right]
$$

where $\mathrm{k}$ is the membrane permeability, $J$ is the flux $\left(\mathrm{L} / \mathrm{m}^{2} . \mathrm{h}\right)$ and TMP is the transmembrane pressure (bar). The permeability recovery for each backwash cycle was

$$
k_{R}=\frac{k_{\text {after backwash }}}{k_{\text {clean membrane }}} \times 100 \quad \text { [\%] }
$$

where $\mathrm{k}_{\mathrm{R}}$ is the permeability recovery, $\mathrm{k}_{\text {after backwash }}$ is the membrane permeability after backwash and $\mathrm{k}_{\text {clean membrane }}$ is the permeability of the virgin membrane.

\subsubsection{Fouling analysis with resistance-in-series model}

To assess the predominant membrane fouling mechanisms, we developed a resistance in series model (Bella and Trapani 2019, Floris et al. 2016, Mulder 2012).

For the flux in porous media we use Darcy's Law (Busch et al. 2007, Ng and Kim 2007) which is given by

$$
J=T M P /\left(v \cdot R_{T}\right) \quad\left[\mathrm{L} / \mathrm{m}^{2} \cdot \mathrm{h} \cdot \mathrm{bar}\right]
$$

where $v$ is the dynamic viscosity of the solution (Pa.s) and $\mathrm{R}_{T}$ is the total resistance to filtration $(1 / \mathrm{m})$ which is the sum of clean membrane resistance $\left(R_{M}\right)$, resistance due to the external cake-layer deposition $\left(\mathrm{R}_{\mathrm{E}}\right)$ and the resistance due to the internal deposition $\left(\mathrm{R}_{\mathrm{I}}\right)$.

$$
R_{T}=R_{M}+R_{E}+R_{I}
$$

We obtain $\mathrm{R}_{\mathrm{M}}$ by filtration of ultrapure water through a virgin membrane according to eq. 4 and is given by

$$
R_{M}=\left(\frac{T M P}{v \cdot J}\right)_{\text {virgin,ultra pure water }}
$$

The filtration of feed water, which includes Fe(III) particles, through a virgin membrane is expected to cause membrane fouling due to particle deposition and therefore $\mathrm{R}_{\mathrm{T}}$ can be obtained as follows.

$$
R_{T}=\left(\frac{T M P}{v \cdot J}\right)_{\text {fouled }}
$$

The internal and external fouling resistance $\left(R_{E}+R_{I}\right)$ is equal to $R_{T}-R_{M}$. 
We further assume that the hydraulic backwash will remove all the external fouling (we checked this assumption by SEM-EDX, see section 6.3.2.2). We therefore obtain $\mathrm{R}_{\mathrm{I}}$ as follows

$$
R_{I}=\left(\frac{T M P}{v \cdot J}\right)_{\text {backwashed }}
$$

We finally determine $R_{E}$ by subtracting the membrane resistance $\left(R_{M}\right)$ and internal resistance $\left(\mathrm{R}_{\mathrm{I}}\right)$ from the total resistance $\left(\mathrm{R}_{\mathrm{T}}\right)$.

\subsection{RESULTS AND DISCUSSION}

\subsubsection{Arsenic removal efficiency}

\subsubsection{Impact of membrane pore size}

The effect of membrane pore size on As $(\mathrm{V})$ removal efficiency was studied using Feed 1 which had been spiked to achieve $5 \mu \mathrm{g} / \mathrm{L} \mathrm{As}(\mathrm{V})$ concentration. The experiments included dosing of different $\mathrm{Fe}(\mathrm{III})$ concentrations $(0-4 \mathrm{mg} / \mathrm{L})$ into the feed solution and filtration-backwash cycles. We observed that in the absence of Fe(III) dose, no As $(\mathrm{V})$ was removed for both MF and UF membranes (Fig 6.4A and 6.4B) due to the small size of As(V) oxyanion (Ahmad et al. 2017, Luong et al. 2018). Also, adsorption of $\mathrm{As}(\mathrm{V})$ to the membranes did not occur because of lack of affinity between As (V) oxyanion (Fig S6.3) and the membranes which have been shown to have a negative surface charge in previous studies (Floris et al. 2016, Li et al. 2011, Trzaskus et al. 2016). With Fe(III) dosing, As(V) removal was significant, due to coprecipitation of As(V) with formed Fe(III)(oxyhydr)oxides (Ghurye et al. 2004). Arsenic removal efficiency increased with increasing Fe(III) dosage for both MF and UF membranes. Also, the removal of Fe close to $100 \%$ was observed in all cases (Fig $6.4 \mathrm{~A}$ and $6.4 \mathrm{~B}$ ). These results indicate that As removal efficiency was independent of membrane pore sizes because the size of Fe(III) particles was larger than, or at least comparable to, the membrane pore sizes. This conclusion is also supported by (Ahmad et al. 2019a) where we observed Fe(III) particle sizes in the range of 2-80 $\mu \mathrm{m}(25 \mu \mathrm{m}$ most abundant). The growth of Fe(III) precipitates to such large sizes can be attributed to the natural presence of high $\mathrm{Ca}$ concentrations in given feed water (Ahmad et al. 2019a).

\subsubsection{Impact of feed water composition and hydraulic residence time}

Arsenic coprecipitation with $\mathrm{Fe}(\mathrm{III})$ (oxyhydr)oxides is known to be sensitive to ionic composition of water (Ahmad et al. 2019a, Qiao et al. 2012, Van Genuchten et al. 2014b). To gain further insights into the effect of water composition on As 

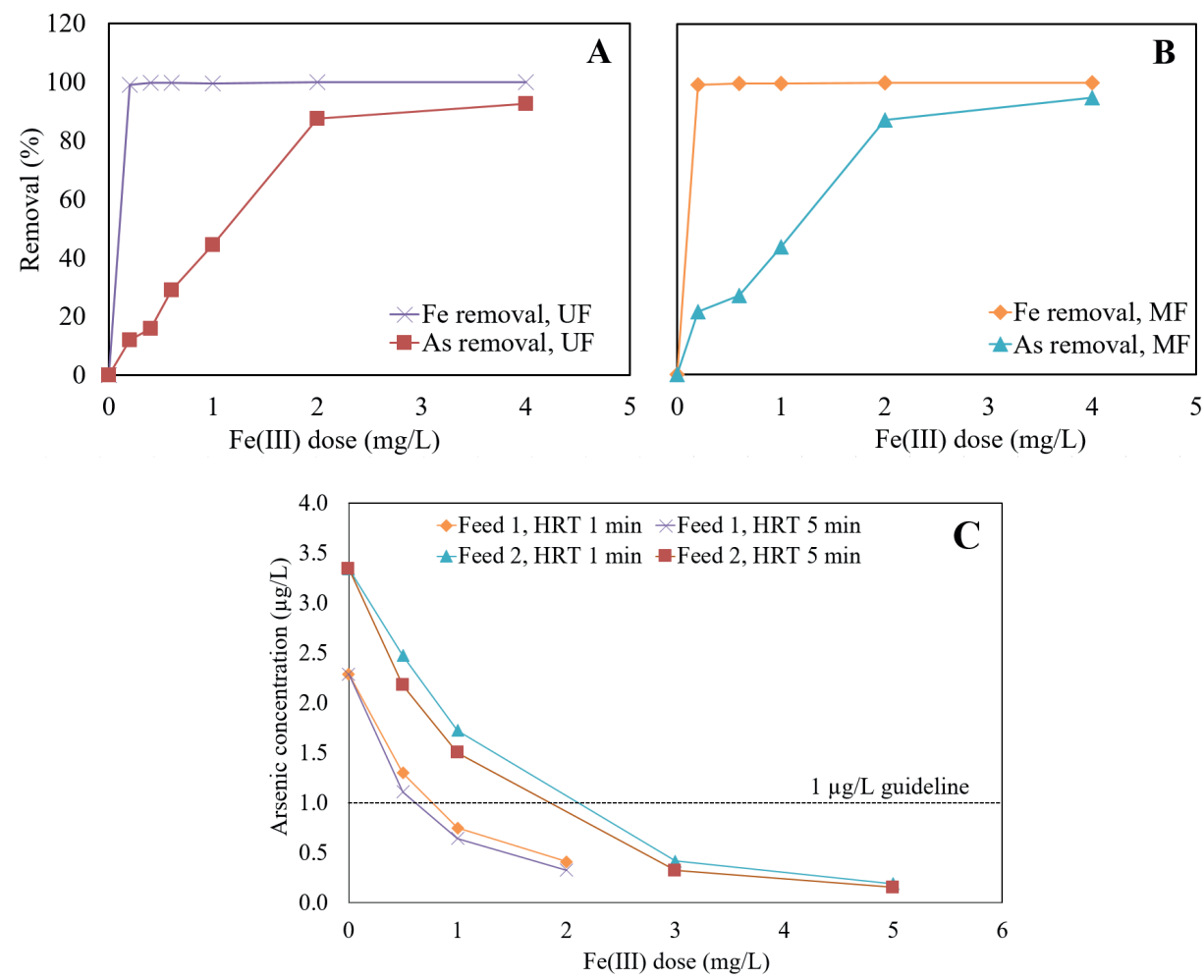

Figure 6.4 Removal efficiency of As and Fe in function of Fe(III) dose in experiments with (A) UF and (B) MF. The experiments were performed with Feed 1 after spiking with $A s(V)$ to achieve initial $A s=A s(V)=5 \mu \mathrm{g} / \mathrm{L}$. The removal of $80 \%$ corresponds to $1 \mu \mathrm{g} / \mathrm{L}$ residual As in water. (C) Residual As in function of $\mathrm{Fe}$ (III) dose, feed water quality and hydraulic residence time between point of $\mathrm{Fe}$ (III) dosing and UF. Feed 1 and Feed 2 were not spiked with additional $\mathrm{As}(\mathrm{V})$.

removal, experiments were carried out with the two feed solutions with different ionic composition using UF membranes. Arsenic concentrations below $1 \mu \mathrm{g} / \mathrm{L}$ were obtained by dosing $1 \mathrm{mg} / \mathrm{L} \mathrm{Fe}(\mathrm{III})$ dose for Feed 1 and $3 \mathrm{mg} / \mathrm{L} \mathrm{Fe}$ (III) dose for Feed 2 (Fig 6.4C). The lower As(V) removal efficiency for Feed 1 compared to Feed 2 can be explained by taking into account the effect of feed water composition on the coprecipitation of $\mathrm{As}(\mathrm{V})$ and $\mathrm{Fe}(\mathrm{III})$ (oxyhydr)oxides. For example, the concentration of phosphate and silicate oxyanions, which compete with $\mathrm{As}(\mathrm{V})$ for adsorption sites on $\mathrm{Fe}(\mathrm{III}$ )(oxyhydr)oxides, is much higher in Feed 2 than Feed 1 (Table 6.1). In addition, Feed 2 has a lower concentration of bivalent cations than Feed $1(90 \mathrm{mg} / \mathrm{L}$ compared to $48 \mathrm{mg} / \mathrm{L} \mathrm{Ca}$ ). It is known that the presence of bivalent cations can enhance the efficiency of $\mathrm{As}(\mathrm{V})$ coprecipitation with $\mathrm{Fe}(\mathrm{III})$ (oxyhydr)oxides involving mechanisms such as neutralization of the $\mathrm{Fe}(\mathrm{III})$ precipitate surface charge by $\mathrm{Ca}$ and 
formation of ternary complexes between $\mathrm{Fe}(\mathrm{III}), \mathrm{As}(\mathrm{V})$ and $\mathrm{Ca}$ (Van Genuchten et al. 2014a, Van Genuchten et al. 2014b, Voegelin et al. 2010). Finally, Feed 1 has a lower $\mathrm{pH}$ compared to Feed 2 which can also contribute to the higher As adsorption to $\mathrm{Fe}(\mathrm{III})$ precipitates due to the fact that $\mathrm{Fe}$ (III) (oxyhydr)oxides at lower $\mathrm{pH}$ will have more positive charge on the surface and hence a higher number of adsorption sites for oxyanions (Kanematsu et al. 2013b, Raven et al. 1998).

Togain insights into the kinetics of $\mathrm{As}(\mathrm{V})$ and $\mathrm{Fe}(\mathrm{III})$ (oxyhydr)oxide coprecipitation, a set of experiments was carried out at an increased HRT of 5 min before removal of the formed $\mathrm{Fe}(\mathrm{III})$ (oxyhydr)oxides by the membranes. Results show that $\mathrm{As}(\mathrm{V})$ concentrations in the permeate at $5 \mathrm{~min}$ HRT is comparable to $\mathrm{As}(\mathrm{V})$ concentrations found in experiments having $1 \mathrm{~min}$ HRT (applied in all experiments) (Fig 6.4C), indicating that $\mathrm{As}(\mathrm{V})$ coprecipitation with $\mathrm{Fe}(\mathrm{III})$ (oxyhydr)oxides rapidly reached equilibrium within $1 \mathrm{~min}$. Such rapid coprecipitation of As has also been reported in previous studies (Fuller et al. 1993, Gude et al. 2017, Raven et al. 1998).

We also studied $\mathrm{As}(\mathrm{V})$ removal as a function of the successive number of filtration cycles (filtration cycles 1, 3 and 6). No differences were observed for $\mathrm{As}(\mathrm{V})$ removal between the filtration cycles (Fig 6.5), confirming that $\mathrm{As}(\mathrm{V})$ uptake by $\mathrm{Fe}(\mathrm{III})$ precipitates reached equilibrium before the suspension entered the membrane, i.e. in $1 \mathrm{~min}$.

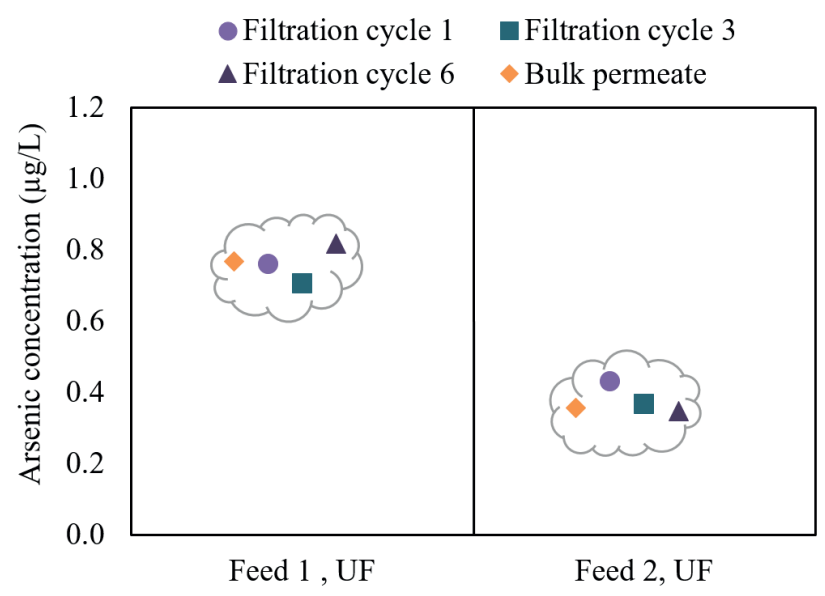

Figure 6.5 Arsenic removal in function of the number of filtration cycles. Only UF membranes were used for this experiment. Fe(III) dose for Feed 1 and Feed 2 was $1 \mathrm{mg} / \mathrm{L}$ and $3 \mathrm{mg} / \mathrm{L}$, respectively. Bulk permeate refers to total permeate volume produced by the 6 filtration cycles. 


\subsubsection{Membrane fouling}

\subsubsection{Clean water flux measurements}

Prior to dosing Fe(III), the membranes were conditioned using ultrapure water at a flux of $250 \mathrm{~L} / \mathrm{m}^{2}$.h until a stable TMP was achieved (normally 1 hour). The calculated permeability $(\mathrm{k})$ and the membrane resistance $\left(\mathrm{R}_{\mathrm{M}}\right)$ (Table 6.3) were used for the permeability recovery calculations (following sections) and to verify the integrity of the membrane modules before each experiment. The TMP for MF was lower than the measurement limit of the sensor in the experimental setup $(0.0008$ bar $)$ and therefore the exact permeability could not be calculated for MF. In the following sections we discuss Fe(III) particle retention and fouling of UF membranes.

Table 6.3 Clean water permeability and corresponding resistance calculated from the ultrapure water flux.

\begin{tabular}{lll}
\hline & UF & MF* $^{*}$ \\
\hline Permeability $\left(\mathrm{L} / \mathrm{m}^{2}\right.$. hour.bar $)$ & $(1.25 \pm 0.08) \times 10^{3}$ & $>3.13 \times 10^{5}$ \\
Membrane resistance $(1 / \mathrm{m})$ & $(2.88 \pm 0.24) \times 10^{11}$ & $<1.15 \times 10^{9}$ \\
\hline *TMP was lower than the lower measurement limit of the sensor $(0.0008$ bar $)$ &
\end{tabular}

\subsubsection{Fouling of UF membranes}

Fig 6.6 presents the effect of Fe(III) particle deposition on TMP during 6 filtrationbackwash cycles for Feed 1 and Feed 2 with 1 and 3 mg/L Fe(III) dosing respectively which resulted in As below $1 \mu \mathrm{g} / \mathrm{L}$ in the permeate. The initial TMP (clean membrane) was similar for both feeds, but the difference in Fe(III) dose produced clear differences in TMP increase during the filtration cycles. For example, the average TMP increase per cycle for Feed 1 and Feed 2 was 0.012 and 0.072 bar/h respectively which shows the higher susceptibility of membrane fouling at a higher Fe(III) dose. Nevertheless, in both cases the initial TMP was effectively restored after the backwash procedure (Fig 6.6 and Fig S6.4), indicating a predominance of reversible fouling at 1 and 3 $\mathrm{mg} / \mathrm{L} \mathrm{Fe}(\mathrm{III})$ dosing. 


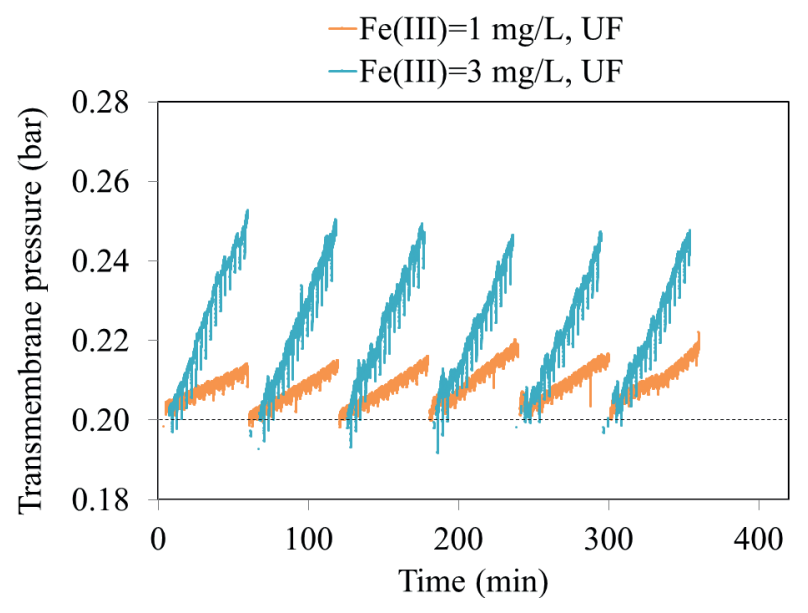

Figure 6.6 Evolution of TMP during UF experiments. During the experiments, flux was constant at $250 \mathrm{~L} / \mathrm{m}^{2}$.h. For MF the TMP was consistently lower than the lower measurement limit $(0.0008 \mathrm{bar})$ therefore not shown in the graph.

To further elucidate fouling mechanisms, membranes were analyzed visually and with SEM-EDX (Fig 6.7 - 6.9). The visual effect of the deposition of Fe(III) precipitates on UF membrane before backwash (i.e. after 6 filtration and 5 backwash cycles) compared to after backwash (i.e. 6 filtration and 6 backwash cycles) in an experiment with Feed 2 dosed with $3 \mathrm{mg} / \mathrm{L} \mathrm{Fe}$ (III) (As below $1 \mu \mathrm{g} / \mathrm{L}$ ) is presented in Fig 6.7. The surface of the UF before backwash is visually very different from both the virgin UF membrane and the backwashed UF membrane. It shows an irregular layer of reddish-brown deposit (As bearing Fe(III) precipitates). No such deposits are observed in the virgin and backwashed UF membranes which implies that the hydraulic backwash effectively removed the Fe(III) deposits.

SEM micrographs and EDX scans of the cross section of the fouled UF membrane (i.e. the membrane specimen shown in Fig 6.7B), show Fe-signal restricted only to an approximate depth of $7 \mu \mathrm{m}$ on the membrane surface (Fig 6.8). This confirms that $\mathrm{Fe}(\mathrm{III})$ particles were deposited as a cake-layer on membrane surface. Thus, based on membrane permeability recovery and complimentary visual and SEMEDX analysis we conclude that the removal of As bearing Fe(III) particles occurred largely on the surface of UF membrane i.e. by cake-layer formation. Membrane permeability was reduced during a filtration cycle probably due to a growing cake on the membrane surface and a hydraulic backwash effectively removed the surface deposits and restored membrane permeability (Fig 6.6 and Fig S6.4). 


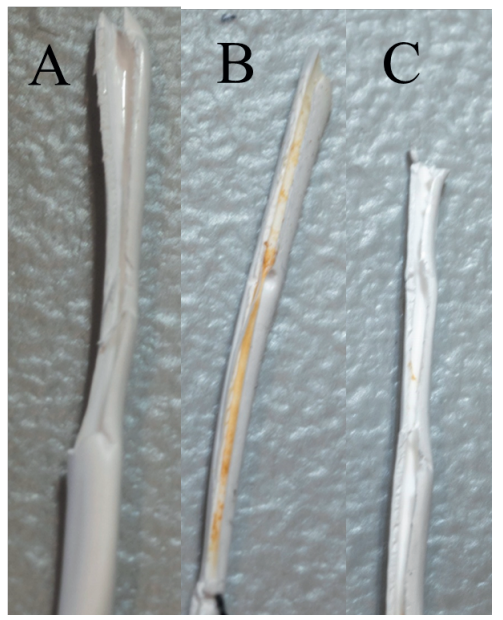

Figure 6.7 The visuals of the UF membranes after experiments with Feed 2 dosed with $3 \mathrm{mg} / \mathrm{L} \mathrm{Fe}(\mathrm{III})$. (A) Virgin membrane after conditioning with ultrapure water, (B) UF before backwash (membrane after 6 filtration and 5 backwash cycles) and (C) UF after backwash ( 6 filtration and 6 backwash cycles).

\subsubsection{Fouling analysis by resistance-in-series model}

The resistance model (see section 6.2.7.3) was used to further understand the fouling and contribution of different resistances during filtration. For both Feed 1 and Feed 2, dosed with different $\mathrm{Fe}(\mathrm{III})$ concentrations, the total resistance was dominated by membrane resistance $\left(R_{M}\right)$ followed by external resistance $\left(R_{E}\right)$ (Fig 6.10A). The internal resistance $\left(\mathrm{R}_{\mathrm{I}}\right)$, on the other hand, was very small and may be due to some internal deposition of $\mathrm{Fe}$ (III) particles which might have penetrated somewhat deeper into the membrane pores (Shi et al. 2014). Particles deposited within the membrane pore structure are likely to be subjected to lower hydraulic shear forces and are therefore not effectively removed by hydraulic backwashing (Fane et al. 2006). The contribution of $R_{E}$ for Feed 2 was higher than Feed 1 which can be explained easily by the higher Fe(III) dose applied for Feed 2 .

The resistance analysis was also carried out with different Fe(III) doses in Feed 1 (Fig 6.10B). The total resistance systematically increased with the increments in $\mathrm{Fe}(\mathrm{III})$ dose. Again, $\mathrm{R}_{\mathrm{M}}$ dominated the total resistance followed by $\mathrm{R}_{\mathrm{E}}$ and the $\mathrm{R}_{\mathrm{I}}$ was the smallest. The systematic increase in the $\mathrm{R}_{\mathrm{E}}$ as a function of $\mathrm{Fe}(\mathrm{III})$ dose is consistent with the trend observed (cake-layer build-up) in the experiments with Feed 1 and Feed 2 at their specific optimum Fe(III) doses required for As removal to below $1 \mu \mathrm{g} / \mathrm{L}$ (Fig 6.10A). Thus, cake-layer formation was found to be the major proportion of fouling resistance. 


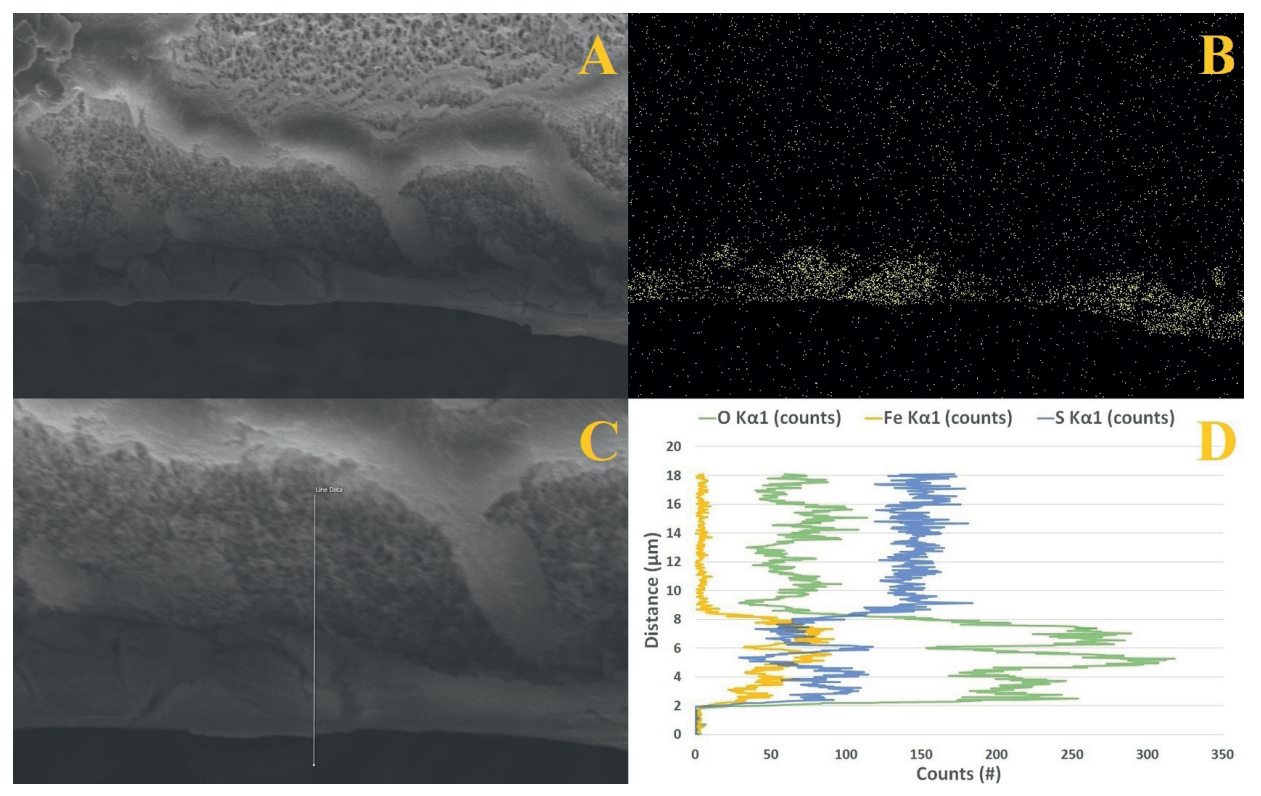

Figure 6.8 SEM micrograph (A and C) and EDX scans (B and D) of the cross section of the UF membrane specimen shown in Fig 6.7B. (A) Cross section of UF membrane before backwash. (B) EDX spectrum of Fig 6.8A, showing signal from Fe-atoms, indicating the presence of a Fe-based cake layer on the membrane surface. (C) enlarged section of Fig 6.8A, indicating the line at which EDX data is acquired. (D) EDX data of the line in Fig 6.8C, highlighting Fe (yellow), $\mathrm{O}$ (green) and $\mathrm{S}$ (blue) signals along the line as function of detector-counts per second (cps). The dot on the line in Fig 6.8C equals $0 \mu \mathrm{m}$ on the $y$-axis of Fig $6.8 \mathrm{D}$. At distance $>8 \mu \mathrm{m}$, increasing sulfur signal indicates the presence of the supporting layer. At distance $8-2 \mu \mathrm{m}$, low sulfur signal and higher iron and oxygen signal indicates the presence (and thickness) of the deposited Fe(III) (oxyhydr)oxide cake-layer.

\subsection{CONCLUSIONS AND IMPLICATIONS FOR THE PRACTICE}

The removal of $\operatorname{As}(\mathrm{V})$ and membrane fouling mechanisms during $\mathrm{Fe}(\mathrm{III})$ based coprecipitation-low pressure membrane filtration were studied for achieving As reduction to very low levels below $1 \mu \mathrm{g} / \mathrm{L}$ in rapid sand filter effluents. We found that $\mathrm{As}(\mathrm{V})$ removal efficiency was independent of the membrane pore size because the size of the $\mathrm{Fe}$ (III) particles was larger than the pore size of UF and MF membranes. Also, As(V) coprecipitation with $\mathrm{Fe}(\mathrm{III})$ (oxyhydr)oxides rapidly reached equilibrium before membrane filtration, within $1 \mathrm{~min}$. This resulted in a stable As removal efficiency even at an increased residence time of 5 min before membrane filtration. The removal efficiency of $\mathrm{As}(\mathrm{V})$ was nevertheless dependent on feed water composition, in such a way that a higher Fe(III) dose was required to reduce As to below $1 \mu \mathrm{g} / \mathrm{L}$ for the feed water which had higher phosphate and silicate concentrations and lower calcium and magnesium concentrations. 

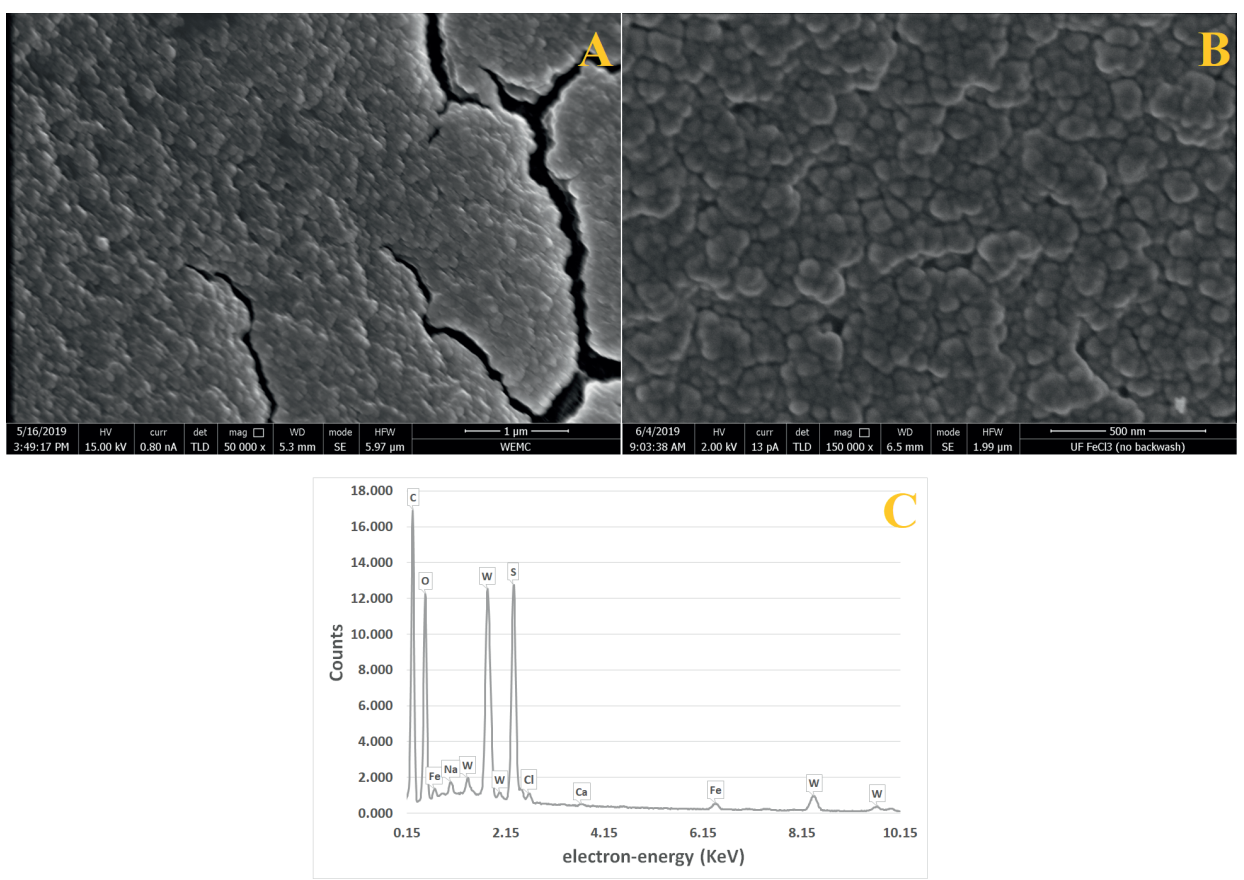

Figure 6.9 SEM-EDX of the solid depositions found on the bored side of the UF membrane. (A) 50 $000 \mathrm{x}$ maginified image (B) $150000 \mathrm{x}$ magnified image. (C) spectrum shows the elemental composition at the bored side of the UF before backwash. $\mathrm{Na}$ and $\mathrm{Cl}$ are present due to the drying and crystallization of $\mathrm{NaCl}$. The small calcium peak can be explained by coprecipitation of calcium with $\mathrm{Fe}$ (III)(oxyhydr) oxides. The high carbon, oxygen and sulfur peaks are from the membrane material (PES, $\left(\mathrm{C}_{12} \mathrm{H}_{8} \mathrm{O}_{3} \mathrm{~S}\right)$ $\left.{ }_{n}\right)$. Tungsten was used to coat the sample. The observed fractures in the cake layer in Fig 6.9A is an artefact and caused by drying during preparation or storage. The deposits in Fig 6.9B appear to consist of primary spherical particles with an average size $65 \mathrm{~nm}$.

In all the UF experiments, Fe(III) particles formed a cake-layer on the membrane surface which reduced membrane permeability during filtration. The cake on the UF membranes was effectively removed with a hydraulic backwash, resulting in nearcomplete restoration of membrane permeability. The fouling mechanisms for MF, on the other hand, could not be studied in detail and therefore it is difficult to draw clear conclusions about MF fouling. However, we postulate for future work that more open low-pressure membranes may be more susceptible to irreversible fouling due to a large pore size which can allow some Fe(III) particles to penetrate deeper into the membrane structure and get immobilized there.

It is noteworthy that direct translation of our results for long-term application may be limited by the fact that we studied the membrane fouling only for 6 filtration and backwash cycles. At water treatment plants, long term membrane operation 
can result in a significant permeability reduction due to slow build-up of internal membrane fouling which was negligibly small in our UF experiments.
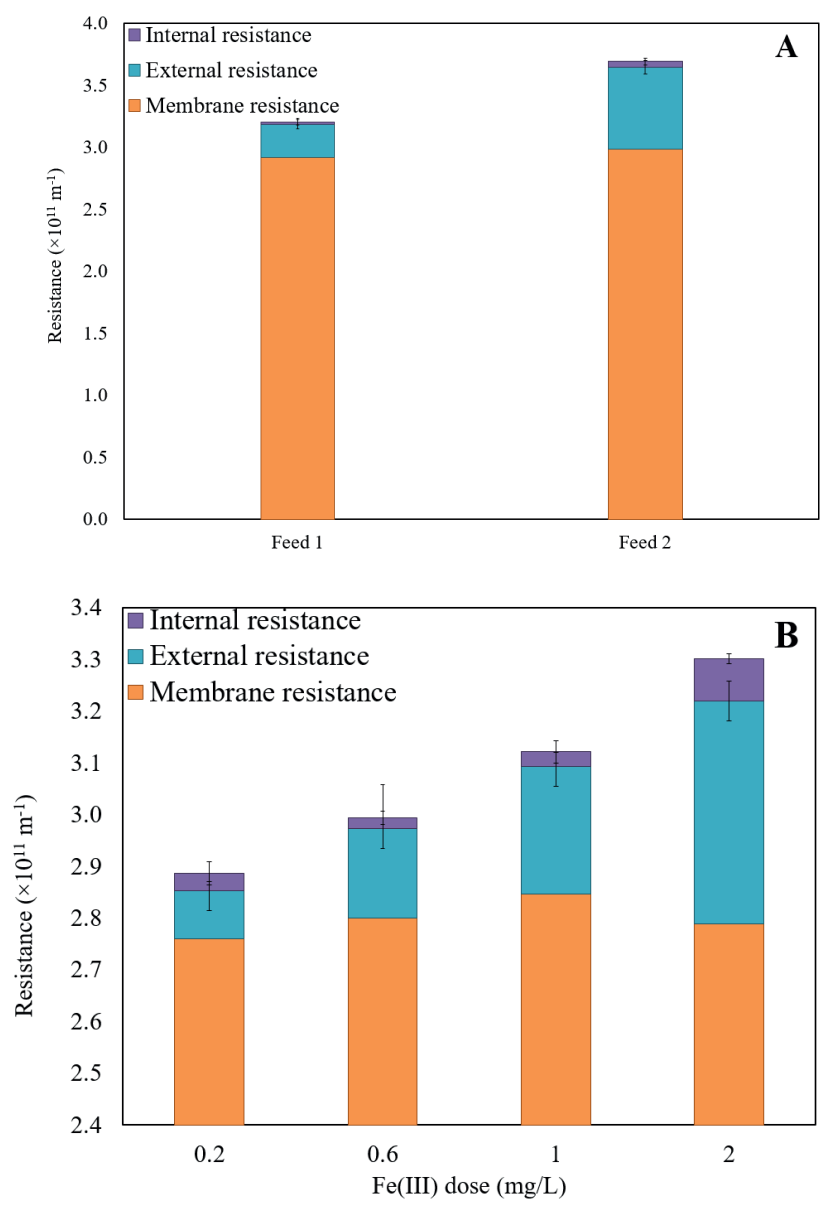

Figure 6.10 Resistance model analysis for the UF experiments for (A) Feed 1 which was dosed with 1 $\mathrm{mg} / \mathrm{L} \mathrm{Fe}(\mathrm{III})$ and Feed 2 which was dosed with $3 \mathrm{mg} / \mathrm{L} \mathrm{Fe}(\mathrm{III})$ and (B) Feed 1 which was dosed with different $\mathrm{Fe}(\mathrm{III})$ doses $(0.2-2 \mathrm{mg} / \mathrm{L})$.

\section{Acknowledgement}

This research is co-financed with PPS-funding from the Topconsortia for Knowledge \& Innovation (TKI's) of the Ministry of Economic Affairs and Climate. AA acknowledges support from Evides Waterbedrijf. We thank Marcel Giesbers and Jelmer Vroom at Wageningen Electron Microscopy Centre for assistance during SEM data collection. 


\section{SUPPLEMENTARY INFORMATION}

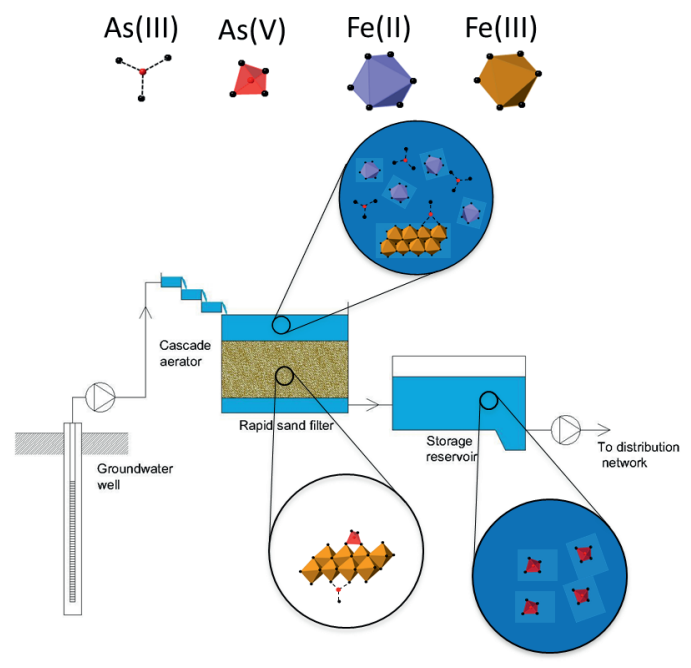

Figure S6.1. The mechanisms controlling the fate and removal of $\mathrm{As}(\mathrm{III})$ and $\mathrm{Fe}(\mathrm{II})$ during conventional groundwater treatment. Modified from (Ahmad et al. 2018). Note that As(III) oxidizes to As(V) in rapid sand filters and the effluent contains only $\mathrm{As}(\mathrm{V})$. 

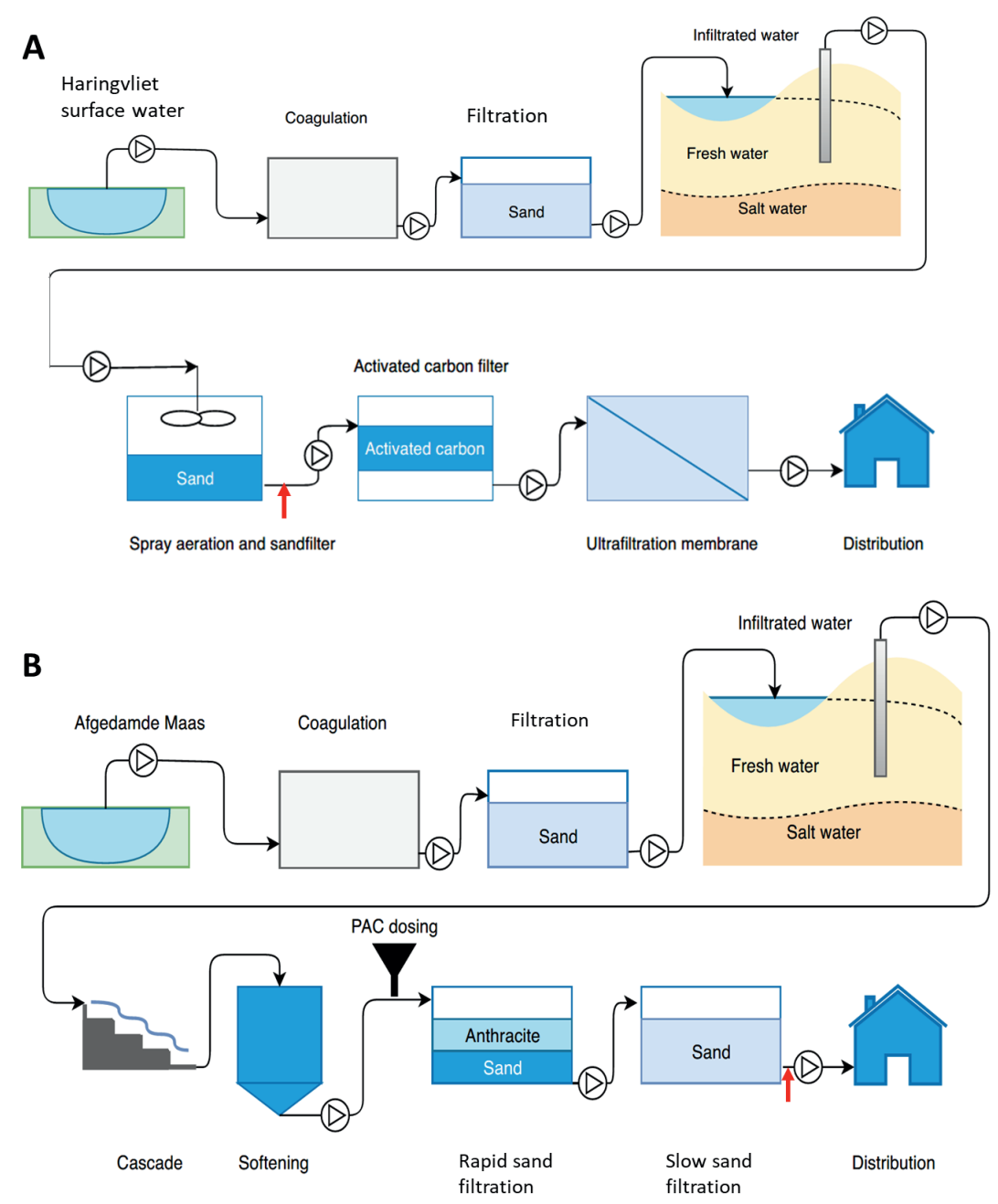

Figure S6.2 Process schemes of water treatment plants (A) Ouddorp and (B) Katwijk. The coprecipitation-low pressure membrane filtration experiments were performed using the effluent samples of the rapid sand filters from both treatment plants (sample points marked by red arrows). 


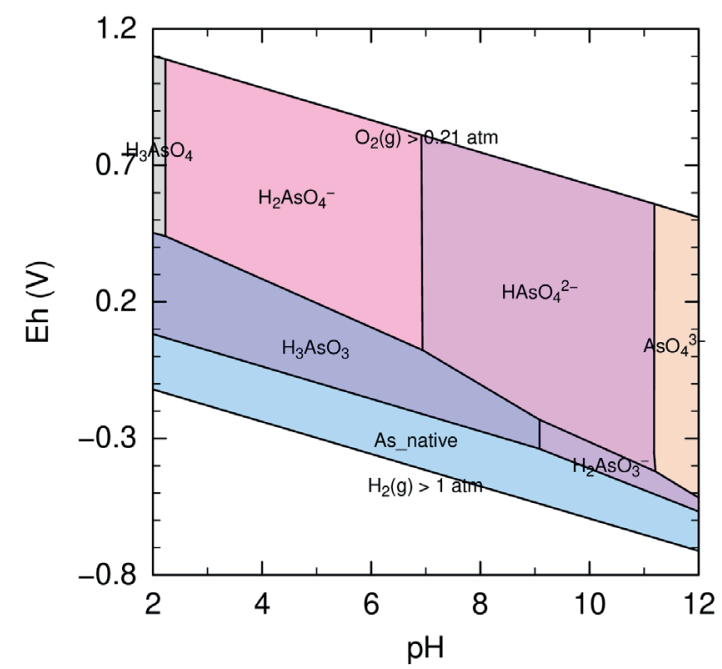

Figure S6.3 $\mathrm{E}_{\mathrm{h}}-\mathrm{pH}$ diagram for aqueous As species in the system $\mathrm{As}-\mathrm{O}_{2}-\mathrm{H}_{2} \mathrm{O}$ at $25^{\circ} \mathrm{C}$ and 1 bar total pressure. This Fig. is created with Phreeqplot using the wateq4f.dat database. All As-species shown are aqueous species except for native As.

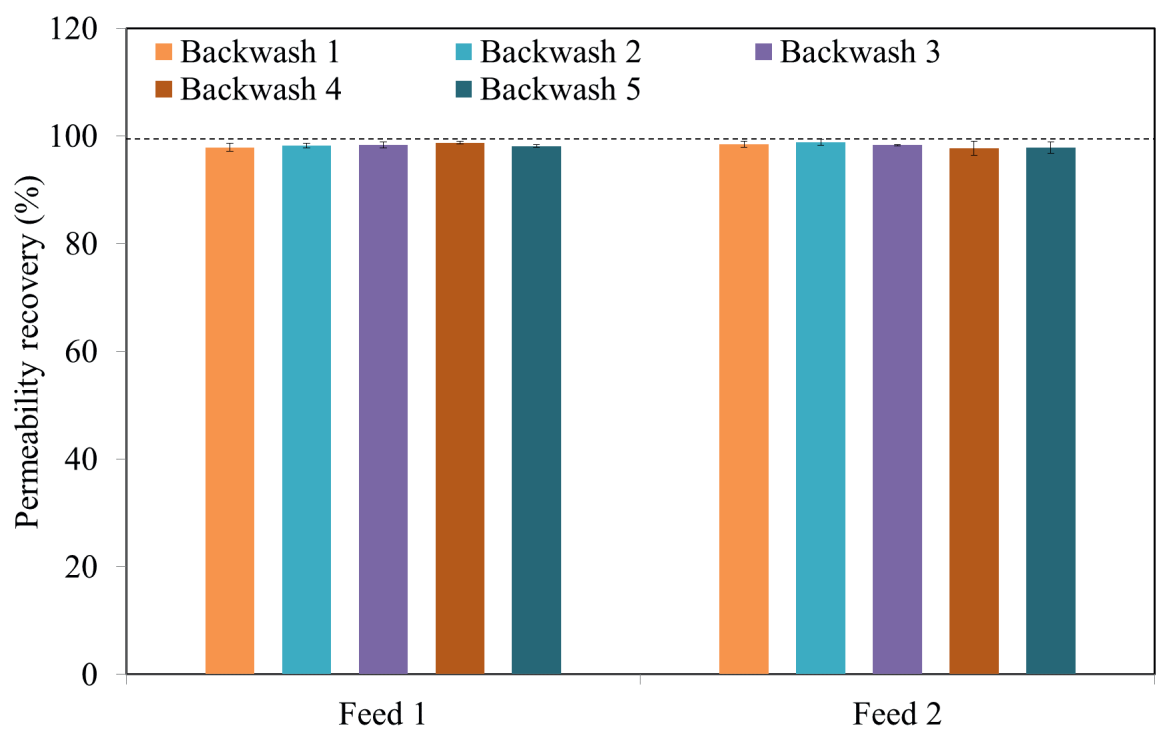

Figure S6.4 Cumulative permeability recovery with respect to the number of backwash cycles in UF experiments with Feed 1 which was dosed in-line with $1 \mathrm{mg} / \mathrm{L} \mathrm{Fe}(\mathrm{III})$ and Feed 2 which was dosed inline with $3 \mathrm{mg} / \mathrm{L} \mathrm{Fe}(\mathrm{III})$. The dotted line represents $100 \%$ recovery of the permeability. 
Table S6.1 Quality of rapid sand filter effluent at WTP Ouddorp and WTP Katwijk in the Netherlands, based on the historical data (2016-2019) provided by the operating water companies.

\begin{tabular}{|c|c|c|c|}
\hline Parameter & Unit & $\begin{array}{l}\text { RSF effluent } \\
\text { Ouddorp } \\
\text { (Feed 1) }\end{array}$ & $\begin{array}{l}\text { RSF effluent } \\
\text { Katwijk } \\
\text { (Feed 2) }\end{array}$ \\
\hline Temp & ${ }^{\circ} \mathrm{C}$ & $9.4-16.2$ & $13.7-16.8$ \\
\hline $\mathrm{pH}$ & & $7.75-7.87$ & $8.37-8.62$ \\
\hline Dissolved Oxygen & $\mathrm{mg} / \mathrm{L} \mathrm{O}_{2}$ & $6.5-8.0$ & 9.7 \\
\hline Electrical Conductivity & $\mathrm{mS} / \mathrm{m}$ & $55-68$ & $48.5-52.6$ \\
\hline Bicarbonate & $\mathrm{mg} / \mathrm{L} \mathrm{HCO}_{3}$ & $235-260$ & $167-184$ \\
\hline Turbidity & NTU & $0.01-0.03$ & $<0.03$ \\
\hline Arsenic & $\mu \mathrm{g} / \mathrm{L}$ As & $1.9-3.2$ & $3.2-3.4$ \\
\hline Iron & $\mathrm{mg} / \mathrm{L} \mathrm{Fe}$ & $<0.01-0.08$ & $<0.01$ \\
\hline Manganese & $\mathrm{mg} / \mathrm{L} \mathrm{Mn}$ & $<0.01$ & $<0.01$ \\
\hline Orthophosphate & $\mu \mathrm{g} / \mathrm{L} P$ & $6.0-120$ & $50-150$ \\
\hline Silicate & $\mathrm{mg} / \mathrm{L} \mathrm{Si}$ & $3.0-4.0$ & $3.5-5.0$ \\
\hline Total organic carbon & $\mathrm{mg} / \mathrm{L} \mathrm{C}$ & $1.5-3.9$ & 2.1 \\
\hline Ammonium & $\mathrm{mg} / \mathrm{L} \mathrm{NH}_{4}$ & $<0.02$ & $<0.02$ \\
\hline Nitrite & $\mathrm{mg} / \mathrm{L} \mathrm{NO}_{2}$ & $<0.007$ & $<0.007$ \\
\hline Nitrate & $\mathrm{mg} / \mathrm{L} \mathrm{NO}_{3}$ & $1.4-2.5$ & $1.7-2.2$ \\
\hline Calcium & $\mathrm{mg} / \mathrm{L} \mathrm{Ca}$ & $77-83$ & $40-46$ \\
\hline Magnesium & $\mathrm{mg} / \mathrm{L} \mathrm{Mg}$ & $9.7-10$ & $7.7-8.3$ \\
\hline Sulphate & $\mathrm{mg} / \mathrm{L} \mathrm{SO}_{4}$ & $30-39$ & $45-51$ \\
\hline Sodium & $\mathrm{mg} / \mathrm{L} \mathrm{Na}$ & $34-50$ & $57-60$ \\
\hline Chloride & $\mathrm{mg} / \mathrm{L} \mathrm{Cl}$ & $67-94$ & $54-56$ \\
\hline
\end{tabular}




\section{REFERENCES}

Ahmad, A., \& Bhattacharya, P. (2019). Arsenic in Drinking Water: Is $10 \mu \mathrm{g} / \mathrm{L}$ a Safe Limit? Current Pollution Reports, 5, 1-3. doi:10.1007/s40726-019-0102-7

Ahmad, A., Cornelissen, E., van de Wetering, S., van Dijk, T., Van Genuchten, C., Bundschuh, J., van der Wal, A., Bhattacharya, P. (2018). Arsenite removal in groundwater treatment plants by sequential Permanganate - Ferric treatment. Journal of Water Process Engineering, 26, 221-229. doi:https://doi.org/10.1016/j.jwpe.2018.10.014

Ahmad, A., Richards, L. A., \& Bhattacharya, P. (2017). Arsenic remediation of drinking water: an overview. In P. Bhattacharya, D. A. Polya, \& D. Jovanovic (Eds.), Best Practice Guide on the Control of Arsenic in Drinking Water (pp. 79-98). IWA Publishing, London, UK

Ahmad, A., Rutten, S., Eikelboom, M., de Waal, L., Bruning, H., Bhattacharya, P., \& van der Wal, A. (2019). Impact of phosphate, silicate and natural organic matter on the size of Fe(III) precipitates and arsenate co-precipitation efficiency in calcium containing water. Separation and Purification Technology, 235, 116117. doi:https://doi.org/10.1016/j.seppur.2019.116117

Ahmad, A., Van der Wens, P., Baken, K., De Waal, L., Bhattacharya, P., \& Stuyfzand, P. (2019). Arsenic reduction to $<1 \mathrm{ug} / \mathrm{L}$ in Dutch drinking water. Environ Int., 134, 105253. doi:10.1016/j. envint.2019.105253

Bella, G. D., \& Trapani, D. D. (2019). A Brief Review on the Resistance-in-Series Model in Membrane Bioreactors (MBRs). Membranes, 9(2), 24. doi:10.3390/membranes9020024

Brandhuber, P., \& Amy, G. (1998). Alternative methods for membrane filtration of arsenic from drinking water. Desalination, 117(1), 1-10. doi:http://dx.doi.org/10.1016/S0011-9164(98)00061-7

Busch, J., Cruse, A., \& Marquardt, W. (2007). Modeling submerged hollow-fiber membrane filtration for wastewater treatment. Journal of Membrane Science, 288(1), 94-111. doi:https://doi. org/10.1016/j.memsci.2006.11.008

Choi, K. Y.-j., \& Dempsey, B. A. (2004). In-line coagulation with low-pressure membrane filtration. Water Research, 38(19), 4271-4281. doi:https://doi.org/10.1016/j.watres.2004.08.006

Dixit, S., \& Hering, J. G. (2003). Comparison of arsenic(V) and arsenic(III) sorption onto iron oxide minerals: Implications for arsenic mobility. Environmental Science and Technology, 37(18), 4182-4189. doi:10.1021/es030309t

Fane, A. G., Xi, W., \& Rong, W. (2006). Chapter 7 - Membrane filtration processes and fouling. In G. Newcombe \& D. Dixon (Eds.), Interface Science and Technology (Vol. 10, pp. 109-132): Elsevier.

Ferreccio, C., González, C., Milosavjlevic, V., Marshall, G., Sancha, A. M., \& Smith, A. H. (2000). Lung cancer and arsenic concentrations in drinking water in Chile. Epidemiology, 11(6), 673679. doi:10.1097/00001648-200011000-00010

Floris, R., Nijmeijer, K., \& Cornelissen, E. R. (2016). Removal of Aqueous nC60 Fullerene from Water by Low Pressure Membrane Filtration. Water Research, 91, 115-125.

Fuller, C. C., Davis, J. A., \& Waychunas, G. A. (1993). Surface chemistry of ferrihydrite: Part 2. Kinetics of arsenate adsorption and coprecipitation. Geochimica et Cosmochimica Acta, 57(10), 2271-2282. doi:10.1016/0016-7037(93)90568-H

Ghurye, G., Clifford, D., \& Tripp, A. (2004). Iron Coagulation and Direct Microfiltration to Remove Arsenic from Groundwater. American Water Works Association, 96(4), 143-152.

Gude, J. C. J., Joris, K., Huysman, K., Rietveld, L. C., \& van Halem, D. (2018). Effect of supernatant water level on As removal in biological rapid sand filters. Water Research X, 1, 100013. doi:https://doi.org/10.1016/j.wroa.2018.100013

Gude, J. C. J., Rietveld, L. C., \& van Halem, D. (2016). Fate of low arsenic concentrations during full-scale aeration and rapid filtration. Water Research, 88, 566-574. doi:10.1016/j. 
watres.2015.10.034

Gude, J. C. J., Rietveld, L. C., \& van Halem, D. (2017). As(III) oxidation by MnO2 during groundwater treatment. Water Research, 111, 41-51. doi:10.1016/j.watres.2016.12.041

Gude, J. C. J., Rietveld, L. C., \& van Halem, D. (2018). Biological As(III) oxidation in rapid sand filters. Journal of Water Process Engineering, 21, 107-115. doi:https://doi.org/10.1016/j. jwpe.2017.12.003

Hering, J. G., Chen, P.-Y., Wilkie, J. A., Elimelech, M., \& Liang, S. (1996). Arsenic removal by ferric chloride. American Water Works Association, 88(4), 155-167.

Kanematsu, M., Young, T. M., Fukushi, K., Green, P. G., \& Darby, J. L. (2013). Arsenic(III, V) adsorption on a goethite-based adsorbent in the presence of major co-existing ions: Modeling competitive adsorption consistent with spectroscopic and molecular evidence. Geochimica et Cosmochimica Acta, 106, 404-428. doi:https://doi.org/10.1016/j.gca.2012.09.055

Kapaj, S., Peterson, H., Liber, K., \& Bhattacharya, P. (2006). Human health effects from chronic arsenic poisoning--a review. J Environ Sci Health A Tox Hazard Subst Environ Eng, 41(10), 2399-2428. doi:10.1080/10934520600873571

Lee, N., Amy, G., Croué, J.-P., \& Buisson, H. (2004). Identification and understanding of fouling in low-pressure membrane (MF/UF) filtration by natural organic matter (NOM). Water Research, 38(20), 4511-4523. doi:https://doi.org/10.1016/j.watres.2004.08.013

Li, S., Heijman, S., Q J C Verberk, J., Le-Clech, P., Lu, J., Kemperman, A., . . Dijk, J. (2011). Fouling control mechanisms of demineralized water backwash: Reduction of charge screening and calcium bridging effects. Water Research, 45(19), 6289-6200. doi: 10.1016/j.watres.2011.08.004

Luong, V. T., Cañas Kurz, E. E., Hellriegel, U., Luu, T. L., Hoinkis, J., \& Bundschuh, J. (2018). Ironbased subsurface arsenic removal technologies by aeration: A review of the current state and future prospects. Water Research, 133, 110-122. doi:https://doi.org/10.1016/j.watres.2018.01.007

McNeill, L. S., \& Edwards, M. (1995). Soluble arsenic removal at water treatment plants. American Water Works Association, 87(4), 105-113.

Mulder, J. (2012). Basic principles of membrane technology: Springer Science \& Business Media.

Ng, A. N. L., \& Kim, A. S. (2007). A mini-review of modeling studies on membrane bioreactor (MBR) treatment for municipal wastewaters. Desalination, 212(1), 261-281. doi:https://doi. org/10.1016/j.desal.2006.10.013

Qiao, J., Jiang, Z., Sun, B., Sun, Y., Wang, Q., \& Guan, X. (2012). Arsenate and arsenite removal by $\mathrm{FeCl} 3$ : Effects of $\mathrm{pH}$, As/Fe ratio, initial As concentration and co-existing solutes. Separation and Purification Technology, 92, 106-114. doi:10.1016/j.seppur.2012.03.023

Raven, K. P., Jain, A., \& Loeppert, R. H. (1998). Arsenite and arsenate adsorption on ferrihydrite: Kinetics, equilibrium, and adsorption envelopes. Environmental Science and Technology, 32(3), 344-349. doi:10.1021/es970421p

Ruiping, L., Lihua, S., Jiuhui, Q., \& Guibai, L. (2009). Arsenic removal through adsorption, sand filtration and ultrafiltration: In situ precipitated ferric and manganese binary oxides as adsorbents. Desalination, 249(3), 1233-1237. doi:https://doi.org/10.1016/j.desal.2009.06.032

Saint-Jacques, N., Brown, P., Nauta, L., Boxall, J., Parker, L., \& Dummer, T. J. B. (2018). Estimating the risk of bladder and kidney cancer from exposure to low-levels of arsenic in drinking water, Nova Scotia, Canada. Environ Int, 110, 95-104. doi:https://doi.org/10.1016/j.envint.2017.10.014

Senn, A. C., Hug, S. J., Kaegi, R., Hering, J. G., \& Voegelin, A. (2018). Arsenate co-precipitation with $\mathrm{Fe}(\mathrm{II})$ oxidation products and retention or release during precipitate aging. Water Research, 131, 334-345. doi:10.1016/j.watres.2017.12.038

Shi, Q., Jing, C., \& Meng, X. (2018). Competing Interactions of As Adsorption and Fe(III) Polymerization during Ferric Coprecipitation Treatment. Environmental Science and Technology, 52(13), 7343-7350. doi:10.1021/acs.est.8b01845

Shi, X., Tal, G., Hankins, N. P., \& Gitis, V. (2014). Fouling and cleaning of ultrafiltration membranes: 
A review. Journal of Water Process Engineering, 1, 121-138. doi:https://doi.org/10.1016/j. jwpe.2014.04.003

Steinmaus, C., Yuan, Y., Kalman, D., Rey, O. A., Skibola, C. F., Dauphine, D., . . Smith, A. H. (2010). Individual differences in arsenic metabolism and lung cancer in a case-control study in Cordoba, Argentina. Toxicology and Applied Pharmacology, 247(2), 138-145. doi:http://dx.doi. org/10.1016/j.taap.2010.06.006

Trzaskus, K. W., Zdeb, A., de Vos, W. M., Kemperman, A., \& Nijmeijer, K. (2016). Fouling behavior during microfiltration of silica nanoparticles and polymeric stabilizers. Journal of Membrane Science, 505, 205-215. doi:https://doi.org/10.1016/j.memsci.2016.01.032

Van der Wens, P., Baken, K., Schriks, M., 2016. Arsenic at low concentrations in Dutch drinking water: assessment of removal costs and health benefits. In: Bhattacharya, P., et al., (Eds.), Arsenic Research and Global Sustainability: Proceedings of the Sixth International Congress on Arsenic in the Environment (As2016), June 19-23, 2016, Stockholm, Sweden, CRC Press, pp. 563-564

Van Genuchten, C. M., Gadgil, A. J., \& Peña, J. (2014). Fe(III) Nucleation in the Presence of Bivalent Cations and Oxyanions Leads to Subnanoscale $7 \AA$ Polymers. Environmental Science \& Technology, 48(20), 11828-11836. doi:10.1021/es503281a

Van Genuchten, C. M., Pena, J., Amrose S, E., \& Gadgil, A. J. (2014). Structure of Fe(III) precipitates genberated by the electrolytric dissolution of $\mathrm{Fe}(0)$ in the presence of groundwater ions. Geochimica et Cosmochimica Acta, 127, 285-304.

Voegelin, A., Kaegi, R., Frommer, J., Vantelon, D., \& Hug, S. J. (2010). Effect of phosphate, silicate, and $\mathrm{Ca}$ on $\mathrm{Fe}(\mathrm{III})$-precipitates formed in aerated $\mathrm{Fe}(\mathrm{II})$ - and $\mathrm{As}(\mathrm{III})$-containing water studied by X-ray absorption spectroscopy. Geochimica et Cosmochimica Acta, 74(1), 164-186. doi:https:// doi.org/10.1016/j.gca.2009.09.020

Zouboulis, A., \& Katsoyiannis, I. (2002). Removal of arsenate from contaminated water by coagulationdirect filtration. Separation Science and Technology, 37(12), 2859-2873. doi:10.1081/SS120005470 



\section{Chapter 7}

General discussion and outlook 


\subsection{MAIN FINDINGS AND PERSPECTIVES}

The objective of this thesis was to provide detailed understanding of arsenic (As) removal during groundwater treatment by co-precipitation with Fe(III)(oxyhydr) oxides under different redox, ion composition and filtration conditions. Moreover, we investigated routes to reduce As in drinking water to below $1 \mu \mathrm{g} / \mathrm{L}$. In the following sections we highlight our main contributions and their significance.

\subsubsection{Rapid sand filters are the arsenic removal hotspots}

From this study we conclude that rapid sand filtration is the most important treatment step for the oxidation and removal of As during groundwater treatment. The removal of As is tightly coupled to Fe removal in rapid sand filters and mainly attributed to co-precipitation of As with Fe(III)(oxyhydr)oxides, which are generated by oxidation and subsequent hydrolysis of Fe(II). No As removal takes place in additional treatment such as granular activated carbon filtration, ultrafiltration or slow sand filtration, due to a lack of hydrolyzing iron in their influent and a lack of adsorption affinity between As and the media surfaces.

The As co-precipitation efficiency with Fe(III)(oxyhydr)oxides is much higher in rapid sand filter beds compared to aeration and supernatant storage. This is ascribed to oxidation of $\mathrm{As}(\mathrm{III})$ to $\mathrm{As}(\mathrm{V})$ in the rapid sand filter beds, potentially executed by manganese oxides and/or As(III) oxidizing bacteria, as both are observed in the coating of rapid sand filter media grains. This study shows that during groundwater treatment $\mathrm{Fe}(\mathrm{II})$ oxidation begins as soon as the raw groundwater is aerated and $\mathrm{Fe}(\mathrm{III})$ (oxyhydr)oxide precipitation proceeds in the supernatant and rapid sand filter bed. On the other hand, the natural As(III) oxidation only occurs in rapid sand filter bed. This prevents effective As-uptake by the formed Fe(III)(oxyhydr)oxides during groundwater treatment. We propose that this problem can be solved by managing the sequence of As(III) and Fe(II) oxidation so that Fe(II) oxidation is delayed during rapid sand filtration, e.g. by lowering the influent $\mathrm{pH}$ which can decrease the rate of Fe(II) oxidation (Van Beek et al. 2016, Van Beek et al. 2012, Vries et al. 2017). The $\mathrm{pH}$ reduction is also expected to increase adsorption of $\mathrm{As}(\mathrm{V})$ to the freshly formed $\mathrm{Fe}(\mathrm{III})$ precipitates in rapid sand filters because Fe(III)(oxyhydr)oxides have a higher number of adsorption sites for As at lower $\mathrm{pH}$.

\subsubsection{Dosing strong oxidant improves arsenic removal but impacts iron and manganese oxidation mechanisms in rapid sand filters}

This study shows that typical aeration techniques (e.g. cascades) are inefficient in oxidizing $\mathrm{As}(\mathrm{III})$ to $\mathrm{As}(\mathrm{V})$ before rapid sand filters at water treatment plants, resulting in inefficient As co-precipitation with Fe(III)(oxyhydr)oxides. Potassium 
permanganate is a strong oxidant which rapidly accomplishes As(III) oxidation to $\mathrm{As}(\mathrm{V})$ and drastically improves As co-precipitation efficiency with Fe(III)(oxyhydr) oxides, resulting in As reduction to very low levels, below $1 \mu \mathrm{g} / \mathrm{L}$.

While no negative effect on the removal efficiency of $\mathrm{Fe}(\mathrm{II}), \mathrm{Mn}(\mathrm{II})$ and $\mathrm{NH}_{4}^{+}$ in rapid sand filters is observed due to $\mathrm{KMnO}_{4}$ dosing, the pre-established $\mathrm{Fe}$ (II) and $\mathrm{Mn}(\mathrm{II})$ removal mechanisms in rapid sand filters are affected due to $\mathrm{KMnO}_{4}$ dosing. Typically, without $\mathrm{KMnO}_{4}$ dosing, a significant part of $\mathrm{Fe}(\mathrm{II})$ oxidation and complete $\mathrm{Mn}$ (II) oxidation occurs in the rapid sand filter bed, due to surface catalytic and biological processes. However when $\mathrm{KMnO}_{4}$ is dosed in the influent of rapid sand filters for As(III) oxidation, both $\mathrm{Fe}(\mathrm{II})$ and $\mathrm{Mn}$ (II) are completely oxidized (and precipitated) before entering the rapid sand filter bed. In this case, the Fe and Mn precipitates are removed primarily by cake-filtration and shorten filter run time. This conclusion underlines the great potential of strong oxidants such as $\mathrm{KMnO}_{4}$ for improving As(III) removal at groundwater treatment plants, but also points out an important practical implication for water treatment which can be solved by adjustments in the design of rapid sand filters, e.g. by replacing the existing filter media with a coarser grain size.

\subsubsection{Oxidant identity impacts the composition and structure of iron and manganese oxidation products}

This study reveals that dosing of strong oxidants in groundwater impacts the composition and structure of the formed Fe and Mn bearing precipitates. In cooxidation of $\mathrm{Fe}(\mathrm{II})$ and $\mathrm{Mn}(\mathrm{II})$ with different oxidants, the $\mathrm{Mn}$ content in the oxidation products increases in the order $\mathrm{O}_{2}<\mathrm{NaOCl}<\mathrm{KMnO}_{4}$, whereby a significant fraction of $\mathrm{Mn}$ in $\mathrm{KMnO}_{4}$ driven oxidation products is $\mathrm{MnO}_{2}$ originating from $\mathrm{KMnO}_{4}$ reduction. The oxidant identity also impacts the speciation of oxidized Fe and $\mathrm{Mn}$ in the precipitates. For example, we show that in the absence of competing ions, $\mathrm{O}_{2}$ produces $\mathrm{Mn}(\mathrm{III})$-incorporated moderately crystalline lepidocrocite, $\mathrm{NaOCl}$ produces $\mathrm{Mn}(\mathrm{III})$-incorporated poorly-ordered hydrous ferric oxide, and $\mathrm{KMnO}_{4}$ produces poorly-ordered $\mathrm{MnO}_{2}$ and poorly-ordered hydrous ferric oxide phases. In general, ion uptake capacity of a poorly-crystalline phase is higher than the crystalline solid phase. Therefore, the diversity of precipitates must be considered when enhancing As(III) oxidation and removal in water treatment processes by the use of strong oxidants.

The formation of $\mathrm{MnO}_{2}$ by $\mathrm{KMnO}_{4}$ addition is fascinating. These types of $\mathrm{Mn}$ (IV) oxides have remarkable reactivity with respect to adsorption of a wide variety of toxic heavy metals (e.g. $\mathrm{Cd}(\mathrm{II}), \mathrm{Pb}(\mathrm{II}), \mathrm{Cu}(\mathrm{II}), \mathrm{Ni}(\mathrm{II})$ ) (Peña et al. 2015, Pena et al. 2010, Villalobos 2015). Our results suggest that Fe(II) oxidation by $\mathrm{KMnO}_{4}$ and the production of mixtures of $\mathrm{Fe}(\mathrm{III})$ and $\mathrm{MnO}_{2}$ would be ideal for concurrent 
treatment of As(III) and heavy metals. This result is particularly important for the co-removal of $\mathrm{As}(\mathrm{III})$ and $\mathrm{Cd}(\mathrm{II})$, which can often occur simultaneously in polluted environments (Perera et al. 2016), since $\mathrm{Cd}(\mathrm{II})$ removal by $\mathrm{Fe}(\mathrm{III})$ precipitates is much less effective than $\mathrm{MnO}_{2}$ (Van Genuchten and Peña 2016b).

\subsubsection{Ionic composition of water affects arsenic removal by iron based co- precipitation}

Arsenic is oxidized during rapid sand filtration. Thus, the use of $\mathrm{KMnO}_{4}$ is avoided and As levels below $1 \mu \mathrm{g} / \mathrm{L}$ are achieved by treating the effluent of rapid sand filter for $\mathrm{As}(\mathrm{V})$ removal by dosing a small amount of $\mathrm{Fe}(\mathrm{III})$ coagulant such as $\mathrm{FeCl}_{3}$. Nevertheless, the ionic composition of water strongly controls As $(\mathrm{V})$ removal, by affecting the adsorption efficiency of $\mathrm{As}(\mathrm{V})$ with $\mathrm{Fe}(\mathrm{III})$ (oxyhydr)oxides and the size of As bearing $\mathrm{Fe}(\mathrm{III})$ particles. We show that $\mathrm{Si}$ and $\mathrm{P}$ reduce $\mathrm{As}(\mathrm{V})$ removal by $\mathrm{Fe}(\mathrm{III})$ based co-precipitation, mainly due to competition with As(V) adsorption to $\mathrm{Fe}(\mathrm{III})$ precipitates. Though $\mathrm{Si}$ and $\mathrm{P}$ oxyanions are known to strongly reduce $\mathrm{Fe}(\mathrm{III})$ precipitate growth, we show that presence of high $\mathrm{Ca}$ concentrations in groundwater (common in the Netherlands and several other parts of the world) counteracts the negative effects of both $\mathrm{Si}$ and $\mathrm{P}$ and promote coagulation of $\mathrm{Fe}(\mathrm{III})$ precipitates to form large particles which are easily separated from water by gravitation settling and rapid sand filtration.

Despite presence of high Ca concentrations, $\mathrm{NOM}$ reduces $\mathrm{As}(\mathrm{V})$ removal quite drastically, attributed largely to the formation of soluble and colloidal Fe(III)-NOM complexes which are not easily separated by conventional filtration. These findings indicate that elevated NOM concentrations, e.g. due to seasonal effects or climate change, can pose an increasing challenge for water utilities for As removal because NOM can seriously inhibit co-precipitation of As with Fe(III)(oxyhydr)oxides and increase the mobility of As during water treatment.

\subsubsection{Ferric based co-precipitation of arsenic in combination with ultrafiltration is a highly viable arsenic removal technology post rapid sand filtration}

At water treatment plants ultrafiltration is frequently used as a final treatment step for disinfection. Arsenic is oxidized in prior rapid sand filters, resulting in $\mathrm{As}(\mathrm{V})$ being the predominant As species in UF feed. In-line dosing of a small amount of $\mathrm{FeCl}_{3}$ before UF is shown to be effective for As reduction to $<1 \mu \mathrm{g} / \mathrm{L}$ in such situations. In this process, $\mathrm{As}(\mathrm{V})$ co-precipitation with $\mathrm{Fe}(\mathrm{III})$ (oxyhydr)oxides rapidly reaches equilibrium, thus little contact time before the membranes is required. Moreover, when As bearing $\mathrm{Fe}(\mathrm{III})$ precipitates grow to sizes larger than the pore size of UF membranes (expected for most Ca bearing groundwaters) the Fe(III) particles foul the membranes mainly by forming a cake-layer on the surface which is effectively removed with a hydraulic backwash. Thus, sustainable long term operation of UF 
membranes with in-line $\mathrm{FeCl}_{3}$ dosing for As removal is highly viable. More open low-pressure membranes may be more susceptible to irreversible fouling than UF due to a large pore size which can allow some Fe(III) particles to penetrate deeper into the membrane structure and get immobilized there, however further research is needed to gain insights into fouling mechanisms in MF membranes.

\subsection{Implementation of results and further considerations}

Triggered by the potential of As toxicity in extremely low concentrations, in this thesis reduction of already low As concentrations in Dutch groundwater to even lower As concentrations, below $1 \mu \mathrm{g} / \mathrm{L}$ was the objective. Nevertheless, the findings in this thesis are also of highly relevance for water utilities which struggle to comply with the current WHO guideline of $10 \mu \mathrm{g} / \mathrm{L}$ As in drinking water, e.g. in several South East Asian, East European and Latin American countries. Building on this work, three groundwater treatment plants in the Netherlands have received an upgrade with $\mathrm{KMnO}_{4}$ dosing, sometimes in combination with $\mathrm{FeCl}_{3}$ dosing for reducing As reduction to below $1 \mu \mathrm{g} / \mathrm{L}$. One treatment plant which makes use of artificially recharged groundwater will receive an upgrade with $\mathrm{FeCl}_{3}$ dosing before the polishing UF step. Several projects are under discussion in Bangladesh, India and Pakistan where As(III) is the predominant species of As in groundwater, for coremoval of $\mathrm{As}$ (III), $\mathrm{Fe}(\mathrm{II})$ and $\mathrm{Mn}$ (II) by dosing $\mathrm{KMnO}_{4}$ in groundwater. The $\mathrm{Fe}(\mathrm{III})$ based co-precipitation in combination with UF method is proposed for As removal in Argentina and Mexico where $\mathrm{As}(\mathrm{V})$ is the predominant As species in groundwater, mobilized predominantly from young volcanic rocks and their weathering products (Bundschuh et al. 2012). Especially, the capability of UF for bacteria and virus removal makes $\mathrm{Fe}$ (III) based co-precipitation-UF an interesting technology for combined As removal and disinfection of groundwater.

Use of $\mathrm{KMnO}_{4}$ may not be appealing to some utilities because of its relatively high cost or extra safety precautions needed for safe storage at water treatment plants. In that case, cleverly exploiting the natural As(III) oxidation capacity of rapid sand filters is required. However, current knowledge of the intricate physicochemical and biological processes in rapid sand filters is limited and clear guidelines for controlling the sequence of $\mathrm{Fe}(\mathrm{II})$ and $\mathrm{As}$ (III) oxidation in rapid sand filters have not been discerned. Research is ongoing to gain a better understanding of As(III) and Fe(II) oxidation in rapid sand filters.

We underline that $\mathrm{As}$ (III) can also be oxidized by oxidative hydrolysis of Fe(II), attributed to the oxidizing radical species ( $\mathrm{Fe}(\mathrm{IV})$ and $\mathrm{H}_{2} \mathrm{O}_{2}$ at near-neutral $\mathrm{pH}$ ) that form during oxidation of $\mathrm{Fe}(\mathrm{II})$ by dissolved $\mathrm{O}_{2}$ (Hug and Leupin 2003, Roberts et al. 2004). The effective exploitation of Fe-catalyzed As(III) oxidation requires a more controlled dosing and oxidation of Fe(II), rather than a single step dose 
of an $\mathrm{Fe}$ (II) bearing solution (e.g. $\mathrm{FeSO}_{4}$ ) (Roberts et al. 2004, Van Genuchten et al. 2018b). In this context Electrocoagulation is a highly promising alternative to chemical coagulation. In Electrocoagulation, in-situ Fe hydroxide species (Fe precipitates) are formed due to electro-dissolution of sacrificial anodes. $\mathrm{Fe}(0)$ oxidizes to dissolved $\mathrm{Fe}$ (II) which is subsequently oxidized to generate Fe precipitates in water. In Electrocoagulation the dissolution rate of Fe electrodes can be conveniently controlled by varying the current. Also, due to its potential low carbon-foot print and high coagulation efficiency.

Management of As-laced treatment residuals is an important consideration in water treatment. In this thesis we observed that in the backwash water, the Fe and As were almost entirely removed by $0.45 \mu \mathrm{m}$ filtration, indicating that As was strongly bound to the $\mathrm{Fe}(\mathrm{III})$ precipitates and easy separation of these As bearing$\mathrm{Fe}(\mathrm{III})$ precipitates from the backwash water should not be problematic. However, it is noteworthy that some $\mathrm{As}(\mathrm{V})$ may be mobilized from the solid phase over years of storage, particularly if the solid phase crystallizes over time (Fuller et al. 1993, Senn et al. 2018) or is exposed to reducing conditions that transform $A s(V)$ and $\mathrm{Fe}(\mathrm{III})$ (oxyhydr)oxides (Meng et al. 2001). The differences in the structure and composition of $\mathrm{Fe}(\mathrm{III})$ precipitates can result in differences in their availability as terminal electron acceptors in redox-sensitive environments (Hyacinthe et al. 2008, Voegelin et al. 2010). More research is required in this area. 


\section{REFERENCES}

Bundschuh, J., Litter, M. I., Parvez, F., Román-Ross, G., Nicolli, H. B., Jean, J.-S., Toujaguez, R. (2012). One century of arsenic exposure in Latin America: A review of history and occurrence from 14 countries. Science of the Total Environment, 429, 2-35. doi:https://doi.org/10.1016/j. scitotenv.2011.06.024

Fuller, C. C., Davis, J. A., \& Waychunas, G. A. (1993). Surface chemistry of ferrihydrite: Part 2. Kinetics of arsenate adsorption and coprecipitation. Geochimica et Cosmochimica Acta, 57(10), 2271-2282. doi:10.1016/0016-7037(93)90568-H

Hug, S. J., \& Leupin, O. (2003). Iron-Catalyzed Oxidation of Arsenic(III) by Oxygen and by Hydrogen Peroxide: pH-Dependent Formation of Oxidants in the Fenton Reaction. Environmental Science \& Technology, 37(12), 2734-2742. doi:10.1021/es026208x

Hyacinthe, C., Bonneville, S., \& Van Cappellen, P. (2008). Effect of Sorbed Fe(II) on the Initial Reduction Kinetics of 6-Line Ferrihydrite and Amorphous Ferric Phosphate by Shewanella putrefaciens. Geomicrobiology Journal, 25(3-4), 181-192. doi:10.1080/01490450802081911

Meng, X., Korfiatis, G. P., Jing, C., \& Christodoulatos, C. (2001). Redox Transformations of Arsenic and Iron in Water Treatment Sludge during Aging and TCLP Extraction. Environmental Science \& Technology, 35(17), 3476-3481. doi:10.1021/es010645e

Peña, J., Bargar, J. R., \& Sposito, G. (2015). Copper sorption by the edge surface of synthetic birnessite nanoparticles. Chemical Geology.

Pena, J., Kwon, K., Refson, K., Bargar, J., \& Sposito, G. (2010). Mechanisms of nickel sorption by a bacteriogenic birnessite. Geochimica Et Cosmochimica Acta, 74(11), 3076-3089. doi:10.1016/j. gca.2010.02.035

Perera, P. A. C. T., Sundarabarathy, T. V., Sivananthawerl, T., Kodithuwakku, S. P., \& Edirisinghe, U. (2016). Arsenic and Cadmium Contamination in Water, Sediments and Fish is a Consequence of Paddy Cultivation: Evidence of River Pollution in Sri Lanka. Achievements in the Life Sciences, 10(2), 144-160. doi:https://doi.org/10.1016/j.als.2016.11.002

Roberts, L. C., Hug, S. J., Ruettimann, T., Billah, M. M., Khan, A. W., \& Rahman, M. T. (2004). Arsenic Removal with Iron(II) and Iron(III) in Waters with High Silicate and Phosphate Concentrations. Environmental Science \& Technology, 38(1), 307-315. doi:10.1021/es0343205

Senn, A. C., Hug, S. J., Kaegi, R., Hering, J. G., \& Voegelin, A. (2018). Arsenate co-precipitation with $\mathrm{Fe}(\mathrm{II})$ oxidation products and retention or release during precipitate aging. Water Research, 131, 334-345. doi:10.1016/j.watres.2017.12.038

Van Beek, C. G. E. M., Dusseldorp, J., Joris, K., Huysman, K., Leijssen, H., Schoonenberg Kegel, F., . . Hofs, B. (2016). Contributions of homogeneous, heterogeneous and biological iron(II) oxidation in aeration and rapid sand filtration (RSF) in field sites. Journal of Water Supply: Research and Technology-AQUA, 65(3), 195-207.

Van Beek, C. G. E. M., Hiemstra, T., Hofs, B., Bederlof, M. M., van Paassen, J. A. M., \& Reijnen, G. K. (2012). Homogeneous, heterogeneous and biological oxidation of iron(II) in rapid sand filtration. Journal of Water Supply: Research and Technology—AQUA, 61(1), 1-2012.

Van Genuchten, C. M., Behrends, T., Kraal, P., Stipp, S. L. S., \& Dideriksen, K. (2018). Controls on the formation of Fe(II,III) (hydr)oxides by Fe(0) electrolysis. Electrochimica Acta, 286, 324-338. doi:https://doi.org/10.1016/j.electacta.2018.08.031

Van Genuchten, C. M., \& Peña, J. (2016). Sorption selectivity of birnessite particle edges: a d-PDF analysis of $\mathrm{Cd}(\mathrm{ii})$ and $\mathrm{Pb}(\mathrm{ii})$ sorption by $\delta-\mathrm{MnO}_{2}$ and ferrihydrite. Environmental Science: Processes \& Impacts, 18(8), 1030-1041. doi:10.1039/C6EM00136J

Villalobos, M. (2015). The Role of Surface Edge Sites in Metal(loid) Sorption to Poorly-Crystalline Birnessites. In X. Feng, W. Li, M. Zhu, \& D. Sparks (Eds.), Advances in the Environmental 
Biogeochemistry of Manganese Oxides: American Chemical Society.

Voegelin, A., Kaegi, R., Frommer, J., Vantelon, D., \& Hug, S. J. (2010). Effect of phosphate, silicate, and $\mathrm{Ca}$ on $\mathrm{Fe}$ (III)-precipitates formed in aerated Fe(II)- and As(III)-containing water studied by X-ray absorption spectroscopy. Geochimica et Cosmochimica Acta, 74(1), 164-186. doi:https:// doi.org/10.1016/j.gca.2009.09.020

Vries, D., Bertelkamp, C., Schoonenberg Kegel, F., Hofs, B., Dusseldorp, J., Bruins, J. H., van den Akker, B. (2017). Iron and manganese removal: Recent advances in modelling treatment efficiency by rapid sand filtration. Water Research, 109, 35-45. doi:10.1016/j.watres.2016.11.032 



\section{Summary \\ Samenvatting \\ List of publications in this thesis \\ Acknowledgements \\ About the author}




\section{SUMMARY}

Arsenic (As) is a well-known human carcinogen, classified in Group 1 by the International Agency for Research on Cancer (IARC). Contamination of groundwater with As is a wide-scale problem affecting health of millions of people around the world. The World Health Organization (WHO) guideline for As in drinking water is currently set at $10 \mu \mathrm{g} / \mathrm{L}$, however recent studies suggest that As can cause a considerable damage to human health even at concentrations lower than the WHO guideline. As a result, several drinking water companies are making efforts to reduce As concentrations in drinking water to very low concentrations, below $1 \mu \mathrm{g} / \mathrm{L}$.

Co-precipitation of As with iron(III)(oxyhydr)oxides [Fe(III)(oxyhydr)oxides] is a widely used As removal method in groundwater treatment. Fe(III)(oxyhydr) oxides are produced in an As contaminated water, typically by oxidation of naturally occurring ferrous iron $[\mathrm{Fe}(\mathrm{II})]$ in groundwater using oxygen $\left(\mathrm{O}_{2}\right)$ and/or dosing a ferric iron $[\mathrm{Fe}(\mathrm{III})]$ coagulant such as Ferric Chloride $\left(\mathrm{FeCl}_{3}\right)$. Arsenic strongly adsorbs to the surface of freshly formed $\mathrm{Fe}(\mathrm{III})$ precipitates and subsequently the As bearing $\mathrm{Fe}(\mathrm{III})$ precipitates are removed by filtration to produce As-safe water. The adsorption efficiency of As onto Fe(III) precipitates and the size of As bearing $\mathrm{Fe}(\mathrm{III})$ particles is governed by several interdependent factors such as the conditions of $\mathrm{Fe}(\mathrm{III})$ (oxyhydr)oxide generation in water, oxidation state of As, solution $\mathrm{pH}$ and the concentration of As and co-occurring ions with respect to $\mathrm{Fe}$ in the initial solution. The overall objective of this thesis is to discern mechanistic understanding of As removal by co-precipitation with $\mathrm{Fe}(\mathrm{III}$ )(oxyhydr)oxides under different redox, ion composition and filtration conditions and to investigate routes to reduce As in drinking water to very low levels, below $1 \mu \mathrm{g} / \mathrm{L}$.

We carried out sampling campaigns at full-scale water treatment plants in the Netherlands to develop detailed understanding of the pertinent As removal mechanisms during groundwater treatment. It was found that rapid sand filtration is the most important treatment step for the oxidation and removal of As during groundwater treatment. The removal of As is tightly coupled to Fe removal in rapid sand filters and mainly attributed to co-precipitation of As with $\mathrm{Fe}(\mathrm{III})$ (oxyhydr) oxides, which are generated by oxidation and subsequent hydrolysis of $\mathrm{Fe}(\mathrm{II})$. The As co-precipitation efficiency with $\mathrm{Fe}(\mathrm{III})$ (oxyhydr)oxides is much higher in rapid sand filter beds compared to aeration and supernatant storage. This is ascribed to oxidation of arsenite $[\mathrm{As}(\mathrm{III})]$ to arsenate $[\mathrm{As}(\mathrm{V})]$ in the rapid sand filter beds, potentially executed by manganese oxides $\left(\mathrm{MnO}_{2}\right)$ and/or As(III) oxidizing bacteria, as both are observed in the coating of rapid sand filter media grains. In the $\mathrm{pH}$ range of most groundwaters, $\mathrm{As}(\mathrm{V})$ adsorbs to $\mathrm{Fe}(\mathrm{III})$ (oxyhydr)oxides much more effectively than As(III). 
Typical aeration techniques such as cascades are inefficient in oxidizing As(III) to $\mathrm{As}(\mathrm{V})$ before rapid sand filters at water treatment plants, resulting in inefficient As co-precipitation with $\mathrm{Fe}(\mathrm{III})$ (oxyhydr)oxides. Nevertheless, dosing a strong oxidant such as potassium permanganate $\left(\mathrm{KMnO}_{4}\right)$ rapidly accomplishes As(III) oxidation to $A s(\mathrm{~V})$ and drastically improves As co-precipitation efficiency with $\mathrm{Fe}(\mathrm{III}$ )(oxyhydr)oxides, resulting in As reduction to very low levels, below $1 \mu \mathrm{g} / \mathrm{L}$. While no negative effect on the removal efficiency of $\mathrm{Fe}(\mathrm{II}), \mathrm{Mn}(\mathrm{II})$ and ammonium $\left(\mathrm{NH}_{4}^{+}\right)$in rapid sand filters is observed due to $\mathrm{KMnO}_{4}$ dosing, the pre-established $\mathrm{Fe}(\mathrm{II})$ and $\mathrm{Mn}(\mathrm{II})$ removal mechanisms in rapid sand filters are altered due to $\mathrm{KMnO}_{4}$ dosing, generating a need for rapid sand filter media replacement. We also found that dosing of strong oxidants during groundwater treatment impacts the composition and structure of the formed $\mathrm{Fe}$ and $\mathrm{Mn}$ bearing precipitates. For example, in the absence of competing ions, $\mathrm{O}_{2}$ produces $\mathrm{Mn}(\mathrm{III})$-incorporated moderately crystalline lepidocrocite, sodium hypochlorite $(\mathrm{NaOCl})$ produces $\mathrm{Mn}(\mathrm{III})$-incorporated poorly-ordered hydrous ferric oxide, and $\mathrm{KMnO}_{4}$ produces poorly-ordered $\mathrm{MnO}_{2}$ and poorly-ordered hydrous ferric oxide phases. This diversity of formed precipitates under different redox conditions should be considered in As removal during groundwater treatment.

In this thesis we show that As levels below $1 \mu \mathrm{g} / \mathrm{L}$ can alternatively be achieved by dosing a small amount of $\mathrm{FeCl}_{3}$ in the effluent of rapid sand filter at groundwater treatment plants. The effluent of rapid sand filter predominantly contains arsenate $[\mathrm{As}(\mathrm{V})]$ which is much more effectively adsorbed to $\mathrm{Fe}(\mathrm{III})$ (oxyhydr)oxides than As(III). In this way use of $\mathrm{KMnO}_{4}$ or other strong oxidants can be avoided at groundwater treatment plants. Nevertheless, the ionic composition of water strongly controls $A s(\mathrm{~V})$ removal by iron based co-precipitation, by affecting the adsorption efficiency of $\mathrm{As}(\mathrm{V})$ with $\mathrm{Fe}(\mathrm{III})$ (oxyhydr)oxides and the size of As bearing $\mathrm{Fe}(\mathrm{III})$ particles. We show that silicate $\left(\mathrm{SiO}_{4}^{-4}\right)$ and phosphate $\left(\mathrm{PO}_{4}^{-3}\right)$ reduce $\mathrm{As}(\mathrm{V})$ removal, mainly due to competition with $\mathrm{As}(\mathrm{V})$ adsorption to $\mathrm{Fe}(\mathrm{III})$ precipitates. Though $\mathrm{SiO}_{4}^{-4}$ en $\mathrm{PO}_{4}^{-3}$ oxyanions are known to strongly reduce $\mathrm{Fe}(\mathrm{III})$ precipitate growth, we show that presence of high calcium $(\mathrm{Ca})$ concentrations in groundwater (common in the Netherlands and several other parts of the world) counteracts the negative effects of both $\mathrm{SiO}_{4}^{-4}$ en $\mathrm{PO}_{4}^{-3}$ and promote coagulation of $\mathrm{Fe}$ (III) precipitates to form large particles which are easily separated from water by gravitation settling and rapid sand filtration. Despite presence of high Ca concentrations, Natural Organic Matter $(\mathrm{NOM})$ reduces $\mathrm{As}(\mathrm{V})$ removal quite drastically, attributed largely to the formation of soluble and colloidal Fe(III)-NOM complexes which are not easily separated by conventional filtration.

In-line dosing of a small amount of $\mathrm{FeCl}_{3}$ in the feed water of ultrafiltration (UF) step (typically used for final polishing and disinfection) is shown to be effective for 
As reduction to $<1 \mu \mathrm{g} / \mathrm{L}$ at water treatment plants which use artificially recharged water as source. In this process, $\mathrm{As}(\mathrm{V})$ co-precipitation with $\mathrm{Fe}(\mathrm{III})$ (oxyhydr) oxides rapidly reaches equilibrium, thus little contact time before the membranes is required. Moreover, when As bearing Fe(III) precipitates grow to sizes larger than the pore size of UF membranes (expected for most Ca bearing groundwaters) the $\mathrm{Fe}$ (III) particles foul the membranes mainly by forming a cake-layer on the surface which is effectively removed with a hydraulic backwash. Thus, we conclude that sustainable long term operation of UF membranes with in-line $\mathrm{FeCl}_{3}$ dosing for As removal is highly viable.

Based on the present work, three groundwater treatment plants in the Netherlands have received an upgrade with $\mathrm{KMnO}_{4}$ dosing for reducing As to below $1 \mu \mathrm{g} / \mathrm{L}$. Another treatment plant, which makes use of artificially recharged groundwater, will receive an upgrade with $\mathrm{FeCl}_{3}$ dosing before the polishing UF step. 


\section{SAMENVATTING}

Arseen (As) staat bekend als zeer carcinogeen voor mensen, en het wordt dan ook door het International Agency for Research on Cancer |(IARC) in Groep 1 geclassificeerd. Verontreiniging van grondwater met As is een probleem dat wereldwijd voorkomt, en de gezondheid van miljoenen mensen over de hele wereld bedreigt. De World Health Organization (WHO) heeft het maximaal toelaatbare gehalte van drinkwater op $10 \mu \mathrm{g} / \mathrm{L}$ vastgesteld, maar recente studies suggereren dat As zelfs bij concentraties lager dan deze limiet ernstige schade aan de menselijke gezondheid kan toebrengen. Daarom proberen verschillende drinkwaterbedrijven de As concentraties in drinkwater te verlagen tot heel lage concentraties, lager zelfs dan $1 \mu \mathrm{g} / \mathrm{L}$.

Co-precipitatie van As met ijzer(III)(oxyhydr)oxides [Fe(III)(oxyhydr)oxides] wordt op grote schaal toegepast als een verwijderingsmethode voor As in grondwaterzuivering. Fe(III)(oxyhydr)oxides worden gevormd in met As vervuild water, door de oxidatie via beluchting $\left(\mathrm{O}_{2}\right)$ van van nature voorkomend ferro-ijzer [Fe(II)] in grondwater, en/of door het doseren van ferri ijzer [Fe(III)] als een vlokmiddel (bijvoorbeeld ferrichloride, $\mathrm{FeCl}_{3}$ ). Arseen adsorbeert sterk op het oppervlak van vers gevormd $\mathrm{Fe}(\mathrm{III})$-neerslag, en vervolgens kan het met As beladen neerslag worden verwijderd via filtratie, om veilig As-vrij water te produceren. De effectiviteit van de adsorptie van As op Fe(III)-neerslag en de grootte van de met As beladen Fe(III)deeltjes wordt bepaald door verscheidene onderling afhankelijke factoren, zoals de omstandigheden waaronder $\mathrm{Fe}(\mathrm{III})$ (oxyhydr)oxide wordt gevormd in water, de oxidatietoestand van As, de $\mathrm{pH}$ van de oplossing en de concentraties van As en andere ionen ten opzichte van ijzer in de oorspronkelijke oplossing. Het doel van deze dissertatie is begrip te krijgen van het mechanisme van As-verwijdering via coprecipitatie met $\mathrm{Fe}(\mathrm{III}$ )(oxyhydr)oxides onder verschillende redox-omstandigheden, als gevolg van de samenstelling van de aanwezige ionen, en van de filtratieomstandigheden. Op deze manier zijn verschillende wegen onderzocht om het Asgehalte van drinkwater te kunnen verlagen tot een laag niveau, bij voorkeur lager dan $1 \mu \mathrm{g} / \mathrm{L}$.

We hebben verschillende monstername-campagnes uitgevoerd bij full-scale drinkwaterprocessen in Nederland, om een gedetailleerd begrip te krijgen van relevante As-verwijderingsmechanismen tijdens de behandeling van grondwater. Het bleek dat snelfiltratie de belangrijkste stap is voor de oxidatie en verwijdering van As hierbij. De verwijdering van As is hierbij sterk gerelateerd aan de verwijdering van ijzer in snelfilters, en wordt vooral toegeschreven aan de co-precipitatie van As met $\mathrm{Fe}(\mathrm{III}$ )(oxyhydr)oxides, die worden gevormd door de oxidatie en daaropvolgende hydrolyse van $\mathrm{Fe}(\mathrm{II})$. De effectiviteit van de As co-precipitatie met deze oxides is veel hoger in snelfilters dan tijdens beluchting en opslag van het supernatant. Dit 
wordt toegeschreven aan de oxidatie van arseniet $[\mathrm{As}(\mathrm{III})]$ naar arsenaat $[\mathrm{As}(\mathrm{V})]$ in snelfilterbedden, mogelijk veroorzaakt door mangaanoxides $\left(\mathrm{MnO}_{2}\right)$ en/of As(III) oxiderende bacteriën, die beiden blijken voor te komen in de coating van de zandkorrels van het filterbed. In het $\mathrm{pH}$-bereik van de meeste grondwateren zal As $(\mathrm{V})$ veel effectiever op Fe(III)(oxyhydr)oxides worden geadsorbeerd dan As(III).

Veel voorkomende beluchtingstechnieken bij drinkwaterbedrijven, zoals cascades, zijn niet effectief voor de oxidatie van $\mathrm{As}(\mathrm{III})$ naar $\mathrm{As}(\mathrm{V})$ vóór snelfilters, wat leidt tot een inefficiënte co-precipitatie van As met $\mathrm{Fe}(\mathrm{III})$ (oxyhydr)oxides. Door echter een sterke oxidator als kalium permanganaat $\left(\mathrm{KMnO}_{4}\right)$ toe te voegen, zal de oxidatie van $\mathrm{As}(\mathrm{III})$ naar $\mathrm{As}(\mathrm{V})$ snel worden voltooid, en verbetert de co-precipitatie met Fe(III) (oxyhydr)oxides significant, waardoor zeer lage concentraties, onder $1 \mu \mathrm{g} / \mathrm{L}$, worden bereikt. Dit gaat niet gepaard met een verlaging van de verwijderingsefficiëntie van de snelfilters voor $\mathrm{Fe}(\mathrm{II}), \mathrm{Mn}(\mathrm{II})$ en ammonium $\left(\mathrm{NH}_{4}^{+}\right)$, maar de bekende verwijderingsmechanismen voor $\mathrm{Fe}(\mathrm{II})$ en $\mathrm{Mn}$ (II) worden door de toevoeging van $\mathrm{KMnO}_{4}$ wel veranderd. Hierdoor moet het zand in de snelfilters eerder verwijderd worden. Verder hebben we vastgesteld dat het doseren van een sterke oxidator tijdens grondwaterbehandeling de samenstelling en structuur van de gevormde $\mathrm{Fe}$ en $\mathrm{Mn}$ bevattende neerslagen verandert. Zo vormt zuurstof bijvoorbeeld in afwezigheid van concurrerende ionen $\mathrm{Mn}$ (III)-houdend matig kristallijn lepidocrociet, terwijl natrium hypochloriet ( $\mathrm{NaOCl}) \mathrm{Mn}(\mathrm{III})$-houdend slecht geordend waterhoudend ijzer(III) oxide vormt, en $\mathrm{KMnO}_{4}$ leidt tot slecht geordende $\mathrm{MnO}_{2}$ - en waterhoudende ijzer oxide-fasen. Tijdens de behandeling van grondwater moet met deze verschillen in de gevormde neerslagen als gevolg van andere redoxomstandigheden rekening worden gehouden.

In deze dissertatie laten we zien dat As-concentraties onder $1 \mu \mathrm{g} / \mathrm{L}$ ook kunnen worden bereikt door een kleine hoeveelheid $\mathrm{FeCl}_{3}$ in het effluent van een snelfilters bij grondwaterbehandeling toe te voegen.

Het effluent van een snelfilter bevat vooral arsenaat $[\mathrm{As}(\mathrm{V})]$, wat veel effectiever op Fe(III)(oxyhydr)oxides geadsorbeerd kan worden dan As(III). Op deze manier kan het gebruik van $\mathrm{KMnO}_{4}$ of andere sterke oxidatoren voorkomen worden bij drinkwaterbedrijven die grondwater gebruiken. Toch bepaalt de samenstelling van de ionen in het water in hoge mate de verwijdering van $A s(V)$ via co-precipitatie gebaseerd op ijzer, door de efficiëntie van de adsorptie van As(V) op Fe(III)(oxyhydr) oxides en de grootte van de met As beladen Fe(III) deeltjes te beïnvloeden. We laten zien dat de aanwezigheid van silicaat $\left(\mathrm{SiO}_{4}^{-4}\right)$ en fosfaat $\left(\mathrm{PO}_{4}^{-3}\right)$ de $\mathrm{As}(\mathrm{V})$-verwijdering verminderen, vooral door concurrentie met $\mathrm{As}(\mathrm{V})$ over adsorptieplekken op $\mathrm{Fe}(\mathrm{III})$ neerslag. Hoewel $\mathrm{SiO}_{4}^{-4}$ en $\mathrm{PO}_{4}^{-3}$ oxyanionen erom bekend staan dat ze de groei van $\mathrm{Fe}(\mathrm{III})$ neerslag verminderen, laten we zien dat de anwezigheid van hoge calcium (Ca) concentraties in grondwater (wat in Nederland en veel andere delen van de 
wereld vaak voorkomt) de negatieve effecten van zowel $\mathrm{SiO}_{4}^{-4}$ en $\mathrm{PO}_{4}^{-3}$ teniet doet, en de coagulatie van $\mathrm{Fe}(\mathrm{III})$ neerslag in grote deeltjes, die gemakkelijk uit water verwijderd kunnen worden via bezinking onder invloed van de zwaartekracht en snelfiltratie, bevordert. Ondanks de anwezigheid van hoge Ca concentraties, vermindert de aanwezigheid van Natuurlijk Organisch Materiaal (NOM) de As(V)verwijdering significant, wat voornamelijk wordt toegeschreven aan de vorming van oplosbare en colloïdale Fe(III)-NOM complexen, die niet gemakkelijk te verwijderen zijn via conventionele filtratie.

Het in-line doseren van een kleine hoeveelheid $\mathrm{FeCl}_{3}$ in het voedingswater van een ultrafiltratiestap (UF), wat veel wordt toegepast voor een laatste behandelingsstap en desinfectie, blijkt effectief te zijn om de As-concentratie te verlagen tot $<1 \mu \mathrm{g} / \mathrm{L}$ bij drinkwaterbedrijven die duin-filtraat als bron gebruiken. In dit proces bereikt $\mathrm{As}(\mathrm{V})$ co-precipitatie met $\mathrm{Fe}(\mathrm{III})$ (oxyhydr)oxides snel een evenwicht, en dus is slechts een korte contacttijd voor de membranen nodig. Bovendien blijkt dat als As-beladen $\mathrm{Fe}(\mathrm{III})$ neerslag grotere deeltjes vormt dan de poriegrootte van UF-membranen (zoals verwacht voor het meeste Ca-houdende grondwater), de Fe(III)-deeltjes de membranen vooral vervuilen door een koeklaag op het oppervlak te vormen, die effectief kan worden verwijderd via hydraulisch terugspoelen. Daarom concluderen we dat een duurzame langdurige toepassing van UF-membranen met in-line $\mathrm{FeCl}_{3}$ dosering erg rendabel is voor As-verwijdering.

Op basis van de huidige studie hebben in Nederland drie drinkwaterbedrijven die grondwater gebruiken een upgrade gekregen met een $\mathrm{KMnO}_{4}$-dosering om de Asconcentratie tot onder $1 \mu \mathrm{g} / \mathrm{L}$ te verlagen. Een ander proces, dat gebruik maakt van bodemfiltraat, zal een upgrade krijgen met $\mathrm{FeCl}_{3}$-dosering voor de laatste UF-stap. 


\section{LIST OF PUBLICATIONS IN THIS THESIS}

Ahmad, A., Richards, L. A., Bhattacharya, P. (2017). Arsenic remediation of drinking water: an overview. In P. Bhattacharya, D. A. Polya, \& D. Jovanovic (Eds.), Best Practice Guide on the Control of Arsenic in Drinking Water (pp. 79-98). IWA Publishing. London, UK

Ahmad, A., van Dijk, T.G., Jink, Van de Wetering, S., Groenendijk, M. and Bhattacharya, P. (2017). Remediation case study: drinking water treatment by AOCF to target $<1$ ug L-1 effluent arsenic concentration. In P. Bhattacharya, D. A. Polya, \& D. Jovanovic (Eds.), Best Practice Guide on the Control of Arsenic in Drinking Water (pp. 219-25). IWA Publishing. London, UK

Ahmad, A., Cornelissen, E., van de Wetering, S., van Dijk, T., Van Genuchten, C., Bundschuh, J., van der Wal, A. Bhattacharya, P. (2018). Arsenite removal in groundwater treatment plants by sequential Permanganate - Ferric treatment. Journal of Water Process Engineering, 26, 221-229.

Ahmad, A., van der Wal, B., Bhattacharya, P., \& Van Genuchten, C. M. (2019). Characteristics of $\mathrm{Fe}$ and $\mathrm{Mn}$ bearing precipitates generated by $\mathrm{Fe}(\mathrm{II})$ and $\mathrm{Mn}$ (II) co-oxidation with $\mathrm{O}_{2}, \mathrm{MnO}_{4}$ and $\mathrm{HOCl}$ in the presence of groundwater ions. Water Research, 161, 505-516.

Ahmad, A., Rutten, S., Eikelboom, M., de Waal, L., Bruning, H., Bhattacharya, P., \& van der Wal, A. (2020). Impact of phosphate, silicate and natural organic matter on the size of $\mathrm{Fe}(\mathrm{III})$ precipitates and arsenate co-precipitation efficiency in calcium containing water. Separation and Purification Technology, 235, 116117.

Ahmad, A., van der Wens, P., Baken, K., de Waal, L., Bhattacharya, P., \& Stuyfzand, P. (2020). Arsenic reduction to $<1 \mu \mathrm{g} / \mathrm{L}$ in Dutch drinking water. Environment International, 134, 105253.

Ahmad, A. Heijnen, L., de Waal, L., Battaglia-Brunet, F., Oorthuizen, W., Pieterse, B., Bhattacharya, P. van der Wal, A. (2020). Mobility and redox transformation of arsenic during treatment of artificially recharged groundwater for drinking water production. Water Research, 115826.

Ahmad, A. Rutten, S., de Waal, L., Vollaard, P., Van Genuchten, C., Bruning, H., Cornelissen, E., van der Wal, A. Mechanisms of arsenic removal and membrane fouling in ferric based coprecipitation-low pressure membrane filtration systems. Separation and Purification Technology, 241, 116644. 


\section{ACKNOWLEDGEMENTS}

I would like to express my sincere gratitude to both my promotors Prof. Dr. Albert van der Wal (WUR) and Prof. Dr. Prosun Bhattacharya (KTH) for their excellent support and supervision. Without their guidance and critical assessment of my work it would not have been possible to complete my $\mathrm{PhD}$ degree. Thanks to Case van Genuchten (GEUS, Denmark), for his help with understanding difficult concepts of molecular scale iron-arsenic chemistry. Thanks to Luuk de Waal (KWR) for the laboratory experiments, data analysis and data visualization. Special thanks to my other colleagues in the team of drinking water treatment at KWR for always being supportive. Special acknowledgment for my colleagues at Dutch drinking water companies, especially at Brabant Water, Evides, Dunea and Aquaminerals, for their collaboration with me and research funding.

Finally, special mention must be made for my wife and daughter who did not ask for too much of my time while I was busy writing my papers. I owe you a wonderful vacation this summer. 


\section{ABOUT THE AUTHOR}

Full name Arslan Ahmad

Date of birth October 26, 1986

Place of birth Lahore, Pakistan

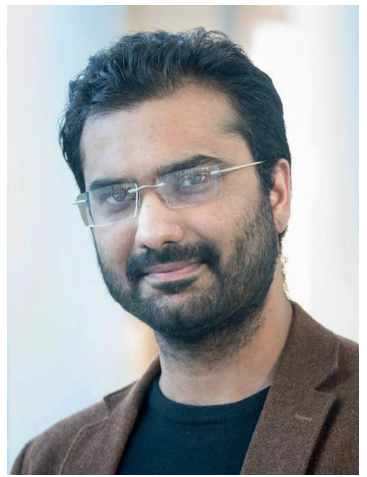

Education

$2016-2020$

$\mathrm{PhD}$ in Water and Environmental Technology

Wageningen University and Research (Wageningen, the Netherlands)

$2010-2012$

$2005-2009$

2019 - Present

2014 - Present

$2018-2020$
Scientific Researcher

KWR Water Research Institute

(Nieuwegein, the Netherlands)

MSc in Environmental Engineering

KTH Royal Institute of Technology

(Stockholm, Sweden)

BSc in Civil Engineering

University of Engineering \& Technology (Lahore, Pakistan)

Visiting Fellow

KTH Royal Institute of Technology

(Stockholm, Sweden)

Advisor Water Treatment

Evides (Rotterdam, the Netherlands) 
2013-2014 Process Engineer

Brabant Water (Breda, the Netherlands)

$2011-2012 \quad$ Process Engineer

Peepoople (Stockholm, Sweden and

Nairobi, Kenya)

$2009-2010 \quad$ Design Engineer

National Engineering Services NESPAK

(Lahore, Pakistan)

Other engagements
Board Member

Vice Chair
International Society of Groundwater for Sustainable Development (ISGSD)

International Water Association (IWA) Specialist Group on Metals and Related Substances in Water Supply Systems 
The research presented in this thesis was financially supported mainly by Dutch drinking water companies: Evides Waterbedrijf, Dunea Duin \& Water and Brabant Water. The financial support from AquaMinerals is also gratefully acknowledged.

This research is co-financed with PPS-funding from the Topconsortia for Knowledge \& Innovation (TKI's) of the Ministry of Economic Affairs and Climate.

Cover design by wenz iD

Printed by ProefschiftMaken.nl 